RENATO RAMIREZ VIANA NEVES

DESEMPENHO DE DEFENSAS RODOVIÁRIAS SUJEITAS AO IMPACTO DE AUTOMÓVEIS 
RENATO RAMIREZ VIANA NEVES

\section{DESEMPENHO DE DEFENSAS RODOVIÁRIAS SUJEITAS AO IMPACTO DE AUTOMÓVEIS}

Dissertação apresentada à Escola Politécnica da Universidade de São Paulo para obtenção do título de Mestre em Ciências 
RENATO RAMIREZ VIANA NEVES

\section{DESEMPENHO DE DEFENSAS RODOVIÁRIAS SUJEITAS AO IMPACTO DE AUTOMÓVEIS}

Dissertação apresentada à Escola Politécnica da Universidade de São Paulo para obtenção do título de Mestre em Ciências

Área de concentração:

Engenharia Mecânica

Orientador: Prof. Livre Docente Marcílio Alves 
Este exemplar foi revisado e alterado em relação à versão original, sob responsabilidade única do autor e com a anuência de seu orientador.

São Paulo, 26 de Março de 2013.

Assinatura do autor

Assinatura do orientador

Neves, Renato Ramirez Viana

Desempenho de defensas rodoviárias sujeitas ao impacto de automóveis / R.R.V. Neves. - versão corr. - São Paulo, 2013. $145 \mathrm{p}$.

Dissertação (Mestrado) - Escola Politécnica da Universidade de São Paulo. Departamento de Engenharia Mecatrônica e de Sistemas Mecânicos.

1. Segurança rodoviária 2. Veículos de passageiros 3. Estruturas de aço 4. Método dos elementos finitos I. Universidade de São Paulo. Escola Politécnica. Departamento de Engenharia Mecatrônica e de Sistemas Mecânicos II. t. 
Dedico aos meus queridos pais. 


\section{AGRADECIMENTOS}

A Deus acima de tudo.

Aos meus pais Welinton e Márcia pelo amor, dedicação e exemplo de pessoas dignas.

Ao professor Marcílio pelos mais de 6 anos de amizade, orientação acadêmica e o crédito que sempre demonstrou ao meu trabalho.

À Va pelo carinho, companheirismo e apoio sem igual em minhas decisões.

À minha família, em especial, Joyce, Luciano, Igor, vô Alberto, vó Eunice, vô Darcy, Vó Yolanda, tio Roberto e tia Cláudia.

Aos amigos de turma da Escola Politécnica da USP Sérgio, Stergios e César.

Aos colegas do GMSIE sempre dispostos em ajudar Gian, Yamassaki, Roberto, Celeghini, Ogro, Leonardo, Miguel, Caio, Esdras e Nelson.

Aos colegas do Simlab Anne, Gaut, Vincent, Maurice, Ida e em especial aos professores Arild e Magnus.

Ao apoio financeiro da FAPESP projeto 2010/04207-0 de 2010 a 2012. 
"A ciência sem religião é manca, a religião sem a ciência é cega."

Albert Einstein 


\section{RESUMO}

As defensas rodoviárias têm a finalidade de redirecionar com segurança um veículo fora de controle de uma colisão frontal ou trajetória mais perigosa. Secundariamente, a absorção de energia através da deformação do sistema de contenção ou outro método de dissipação da energia de impacto é ressaltado como um benefício em prol da segurança dos ocupantes. Considerando as premissas anteriores e os índices de severidade ao ocupante ASI, THIV e PHD, os desempenhos de uma defensa metálica e outras defensas de concreto são então classificados. Além disso, investiga-se o mecanismo de falha das conexões parafusadas e a sua influência no resultado do impacto de um automóvel leve contra uma defensa metálica. Importância é dada à modelagem do comportamento do material da defensa metálica sob baixas e altas taxas de deformação. Dessa forma, a necessidade de avaliar as propriedades dinâmicas do material motivou o projeto e construção de uma Barra de Hopkinson para testes de tração e compressão até $5000 \mathrm{~s}^{-1}$. Adicionalmente, um modelo analítico simplificado da defensa metálica sob ação de uma força estática foi equacionado para validar um modelo em elementos finitos. Um estudo paramétrico da falha da conexão parafusada foi levantado através de diversas simulações estáticas e também do impacto de um veículo leve em uma defensa metálica de acordo com a norma EN 1317. Os resultados das simulações de impacto utilizando um modelo de veículo leve e diferentes sistemas de contenção foram comparados em função dos índices de severidade ao ocupante, indicando que a defensa metálica é mais segura do que uma defensa de concreto com perfil New Jersey ou vertical.

Palavras-chave: Defensa metálica, impacto, segurança viária, barra de hopkinson, método dos elementos finitos. 


\begin{abstract}
The main function of a road guardrail is to redirect an out of control vehicle avoiding a frontal collision or a dangerous veering off the road trajectory. Secondarily, the energy absorption measured by barrier deformation or any other energy dissipation method is beneficial to the car occupant safety. Considering the previous tasks and some severity occupant index like ASI, THIV and PHD, the performance of a guardrail and other concrete barriers are classified. Besides, it is investigated the fail mechanism of bolted connections and its influence on the guardrail impact result of an automobile. Special attention was taken into the material behavior modeling under low and high strain rates. Thereby, the need of accessing dynamic material properties motivated the design and manufacture of a Hopkinson Bar set-up for tension and compression tests up to $5000 \mathrm{~s}^{-1}$. In addition, a simplified analytical model of a guardrail subjected to a static force was settled in order to validate a guardrail finite element model. A parametric study of the bolted connection failure was performed through several impact simulations of a light car model and a guardrail according to EN 1317 standard. The impact simulation results using a light vehicle car model and different barriers types were compared through the occupant severity index showing that the guardrail is a safer system than concrete barrier with New Jersey or vertical profile.
\end{abstract}

Keywords: guardrail, impact, road safety, hopkison bar, finite element method. 


\section{LISTA DE ILUSTRAÇÕES}

Figura 1 - Em (a) barreira de concreto (RÁDIO CRICIUMA, 2010), (b) defensa metálica (LISY, 2008) e (c) barreira de cabos de aço (REEDING.COM, 2009).

Figura 2 - Impacto em uma barreira de concreto a $80 \mathrm{~km} / \mathrm{h}$ e $45^{\circ}$ (Grzebieta et al., 2005)...... 22

Figura 3 - O perigo das barreiras de cabos de aço (a) para motociclistas (RIGHT TO RIDE, 2005) e (b) para automóveis (EASTWICK PRESS, 2009).

Figura 4 - Tensão de escoamento da defensa metálica sob diferentes taxas de deformação obtidas em máquina universal quase-estática, máquina servo-hidráulica e sistema de barras.

Figura 5 - Resultado de um acidente de um veículo no qual a defensa metálica sofre falha devido a uma conexão parafusada frágil (NEWS FROM THE POST-STANDARD, 2010).

Figura 6 - Estado de conservação geral da malha rodoviária em 2010. (Confederação Nacional de Transportes, 2011)

Figura 7 - À esquerda, avaliação qualitativa da presença de pelo menos uma curva perigosa a cada $10 \mathrm{~km}$ avaliados. À direita, avaliação da presença de defensas nas curvas perigosas.

Figura 8-TME (taxa de mortalidade específica) por acidentes de transporte no Brasil na década de 1998 a 2008 segundo dados do Ministério da Saúde (2009) e RIPSA (2009).

Figura 9 - Número de mortos em cada 100 acidentes de trânsito segundo tipo (IPEA/DENATRAN/ANTP, 2006)

Figura 10 - Esquema de funcionamento da $\mathrm{BH}$

Figura 11 - Definição das fronteiras do espécime

Figura 12 - Impacto coaxial do striker e a barra de entrada. 
Figura 13 - Esquema das barras para o teste de compressão, destacando o uso do corpo de prova anelar.

Figura 14 - Esquema das barras para o teste de tração, destacando o uso do corpo de prova em chapa e geometria tipo "dog bone".

Figura 15 - Em (a) e (b) são apresentadas duas vistas isométricas da máquina. Em (c) é ilustrada uma vista lateral.

Figura 16 - Fotos da BH de compressão e tração.

Figura 17 - Estrutura de suporte e fixação dos diversos módulos.

Figura 18 - Mancal de suporte e ajuste de posição das barras. Em (a) componente fabricado e montado sobre a mesa e em (b) vista isométrica do projeto. 48

Figura 19 - Em (a) é apresentado o esquema pneumático da máquina, em (b) o projeto do painel de atuadores pneumáticos e em (c) o painel montado.

Figura 20 - Reservatório, canhão, barra e suportes da BH de compressão.

Figura 21 - Reservatório, canhão, barra, suportes e sistema de frenagem da BH de tração....50

Figura 22 - Sistema de frenagem e amortecimento.

Figura 23 - Regiões avaliadas na defensa metálica

Figura 24 - Comparação entre o comportamento do material de acordo com a região da seção transversal.

Figura 25 - Comparação entre os resultados de tensão de engenharia versus deformação de engenharia e tensão verdadeira versus deformação logarítmica.

Figura 26 - Geometria de corpo de prova utilizada nos testes quase-estático.

Figura 27 - Teste de tração quase-estático no início do teste, após falha do material e no detalhe a região de empescoçamento.

Figura 28 - Em (a) perfil de carga aplicada nos testes quase-estáticos com 3 ciclos de carga cíclica no regime elástico. Em (b) cálculo do Módulo de Elasticidade do material. .58 
Figura 29 - Curvas de tensão versus deformação sob diferentes taxas de deformação em regime quase-estático.

Figura 30 - Método de obtenção da tensão de escoamento. 60

Figura 31 - (a) Dimensões do corpo de prova para testes dinâmicos e em (b) corpo de prova fabricado em máquina de corte a laser.

Figura 32 - Detalhes do corpo de prova e a fixação por cola nos adaptadores

Figura 33 - Sinais típicos da BH obtidos em um teste de tração

Figura 34 - Em (a), pulsos deslocados no tempo. Em (b), equilíbrio de forças avaliado pela relação entre os pulsos de deformação.

Figura 35 - Histórico de tensões no corpo de prova e definição da região de equilíbrio de forças.

Figura 36 - Em (a), comparação dos resultados de deformações de engenharia e logarítmica.

Em (b), taxa de deformação do corpo de prova baseada no pós-processamento dos pulsos

Figura 37 - Comportamento quase-estático e dinâmico do material. Reta vertical indicando nível de deformação plástica utilizado como referência para calibração dos modelos dinâmicos.

Figura 38 - Curvas de tensão deformação obtidas em testes na BH. 67

Figura 39 - Ajuste dos parâmetros de Cowper-Symonds 68

Figura 40- Em (a) defensa metálica representada no software de CAD 3D Inventor

Professional. A foto (b) foi clicada de uma defensa metálica instalada na Rodovia Doutor. Avelino Junior em Cruzeiro/SP.

Figura 41 - Sistema analisado composto de guia de deslizamento w, poste e conexão parafusada. 
Figura 43 - Conexão entre a guia de deslizamento w e o poste no comprimento médio da primeira.

Figura 44 - Defensa metálica após colisão com um veículo evidenciando a falha das conexões entre o poste e a guia de deslizamento. As conexões entre as vigas W não sofrem danos significativos (LIER, 2004).....

Figura 45 - Sistema composto por viga e poste engastado.

Figura 46 - Poste antes e depois de sofrer deformação.

Figura 47 - (a) Simplificação geométrica da guia de deslizamento w, (b) perfil original da

guia e em (c) sobreposição do perfil original e simplificado.

Figura 48 - Critério de escoamento da guia de deslizamento w.

Figura 49 - Gráfico de força aplicada sobre sistema pela flecha máxima da guia de deslizamento $\mathrm{w}$. 79

Figura 50 - Vista frontal e lateral do modelo 80

Figura 51 - Malha na região da conexão parafusada e corte na conexão entre o poste e a guia de deslizamento $w$. 80

Figura 52 - Área onde o carregamento foi aplicado, sendo (a) uma vista superior da região central do modelo e em (b) uma vista isométrica.

Figura 53 - Comportamento global da estrutura sob carregamento.

Figura 54 - Deformação plástica na estrutura no tempo de $0,61 \mathrm{~s}$ ou $73,6 \mathrm{kN}$ de força aplicada. As três rótulas plásticas na guia de deslizamento w e outra na base do poste são evidentes 82

Figura 55 - Em (a) análise de convergência dos modelos de parafuso com diferentes malhas apresentadas em (b)....

Figura 56 - Comparação entre os resultados obtidos pelo modelo analítico e via elementos finitos.

Figura 57 - Comparação entre a força resultante dos modelos com e sem parafuso. 
Figura 58 - Tensão de Von Mises em unidades MPa na conexão parafusada.

Figura 59 - Deformação plástica na conexão parafusada.

Figura 60 - Força normal obtida na conexão com e sem parafuso. .86

Figura 61 - Força de cisalhamento obtida na conexão com e sem parafuso. .86

Figura 62 - Relação entre a força resultante na conexão spotweld e a forças de carregamento.

Figura 63 - Análise paramétrica da falha da conexão spotweld.

Figura 64 - Em (a) energia interna acumulada nos componentes da defensa e em (b) energia interna acumulada nos modelos de conexão durante a deformação da estrutura. 88

Figura 65 - Seções transversais utilizadas em diversos países (Reid at al., 1997). 91

Figura 66 - Exemplos dos perfis analisados por (Reid et al., 1997) ..... .92

Figura 67 - Comparação entre o estado de deformações da defensa e do veículo no teste em escala real e simulação numérica em (a) e em (b) da velocidade do CG do veículo estudada por Plaxico et al. (2000).

Figura 68 - Referenciais adotados e posição teórica da cabeça (EN 1317-1, 1998).

Figura 69 - Impacto da cabeça teórica no lado esquerdo do veículo (EN 1317-1, 1998)...... 100

Figura 70 - Deflexão dinâmica (D) e deslocamento de trabalho (W) (EN 1317-1, 1998)... 102

Figura 71 - Dimensões principais do modelo Geo-Metro. 105

Figura 72 - Vista frontal (a) e vista de topo (c) da malha do veículo. Em (b) vista isométrica com detalhe da posição do acelerômetro e em (d) acelerômetro.

Figura 73 - (a) Situação inicial de impacto no teste realizado por (LIER, 2004) e (b) situação equivalente no cenário modelado em elementos finitos. Em (c) detalhe da fixação do poste ao asfalto e em (d) configuração do modelo numérico. 108

Figura 74 - Configuração de impacto inicial do modelo numérico. 108 
Figura 75 - (a) Malha do poste e em (b) da guia de deslizamento.

Figura 76 - Ilustração dos nós onde soldas pontuais foram definidas para simplificação da conexão parafusada.

Figura 77 - (a) Guias de deslizamento sobrepostas. (b) Detalhe da concordância.

Figura 78 - Posição do CG do GeoMetro para simulações com diferentes critérios de falha da conexão entre o poste e a guia de deslizamento w.

Figura 79 - Imagens do cenário resultante do impacto do veículo para os parâmetros PS avaliados.

Figura 80 - Resultados do índice ASI no impacto do veículo com a defensa metálica.

Figura 81 - Resultados do índice THIV (a) e PHD (b) no impacto do veículo com a defensa metálica.

Figura 82 - Comparação das imagens do teste segundo (LIER, 2004) e da simulação com $\mathrm{PS}=0,9$.

Figura 83 - (a) Imagem obtida no final da simulação numérica PS=0,5 e (b) foto no fim do teste realizado por (LIER, 2004)

Figura 84 - (a) Defensa de concreto retangular testada em (LIER, 2004). Em (b) dimensões principais do bloco de concreto.

Figura 85 - Malha da barreira de concreto vertical.

Figura 86 - Comparação das imagens do teste segundo (LIER, 2002) e da simulação com coeficiente de atrito $\mu=0,1-0,05$

Figura 87 - Resultados do índice ASI no impacto do veículo com a defensa de concreto vertical.

Figura 88 - Resultados do índice THIV (a) e PHD (b) no impacto do veículo com a defensa de concreto vertical. 
Figura 89 - Desvios em relação aos valores do teste para simulações com diferentes coeficientes de atrito entre as superfícies de contato do veículo e a defensa de concreto vertical.

Figura 90 - Geometria da barreira de concreto New Jersey (a) e em (b) perfil da malha gerada em elementos finitos.

Figura 91 - Malha da defensa de concreto New Jersey.

Figura 92 - Sequência de imagens em intervalos de $0,05 \mathrm{~s}$ da simulação de impacto em uma defensa de concreto com perfil New Jersey e coeficiente de atrito $\mu=0,1-0,05 \ldots \ldots .125$

Figura 93 - Resultados do índice ASI no impacto do veículo com a defensa New Jersey.... 126

Figura 94 - Resultados do índice THIV e PHD no impacto do veículo com a defensa New Jersey.

Figura 95 - Exemplos de dispositivos aplicados nas defensas metálicas para proteção de motociclistas (European Road Assesment Programme, 2008). 128

Figura 96 - Dimensões do poste. 141

Figura 97 - Dimensões e geometria da guia de deslizamento w 141

Figura 98 -Dimensões do parafuso M10 142

Figura 99 - Dimensões da porca. 142

Figura 100 - Dimensões da arruela 30x30x3. 143

Figura 101 - Dimensões da arruela 115x40x5. 143

Figura 102 - Deslocamento do centro de gravidade devido ao impacto em uma defensa (EN 1317-1, 1998). 


\section{LISTA DE TABELAS}

Tabela 1 - Presença de defensas em $89.552 \mathrm{~km}$ de rodovias avaliadas (Confederação Nacional

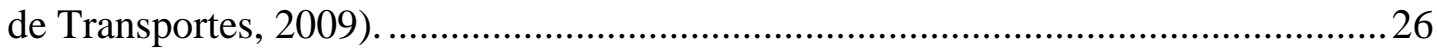

Tabela 2 - Dimensionamento da máquina à baixa taxa de deformação $1000 \mathrm{~s}^{-1} \ldots \ldots \ldots \ldots \ldots \ldots . . . . .44$

Tabela 3 - Dimensionamento da máquina à alta taxa de deformação $5000 \mathrm{~s}^{-1}$......................4 44

Tabela 4 - Dimensionamento da máquina à baixa taxa de deformação $1000 \mathrm{~s}^{-1}$....................4 44

Tabela 5 - Dimensionamento da máquina à alta taxa de deformação $5000 \mathrm{~s}^{-1}$...................... 45

Tabela 6 - Tensão de escoamento obtida para cada taxa de deformação testada ....................6 60

Tabela 7 - Parâmetros do modelo de Cowper-Symonds..................................................... 68

Tabela 8 - Propriedades mecânicas adotadas na simulação numérica .................................... 81

Tabela 9 - Tempo total despendido em cada modelo no software LS-Dyna Implicit ............. 89

Tabela 10 - Classes e parâmetros para teste de impacto de defensas ................................... 95

Tabela 11 - Níveis de contenção de uma barreira rodoviária ............................................. 96

Tabela 12 - Recomendações para aplicação de defensas (Patane, 2012) .............................. 96

Tabela 13 - Classificação de severidade ao ocupante....................................................... 102

Tabela 14 - Classificação do deslocamento da defensa ................................................... 103

Tabela 15 - Nível de contenção de defensas rodoviárias.................................................. 104

Tabela 16 - Resultados dos índices de severidade para defensa metálica. .......................... 114

Tabela 17 - Resultados dos índices de severidade para defensa de concreto vertical. ..........121

Tabela 18 - Comparação dos resultados de simulação para diferentes coeficientes de atrito

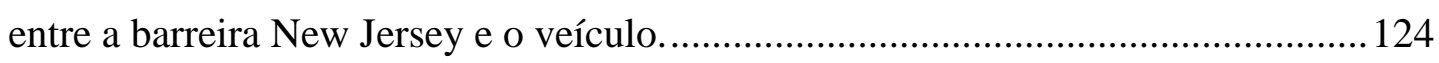


Tabela 19 - Comparação dos índices de severidade das defensas. ...................................... 127 


\section{LISTA DE ABREVIATURA E SIGLAS}

$\begin{array}{ll}\text { ASI } & \text { Acceleration Severity Index } \\ \text { BH } & \text { Barra de Hopkinson } \\ \text { CS } & \text { Cowper-Symonds } \\ \text { GMSIE } & \text { Grupo de Mecânica dos Sólidos e Impacto em Estruturas } \\ \text { JC } & \text { Johnson-Cook } \\ \text { NCAC } & \text { National Crash Analysis Center } \\ \text { NCHRP } & \text { National Cooperative Highway Research Program } \\ \text { OIV } & \text { Occupant Impact Velocity } \\ \text { PHD } & \text { Post-impact Head Deceleration } \\ \text { THIV } & \text { Theoretical Head Impact Velocity } \\ \text { USP } & \text { Universidade de São Paulo }\end{array}$




\section{SUMÁRIO}

1 INTRODUÇÃO

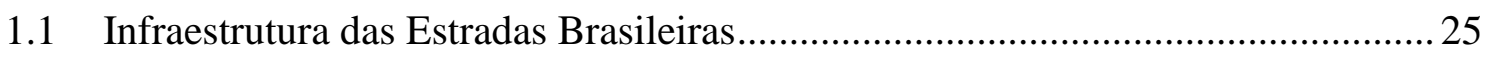

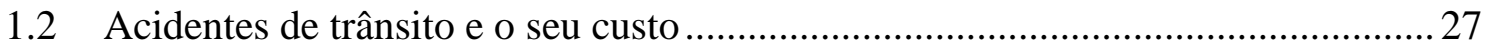

2 OBJETIVOS

3 PROJETO DE UMA BARRA DE HOPKINSON 33

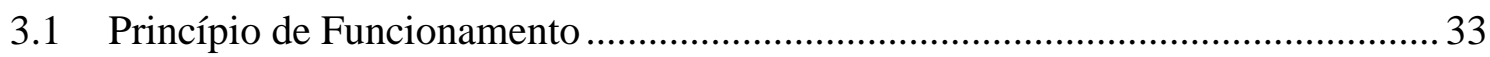

3.2 Modelagem matemática da Barra de Hopkinson.................................................. 37

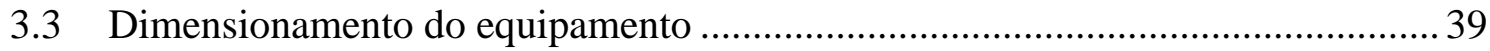

3.4 Barra de Hopkinson de Tração e Compressão.......................................................... 45

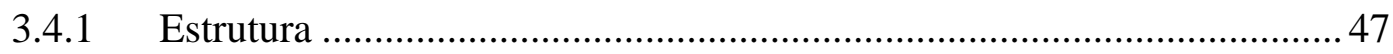

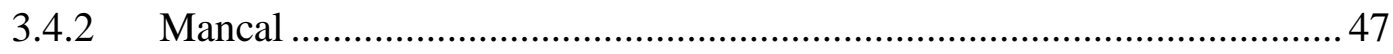

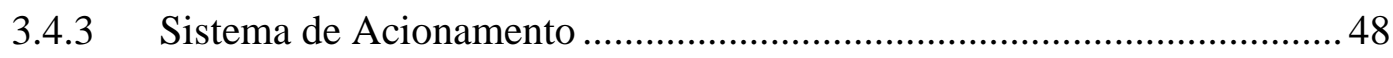

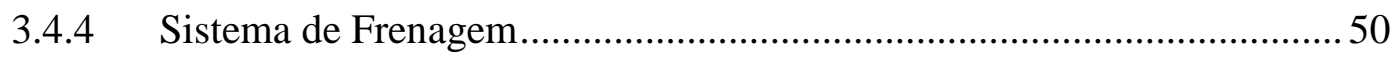

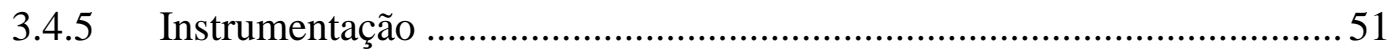

4 CARACTERIZAÇÃO MECÂNICA DO MATERIAL 53

4.1 Material utilizado para confecção dos corpos de prova........................................5 53

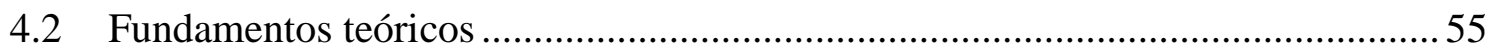

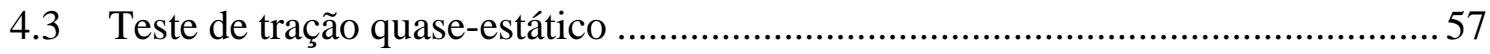

4.4 Definiçãa da geometria do corpo de prova em testes dinâmicos........................... 61

4.5 Testes de tração em altas taxas de deformação .................................................... 63

4.6 Identificação dos parâmetros do modelo de cowper-symonds .............................. 67

5 EQUACIONAMENTO SIMPLIFICADO DE UMA DEFENSA METÁLICA SUJEITA A UMA FORÇA ESTÁTICA

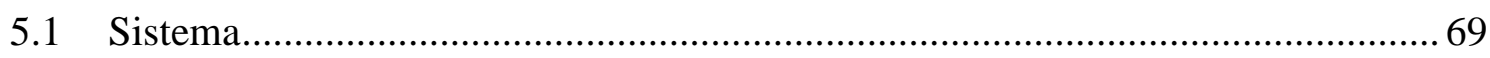

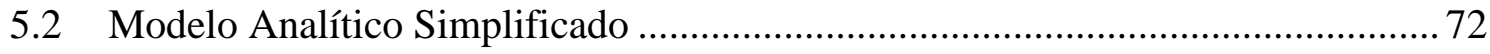

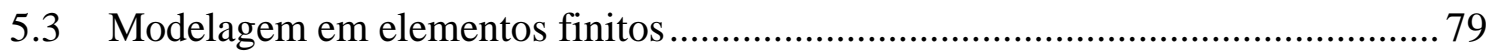

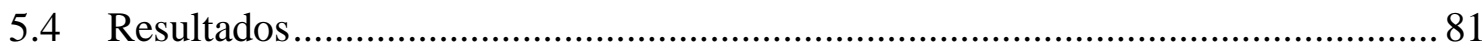


6 SIMULAÇÕES NUMÉRICAS 90

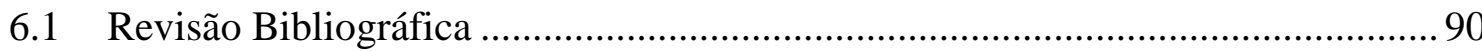

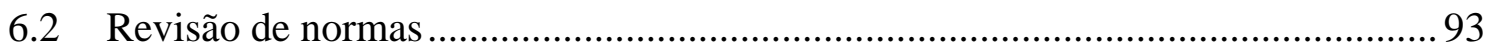

6.3 Modelo em elementos finitos do veículo de 900kg Geo-metro............................ 104

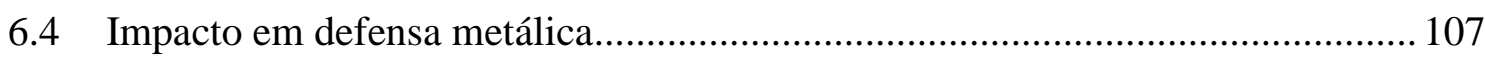

6.4.1 Modelagem em elementos finitos.................................................... 107

6.4.2 Influência da resistência da conexão parafusada .................................... 111

6.4.3 Resultados numéricos e comparação com teste em escala real ..............112

6.5 Impacto em defensa de concreto vertical...................................................... 116

6.5.1 Modelagem em elementos finitos...................................................... 116

6.5.2 Resultados numéricos e comparação com teste em escala real ............. 118

6.6 Impacto em defensa de concreto New Jersey ............................................... 122

6.6.1 Modelagem em elementos finitos.................................................... 122

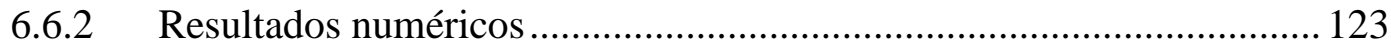

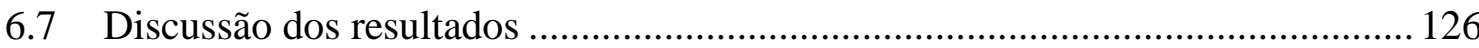

7 CONCLUSÕES 130

8 REFERÊNCIAS BIBLIOGRÁFICAS

$\begin{array}{ll}\text { APÊNDICE A } & 137\end{array}$

APÊNDICE B 141

$\begin{array}{ll}\text { APÊNDICE C } & 144\end{array}$ 


\section{INTRODUÇÃO}

Em todo o mundo, os acidentes de trânsito causam a morte de 1,2 milhões de pessoas ao ano, a sua maioria em países subdesenvolvidos, segundo World Health Organization (2004). O mesmo estudo aponta uma projeção de que o número de fatalidades ainda deve aumentar $65 \%$ nos próximos 20 anos. Apesar disso, uma estimativa dos custos gerados com saúde e danos materiais relativos a esses acidentes alcança o patamar de US\$518 bilhões anuais, enquanto o investimento em pesquisa e desenvolvimento de sistemas de segurança aplicados em rodovias soma apenas US\$24-33 milhões.

Dentre os sistemas disponíveis para segurança nas estradas, as defensas têm a função de redirecionar o veículo desgovernado de zonas de risco como: barrancos, pilares de viadutos, faixas de sentidos opostos, limites laterais de uma ponte, áreas de circulação de pedestres, etc. Alguns exemplos de defensas rodoviárias são ilustrados na Figura 1, como barreiras de concreto, defensas metálicas e barreiras com cabos de aço.. A aplicação e as características de cada sistema serão comentadas a seguir.

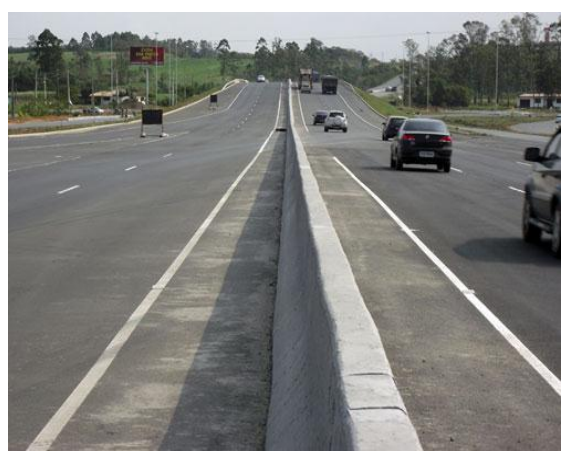

(a)

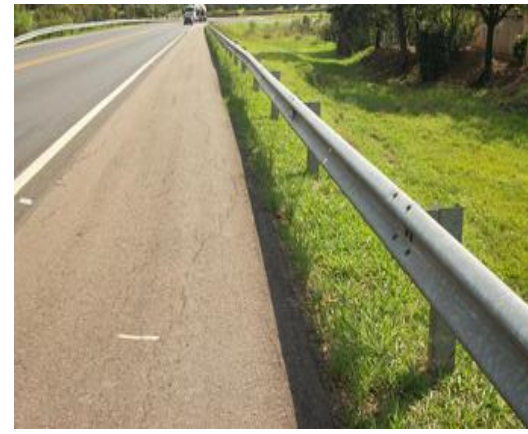

(b)

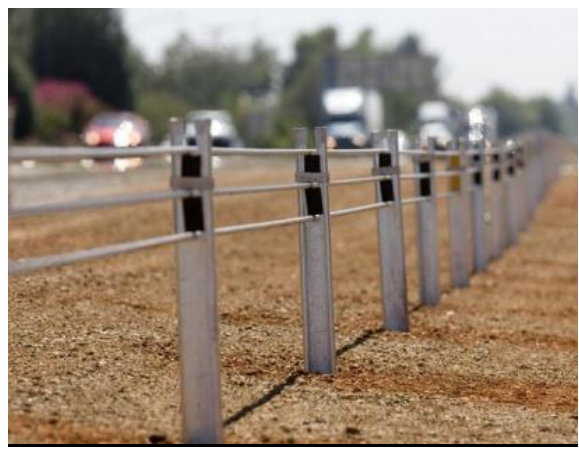

(c)

Figura 1 - Em (a) barreira de concreto (RÁDIO CRICIUMA, 2010), (b) defensa metálica (LISY, 2008) e (c) barreira de cabos de aço (REEDING.COM, 2009). 
Barreiras de concreto são usualmente instaladas em áreas estreitas onde não existe espaço para barreiras deformáveis, ou onde o risco de trafegar fora da faixa seja fatal. Apesar do alto custo inicial de instalação, o sistema requer quase nenhuma manutenção. Por outro lado, testes de impacto realizados por Grzebieta et al. (2005) apontam pouca dissipação de energia e grande tendência de capotamento de veículos pequenos a médios. O estudo revela que em um teste realizado a $80 \mathrm{~km} / \mathrm{h}$ e ângulo de impacto de $45^{\circ}$, o veículo é lançado ao ar e em seguida capota, conforme sequência de imagens da Figura 2.
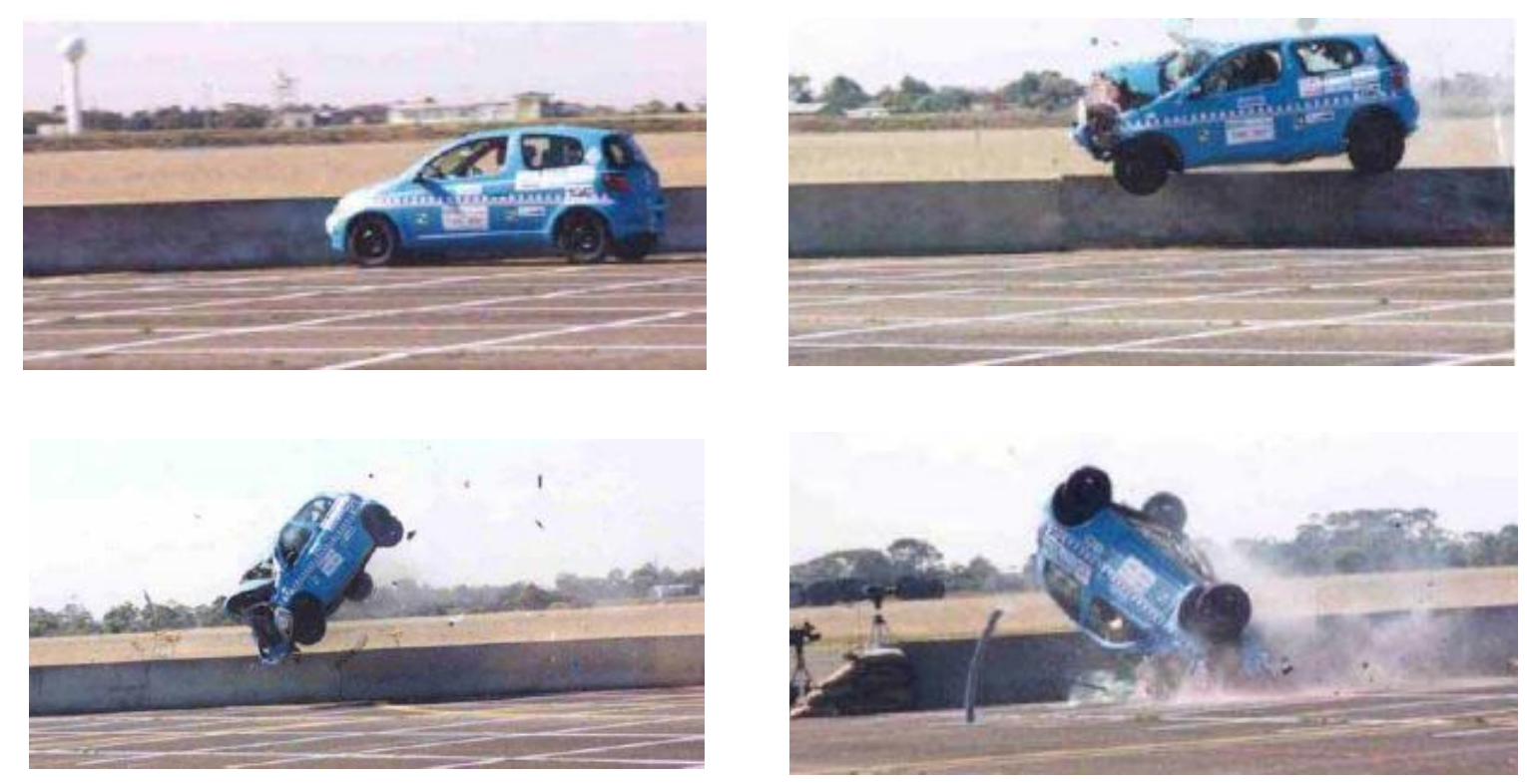

Figura 2 - Impacto em uma barreira de concreto a $80 \mathrm{~km} / \mathrm{h}$ e $45^{\circ}$ (Grzebieta et al., 2005).

Barreiras de cabos de aço são sistemas mais recentes e exemplos são encontrados na Austrália, Europa e Estados Unidos. O custo de instalação desse sistema é menor dentre os três tipos citados. Dada a sua maior flexibilidade o veículo sofre desaceleração mais suave. No entanto, duas questões importantes pesam contra essa alternativa. A primeira e mais importante referese à colisão de motocicletas, pois os cabos de aço transformam-se em perigosos elementos cortantes em situações de impacto contra o motociclista. Em segundo plano, verifica-se que a baixa tensão nos cabos devido à instalação incorreta ou falta de manutenção pode comprometer seriamente o desempenho do sistema. Nesse caso, o veículo tende atravessar a barreira por baixo dos cabos causando riscos à integridade dos ocupantes. Na Figura 3 são ilustrados os exemplos da periculosidade da barreira composta por cabos de aço. 


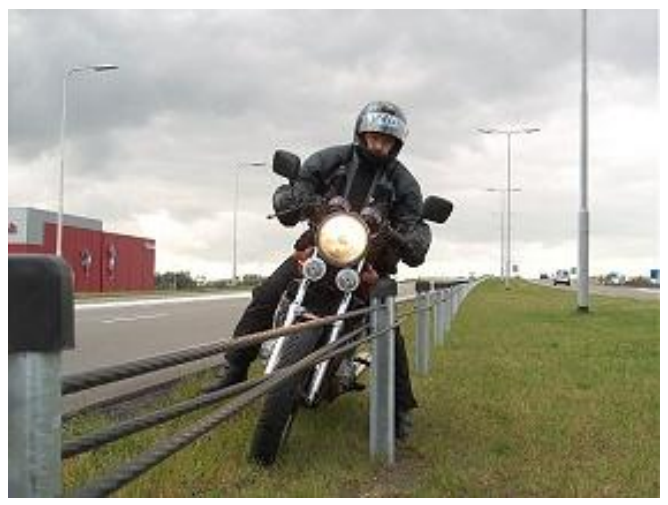

(a)

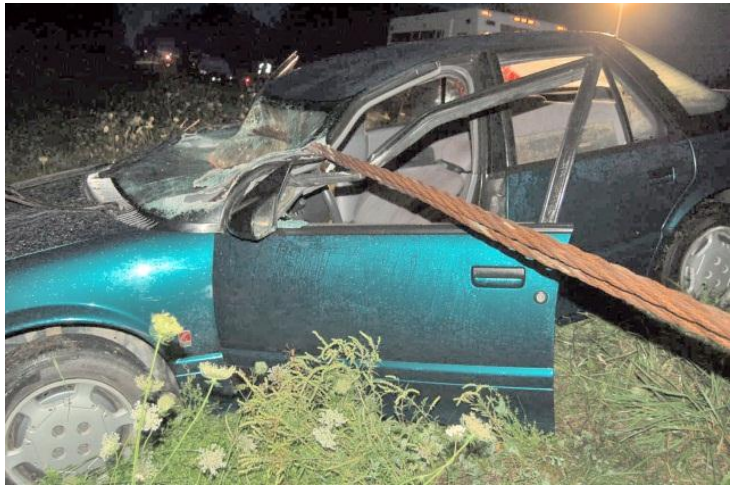

(b)

Figura 3 - O perigo das barreiras de cabos de aço (a) para motociclistas (RIGHT TO RIDE, 2005) e (b) para automóveis (EASTWICK PRESS, 2009).

A defensa metálica ou guardrail (termo usado na língua inglesa) é composta por guias de deslizamento e postes metálicos conectados por parafusos. São estruturas mais baratas que as barreiras de concreto e normalmente exigem manutenção após uma colisão, quando alguns componentes devem ser substituídos devido à sua deformação plástica residual. A defensa metálica possui boa capacidade de absorção de impacto para veículos pequenos a médios. Entre outros aspectos técnicos, as defensas metálicas instaladas atualmente necessitam de mudanças para adequar-se ao impacto de motocicletas e veículos pesados.

Mesmo considerando as desvantagens de cada sistema, a presença destes dispositivos é crucial para sobrevivência de ocupantes dos veículos em acidentes. No escopo do presente trabalho, a defensa metálica será abordada em maiores detalhes, desde a caracterização das propriedades mecânicas dos seus componentes, análise teórica e simulação numérica em elementos finitos, incluindo casos de impacto com automóveis.

Quando ocorre a colisão de um veículo contra uma defensa metálica são gerados carregamentos dinâmicos ao longo de toda sua estrutura. Para certos materiais, notadamente os aços, é verificado um aumento significativo da resistência mecânica quando a taxa de deformação é aumentada, conforme Figura 4, onde é demonstrado um aumento da tensão de escoamento devido à variação da taxa de deformação. Por isso é imprescindível descrever as propriedades mecânicas da defensa metálica sob a ótica de uma faixa ampla de deformação visando a utilização de modelos constitutivos como o de Cowper-Symonds ou Jhonson-Cook, por exemplo. 


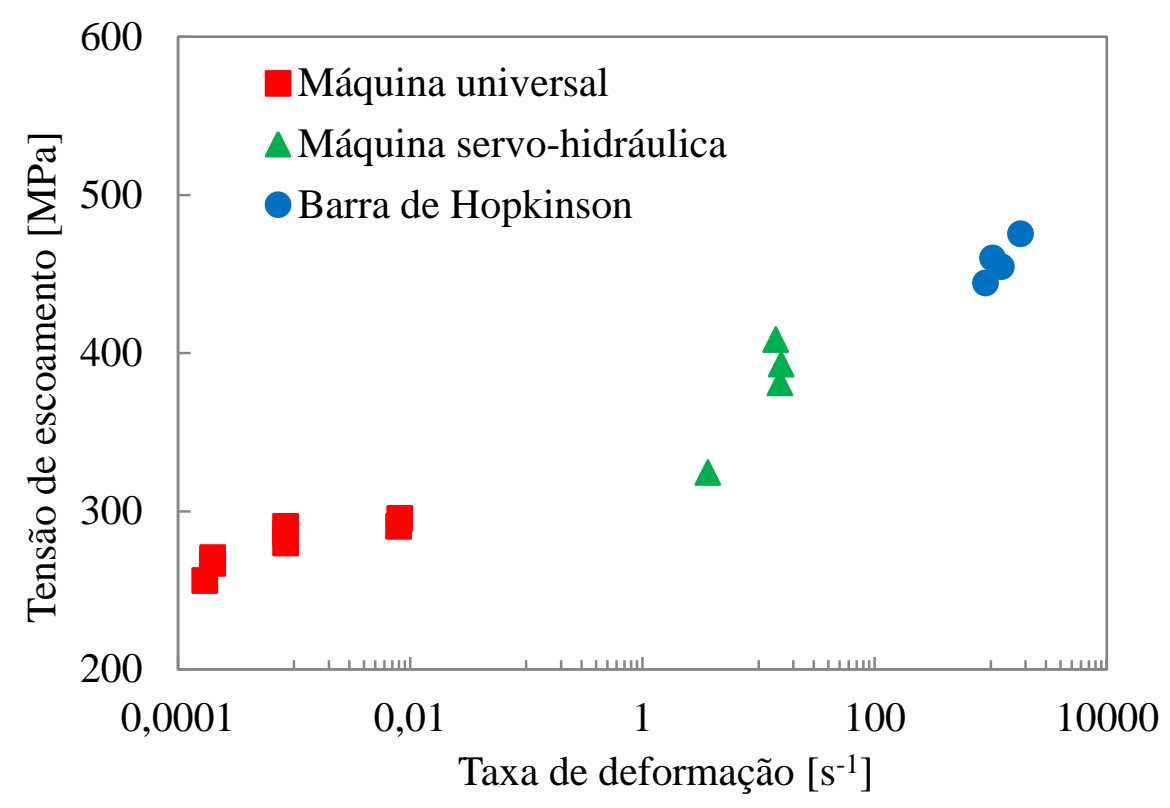

Figura 4 - Tensão de escoamento da defensa metálica sob diferentes taxas de deformação obtidas em máquina universal quase-estática, máquina servo-hidráulica e sistema de barras.

O modelo analítico de um módulo da defensa metálica composto de apenas um poste e uma guia de deslizamento é abordado simplificadamente a fim de elucidar a característica dos carregamentos impostos no sistema de contenção simplificado. Os resultados obtidos através desse modelo matemático foram comparados com simulações equivalentes em elementos finitos, demonstrando boa correlação entre ambas estratégias de modelagem. Uma análise da conexão parafusada utilizando elementos sólidos e um modelo de solda pontual denominado pelo cartão *CONSTRAINED_SPOTWELD no Ls-Dyna centraram as discussões sobre o efeito de cada modelagem e da falha da conexão no resultado final de deformação da estrutura.

A investigação do impacto de um automóvel contra a defensa metálica tem sido desenvolvida ao longo dos anos e uma análise da influência da falha da conexão parafusada entre a viga e o poste da defensa metálica indica que este fenômeno afeta sobremaneira o comportamento global do sistema, sendo decisivo sobre o sucesso ou fracasso no redirecionamento de um automóvel em colisão. Implica dizer que quando a conexão é mais frágil que um determinado limite, a barreira longitudinal desconecta-se prematuramente do poste e o veículo atravessa a barreira longitudinal por baixo da guia de deslizamento, conforme exemplo na Figura 5. 
Além disso, são comparados os desempenhos de dois tipos diferentes de defensas de concreto e um modelo de defensa metálica em função dos índices de severidade ao ocupante ASI, THIV e PHD definidos pela EN 1317-1 (1998). Os resultados de testes reais do impacto de um veículo contra uma defensa de concreto vertical (LIER, 2002) e uma defensa metálica (LIER, 2004) é apresentada de modo a validar e avaliar a assertividade dos dados obtidos pelas simulações numéricas.

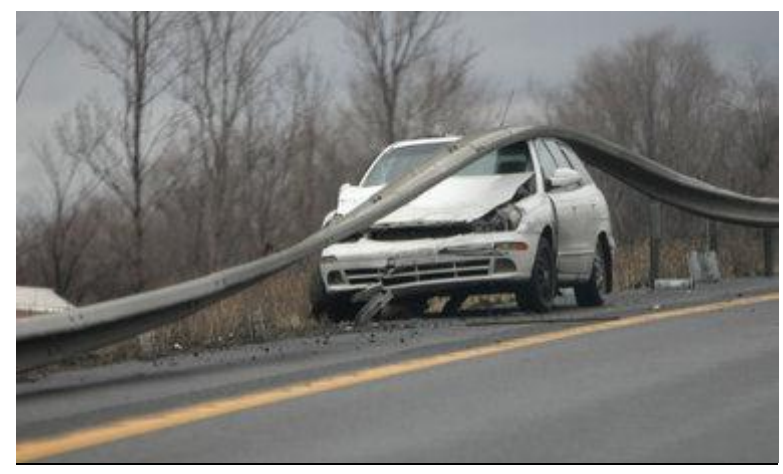

Figura 5 - Resultado de um acidente de um veículo no qual a defensa metálica sofre falha devido a uma conexão parafusada frágil (NEWS FROM THE POST-STANDARD, 2010).

É apropriado, no entanto, antes de se avançar para o próximo capítulo, apresentar um panorama da infraestrutura das estradas no Brasil com ênfase nos sistemas de contenção rodoviária existentes. Uma discussão acerca das estimativas de acidentes nas estradas brasileiras e as suas implicações socioeconômicas será abordada através de dados obtidos na literatura nos itens seguintes.

\subsection{INFRAESTRUTURA DAS ESTRADAS BRASILEIRAS}

As estradas são o mais importante meio de transporte terrestre em termos de distribuição de cargas e locomoção de pessoas no país, com mais da metade da importância no setor. Esse é um resultado da estratégia política e econômica do país desde 1920 e que tem se mantido até hoje.

Apesar da importância, as rodovias brasileiras não oferecem boa qualidade de infraestrutura e segurança aos passageiros de acordo com o estudo da Confederação Nacional de Transportes, (2011), cujo cenário pode ser constatado através do estado de conservação da malha rodoviária brasileira ilustrada na Figura 6 . Na pesquisa, $89.552 \mathrm{~km}$ de estradas foram percorridas e 
menos da metade, ou seja, 41,2\% delas foi considerada boa ou ótima, com 25,4\% sendo avaliadas como ruim e péssima. Nesse estudo foi analisada a sinalização, o pavimento e a geometria da via.

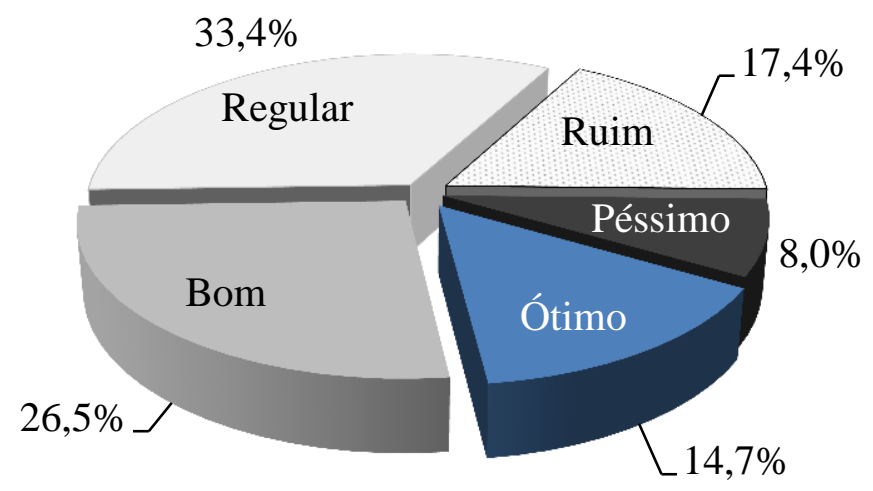

Figura 6 - Estado de conservação geral da malha rodoviária em 2010. (Confederação Nacional de Transportes, 2011).

Segundo Confederação Nacional de Transportes (2009) a ausência de defensas nas situações em que essa é necessária - barrancos, pilares de viadutos e passarelas - é verificada em 29,1\% da extensão total avaliada. Em $11,4 \%$ as defensas estão instaladas, mas apenas em parte do percurso. Os dados estão reproduzidos na Tabela 1.

Tabela 1 - Presença de defensas em $89.552 \mathrm{~km}$ de rodovias avaliadas (Confederação Nacional de Transportes, 2009).

\begin{tabular}{|c|c|c|}
\hline Defensas & km & $\%$ \\
\hline Presente quando necessária, em todo o percurso & 9034 & $10.1 \%$ \\
\hline Presente quando necessária, em parte do percurso & 10241 & $11.4 \%$ \\
\hline Ausente mas necessária em todo o percurso & 26090 & $29.1 \%$ \\
\hline Ausente e não necessária & 44187 & $49.3 \%$ \\
\hline TOTAL & 89552 & $100.0 \%$ \\
\hline
\end{tabular}

Em aproximadamente um quarto da extensão das estradas, existe uma curva perigosa a cada $10 \mathrm{~km}$ (Confederação Nacional de Transportes, 2009), o equivalente a $21214 \mathrm{~km}$ de trechos sinuosos. Uma averiguação da instalação de defensas nesses trechos mostra uma realidade 
assustadora: em 82,9\% deles não existe a presença de defensas, conforme Figura 7 (Confederação Nacional de Transportes, 2009).

Diante desse cenário percebe-se que a baixa qualidade de infraestrutura e a ausência de defensas em diversos trechos perigosos contribuem de maneira substancial para a alta taxa de acidentes e fatalidades nas rodovias brasileiras. Além das perdas sociais, o custo econômico associado aos acidentes responde por boa parcela da economia nacional, conforme será discutido a seguir.

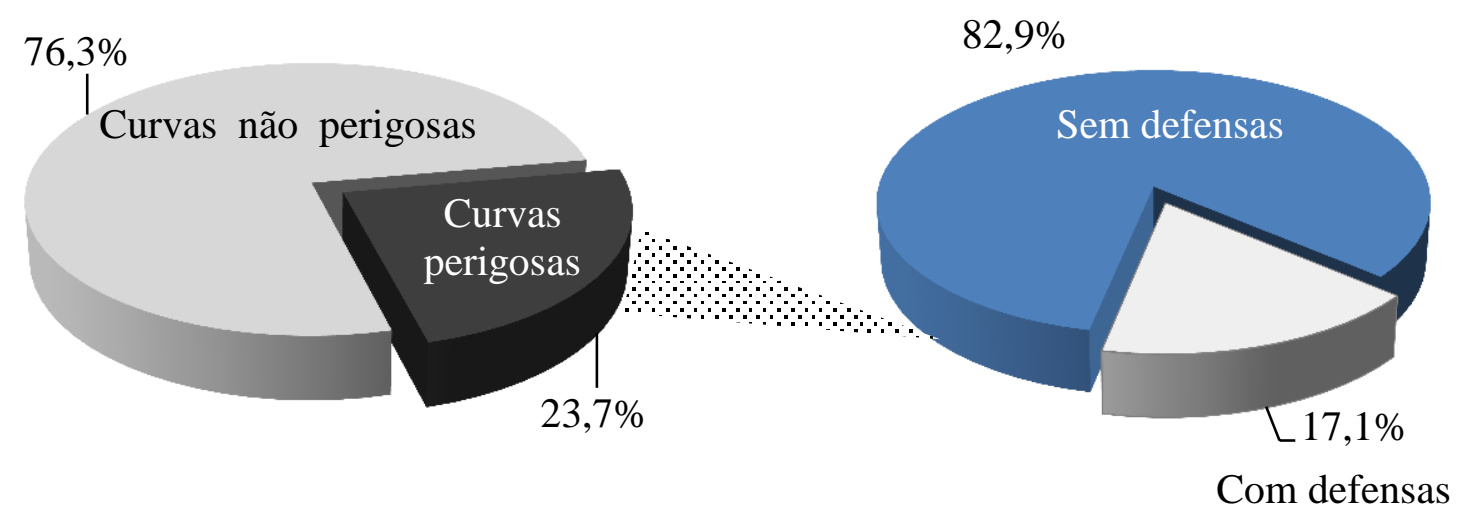

Figura 7 - À esquerda, avaliação qualitativa da presença de pelo menos uma curva perigosa a cada $10 \mathrm{~km}$ avaliados. À direita, avaliação da presença de defensas nas curvas perigosas.

\subsection{ACIDENTES DE TRÂNSITO E O SEU CUSTO}

No Brasil, dentre o número total de óbitos por causas externas, aqueles causados por acidentes de transporte são o segundo em relevância. Em torno de 38404 pessoas morreram em situações relacionadas ao trânsito no ano de 2007, o equivalente a 4,0\% do total de óbitos segundo (Ministério da Saúde, 2009).

A taxa de mortalidade por 100 mil habitantes também denominada pela abreviação TME (Taxa de Mortalidade Específica) pode ser mensurada e tomada como um indicador do nível de segurança oferecido nesse quesito em um país. Na Figura 8 os valores desse indicador são apresentados entre os anos de 1998 a 2008 (Ministério da Saúde, 2009; RIPSA, 2009). Uma tendência de evolução do valor total é notável desde 2000. O valor desse índice em 2007 alcançou 20,3. Comparativamente à Suécia, o Brasil apresenta mais do que quatro vezes a mortalidade em acidentes desse tipo (World Health Organization, 2009). Além disso, enquanto a 
tendência nesses países e em outros qualificados como desenvolvidos é de redução, no Brasil a tendência é oposta.

No grupo considerado como acidentes de transporte são incluídos, além dos acidentes de trânsito, casos envolvendo acidentes com barcos, aviões e trens, mas de pequena contribuição. Especificamente nos casos envolvendo acidentes de trânsito, as vítimas podem ser classificadas em três grupos: motociclista, ocupante (passageiros ou condutores de veículos automotores) e pedestre. Segundo essa classificação houve maior crescimento das taxas de mortalidade dos motociclistas, que evoluíram de 0,5 óbitos por 100 mil habitantes em 1996 para 4,5 em 2008, de acordo com a Figura 8, superando o índice dos ocupantes. Este, por sua vez, tem mantido uma taxa relativamente constante nos últimos anos, fato que pode ser atribuído à evolução contínua nos sistemas de segurança embarcados em automóveis mais novos e duplicações e melhorias em rodovias a partir de 2001.

Note que o número da frota de veículos, excluindo-se as motocicletas, aumenta a uma taxa média de 7,4\% ao ano (SINDIPEÇAS/ABIPEÇAS, 2011). O número de motocicletas nas ruas brasileiras aumenta em média 15\% ao ano desde 2000 (SINDIPEÇAS/ABIPEÇAS, 2011) e as políticas de segurança aplicadas em estradas exclusivas aos motociclistas são inexistentes.

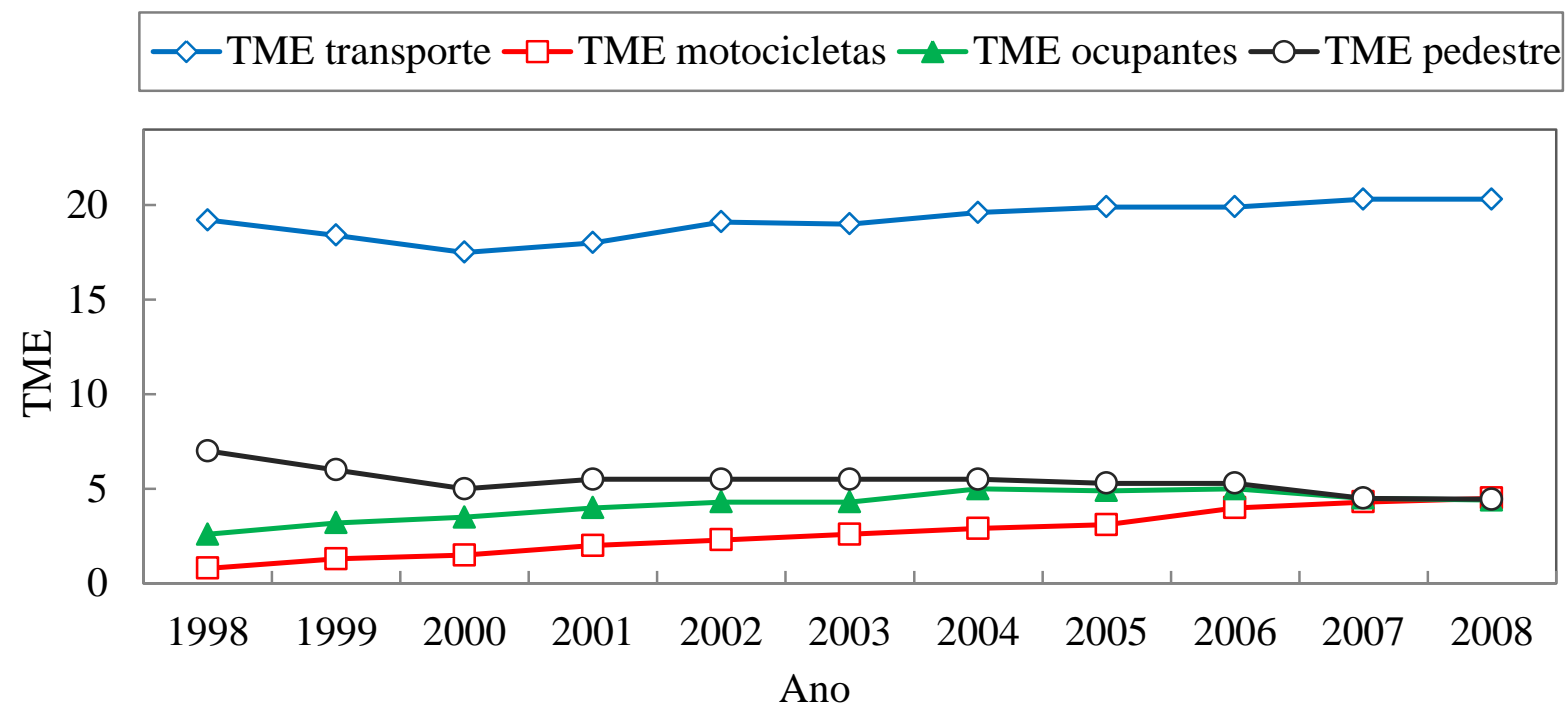

Figura 8 - TME (taxa de mortalidade específica) por acidentes de transporte no Brasil na década de 1998 a 2008 segundo dados do Ministério da Saúde (2009) e RIPSA (2009). 
O risco à morte em acidentes de trânsito é possível de ser estimado através do número de mortes geradas para cada número de cem acidentes do mesmo tipo. Esse indicador é apresentado na Figura 9. Os três casos de maior risco à morte em acidentes de trânsito são causados por colisão frontal, seguida de atropelamento de pedestre e capotamento.

O risco à morte devido a saída de pista representa 3,48\% aos envolvidos, colocando-se como um dos cinco acidentes mais perigosos. Mortes causadas por saída de pista poderiam ser evitadas através da instalação de defensas em locais necessários, o que certamente diminuiria bastante as fatalidades incluídas nessa categoria. As mortes causadas por colisão frontal, acidente de maior periculosidade, também pode ser reduzida com a implantação de vias duplas dividas por defensas.

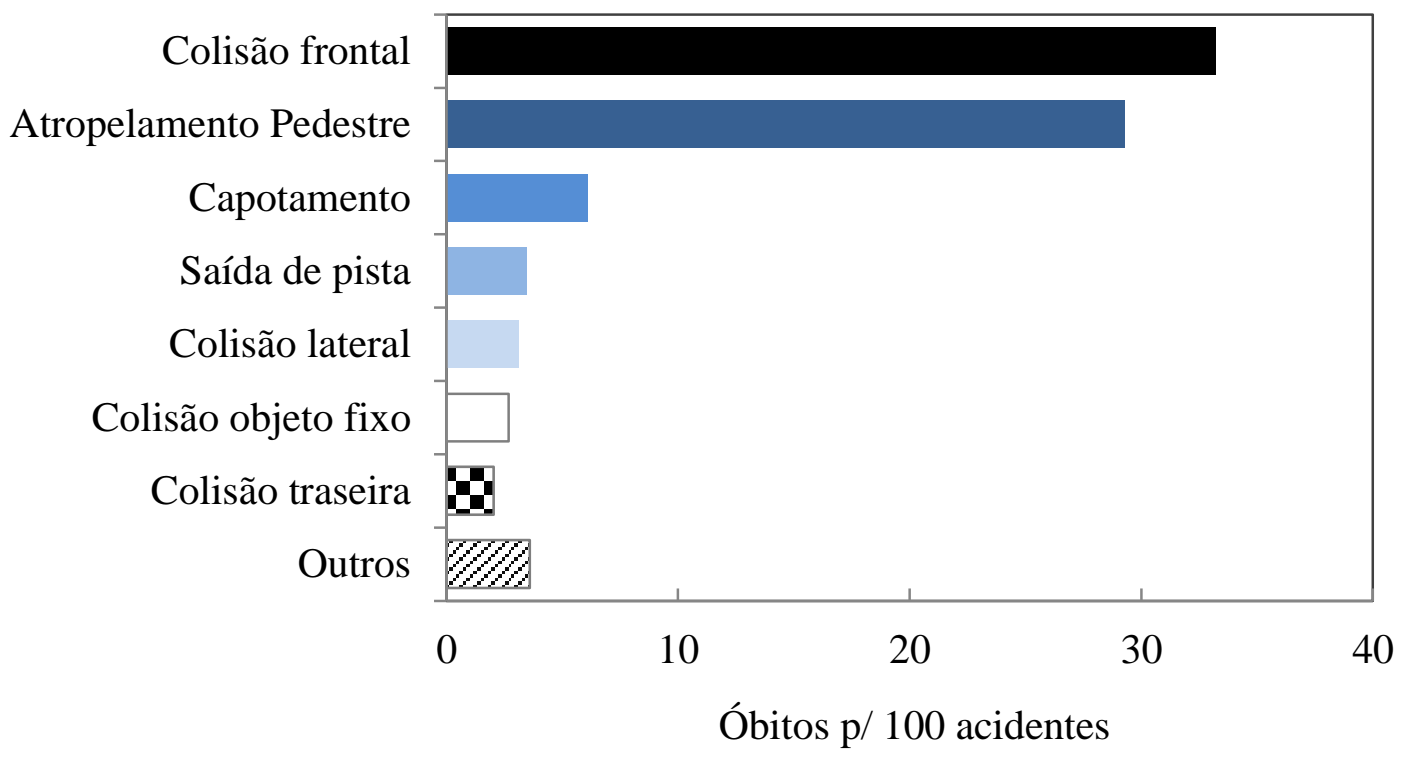

Figura 9 - Número de mortos em cada 100 acidentes de trânsito segundo tipo (IPEA/DENATRAN/ANTP, 2006)

Segundo o (IPEA/DENATRAN/ANTP, 2006), o custo total dos acidentes de trânsito ocorridos entre julho de 2004 a junho de 2005 foi de cerca de 22 bilhões de reais (valores de dezembro de 2005). Nesse resultado estão incluídos os seguintes prejuízos: cuidados com saúde, relativos ao veículo, à via, ao ambiente e atendimento ao acidente. A ordem de grandeza dos custos médios de um óbito em uma rodovia federal foi estimada em 418 mil reais, no mesmo período. 
Nesse cenário, fica evidente que há uma carência na disponibilidade e na qualidade da aplicação de sistemas de segurança oferecidos aos ocupantes, motociclistas e pedestres nas estradas brasileiras. O desempenho dos principais sistemas de contenção rodoviária utilizados no país como a defensa metálica e a defensa de concreto serão avaliadas neste trabalho considerando o impacto de um automóvel leve e as suas consequências de severidade aos ocupantes. 


\section{OBJETIVOS}

A necessidade de investigar o desempenho de uma defensa metálica comparativamente a outros modelos de defensa rígida sujeitas ao impacto de um automóvel é o motivo dos estudos e discussões presentes neste trabalho. A metodologia de comparação entre os sistemas de contenção escolhidos é fundamentada por índices de severidade ao ocupante, os quais são definidos por norma.

No contexto da defensa metálica, modelos analítico e numérico são desenvolvidos para examinar a influência da resistência da conexão parafusada no mecanismo de deformação da defensa metálica. O método convencional de modelagem considera valores empíricos para o critério de falha das conexões, os quais podem ser críticos para o desempenho de uma defensa. Propõe-se então uma metodologia baseada em resultados de simulações numéricas para avaliar o parâmetro de falha de um modelo de conexão simplificado de acordo com a capacidade de uma defensa metálica em redirecionar um veículo.

A caracterização do material da defensa é tratada como fator determinante para correta representação numérica. Visto que a mudança do comportamento do material frente à solicitação dinâmica é relevante, são então medidas as propriedades mecânicas da defensa metálica em baixas e altas taxas de deformação. Pretendeu-se com isto identificar os parâmetros do modelo dinâmico de Cowper-Symonds para uma predição adequada do comportamento do material.

Frente à necessidade de realizar testes dinâmicos, uma máquina baseada no princípio de propagação de ondas longitudinais em barras cilíndricas proposto por Hopkinson e Kolsky foi projetada, construída e testada. A máquina realiza testes de tração ou compressão a taxas de

deformação entre $1000 \mathrm{~s}^{-1}$ e $5000 \mathrm{~s}^{-1}$, dependendo de fatores como a geometria e/ou material do corpo de prova.

Na busca dessas metas, o Capítulo 3 apresenta o projeto e fabricação da Barra de Hopkinson. No Capítulo 4 realiza-se a caracterização quase-estática e dinâmica do material da defensa metálica, incluindo a calibração dos parâmetros do modelo Cowper-Symonds. Um modelo analítico simplificado da defensa é resolvido em seguida no Capítulo 5, onde a validação de um modelo em elementos finitos equivalente é realizada a partir dos resultados teóricos. Os 
resultados das simulações numéricas de impacto de veículos contra defensas, a influência da resistência da conexão parafusada na trajetória do automóvel e o cálculo dos índices de severidade ao ocupante de cada tipo de defensa são tratadas no Capítulo 6. Por último, o Capítulo 7 encerra o trabalho com as principais conclusões obtidas. 


\section{PROJETO DE UMA BARRA DE HOPKINSON}

O sucesso no emprego adequado de materiais requer uma correta adequação entre propriedades e a finalidade de uso. Na hierarquia das propriedades mecânicas, um assunto cada vez mais relevante é a resposta dinâmica dos materiais. O equipamento mais utilizado para medição de propriedades mecânicas em altas taxas de deformação é a Barra de Hopkinson. Seu princípio de funcionamento se baseia na propagação de ondas elásticas em duas barras longas, de entrada e de saída. Uma amostra a ser testada é colocada entre as barras e os pulsos incidente, refletido e transmitido são medidos, permitindo obter a curva tensão-deformação do material a uma certa taxa de deformação (Gallina, 2004).

Neste trabalho são desenvolvidas as equações de propagação de ondas em meios elásticos e em seguida aplicadas ao caso de propagação em barras cilíndricas, utilizando a teoria elemen$\operatorname{tar}$ (Timoshenko \& Goodier, 1980).

A seguir serão desenvolvidas as equações simplificadas para o projeto de uma Barra de Hopkinson de compressão ou tração.

\subsection{PRINCÍPIO DE FUNCIONAMENTO}

Diferentemente dos testes de tração quase-estáticos, o teste na Barra de Hopkinson BH, visa a caracterização do material a altas taxas de deformação. Segundo (Govender, 2005), os resultados obtidos por esse dispositivo permitem avaliar o comportamento do material sob taxas de deformação de até $10^{4} \mathrm{~s}^{-1}$, em testes compressivos, e $5 \times 10^{3} \mathrm{~s}^{-1}$, para testes de tensão e torção.

A Figura 10 apresenta o princípio de funcionamento para caracterização dinâmica em compressão. Desde a sua invenção em 1949, a BH sofreu diversas alterações, sendo adaptada para testes de tração, torção, entre outros. A BH permite levantar curvas de tensão-deformação a diversas taxas de deformação, o que é útil para a determinação dos parâmetros utilizados na modelagem matemática dos materiais, como os modelos de Cowper-Symods e Johnson Cook. 


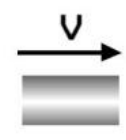

STRIKER

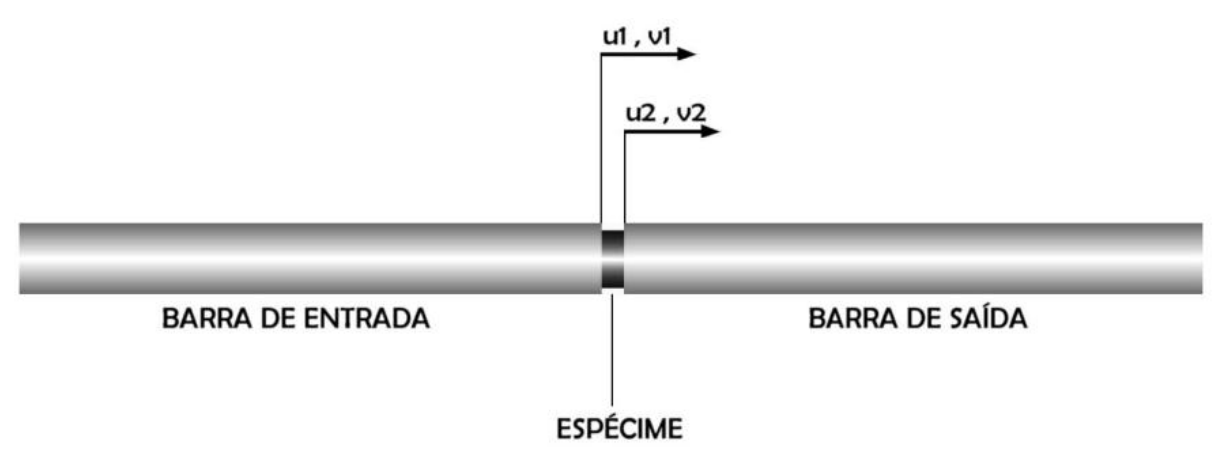

Figura 10 - Esquema de funcionamento da BH

O teste consiste em atirar com uma pistola de pressão uma pequena barra cilíndrica, chamada striker, contra um conjunto de três elementos: barra de entrada, espécime, barra de saída. O choque do striker na barra de entrada gera uma onda de deformação incidente, $\varepsilon_{i}(t)$ que a percorre. Ao atingir o corpo de prova, parte da onda é refletida $\varepsilon_{r}(t)$, e parte percorre o corpo de prova sendo transmitida para a outra barra $\varepsilon_{t}(t)$.

A técnica de medição comumente utilizada na BH necessita que os pontos de medição das deformações da barra estejam distantes do corpo de prova para evitar superposição dos pulsos incidente e refletido. Mas devido ao fenômeno de dispersão esses sinais não são exatamente iguais na interface com o corpo de prova, o qual se desejaria medir (Govender, 2005). Resultados demonstram que a correção do sinal depende do material e da geometria da barra e foi evidenciado em testes preliminares que seu efeito é desprezível para o caso das barras projetadas.

Para o cálculo das curvas de tensão e deformação do material através da BH, utiliza-se a teoria de propagação de ondas unidimensional, o que impõe as seguintes hipóteses simplificadoras:

(i) O campo de tensões e de deformações é uniforme na direção axial no espécime;

(ii) Os efeitos de inércia e de atrito no espécime são desprezados;

(iii) Efeitos de dispersão são negligenciados. 
Tais considerações apontam limitações ao teste. Em relação aos materiais metálicos a curva média de tensão-deformação é bem aceita. Para materiais não metálicos como concreto, rochas, polímeros e espumas poliméricas, a acurácia da curva é menor.

Apesar disso, a BH segue em uso principalmente pela vantagem construtiva de simplicidade em relação aos outros métodos disponíveis para o mesmo fim, como as máquinas de teste hidráulicas de alta velocidade. Por outro lado, existem métodos para correção dos dados obtidos em um ensaio descartando as hipóteses anteriores, como o método da correção de dispersão de Pochammer-Chree.

Os pulsos de deformação incidente, refletido e transmitido são medidos em pontos estratégicos nas barras de entrada e saída utilizando-se extensômetros. $\mathrm{O}$ efeito de inércia lateral durante a propagação das ondas causa o efeito de dispersão, que muda o formato do pulso durante sua propagação. Por isso a acurácia na medição das deformações no espécime pode ser melhorada com o uso de métodos de correção de dispersão quando esta não é desprezível.

Pochammer (1876) e Chree (1941) chegaram na mesma solução da equação diferencial de propagação de ondas em barras cilíndricas. $\mathrm{O}$ método define que a velocidade de propagação da onda é uma função do seu comprimento, apresentando de maneira implícita o fenômeno da disperção. Uma tentativa de introduzir os efeitos de inércia lateral na vibração longitudinal foi apresentada também por (Rayleigh, 1945). Em seguida, surgiram métodos numéricos para a solução das equações de dispersão de Pochammer-Chree.

Baseado nas deduções feitas para alcançar as expressões da propagação de onda longitudinal e distorcional desenvolvidas no Apêndice A, as equações de onda de tensão em um corpo sólido com características de isotropia e comportamento elástico linear podem ser encontradas aplicando-se as condições de contorno apropriadas à equação (A.21). No entanto, devido à grande complexidade dessas equações, ainda não foram encontradas soluções exatas para barras cilíndricas de comprimento finito, de modo que o problema é resolvido utilizando aproximações.

A hipótese fundamental para desenvolver tal solução baseia-se na consideração de uma barra cilíndrica cujo diâmetro é muito menor que o seu comprimento. Além disso, é necessário as- 
sumir as seguintes hipóteses simplificadoras para obter uma solução analítica da propagação de ondas de modo unidirecional:

1. Barra prismática;

2. Homogeneidade do material;

3. Secções planas e paralelas permanecem planas e paralelas após deformação;

4. Tensão uniaxial.

De acordo com a hipótese 4, existe tensão apenas na direção de propagação da barra, porém o estado de deformações não será uniaxial.

Sendo $x$ a coordenada de propagação do pulso que possui deslocamento $u(x, t)$ e $\rho$ a densidade do material, o equilíbrio dinâmico entre duas secções transversais $x$ e $x+d x$ é escrito por:

$$
-\sigma A+\left(\sigma+\frac{\partial \sigma}{\partial x}\right) A=\rho A d x \frac{\partial^{2} u}{\partial t^{2}}
$$

onde $A$ é a área da seção transversal. Simplificando a equação (3.1),

$$
\frac{\partial \sigma}{\partial x}=\rho \frac{\partial^{2} u}{\partial t^{2}}
$$

A equação (3.2) descreve a equação governante para problemas elásticos e não-elásticos, pois nenhuma característica do material foi adotada. Mas, considerando um material elástico-linear cujo módulo de elasticidade é definido por $E$, sabe-se que:

$$
\sigma=E \frac{\partial u}{\partial x}
$$

Substituindo na equação (3.2), resulta: 


$$
\frac{\partial^{2} u}{\partial x^{2}}=\frac{\rho}{E} \frac{\partial^{2} u}{\partial t^{2}}
$$

Definindo a velocidade de onda $c$ :

$$
\begin{gathered}
c=\sqrt{\frac{E}{\rho},} \\
\frac{\partial^{2} u}{\partial t^{2}}=c^{2} \frac{\partial^{2} u}{\partial x^{2}} .
\end{gathered}
$$

\subsection{MODELAGEM MATEMÁTICA DA BARRA DE HOPKINSON}

As equações utilizadas para o tratamento de sinais da BH são obtidas levando-se em conta a guisa de hipóteses 1 a 4 levantadas no item anterior e ainda considerando que:

5. O intervalo de tempo no qual as ondas de tensão percorrem o corpo de prova é muito menor que o tempo total do teste, permitindo que diversas reflexões ocorram nas extremidades do corpo de prova. Isso implica que o corpo de prova mantém-se em equilíbrio dinâmico durante o teste.

6. As tensões e velocidades nas extremidades do corpo de prova são transmitidas sem dispersão pela barra de entrada e saída.

Adotando o mesmo material e área transversal para as barras de entrada e saída, obtemos expressões simples para a tensão, deformação e taxa de deformação no corpo de prova.

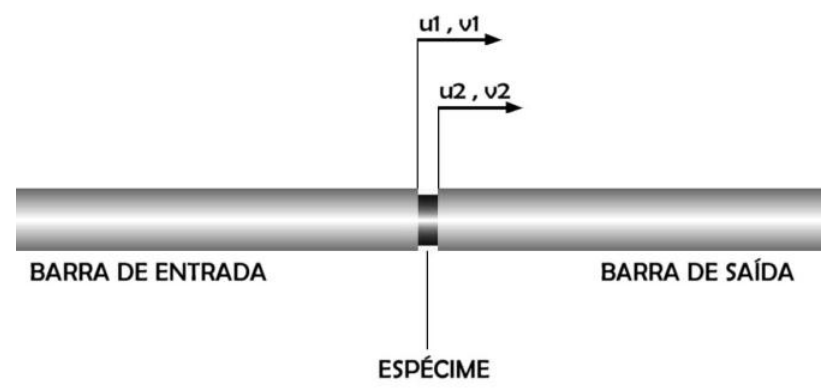

Figura 11 - Definição das fronteiras do espécime 
Considerando as fronteiras do corpo de prova como sendo: 1 a fronteira com a barra de entrada e 2 a fronteira com a barra de saída. Os pulsos incidente, refletido e transmitido são representados por $\varepsilon_{i}(t), \varepsilon_{r}(t), \varepsilon_{t}(t)$ e sendo $u_{1}$ e $u_{2}$ os deslocamentos nas fronteiras.

$$
\begin{gathered}
u_{1}(t)=\int_{0}^{t} c\left[\varepsilon_{i}(t)-\varepsilon_{r}(t)\right] d t \\
u_{2}(t)=\int_{0}^{t} c \varepsilon_{t}(t) d t
\end{gathered}
$$

onde $c$ é a velocidade de onda expressa por (3.5).

Como o estado de tensão do corpo de prova é admitido constante ao longo do tempo, a deformação no corpo de prova $\varepsilon_{c p}$ é dada por,

$$
\varepsilon_{c p}(t)=\frac{u_{2}(t)-u_{1}(t)}{L_{c p}}
$$

sendo $L_{c p}$ o comprimento do corpo de prova. Substituindo as equações (3.7) e (3.8) na equação (3.9),

$$
\varepsilon_{c p}(t)=\frac{c}{L_{c p}} \int_{0}^{t}\left[\varepsilon_{i}(t)-\varepsilon_{r}(t)-\varepsilon_{t}(t)\right] d t
$$

As forças nas extremidades do corpo de prova são obtidas de:

$$
\begin{gathered}
P_{1}(t)=E A\left[\varepsilon_{i}(t)+\varepsilon_{r}(t)\right], \\
P_{2}(t)=E A \varepsilon_{t}(t),
\end{gathered}
$$

sendo $E$ e $A$ o módulo de elasticidade e a área das barras de entrada e saída. Por hipótese, $P_{1}=P_{2}$ então:

$$
\varepsilon_{t}(t)=\varepsilon_{i}(t)+\varepsilon_{r}(t)
$$

Portanto, 


$$
\begin{gathered}
\varepsilon_{c p}(t)=\frac{c}{L_{c p}} \int_{0}^{t}\left[\varepsilon_{i}(t)-\varepsilon_{r}(t)-\varepsilon_{t}(t)\right] d t, \\
\dot{\varepsilon}_{c p}(t)=\frac{c}{L_{c p}}\left[\varepsilon_{i}(t)-\varepsilon_{r}(t)-\varepsilon_{t}(t)\right], \\
\sigma_{c p}(t)=E \frac{A}{A_{c p}} \varepsilon_{t}(t),
\end{gathered}
$$

onde $\sigma_{c p}$ é a tensão no corpo de prova, $A_{c p}$ a área da seção transversal do corpo de prova e $\dot{\varepsilon}_{c p}$ a taxa de deformação do espécime.

\subsection{DIMENSIONAMENTO DO EQUIPAMENTO}

Os requisitos de projeto especificados para a máquina de ensaios a alta taxa deformação são:

- Tipo de teste: compressão e tração;

- Materiais do espécime: metais;

- Temperatura: ambiente;

- Taxa de deformação: de $1000 \mathrm{~s}^{-1}$ a $5000 \mathrm{~s}^{-1}$;

- Máxima tensão no corpo de prova: $1500 \mathrm{MPa}$;

- Deformação máxima: 20\%;

Considerando os requisitos acima o projeto é desenvolvido considerando as condições críticas de operação da máquina - sob a mínima taxa de deformação e a máxima - a partir da qual serão obtidos o comprimento e diâmetro das barras; velocidade e comprimento do striker.

Para obter esses dados, considere a seguinte situação onde o striker colide com a barra de entrada. Considerando a Figura 12, antes do impacto o striker tem velocidade $v_{s t}$ enquanto a barra de entrada encontra-se em repouso. No momento de impacto, a força agindo na interface é 
a mesma, de acordo com o princípio da ação e reação. A velocidade na interface de contato também deve ser a mesma, e deve ser tal que $0<v_{i}<v_{s t}$. Se $\sigma_{s t}$ e $\sigma_{i}$ forem as tensões geradas no striker e na Barra de entrada, respectivamente, a seguinte expressão é válida.

$$
A_{s t} \sigma_{s t}=A \sigma_{i}
$$

sendo $A_{s t}$ a área da seção transversal do striker. As tensões nas barras estão relacionadas com a velocidade na interface comum, assim:

$$
\begin{gathered}
\sigma_{s t}=\rho_{s t} c_{s t}\left(v_{s t}-v_{i}\right), \\
\sigma_{i}=\rho c_{0} v_{i},
\end{gathered}
$$

sendo $\rho_{s t}$ a densidade do striker, $\rho$ a densidades da barra de entrada, $c_{s t}$ a velocidade de progação de onda elástica no striker e $c_{0}$ a velocidades de propagação da onda elástica na barra de entrada.

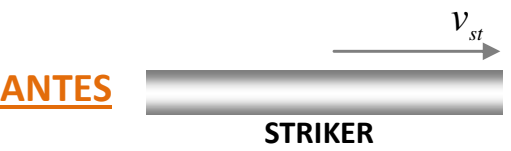
STRIKER $v=0$

BARRA DE ENTRADA

\section{DEPOIS}

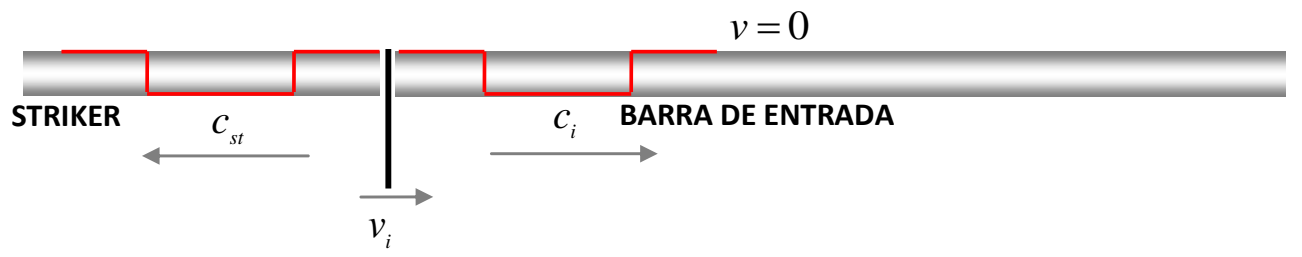

Figura 12 - Impacto coaxial do striker e a barra de entrada.

Substituindo (3.19) e (3.18) em (3.17) obtém-se,

$$
v_{i}=\frac{\beta v_{s t}}{1+\beta}
$$

onde a constante $\beta$ depende apenas das propriedades do material da barra e do striker, como segue: 


$$
\beta=\frac{A_{s t} \rho_{s t} c_{s t}}{A \rho c_{0}}
$$

Substituindo agora as equações acima em (3.18) e (3.19) obtém-se uma forma de calcular a tensão no striker $\sigma_{s t}$ e na barra de entrada $\sigma_{i}$. O valor da tensão depende da velocidade de impacto do striker e de constantes do material. Portanto, para garantir um funcionamento adequado das barras, essas tensões devem estar sempre abaixo do limite de escoamento do material.

$$
\begin{gathered}
\sigma_{s t}=\frac{\rho_{s t} c_{s t} v_{s t}}{1+\beta}, \\
\sigma_{i}=\frac{\rho c_{0} \beta v_{s t}}{1+\beta} .
\end{gathered}
$$

O striker e a barra de entrada permanecem em contato até que o pulso gerado no striker reflita na extremidade oposta e retorne à interface de contato. $\mathrm{O}$ tempo $t_{p}$ necessário para que o pulso retorne à interface de contato é igual a:

$$
t_{p}=\frac{2 L_{s t}}{c_{s t}}
$$

sendo $L_{s t}$ o comprimento do striker. Portanto, o comprimento do pulso $L_{p}$ gerado na barra de entrada é,

$$
L_{p}=c_{0} t_{p}=2 L_{s t} \frac{c_{0}}{c_{s t}}
$$

O comprimento do pulso gerado pelo striker determina o comprimento mínimo das barras afim de que não haja interposição do sinal medido pelos extensômetros. Ambas as barras devem possuir comprimento total sempre maior que o comprimento do pulso $L_{p}$; no entanto a posição dos extensômetros depende de outros aspectos.

O pulso de tensão gerado pelo striker propaga-se ao longo da barra de entrada e ao atingir a interface de contato com o espécime é parcialmente refletido e parcialmente transmitido. Por 
isso, na barra de entrada, os extensômetros devem ser posicionados de tal modo que a distância entre a interface de contato com o espécime e o ponto de medição seja sempre maior que comprimento do pulso $L_{p}$, pois o sinal incidente e refletido deve ser medido sem interferência. $\mathrm{Na}$ barra de saída, o extensômetro pode ser posicionado mais próximo da interface, pois apenas o pulso transmitido é de interesse.

A intensidade do pulso transmitido $\sigma_{t}$ deve garantir que o corpo de prova seja solicitado segundo a tensão especificada $\sigma_{c p}$. De acordo com a equação (3.16) a tensão deve ser dada por:

$$
\sigma_{t}=\frac{A_{c p}}{A} \sigma_{c p}
$$

A taxa de deformação do corpo de prova é proporcional ao pulso refletido de acordo com equação (3.15). Como o valor da taxa de deformação é um dado de entrada, é possível relacionar a tensão refletida $\sigma_{r}$ e a taxa de deformação pretendida:

$$
\sigma_{r}=\frac{E L_{c p}}{-2 c_{0}} \dot{\varepsilon}_{c p}
$$

Recordando a equação (3.13), é possível escrevê-la em função das tensões bastando multiplicar os fatores pelo Módulo de Elasticidade das barras $E$. Substituindo então os resultados (3.26) e (3.27),

$$
\sigma_{i}=\frac{A_{c p}}{A} \sigma_{c p}+\frac{E L_{c p}}{-2 c_{0}} \dot{\varepsilon}_{c p} .
$$

Para obter uma expressão que relaciona a velocidade do striker $v_{s t}$ às variáveis de projeto $\sigma_{c p} \mathrm{e}$ $\dot{\varepsilon}_{c p}$, substitui-se a equação (3.23) na (3.28), o que fornece:

$$
v_{s t}=\frac{1+\beta}{\rho c_{0} \beta}\left(\frac{A_{c p}}{A} \sigma_{c p}+\frac{E L_{c p}}{2 c_{0}} \dot{\varepsilon}_{c p}\right) .
$$

Conforme pode ser observado pela equação (3.14), a deformação no corpo de prova é diretamente proporcional à intensidade e o tempo de duração do pulso refletido. Admitindo intensi- 
dade constante do pulso refletido, a seguinte expressão pode ser desenvolvida para o tempo de duração do pulso $t_{p}$ em função dos dados de entrada $\varepsilon_{c p}$ e $L_{c p}$ :

$$
t_{p}=\frac{\varepsilon_{c p} L_{c p}}{-2 c_{0} \varepsilon_{r}}
$$

Substituindo a expressão anterior na equação (3.25) obtém-se o comprimento do pulso de tensão $L_{p}$ - variável que determina automaticamente o comprimento do striker $L_{s t}$ - requerido para um dado corpo de prova cuja deformação máxima $\varepsilon_{c p}$ seja fixada.

$$
\begin{gathered}
t_{p}=\frac{\varepsilon_{c p} L_{c p}}{-2 c_{0} \varepsilon_{r}}, \\
L_{p}=\frac{\varepsilon_{c p} L_{c p}}{-2 \varepsilon_{r}}, \\
L_{s t}=\frac{L_{p}}{2} \frac{c_{s t}}{c_{0}} .
\end{gathered}
$$

Considerando barras de diâmetro de 25,4 mm fabricados em aço, cujo Módulo de Elasticidade é $205 \mathrm{GPa}$ e densidade de $7850 \mathrm{~kg} / \mathrm{m}^{3}$; corpos de prova em aço com geometria anelar descrita por diâmetro externo de $12,7 \mathrm{~mm}$, espessura de $1 \mathrm{~mm}$ e comprimento de $3 \mathrm{~mm}$, foram adotados no dimensionamento. O esquema de funcionamento e a disposição das barras são ilustrados na Figura 13. Os resultados expressos na Tabela 2 e Tabela 3 foram obtidos para as condições críticas de operação no teste de compressão.

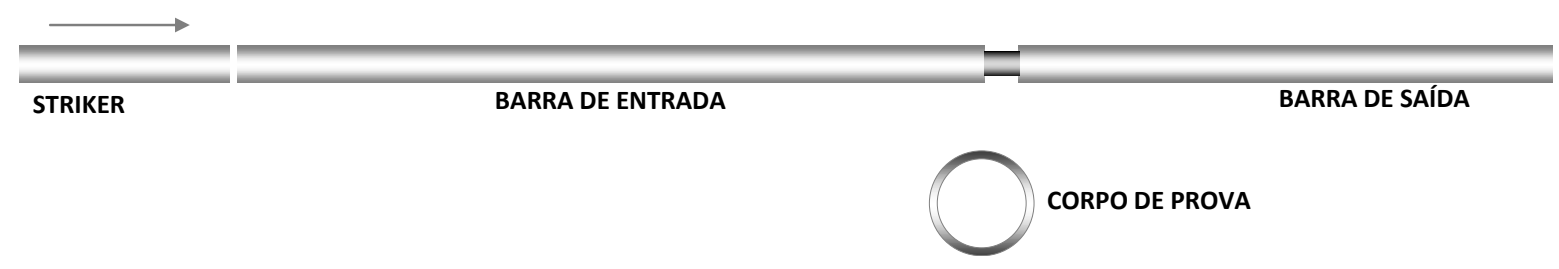

Figura 13 - Esquema das barras para o teste de compressão, destacando o uso do corpo de prova anelar. 
Tabela 2 - Dimensionamento da máquina à baixa taxa de deformação $1000 \mathrm{~s}^{-1}$.

\begin{tabular}{ccccc}
\hline \multicolumn{5}{c}{ ENTRADAS } \\
\hline$\sigma_{\mathrm{cp}}$ & $\varepsilon_{\text {máx }}^{\cdot}$ & $\mathrm{A}_{\mathrm{cp}}$ & $\mathrm{L}_{\mathrm{cp}}$ & $\varepsilon_{\mathrm{cp}}$ \\
$\mathrm{MPa}$ & $\mathrm{s}^{-1}$ & $\mathrm{~m}^{2}$ & $\mathrm{~m}$ & - \\
\hline 1500 & 1000 & $3,5 \mathrm{E}-05$ & 0,003 & 0,20 \\
\hline
\end{tabular}

\begin{tabular}{ccccccc}
\hline \multicolumn{7}{c}{ SAÍDAS } \\
\hline $\mathrm{V}_{\mathrm{st}}$ & $\mathrm{L}_{\mathrm{st}}$ & $\sigma_{\mathrm{i}}$ & $\sigma_{\mathrm{r}}$ & $\sigma_{\mathrm{t}}$ & $\mathrm{L}_{\mathrm{p}}$ & $\mathrm{t}_{\mathrm{p}}$ \\
$\mathrm{m} / \mathrm{s}$ & $\mathrm{m}$ & $\mathrm{MPa}$ & $\mathrm{MPa}$ & $\mathrm{MPa}$ & $\mathrm{m}$ & $\mu \mathrm{s}$ \\
\hline 8,1 & 0,511 & 162,5 & 60,2 & 102,3 & 1,02 & 200,0 \\
\hline
\end{tabular}

Tabela 3 - Dimensionamento da máquina à alta taxa de deformação $5000 \mathrm{~s}^{-1}$.

\begin{tabular}{ccccc}
\hline \multicolumn{5}{c}{ ENTRADAS } \\
\hline$\sigma_{\mathrm{cp}}$ & $\varepsilon_{\text {máx }}^{\cdot}$ & $\mathrm{A}_{\mathrm{cp}}$ & $\mathrm{L}_{\mathrm{cp}}$ & $\varepsilon_{\mathrm{cp}}$ \\
$\mathrm{MPa}$ & $\mathrm{s}^{-1}$ & $\mathrm{~m}^{2}$ & $\mathrm{~m}$ & - \\
\hline 1500 & 5000 & $3,5 \mathrm{E}-05$ & 0,003 & 0,10 \\
\hline
\end{tabular}

\begin{tabular}{ccccccc}
\hline \multicolumn{7}{c}{ SAÍDAS } \\
\hline $\mathrm{V}_{\mathrm{st}}$ & $\mathrm{L}_{\mathrm{st}}$ & $\sigma_{\mathrm{i}}$ & $\sigma_{\mathrm{r}}$ & $\sigma_{\mathrm{t}}$ & $\mathrm{L}_{\mathrm{p}}$ & $\mathrm{t}_{\mathrm{p}}$ \\
$\mathrm{m} / \mathrm{s}$ & $\mathrm{m}$ & $\mathrm{MPa}$ & $\mathrm{MPa}$ & $\mathrm{MPa}$ & $\mathrm{m}$ & $\mu \mathrm{s}$ \\
\hline 20,1 & 0,051 & 403,2 & 300,9 & 102,3 & 0,10 & 20,0 \\
\hline
\end{tabular}

Considerando barras de diâmetro de 25,4 mm fabricados em alumínio, cujo Módulo de Elasticidade é $71,7 \mathrm{GPa}$ e densidade de $2810 \mathrm{~kg} / \mathrm{m}^{3}$; corpos de prova em aço com geometria "dog bone" descrita por uma área transversal de $30 \mathrm{~mm}^{2}$ e comprimento de $10 \mathrm{~mm}$, foram adotados no dimensionamento. O esquema de funcionamento e a disposição das barras são ilustrados na Figura 14. Os resultados expressos na Tabela 4 e Tabela 5 foram obtidos para as condições críticas de operação no teste de compressão.

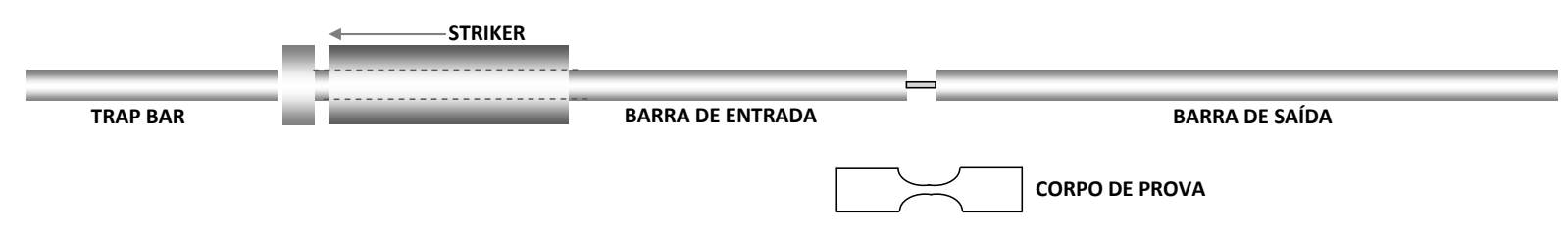

Figura 14 - Esquema das barras para o teste de tração, destacando o uso do corpo de prova em chapa e geometria tipo "dog bone".

Tabela 4 - Dimensionamento da máquina à baixa taxa de deformação $1000 \mathrm{~s}^{-1}$.

\begin{tabular}{cccccc}
\hline \multicolumn{6}{c}{ ENTRADAS } \\
\hline$\sigma_{\mathrm{cp}}$ & $\varepsilon_{\text {máx }}^{\cdot}$ & $\beta$ & $\mathrm{A}_{\mathrm{cp}}$ & $\mathrm{L}_{\mathrm{cp}}$ & $\varepsilon_{\mathrm{cp}}$ \\
$\mathrm{MPa}$ & $\mathrm{s}^{-1}$ & - & $\mathrm{m}^{2}$ & $\mathrm{~m}$ & - \\
\hline 1500 & 1000 & 0,8784 & $4,8 \mathrm{E}-06$ & 0,003 & 0,20 \\
\hline
\end{tabular}

\begin{tabular}{ccccccc}
\hline \multicolumn{7}{c}{ SAÍDAS } \\
\hline $\mathrm{V}_{\mathrm{st}}$ & $\mathrm{L}_{\mathrm{st}}$ & $\sigma_{\mathrm{i}}$ & $\sigma_{\mathrm{r}}$ & $\sigma_{\mathrm{t}}$ & $\mathrm{L}_{\mathrm{p}}$ & $\mathrm{t}_{\mathrm{p}}$ \\
$\mathrm{m} / \mathrm{s}$ & $\mathrm{m}$ & $\mathrm{MPa}$ & $\mathrm{Mpa}$ & $\mathrm{MPa}$ & $\mathrm{m}$ & $\mu \mathrm{s}$ \\
\hline 5,4 & 0,505 & 36,0 & 21,3 & 14,7 & 1,01 & 200,0
\end{tabular}


Tabela 5 - Dimensionamento da máquina à alta taxa de deformação $5000 \mathrm{~s}^{-1}$.

\begin{tabular}{cccccc}
\hline \multicolumn{6}{c}{ ENTRADAS } \\
\hline$\sigma_{\mathrm{cp}}$ & $\varepsilon_{\text {máx }}$ & $\beta$ & $\mathrm{A}_{\mathrm{cp}}$ & $\mathrm{L}_{\mathrm{cp}}$ & $\varepsilon_{\mathrm{cp}}$ \\
$\mathrm{MPa}$ & $\mathrm{s}^{-1}$ & - & $\mathrm{m}^{2}$ & $\mathrm{~m}$ & - \\
\hline 1500 & 5000 & 0,8784 & $4,8 \mathrm{E}-06$ & 0,003 & 0,20 \\
\hline
\end{tabular}

\begin{tabular}{ccccccc}
\hline \multicolumn{8}{c}{ SAÍDAS } \\
\hline $\mathrm{V}_{\mathrm{st}}$ & $\mathrm{L}_{\mathrm{st}}$ & $\sigma_{\mathrm{i}}$ & $\sigma_{\mathrm{r}}$ & $\sigma_{\mathrm{t}}$ & $\mathrm{L}_{\mathrm{p}}$ & $\mathrm{t}_{\mathrm{p}}$ \\
$\mathrm{m} / \mathrm{s}$ & $\mathrm{m}$ & $\mathrm{MPa}$ & $\mathrm{MPa}$ & $\mathrm{MPa}$ & $\mathrm{m}$ & $\mu \mathrm{s}$ \\
\hline 18,2 & 0,101 & 121,1 & 106,5 & 14,7 & 0,20 & 40,0 \\
\hline
\end{tabular}

Segundo a técnica tradicional da $\mathrm{BH}$, o comprimento das barras de entrada e de saída deve ser maior que pelo menos duas vezes o comprimento do maior pulso que será transmitido pelas mesmas. Este requisito é necessário para que não haja interferência nos extensômetros entre o pulso de tensão e suas respectivas reflexões nas extremidades das barras. Assim tomando o comprimento do maior pulso para a barra de compressão o comprimento deve ser no mínimo de $2 \mathrm{~m}$. Para a barra de tração o comprimento mínimo das mesmas deve ser de 2,5 m.

A análise realizada até o momento pressupõe que as barras de entrada, de saída e de impacto operam no regime elástico, portanto deve-se checar durante a escolha das barras se as tensões estão abaixo do limite de escoamento do material. Por isso, as barras de compressão escolhidas são fabricadas em Aço ABNT4340 com tensão de escoamento superior a $700 \mathrm{MPa}$ e as barras de tração fabricadas em Alumínio 7075 T651, cuja tensão de escoamento é aproximadamente $460 \mathrm{MPa}$.

\subsection{BARRA DE HOPKINSON DE TRAÇÃO E COMPRESSÃO}

A solução desenvolvida para realização dos ensaios dinâmicos sob cargas de compressão e tração compreende dois dispositivos independentes instalados sobre a mesma estrutura, conforme ilustrado nas imagens da Figura 15, obtidas modelo tridimensional da $\mathrm{BH}$ desenvolvido no software Inventor Professional. Reservatórios de ar independentes alimentam o disparo do striker da BH de compressão, reservatório posicionado sobre a mesa, e BH tração, reservatório sob a mesa. O comprimento total da máquina é de aproximadamente $10 \mathrm{~m}$ e a largura da mesa de 0,41m na altura da mesa. Três bases em forma de A suportam toda a estrutura apoiados por pés de borracha. Toda a alimentação de ar da máquina é realizada através de um painel automatizado com a opção de operação por um controle eletrônico ou via computador. Fotos da máquina construída são ilustradas na Figura 16. 


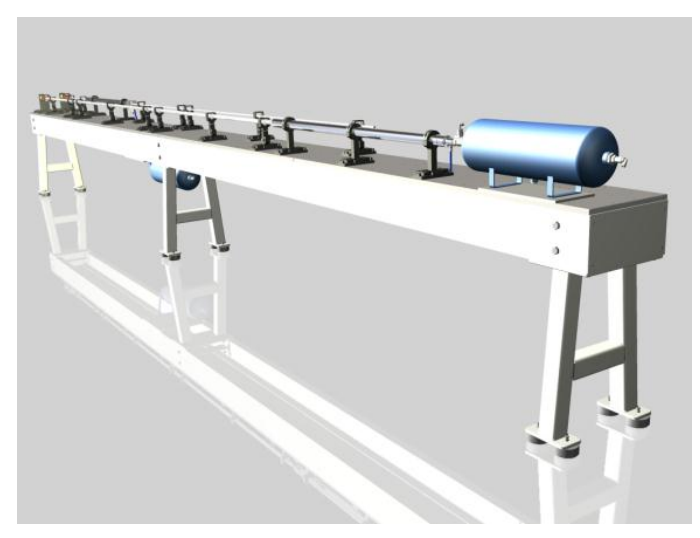

(a)

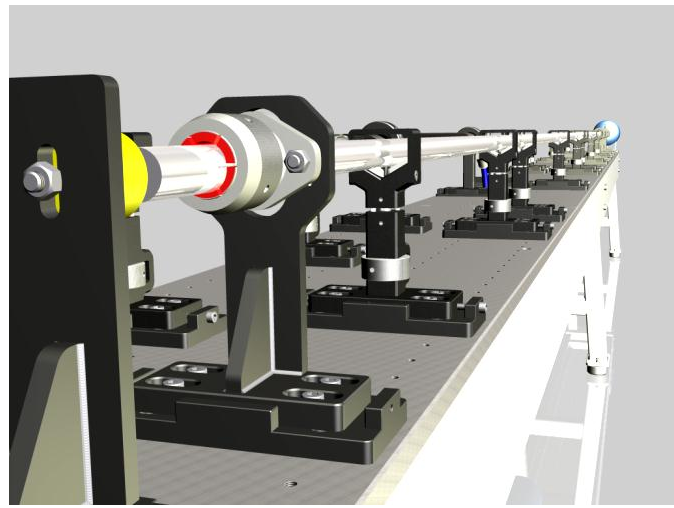

(b)

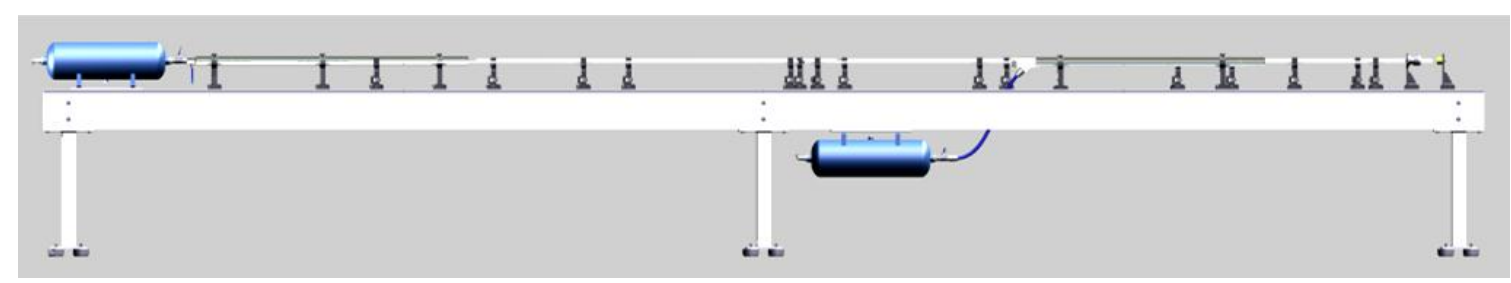

(c)

Figura 15 - Em (a) e (b) são apresentadas duas vistas isométricas da máquina. Em (c) é ilustrada uma vista lateral.

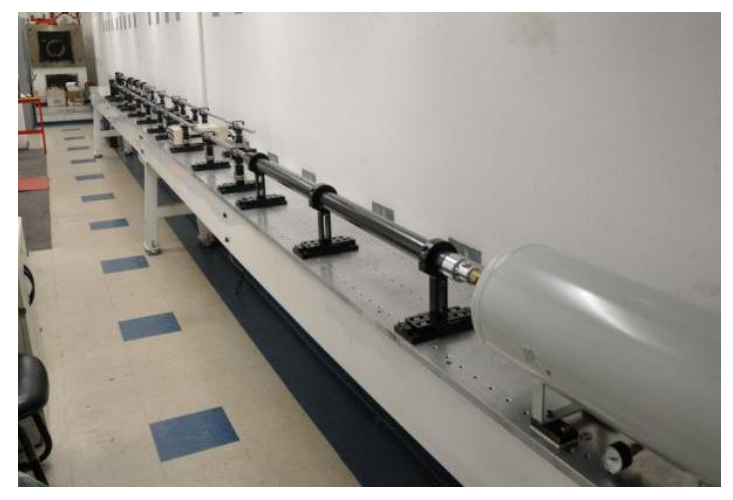

(a)

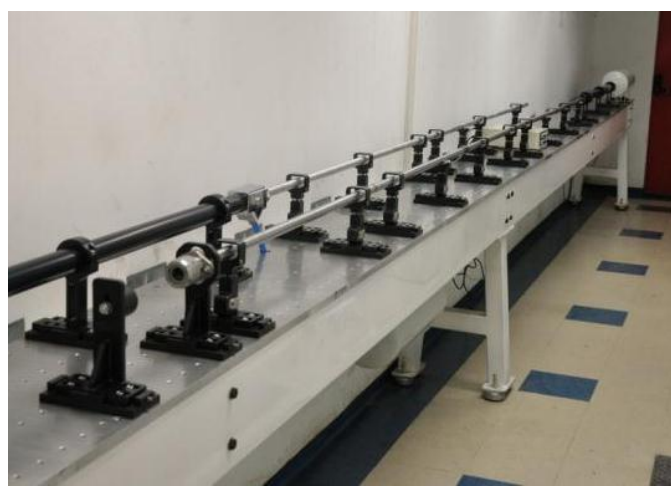

(b)

Figura 16 - Fotos da BH de compressão e tração.

A máquina de ensaios de compressão e tração dinâmica pode ser dividida nos seguintes módulos: estrutura, mancal, sistema de acionamento, sistema de frenagem das barras, instrumentação, barras, striker e corpo de prova. Seguindo essa ordem, algumas características principais serão destacadas a respeito do funcionamento e especificações de cada um desses módulos. 


\subsubsection{Estrutura}

A estrutura de uma $\mathrm{BH}$ precisa ser rígida e possuir grande inércia para absorver vibrações resultantes do impacto do striker e a barra de entrada. Devido a esses eventos ondas percorrem toda a estrutura excitando vibrações que podem ser prejudiciais à qualidade da medição. Por isso, um conjunto rígido e de grande massa composto por vigas $U$ estruturais de $200 \mathrm{~mm}$ de alma e 10m foram adotadas para fixar chapas de Alumínio 6061 com 19,1mm de espessura e 410mm de largura, formando uma mesa de apoio aos dispositivos de barras. O conjunto é sustentado por 3 bases em forma de A, fabricados com perfis caixão de aço de 80x 80mm e $5 \mathrm{~mm}$ de espessura, em cujos pés são fixados 4 amortecedores de vibração. A estrutura desenvolvida forma uma espécie de mesa dotada de uma série de furos roscados padronizados para fixação dos mancais, reservatórios e demais componentes, conforme esquema apresentado na Figura 17.
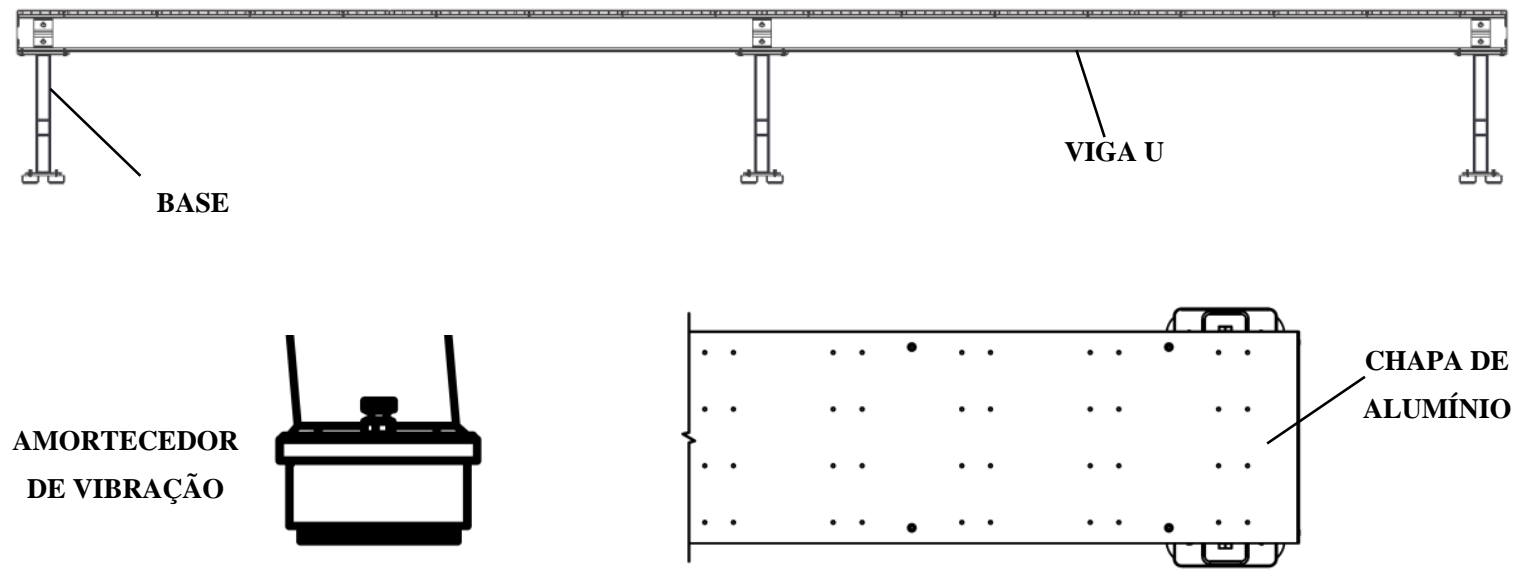

Figura 17 - Estrutura de suporte e fixação dos diversos módulos.

\subsubsection{Mancal}

O posicionamento coaxial das barras de entrada, saída e o striker é um dos pontos cruciais no projeto de uma $\mathrm{BH}$, dado que essa é uma das hipóteses consideradas para formulação do modelo matemático do dispositivo. Essa condição estabelece uma orientação longitudinal à propagação das ondas quando do impacto do striker. Nesse sentido, desvios no posicionamento das barras fogem a condição de impacto coaxial. 
Diversas opções comerciais podem ser utilizadas como um mancal de uma barra cilíndrica. No entanto, alguns detalhes específicos sobre o funcionamento, a flexibilidade e os ajustes requisitados por um projeto desse tipo tornam qualquer solução comercial inviável. Estudos realizados por (Itabashi, 2009) mostram que o uso de mancais abertos do tipo V têm vantagens na qualidade do sinal medido na barra quando comparados com mancais fechados. Principalmente devido à dilatação ou contração causadas pela propagação da onda, também por restringirem mais graus de liberdade que o necessário - mancais do tipo $\mathrm{V}$ bem projetados suportam a barra geralmente em dois pontos de apoio. Do ponto de vista da flexibilidade, diâmetros diferentes de barra são utilizados dependendo da necessidade do ensaio, o que necessitaria de uma quantidade muito grande de conjuntos de mancais fechados para cada medida. Por último e não menos importante, ajustes de posicionamento horizontal e vertical são uma necessidade recorrente devido ao próprio desalinhamento da estrutura.

Ante as necessidades apontadas, foi desenvolvido um mancal do tipo aberto dotado de regulagem de posição vertical e horizontal para barras de 10 a 30mm de diâmetro, ilustrado na Figura 18 . O mancal tem capacidade para ajuste de $20 \mathrm{~mm}$ na direção horizontal e $15 \mathrm{~mm}$ na direção vertical.

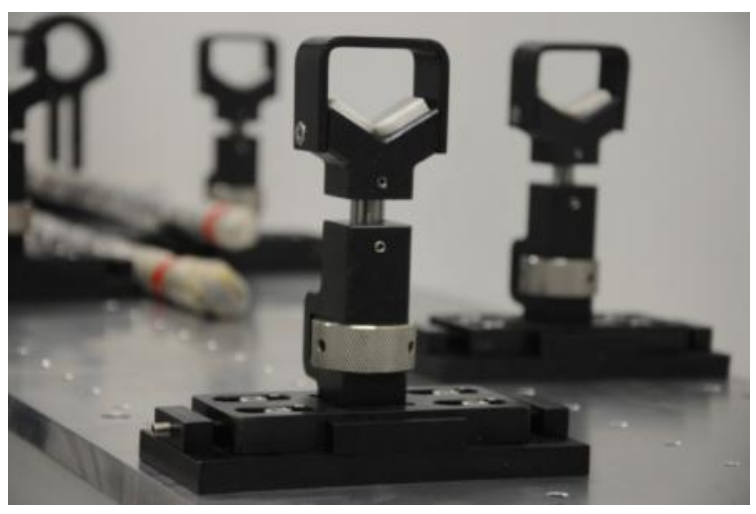

(a)

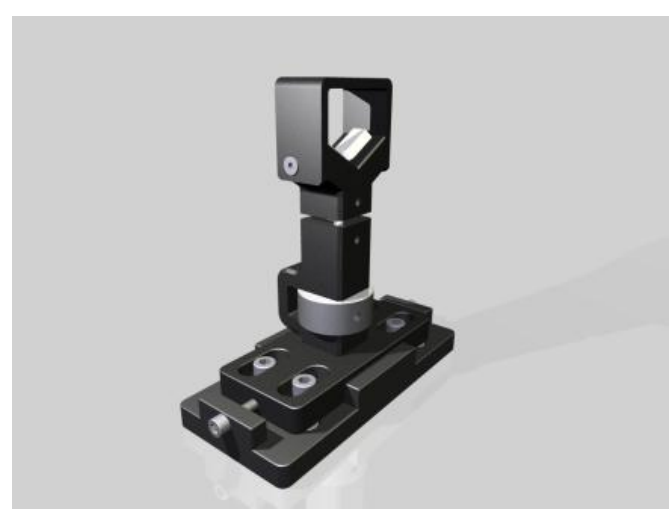

(b)

Figura 18 - Mancal de suporte e ajuste de posição das barras. Em (a) componente fabricado e montado sobre a mesa e em (b) vista isométrica do projeto.

\subsubsection{Sistema de Acionamento}

O acionamento do striker é composto por um sistema pneumático de atuação pilotada cujo esquema é apresentado na Figura 19. O esquema indica a abertura da válvula de processo válvula que alivia o reservatório de ar com alta pressão disparando o striker contido no canhão 
de compressão ou tração - através de uma válvula piloto. Uma válvula proporcional ajusta a pressão dos reservatórios. Os dois sistemas são inteiramente independentes. O controle do painel é realizado através de controle manual ou pelo computador.

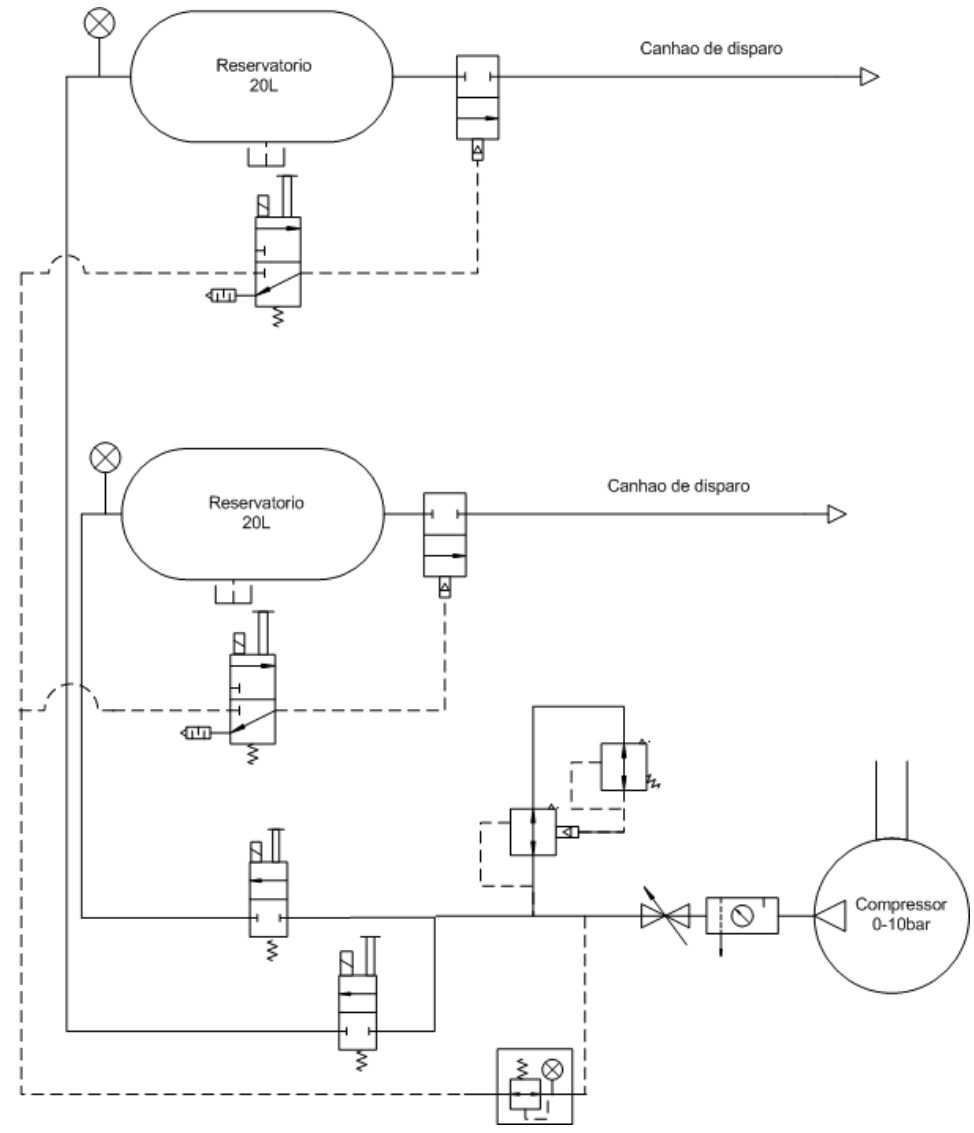

(a)

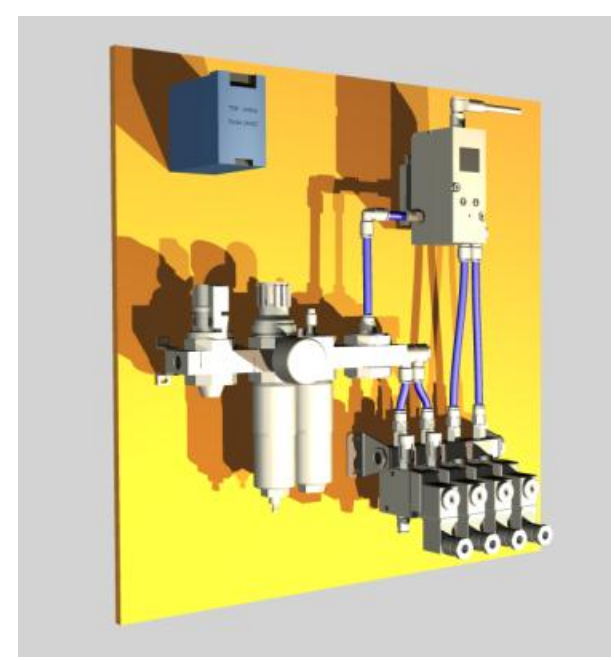

(b)

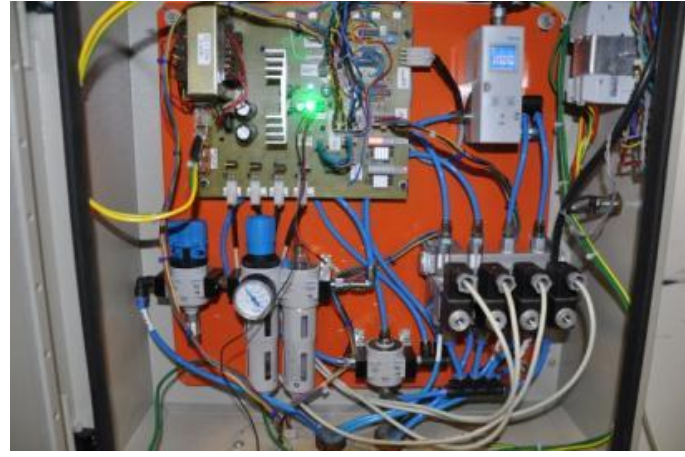

(c)

Figura 19 - Em (a) é apresentado o esquema pneumático da máquina, em (b) o projeto do painel de atuadores pneumáticos e em (c) o painel montado. 
Nas Figura 20 e Figura 21 estão ilustrados o sistema de disparo do striker para o teste de compressão e tração, respectivamente. A faixa de operação varia de 1 a 10bar para ambos os reservatórios. O canhão de compressão possui $1,5 \mathrm{~m}$ de comprimento e diâmetro interno de $28 \mathrm{~mm}$, podendo acelerar o striker até aproximadamente $20 \mathrm{~m} / \mathrm{s}$. O canhão de tração possui $1,2 \mathrm{~m}$ de comprimento e diâmetro interno de $35 \mathrm{~mm}$, podendo acelerar o striker até aproximadamente $18 \mathrm{~m} / \mathrm{s}$.

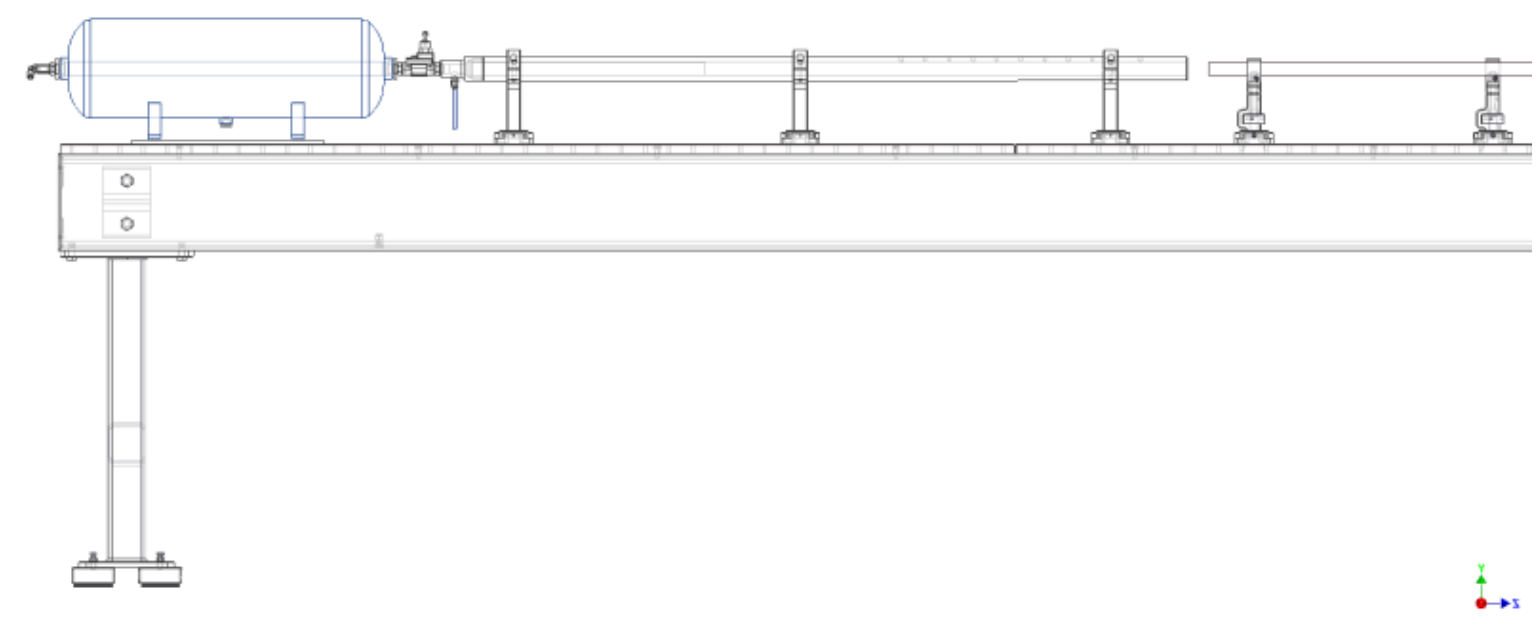

Figura 20 - Reservatório, canhão, barra e suportes da BH de compressão.

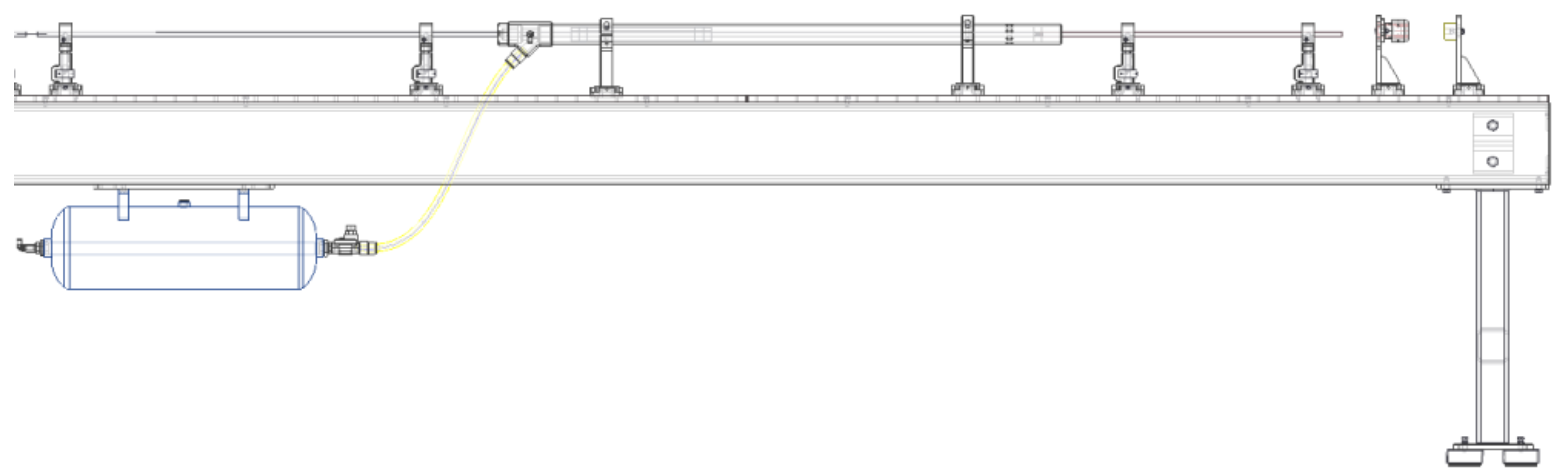

Figura 21 - Reservatório, canhão, barra, suportes e sistema de frenagem da BH de tração.

\subsubsection{Sistema de Frenagem}

O sistema de frenagem tem a função de reduzir o movimento de corpo rígido das barras de entrada e saída após o impacto do striker. A propagação da onda resulta em deslocamento da barra de saída, por isso uma terceira barra com comprimento superior a duas vezes o comprimento do striker, chamada de "trap bar" e posicionada em contato com a barra de saída. Desse 
modo, a onda propagada na barra de saída é transmitida ao "trap bar" evitando um deslocamento excessivo da barra de saída.

A "trap bar" possui uma extremidade com formato cônico que penetra em um freio de diâmetro interno regulável, assim essa barra sofre uma frenagem até parar completamente em uma batente de borracha, conforme indicado na Figura 22.

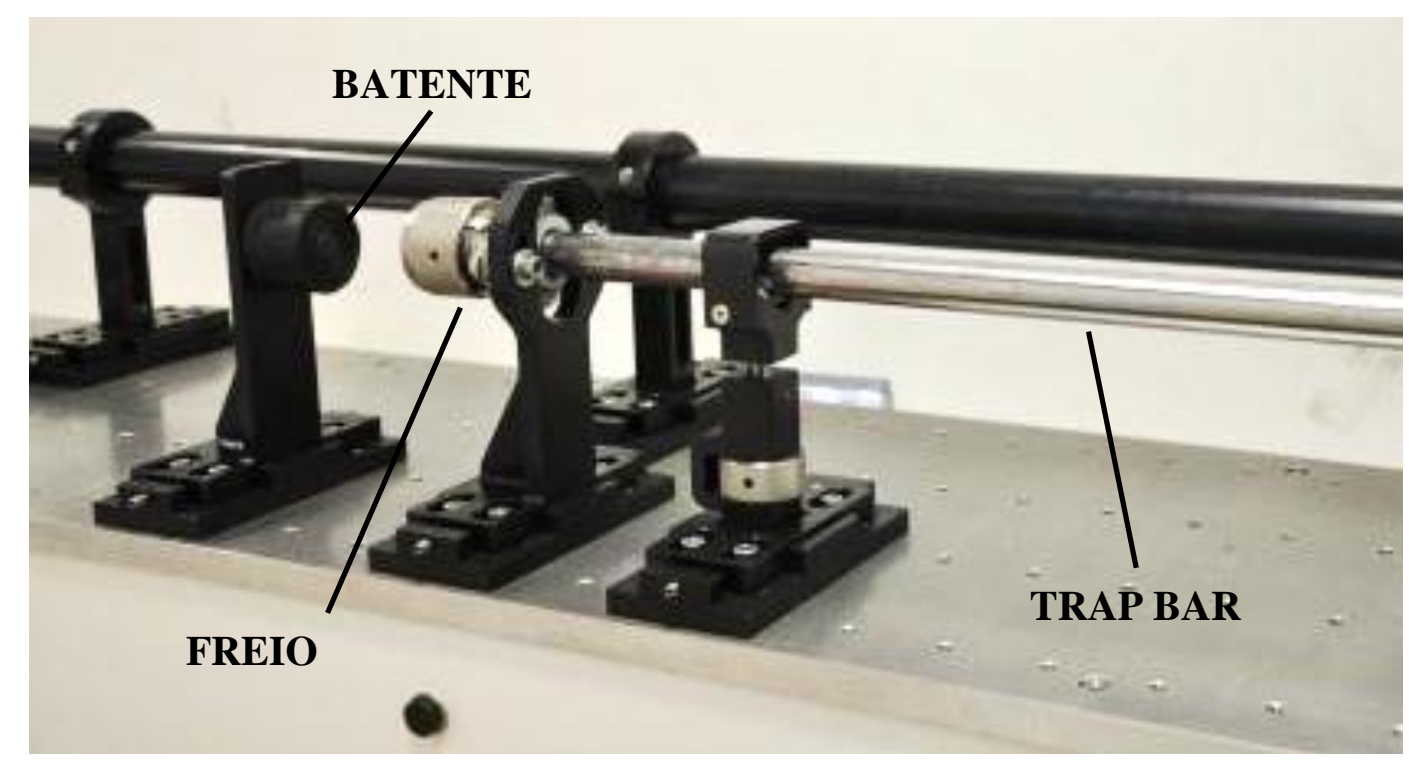

Figura 22 - Sistema de frenagem e amortecimento.

\subsubsection{Instrumentação}

A instrumentação típica de uma BH consiste de extensômetros, um osciloscópio ou um gravador transiente acoplado a um computador, um circuito de disparo, suprimento de energia e um sistema de medição de velocidade. Seguindo o layout convencional, coloca-se um par de extensômetros no meio da barra de entrada e outro par no meio da barra de saída. Os extensômetros de cada par são dispostos em lados diametralmente opostos. Isto permite cancelar qualquer efeito de flexão presente nas barras devido ao desalinhamento entre a barra de entrada, barra de saída, corpo de prova e striker.

Um osciloscópio ou gravador transiente pode ser utilizado para registrar sinais de deformação medidos pelos extensômetros. No entanto, essa tarefa foi realizada por um computador utilizando um software desenvolvido em MATLAB para gravar e efetuar cálculos com os dados dos extensômetros. 
Um sistema de medição de velocidade do striker é interessante para avaliar melhor as condições de ensaio e assim controlar a repetibilidade dos testes. Duas técnicas de medição são comumente empregadas: um contador de intervalos de tempo (time interval counter) associado a um sensor magnético ou um composto por fotocélulas e fontes de luz. Porém, nenhum sistema foi empregado na máquina. 


\section{CARACTERIZAÇÃO MECÂNICA DO MATERIAL}

As análises numérica e teórica da defensa metálica exigem o conhecimento do comportamento do material nas condições de baixa e alta taxa deformação. E isso se deve a mudança sensível nas curvas de tensão versus deformação conforme a velocidade do carregamento aumenta. Essa variação pode ser compreendida pela influência da microestrutura do material e a variação de temperatura devido à plastificação.

Segundo a teoria das discordâncias (Dieter, 1986) a plastificação ocorre por meio da modificação da estrutura cristalina. Em outros termos, a ductilidade ou dureza de um material dependem da facilidade com que as discordâncias se movimentam por barreiras como contornos de grão, elementos de liga ou impurezas. Portanto, quanto maior a taxa de deformação mais difícil seria ultrapassar tais barreiras e consequentemente o material torna-se mais duro.

Quanto à influência da temperatura, nos casos cuja taxa de deformação é baixa, a plastificação desenvolve-se lentamente e por isso é possível considerar o processo como isotérmico. Ao contrário, quando a plastificação ocorre muito rapidamente e a transferência de calor é bastante reduzida, o processo caracteriza-se como adiabático (Kapoor \& Nemat-Nasser, 1998), a temperatura se eleva reduzindo a resistência do material. Desse modo, define-se a segunda parcela de variação do comportamento do material devido ao aumento da taxa de deformação.

A descrição do comportamento de um material sob diferentes taxas de deformação pode ser realizada utilizando modelos como o de Cowper-Symonds ou Johnson-Cook, por exemplo. Em ambos os casos, são necessários inúmeros testes sob diferentes taxas de deformação para calibração dos parâmetros do modelo. No entanto, o modelo de Cowper-Symonds não considera o efeito da temperatura variável, que foi desconsiderada na presente caracterização.

\subsection{MATERIAL UTILIZADO PARA CONFECÇÃO DOS CORPOS DE PROVA}

Os corpos de prova avaliados nesse projeto foram extraídos de uma defensa metálica vendida comercialmente no Brasil. Como o produto passa por diversos etapas de fabricação existe a possibilidade de alteração das propriedades do material ao longo do processo produtivo. 
Para fabricação de uma defensa metálica, uma chapa plana é submetida a um processo de conformação por rolos ou prensagem. E é possível que em determinadas regiões haja alterações sensíveis da propriedade do material. Na Figura 23, são indicadas as regiões onde o material da defensa metálica foi extraído para análise das curvas de tensão versus deformação.
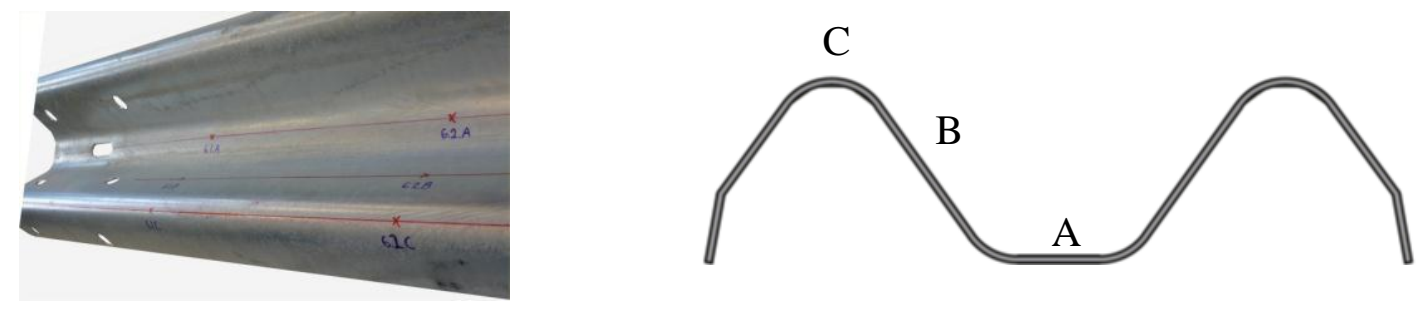

Figura 23 - Regiões avaliadas na defensa metálica

Na Figura 24 são comparados os resultados das curvas de força por deslocamento dos materiais extraídos das regiões $\mathrm{A}, \mathrm{B}$ e $\mathrm{C}$ da seção transversal da defensa metálica. A análise do comportamento das curvas permite inferir que nas regiões $\mathrm{A}$ e $\mathrm{C}$ o material sofre algum tipo de encruamento devido ao processo de conformação. Na região B, o escoamento se mantém um pouco abaixo, o que indica menor influência do processo. Apesar disso, os resultados diferem da ordem de $10 \%$. Tal variação no comportamento do material foi desprezada para se permitir uma simplificação dos cálculos e uma redução substancial de testes. Os corpos de prova fabricados e testados para caracterização da defensa foram extraído da região B.

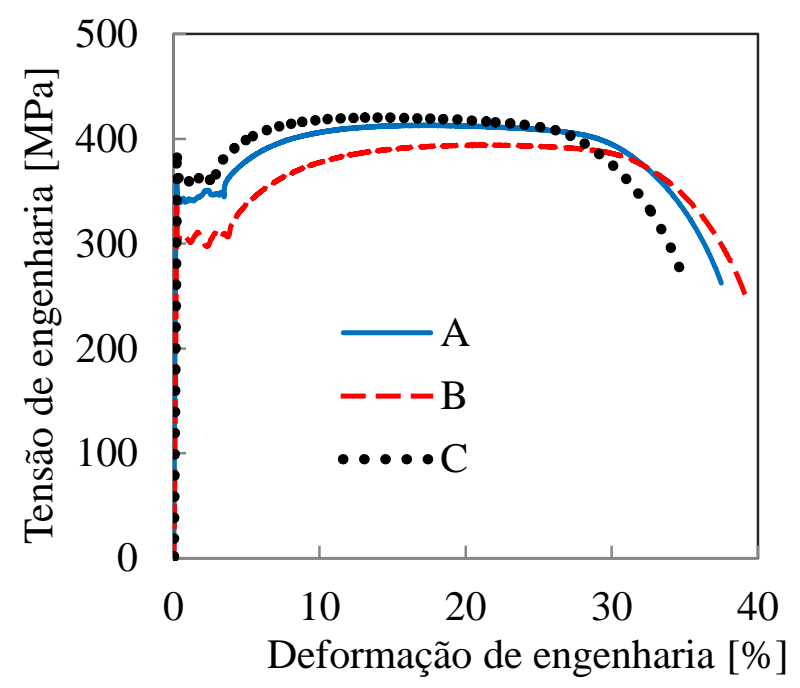

Figura 24 - Comparação entre o comportamento do material de acordo com a região da seção transversal. 


\subsection{FUNDAMENTOS TEÓRICOS}

Em um teste uniaxial de tração ou de compressão convencional, uma célula de carga determina a força $F$ aplicada no corpo de prova, enquanto o deslocamento axial $u$ é medido por um sensor de deslocamento, geralmente um extensômetro. Tais grandezas dependem da geometria do material e, para fins comparativos ou análises estruturais, devem ser transformadas em unidades de tensão e deformação. O cálculo da tensão que considera a área transversal do corpo de prova constante resulta na tensão de engenharia, $\sigma_{E}(t)$, expressa por,

$$
\sigma_{E}(t)=\frac{F(t)}{A_{0}},
$$

onde $A_{0}$ é a área da seção transversal do corpo de prova antes do início do testes e $t$ o tempo. Dado que o deslocamento sofrido pelo corpo de prova é $u(t)$, a deformação de engenharia $\varepsilon_{E}$ é obtida através da relação

$$
\varepsilon_{E}(t)=\frac{u(t)}{L_{0}},
$$

sendo $L_{0}$ o comprimento do corpo de prova medido entre as garras do sensor de deslocamento, ou o comprimento inicial do pescoço do corpo de prova medido antes do teste.

Os resultados de tensão de engenharia e deformação de engenharia são adequados para análises elásticas. Por outro lado, nos casos que envolvem grandes deformações, a área transversal do corpo de prova muda sensivelmente. Dessa forma, uma medida mais real da tensão no material pode ser definida como,

$$
\sigma_{T}(t)=\frac{F(t)}{A_{s}(t)},
$$

onde a variável $\sigma_{T}(t)$ representa a tensão verdadeira como função da área seção transversal corrente $A_{s}$. Essa área não é facilmente aferida em um teste de tração ou compressão, mas considerando a hipótese de conservação de volume, ela pode ser determinada através da relação, 


$$
A_{s} L_{s}=A_{0} L_{0} \Rightarrow A_{s}=A_{0} \frac{L_{0}}{L_{s}}=A_{0} \frac{L_{0}}{L_{0}+u} \therefore A_{s}=\frac{A_{0}}{1+\varepsilon_{E}} .
$$

O comprimento $L_{s}$ é a região do corpo de prova que se deforma e geralmente está delimitada pelo sensor de deslocamento.

Substituindo-se a equação (4.4) na equação (4.3) obtém-se uma relação prática para o cálculo da tensão verdadeira

$$
\sigma_{T}=\sigma_{E}\left(1+\varepsilon_{E}\right)
$$

A deformação de engenharia também deve ser substituída por uma formulação coerente com a variação da geometria do corpo de prova. A definição da deformação verdadeira $\varepsilon_{T}$, ou deformação logarítmica, é obtida integrando-se as pequenas variações de deformação desde o comprimento inicial, $L_{0}$, até o comprimento final $L_{s}$,

$$
\varepsilon_{T}=\int_{L_{0}}^{L_{s}} d \varepsilon_{T}=\int_{L_{0}}^{L_{s}} \frac{d L}{L}=\ln \left(\frac{L_{s}}{L_{0}}\right)
$$

Para fins práticos, a equação (4.6) pode ser reescrita de modo que a deformação verdadeira e a de engenharia fiquem relacionadas como,

$$
\varepsilon_{T}=\ln \left(\frac{L_{s}}{L_{0}}\right)=\ln \left(\frac{L_{0}+u}{L_{0}}\right)=\ln \left(1+\varepsilon_{E}\right) .
$$

Na Figura 25 é exemplificado o comportamento das curvas de tensão versus deformação do material seguindo as tratativas de tensão/deformação verdadeiras e tensão/deformação de engenharia. 


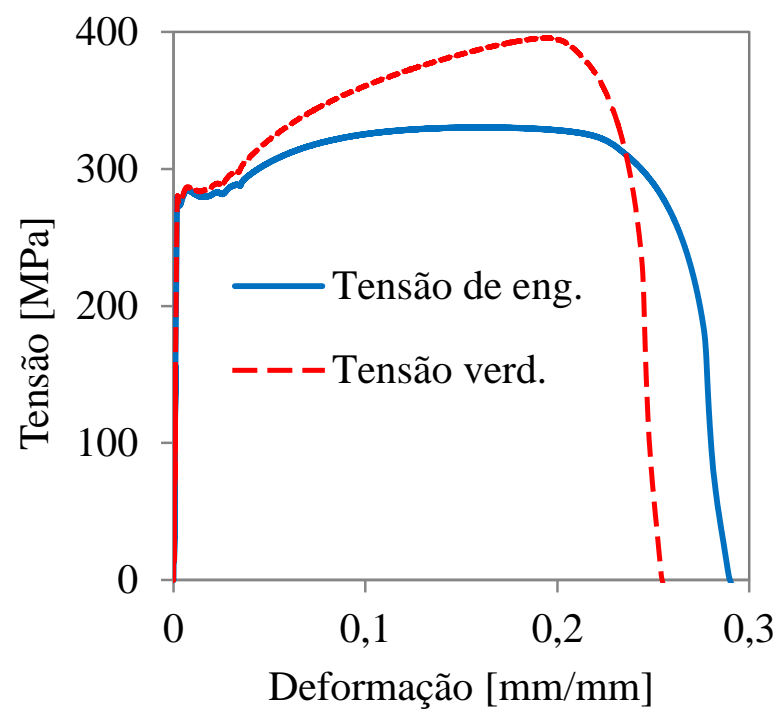

Figura 25 - Comparação entre os resultados de tensão de engenharia versus deformação de engenharia e tensão verdadeira versus deformação logarítmica.

\subsection{TESTE DE TRAÇÃO QUASE-ESTÁTICO}

Os corpos de prova utilizados nos testes quase-estáticos de tração seguem o padrão e as dimensões apresentadas na Figura 26. Eles foram fabricados a partir de cortes de lâminas retangulares da região B da defensa e na direção longitudinal (verificar posição na Figura 23).
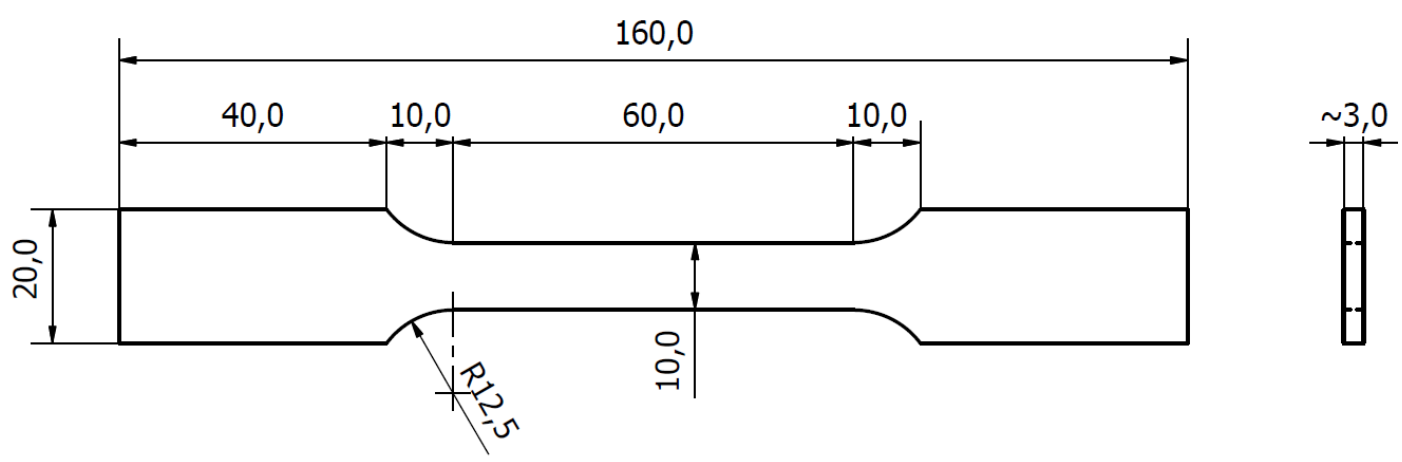

Figura 26 - Geometria de corpo de prova utilizada nos testes quase-estático.

Os corpos de prova foram fixados através de mordentes que possuem um sistema de autotravamento por cunhas. $\mathrm{O}$ detalhe do posicionamento do sensor de deslocamento nas posições inicial e final do teste pode ser visualizado na Figura 27. Além disso, verifica-se que a região 
de estricção é relativamente pequena, o que possibilita a consideração de um estado uniaxial de tensões até momentos antes da falha.
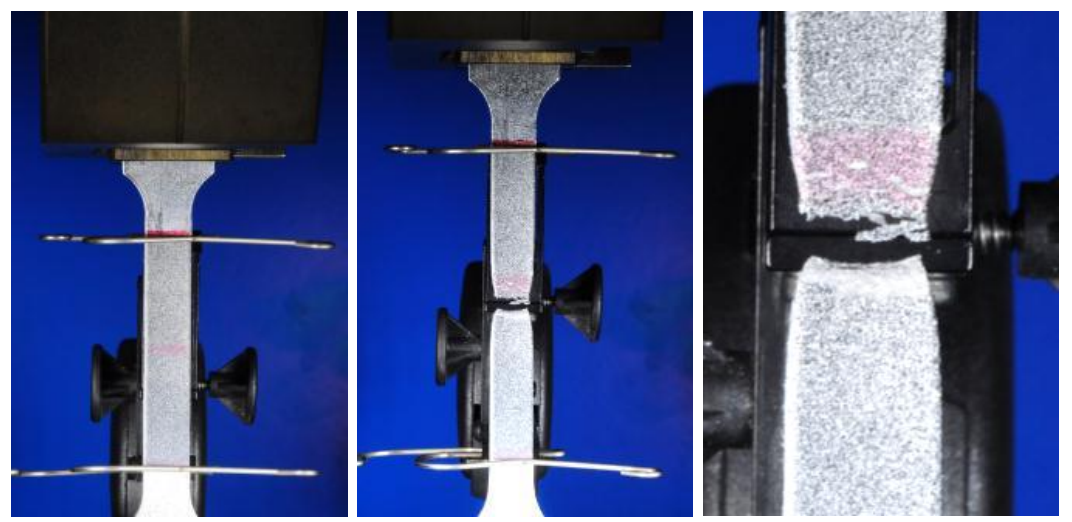

Figura 27 - Teste de tração quase-estático no início do teste, após falha do material e no detalhe a região de empescoçamento.

Os testes quase-estático de tração foram realizados conforme perfil de carga exemplificado na Figura 28. Antes da aplicação contínua de tração que leva à ruptura do material foram incluídos três ciclos de tração e descarregamento no regime elástico. Esse procedimento proporcionou uma melhor acomodação dos mordentes e também a avaliação do Módulo de Elasticidade do material cujo valor médio calculado foi de aproximadamente 201GPa, também explícito na Figura 28.

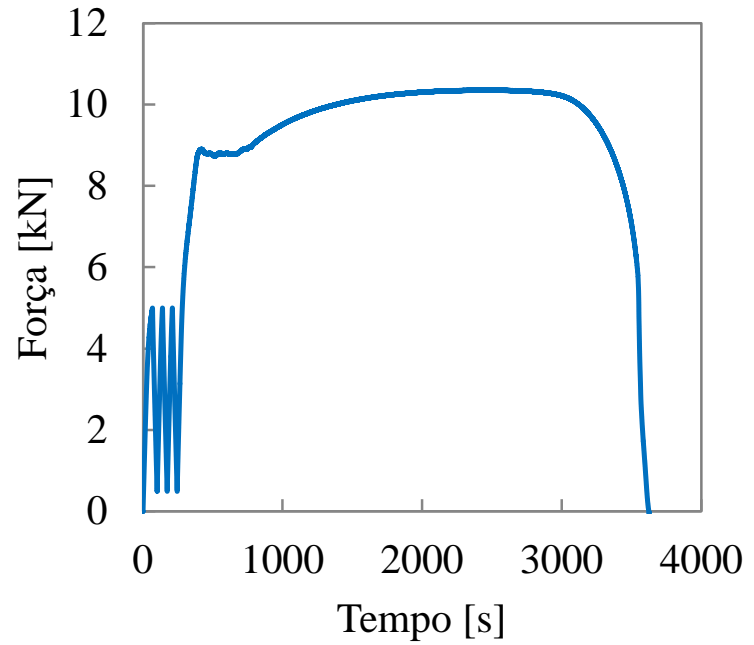

(a)

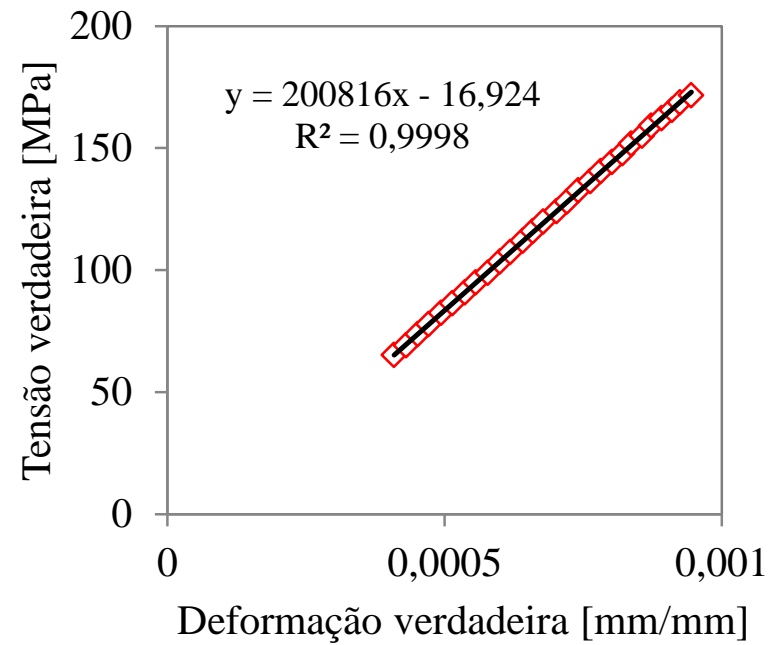

(b)

Figura 28 - Em (a) perfil de carga aplicada nos testes quase-estáticos com 3 ciclos de carga cíclica no regime elástico. Em (b) cálculo do Módulo de Elasticidade do material. 
Utilizando o método de tração anterior, as equações (4.3) e (4.6) foram avaliadas três taxas de deformação no regime quase-estático cujos resultados estão apresentados na Figura 29. A taxa mínima de deformação de $0,0002 \mathrm{~s}^{-1}$ foi adotada como referência em uma velocidade de deslocamento dos mordentes a $0,3 \mathrm{~mm} / \mathrm{min}$. Adicionalmente, taxas de $0,0009 \mathrm{~s}^{-1}$ e $0,0082 \mathrm{~s}^{-1}$ foram analisadas sob as mesmas condições na máquina de testes universais Instron de $50 \mathrm{kN}$.

Observa-se nas curvas apresentadas na Figura 29 um comportamento típico de metais, com pequena e delimitada região elástica; uma fase de acomodação da rede cristalina, no início do regime plástico; seguido de encruamento e, finalmente, amolecimento acompanhado de falha. Na comparação entre as três taxas de deformação, o endurecimento do material é notável a partir da elevação do platô que define o escoamento e diminuição da deformação de ruptura do material.
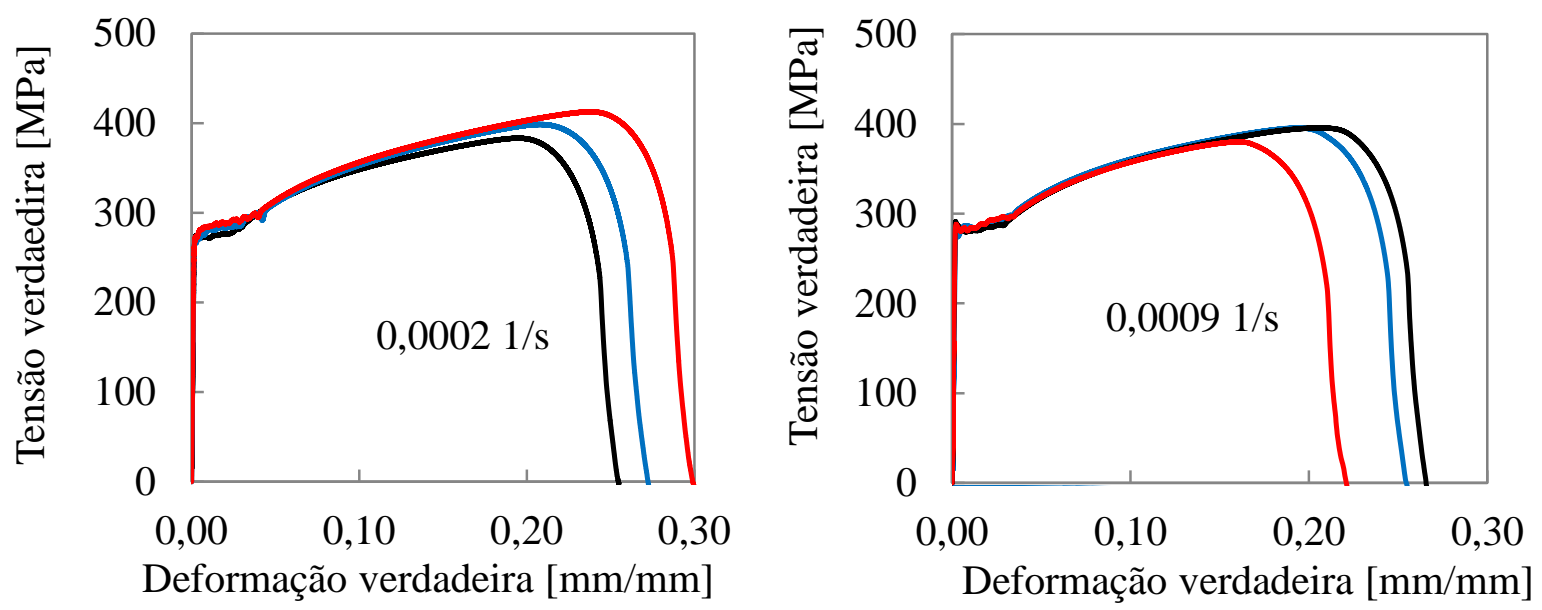

Deformação verdadeira $[\mathrm{mm} / \mathrm{mm}]$

Deformação verdadeira $[\mathrm{mm} / \mathrm{mm}]$

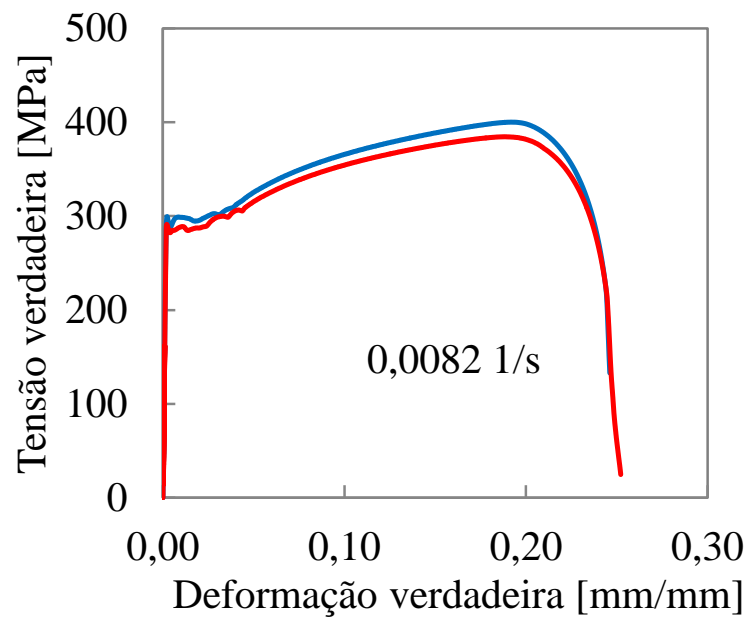

Figura 29 - Curvas de tensão versus deformação sob diferentes taxas de deformação em regime quase-estático. 
Para cada curva de tração obtida foi traçada uma reta com inclinação igual ao valor médio do Módulo de Elasticidade a partir de uma deformação de $0,02 \%$. O valor definido pela intersecção dessa reta e a curva do material determinou a tensão de escoamento, conforme Figura 30.

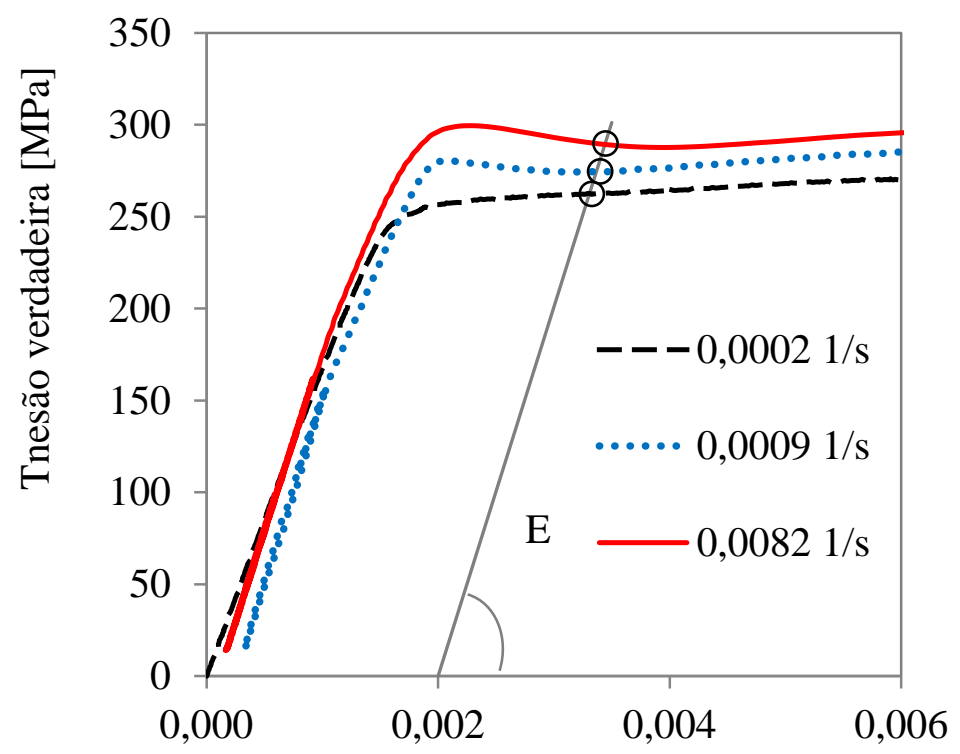

Deformação verdadeira $[\mathrm{mm} / \mathrm{mm}]$

Figura 30 - Método de obtenção da tensão de escoamento.

No regime quase-estático foram realizados três testes em cada uma das três diferentes taxas de deformação, apenas no ensaio realizado a 0,0082 1/s dois resultados foram utilizados devido a falha durante a execução do experimento. Na Tabela 6 estão listadas as tensões de escoamento obtidas para cada uma dos testes, cujas curvas foram apresentadas na Figura 21.

Tabela 6 - Tensão de escoamento obtida para cada taxa de deformação testada

\begin{tabular}{|c|c|}
\hline $\begin{array}{c}\varepsilon^{\cdot} \\
{[1 / \mathrm{s}]}\end{array}$ & $\begin{array}{c}\sigma e s c \\
{[\mathrm{MPa}]}\end{array}$ \\
\hline 0,0002 & 270,426 \\
\hline 0,0002 & 266,762 \\
\hline 0,0002 & 269,354 \\
\hline 0,0009 & 279,747 \\
\hline 0,0009 & 290,172 \\
\hline 0,0009 & 285,817 \\
\hline 0,0082 & 290,244 \\
\hline 0,0082 & 295,388 \\
\hline
\end{tabular}




\subsection{DEFINIÇÃO DA GEOMETRIA DO CORPO DE PROVA EM TESTES DINÂMICOS}

Para realização dos testes dinâmicos faz-se necessário a modificação da geometria do corpo de prova por questões que envolvem a energia para realização do teste, a taxa de deformação desejada e a distribuição de tensões na região de deformação.

A taxa de deformação $\dot{\varepsilon}$ obtida para uma dada velocidade de tração $V_{t}$ é inversamente proporcional ao comprimento do corpo de prova $L_{o}$ de acordo com a relação

$$
\dot{\varepsilon}=\frac{V_{t}}{L_{0}} .
$$

Portanto, a redução do comprimento da região deformável do corpo de prova facilita a análise de taxas de deformação mais elevadas, considerando uma velocidade de tração constante.

Relacionando a taxa de deformação desejada e a força necessária para realização do teste para uma dada geometria do corpo de prova obtém-se uma estimativa da potência despendida no processo que pode ser expressa por,

$$
P_{u}=V_{t} \cdot F=\left(L_{0} \cdot \dot{\varepsilon}\right) \cdot\left(\sigma \cdot A_{0}\right)
$$

onde $P_{u}$ é a potência útil envolvida no fenômeno e $\sigma$ o pico de tensão estimado no corpo de prova.

Para ilustrar um fenômeno real considere, por exemplo, que o comprimento do corpo de prova é de $60 \mathrm{~mm}$, assim como no teste quase-estático, e a taxa de deformação seja de 2000 1/s. Substituindo esses valores na equação (4.8), resulta que a velocidade de tração necessária é de,

$$
V_{t}=L_{0} \cdot \dot{\varepsilon}=0,06[m] \cdot 2000\left[\frac{1}{s}\right]=120 \mathrm{~m} / \mathrm{s}
$$

Para o cálculo da força envolvida no teste, considere uma tensão máxima de $800 \mathrm{MPa}$ e a área de seção transversal equivalente a $30 \mathrm{~mm}^{2}$ (também como nos testes quase-estático). Então, a magnitude da força seria, 


$$
F=\sigma \cdot A_{0}=800[\mathrm{MPa}] \cdot 30\left[\mathrm{~mm}^{2}\right]=24 k N
$$

A potência necessária para realização de tal teste é obtida através da substituição dos resultados das equações (4.10) e (4.11) na equação (4.9), o que resulta em

$$
P_{u}=V_{t} \cdot F=120[\mathrm{~m} / \mathrm{s}] \cdot 24[\mathrm{kN}]=2,88 M W
$$

Portanto, uma adequação da geometria do corpo de prova torna-se imperativa na viabilidade de um teste em altas taxas de deformação. Baseado em um estudo sobre o estado de equilíbrio de tensões na região de deformação em um teste a alta taxa de deformação, o trabalho desenvolvido por (Slycken, 2008) definiu a geometria de um corpo de prova conforme Figura 31. Essa geometria garante uma distribuição uniforme das tensões no corpo de prova concentrada majoritariamente na região definida pelo pescoço. Com isso uma parcela mínima da área deformada é distribuída além dessa área.

O corpo de prova foi fabricado através da extração de lâminas na região B da defensa. Essas lâminas foram fresadas para redução de espessura e em seguida retificadas. As lâminas usinadas foram finalmente submetidas a um processo de corte a laser para obtenção da geometria final do corpo de prova conforme Figura 31.

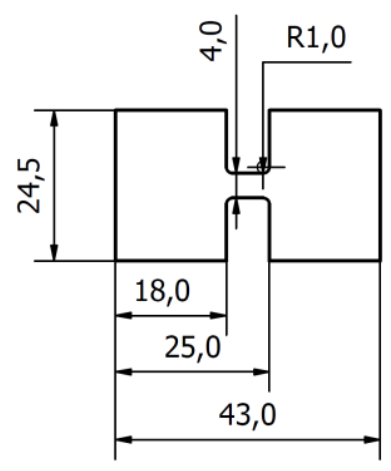

(a)

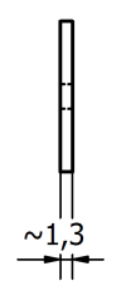

(b)

Figura 31 - (a) Dimensões do corpo de prova para testes dinâmicos e em (b) corpo de prova fabricado em máquina de corte a laser. 


\subsection{TESTES DE TRAÇÃO EM ALTAS TAXAS DE DEFORMAÇÃO}

O procedimento de utilização da $\mathrm{BH}$ consiste em: colar o corpo de prova nos adaptadores conforme Figura 32, rosquear o conjunto entre as barras, posicionar o striker no interior do canhão e próximo à saída de ar comprimido, pressurizar a câmara de ar comprimido, balancear a ponte no módulo FYLDE, calibrar o fator de proporcionalidade entre a deformação e a tensão, acionar o trigger na rotina do programa MATLAB e então disparar o striker através da liberação da válvula de descarga do reservatório.

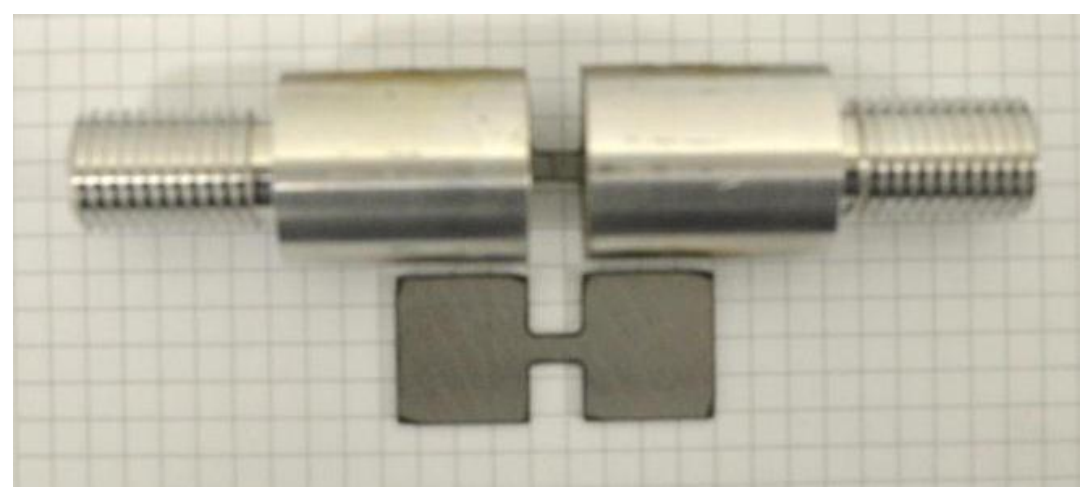

Figura 32 - Detalhes do corpo de prova e a fixação por cola nos adaptadores.

A Figura 33 apresenta sinais típicos da $\mathrm{BH}$ em um teste de tração com corpo de prova definido no item 4.4. Estes sinais serão utilizados para demonstração do pós-processamento dos dados e obtenção da curva de tensão versus deformação do corpo de prova.

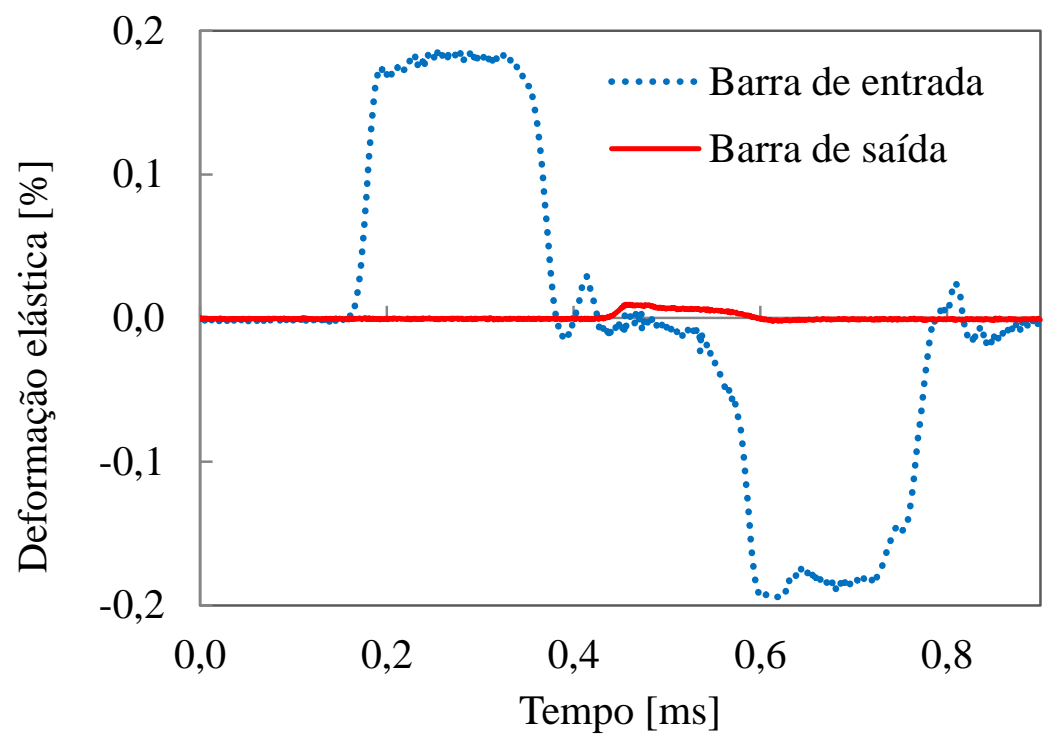

Figura 33 - Sinais típicos da BH obtidos em um teste de tração 
A aplicação do equacionamento da BH, equações (3.14), (3.15), (3.16), exige a soma e subtração dos pulsos. Para isso é preciso separá-los, definindo-se o início de cada um. Admitindo um instante inicial para o pulso incidente, o início dos outros dois pulsos pode ser calculado sabendo-se a distância percorrida e a velocidade da onda na barra. Para o pulso refletido temse o percurso de duas vezes a distância do extensômetro da barra de entrada até a interface com o corpo de prova. Para o pulso transmitido tem-se a distância medida entre o extensômetro da barra de entrada e o extensômetro da barra de saída. Aplicando esses cálculos chega-se no resultado mostrado na Figura 34 (a). Após o deslocamento dos pulsos no tempo é interessante avaliar o estado de equilíbrio das forças nas extremidades do corpo de prova, de modo que utilizando a equação (3.13) a seguinte igualdade deve ser verificada,

$$
\varepsilon_{i}(t)=\varepsilon_{t}(t)-\varepsilon_{r}(t)
$$

Dessa forma, calculam-se as curvas expostas na Figura 34 (b) afim de validar o teste. Nela percebem-se a existência de uma região transiente, na qual não ocorre equilíbrio, no início do carregamento e no final. Nos instantes iniciais do teste entre 0,05 e $0,1 \mathrm{~ms}$, poucas reflexões de ondas ocorreram no corpo de prova. Na faixa entre 0,1 e $0,2 \mathrm{~ms}$ há uma condição de equilíbrio satisfatória onde ocorre a maior parte do trabalho plástico. Após $0,2 \mathrm{~ms}$, ocorre novamente uma região de instabilidade, mas agora devido à falha do material, o que fica evidenciado no histórico de tensões calculadas no corpo de prova conforme ilustrado na Figura 35.

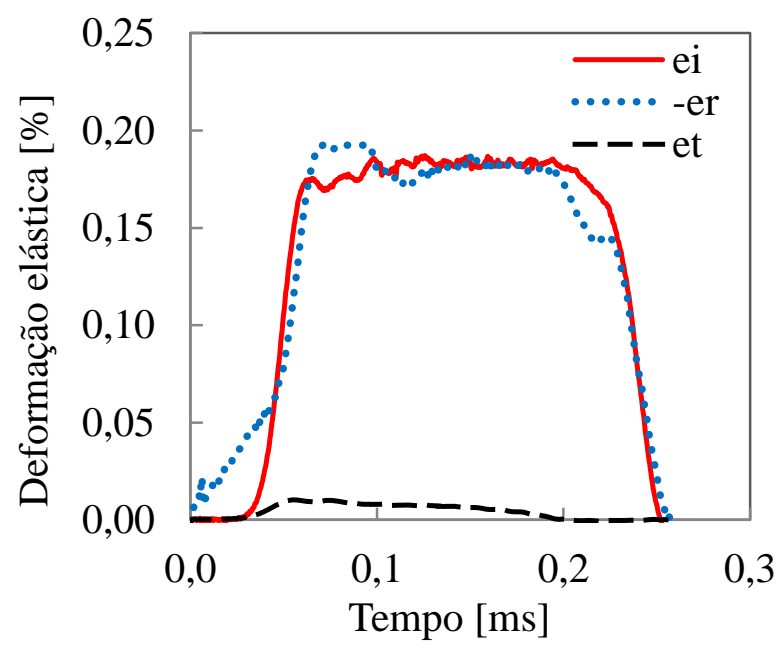

(a)

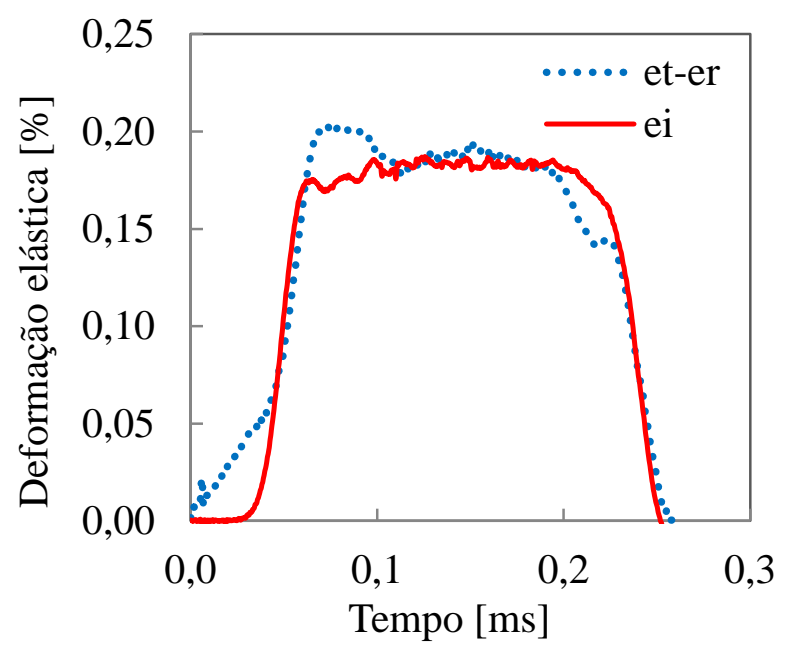

(b)

Figura 34 - Em (a), pulsos deslocados no tempo. Em (b), equilíbrio de forças avaliado pela relação entre os pulsos de deformação. 


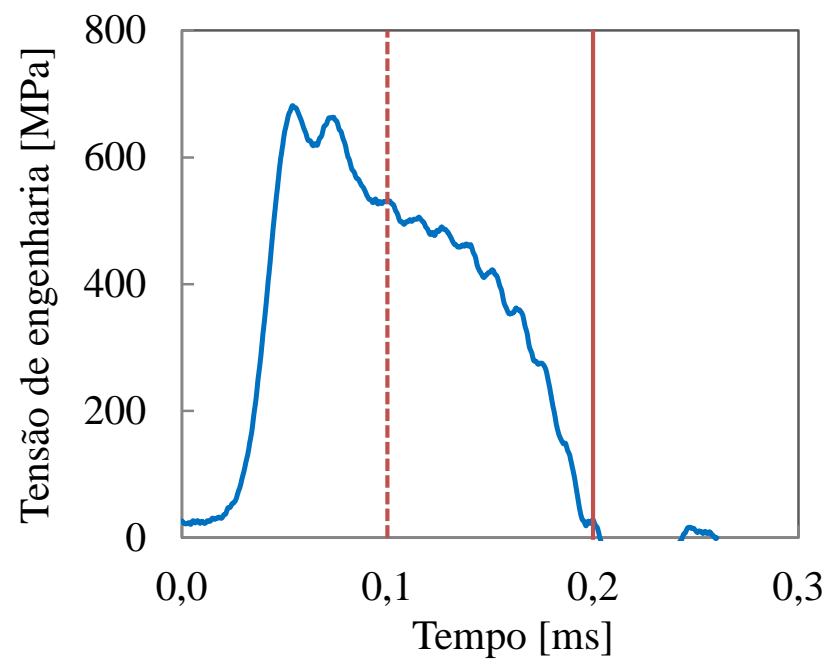

Figura 35 - Histórico de tensões no corpo de prova e definição da região de equilíbrio de forças.

Para calcular a taxa de deformação no corpo de prova dois métodos podem ser utilizados: o resultado do coeficiente angular de uma regressão linear do histórico de deformações ao longo tempo, ou a média das taxas de deformação. Para ilustrar uma comparação de cada método observe a Figura 36. A Figura 36 (a) ilustra a curva de deformação de engenharia obtida como resultado da equação (3.14), na qual uma regressão linear é avaliada entre os instantes 0,1 e 0,2 ms, resultando em uma taxa de deformação média de $2604 \mathrm{~s}^{-1}$. Na Figura 36 (b), a aplicação da equação (3.15) nos pulsos mensurados resulta em uma curva cuja média nos instantes 0,1 e $0,2 \mathrm{~ms}$ é de $2598 \mathrm{~s}^{-1}$. A diferença entre os valores estimados é de apenas $0,2 \%$ indicando boa correlação entre os métodos. De modo a unificar o procedimento de cálculo para os demais testes será adotado o método exposto na Figura 36 (b).

Na Figura 37 são apresentados os valores equivalentes de tensão e deformação a taxa de $2598 \mathrm{~s}^{-1}$ juntamente com uma curva quase-estática, para facilitar a visualização e a avaliação da influência da taxa de deformação no comportamento do material. Comprova-se no exame da Figura 37 que os testes dinâmicos não são indicados para medir o comportamento do material em pequenas deformações. Somente a partir de $10 \%$ de deformação é que a curva demonstra maior coerência porém ainda com oscilação do nível de tensão devido a pequenas vibrações consequentes da folga entre os filetes de rosca dos adaptadores e/ou ruídos no sinal. Comparando-se o comportamento das curvas, observa-se significativa sensibilidade à taxa de deformação com endurecimento do material. 


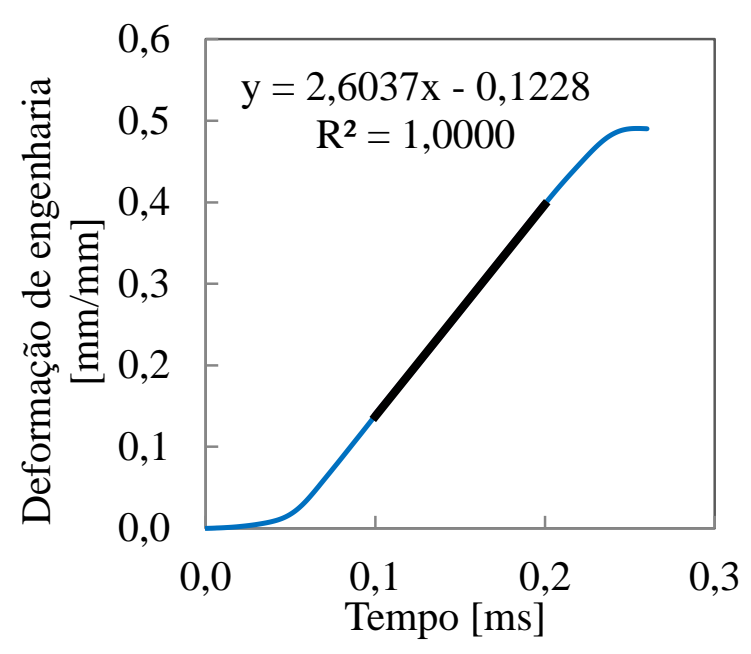

(a)

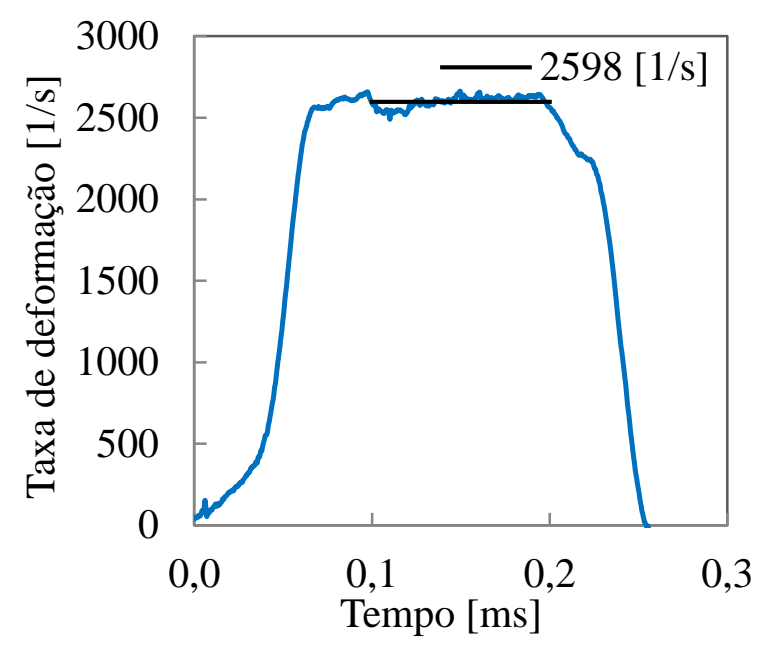

(b)

Figura 36 - Em (a), comparação dos resultados de deformações de engenharia e logarítmica. Em (b), taxa de deformação do corpo de prova baseada no pós-processamento dos pulsos.

Admitindo que o escoamento nas curvas dinâmicas ocorra na mesma deformação que na curva quase-estática, pode-se restringir as curvas à região plástica de modo a adequá-las ao cálculo dos coeficientes do modelo de Cowper-Symonds. Desse modo optou-se por adotar a deformação plástica de $20 \%$ como referência.

Repetindo-se esses passos em outros três testes e utilizando diferentes pressões foram avaliadas taxas de deformação distintas, resultado ilustrado pelas curvas mostradas na Figura 38.

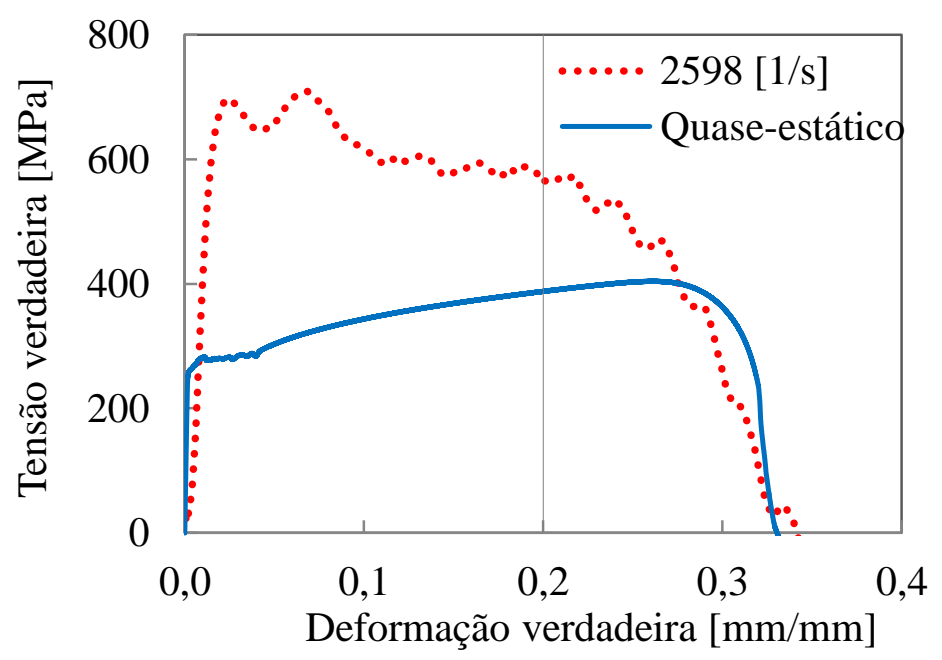

Figura 37 - Comportamento quase-estático e dinâmico do material. Reta vertical indicando nível de deformação plástica utilizado como referência para calibração dos modelos dinâmicos. 


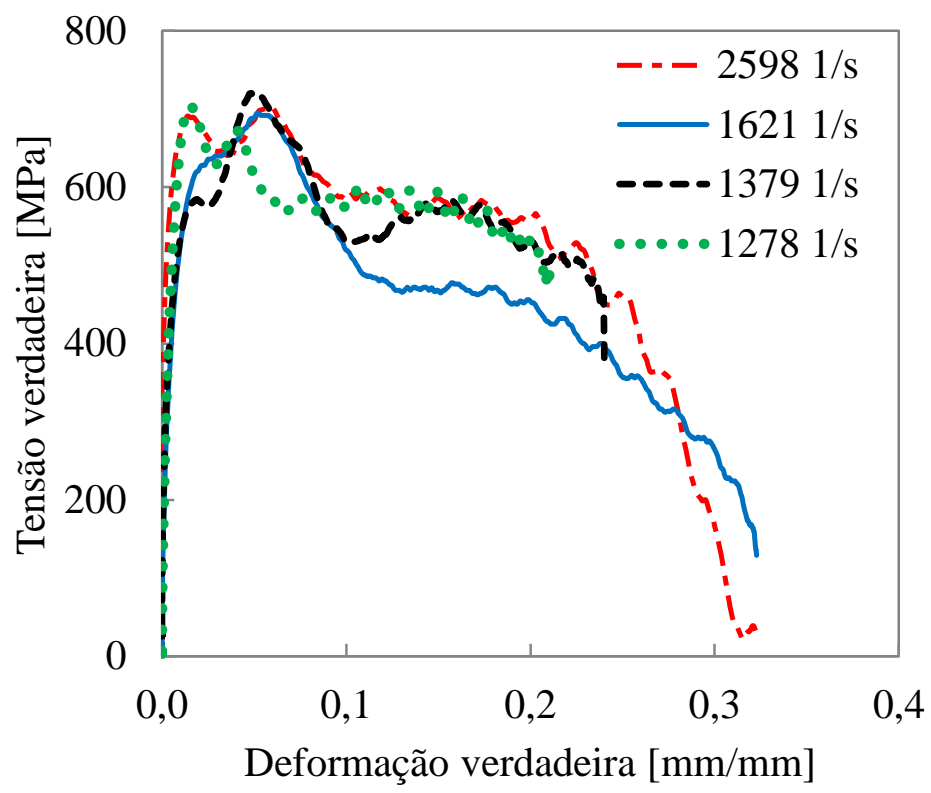

Figura 38 - Curvas de tensão deformação obtidas em testes na BH

\subsection{IDENTIFICAÇÃO DOS PARÂMETROS DO MODELO DE COWPER-SYMONDS}

O modelo de Cowper-Symonds descreve o comportamento do material como uma função da taxa de deformação através da relação

$$
\frac{\sigma}{\sigma_{0}}=1+\left(\frac{\dot{\varepsilon}_{p}}{C}\right)^{1 / p}
$$

onde $C$ e $p$ são os parâmetros do material assim como definidos no programa Ls-Dyna (LSTC, 2007). É possível reescrever a equação (4.14) de forma que as constantes $V_{k}=\sigma_{o}(1 /$ $C)^{1 / p}$ e $\mathrm{V}_{\mathrm{m}}=1 / p$ fiquem explícitas,

$$
\sigma=\sigma_{0}+\sigma_{0}\left(\frac{1}{C}\right)^{1 / p}\left(\dot{\varepsilon}_{p}\right)^{1 / p}
$$

$\mathrm{ou}$

$$
\sigma-\sigma_{0}=V_{k} \dot{\varepsilon}_{p}^{V_{m}} \text { para } \sigma>\sigma_{0}
$$

de modo que essa é outra forma de representação do modelo de Cowper-Symonds. 
Aplicando-se o logaritmo neperiano em ambos os lados da equação (4.16) obtém-se a equação

$$
\ln \left(\sigma-\sigma_{0}\right)=\ln \left(V_{k}\right)+V_{m} \ln \left(\dot{\varepsilon}_{p}\right)
$$

que descreve o comportamento de uma reta cujo coeficiente linear é $V_{k}$ e o angular $V_{m}$. Para esse propósito são utilizados os resultados da tensão de escoamento obtidos nos testes de tração quase-estático e dinâmico e as suas respectivas taxas de deformação. O logaritmo neperiano da diferença entre os valores de tensão dinâmica e estática pelo logaritmo neperiano da respectiva taxa de deformação estão expostos na Figura 39.

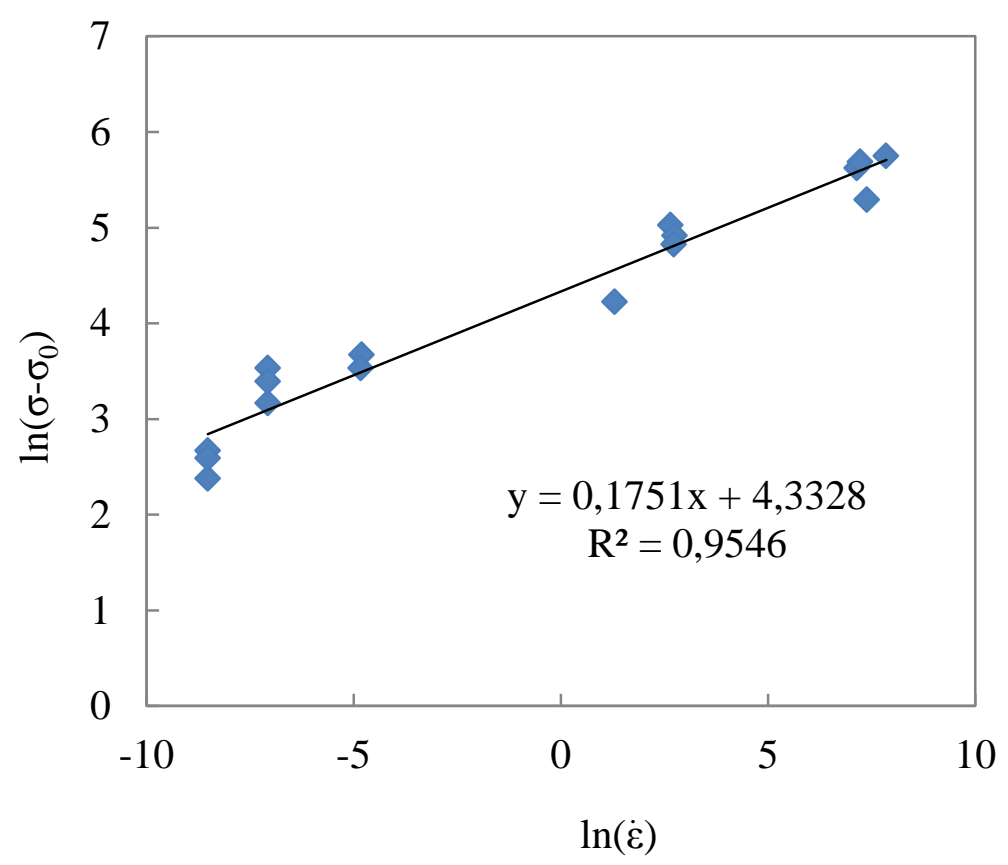

Figura 39 - Ajuste dos parâmetros de Cowper-Symonds

Utilizando o método dos mínimos quadrados para ajuste de uma reta entre os pontos resultam os coeficientes $V_{k}, V_{m}$. $C$ e $p$ expressos na Tabela 7.

Tabela 7 - Parâmetros do modelo de Cowper-Symonds

\begin{tabular}{cccc}
\hline $\mathrm{V}_{\mathrm{k}}$ & $\mathrm{V}_{\mathrm{m}}$ & $\mathrm{C}$ & $\mathrm{p}$ \\
$\mathrm{MPa} . \mathrm{s}$ & - & $\mathrm{s}-1$ & - \\
\hline 76,16 & 0,18 & 1016,29 & 5,71 \\
\hline
\end{tabular}




\section{EQUACIONAMENTO SIMPLIFICADO DE UMA DEFEN- SA METÁLICA SUJEITA A UMA FORÇA ESTÁTICA}

Uma análise teórica e numérica é abordada considerando uma estrutura simplificada defensa metálica, cujo alvo central é realizar uma validação de um modelo numérico em elementos através da comparação com os resultados analíticos.

A metodologia empregada na formulação analítica do problema baseia-se na teoria da plasticidade. Essa estratégia considera que o comportamento da defensa é regido predominantemente por deformações permanentes e localizadas em rótulas plásticas. Diante desse cenário, as forças globais e o comportamento envolvido na deformação da estrutura serão estimados como resultado da aplicação de uma carga estática.

Duas estratégias diferentes de modelagem da conexão parafusada entre o poste e a guia de deslizamento foram avaliadas, em uma todos os componentes da conexão são representados por elementos sólidos na outra a conexão é simplificada por uma viga definida pelo cartão *CONSTRAINED_SPOTWELD. Os dois modelos são comparados diante dos resultados das forças internas envolvidas na conexão e o seu custo computacional. Além disso, foi desenvolvida uma avaliação da sensibilidade ao parâmetro de falha de deformação plástica da conexão spotweld.

Outras questões também discutidas nesse capítulo envolvem o mecanismo de absorção de energia de uma defensa metálica, a característica das forças aplicadas no parafuso e como é o mecanismo de falha desse componente.

\subsection{SISTEMA}

A defensa metálica mais enxuta utilizada no Brasil possui os seguintes componentes principais segundo (NBR 6971, 1999): postes, guias de deslizamento w, espaçadores, parafusos e arruelas. A montagem desse sistema de contenção em uma rodovia é exemplificada na Figura 40. O sistema simplificado que será abordado neste capítulo inclui apenas um módulo da defensa metálica, ou seja, um conjunto representativo desse sistema com apenas uma guia de deslizamento, um poste e uma conexão parafusada de fixação dos componentes anteriores o qual está representado na Figura 41. 


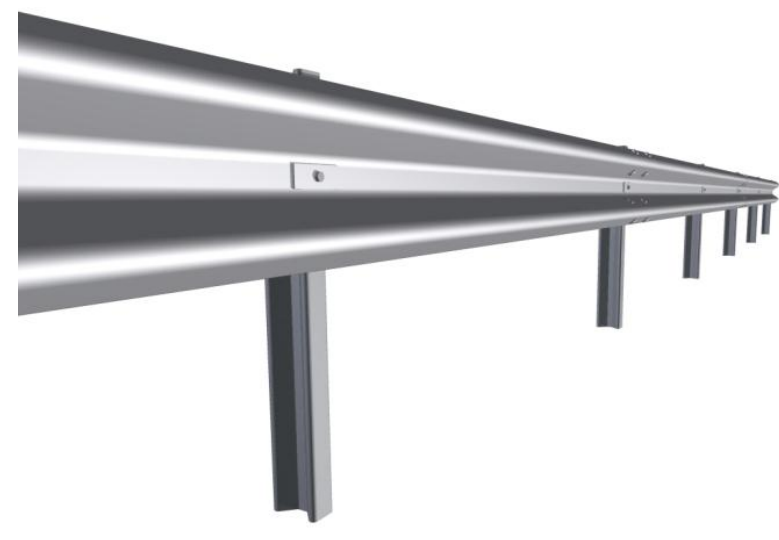

(a)

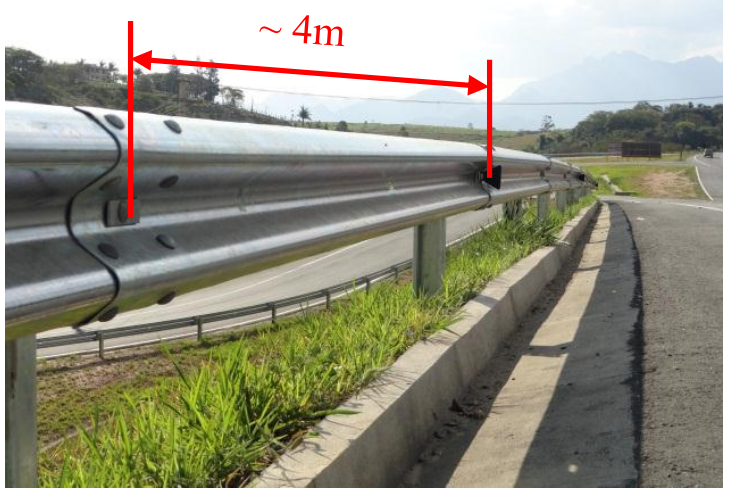

(b)

Figura 40- Em (a) defensa metálica representada no software de CAD 3D Inventor Professional. A foto (b) foi clicada de uma defensa metálica instalada na Rodovia Doutor. Avelino Junior em Cruzeiro/SP.
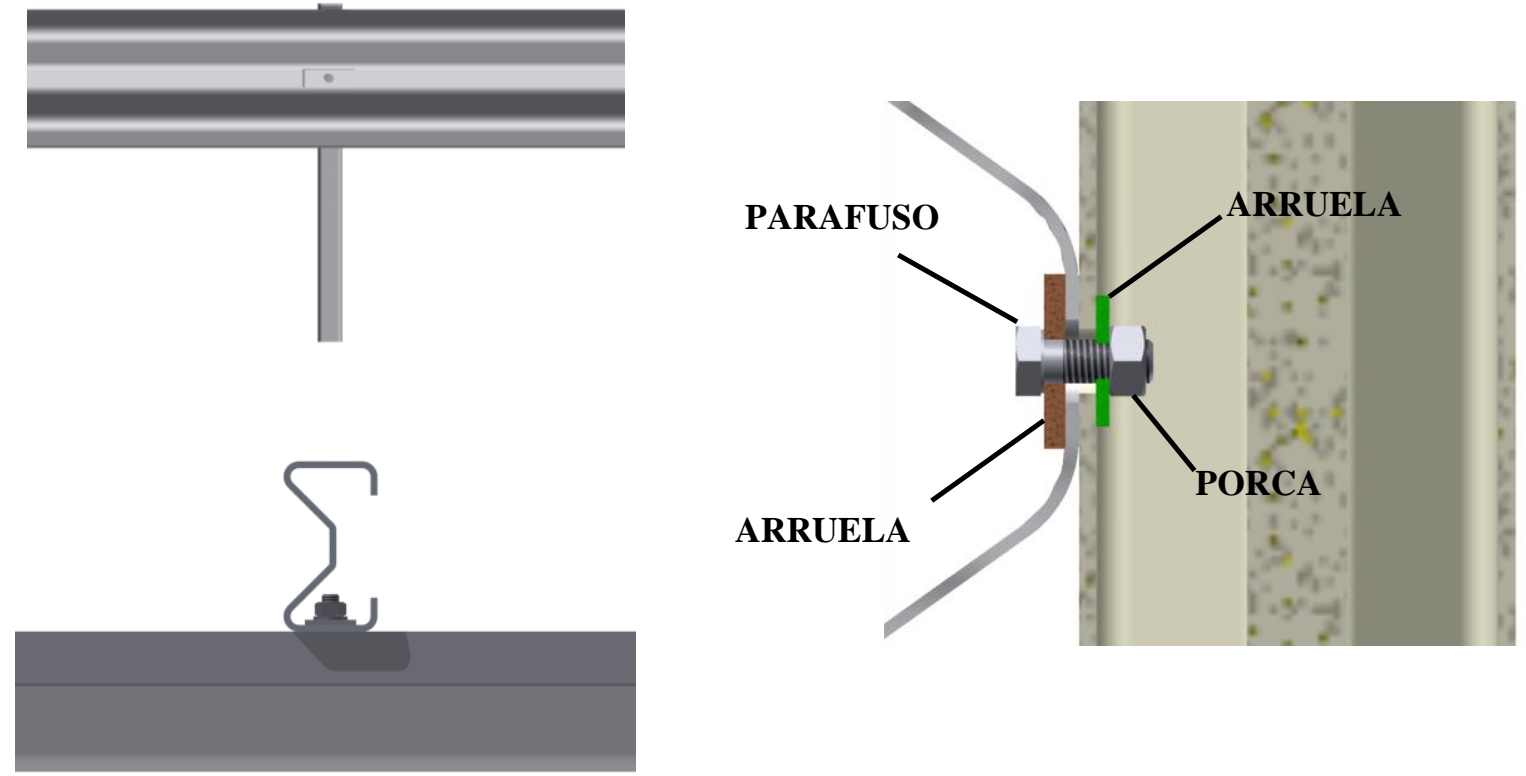

Figura 41 - Sistema analisado composto de guia de deslizamento w, poste e conexão parafusada.

A fixação dos postes ao solo é uma variável importante no comportamento da defensa metálica. No entanto, as características mecânicas do solo serão desprezadas neste trabalho, sendo substituídas por um engastamento puro, fato semelhante à fixação do poste em áreas carentes de zona de escape, como pontes, por exemplo. Nesse caso, o comportamento da barreira é 
ainda mais importante pois uma falha do sistema tem implicações muito severas aos ocupantes do veículo.

A guia de deslizamento w possui em média $4 \mathrm{~m}$ de comprimento e pode ter postes distribuídos em espaços regulares de 1m, 2 m ou 4 m. A segunda opção foi convencionada nos estudos a seguir, porém a terceira ou espaçamento regular de $4 \mathrm{~m}$ é mais comum nas rodovias brasileiras fato que será abordado na discussão dos resultados apresentadas no Capítulo 6. A conexão entre o poste e a guia deslizamento possui um parafuso M10, porca e arruelas especiais, conforme Figura 41. Nas conexões de duas guias, um conjunto de 8 parafusos M16 e porcas são utilizados para fixação (NBR 6971, 1999), conforme Figura 42. Prática comum é que essa conexão entre vigas coincida com a fixação dos postes.

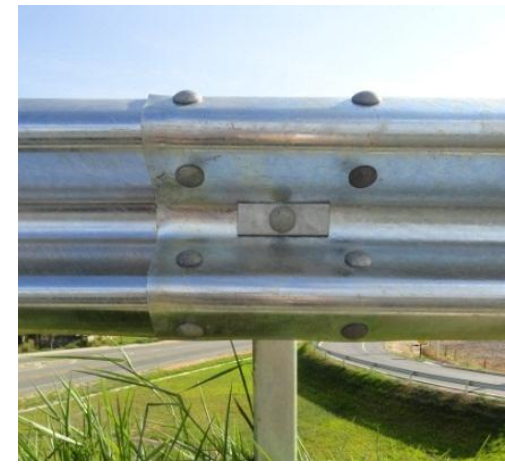

(a)

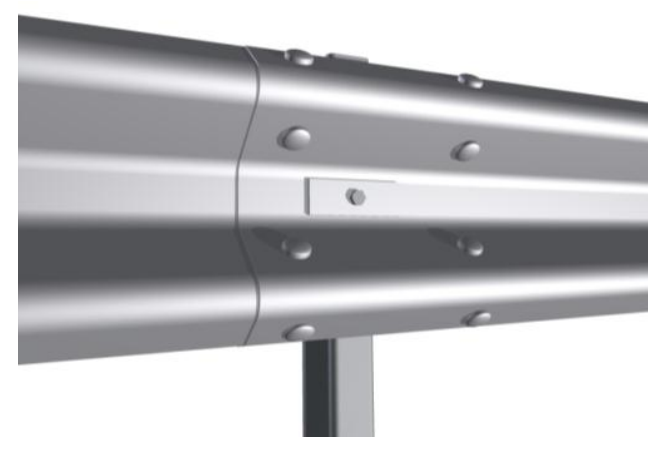

(b)

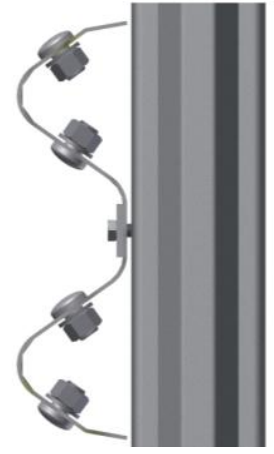

(c)

Figura 42 - Conexão entre duas guia de deslizamento w.

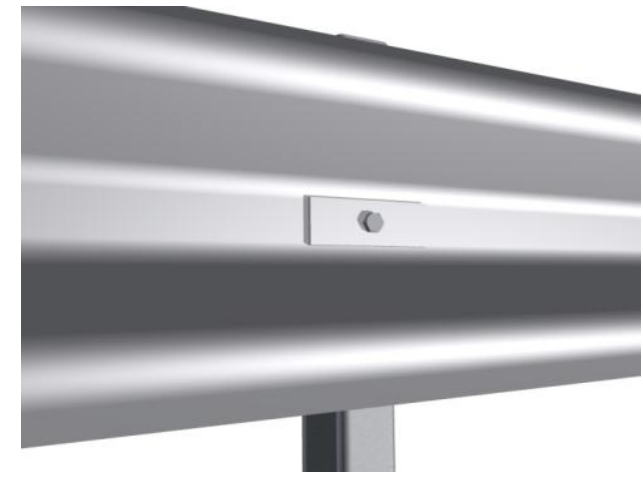

Figura 43 - Conexão entre a guia de deslizamento w e o poste no comprimento médio da primeira. 
As conexões entre o poste e a guia de deslizamento sofrem falha geralmente na área de impacto com o veículo de acordo com a foto obtida de um teste em escala real de um veículo leve com uma defensa metálica (LIER, 2004) apresentada na Figura 44. Por isso, o objetivo da análise é investigar o mecanismo de carregamento e falha dessas conexões de modo que seja possível desenvolver um modelo em elementos finitos adequado a representação do comportamento da defensa sob o impacto de um veículo.

Sobre a os graus de liberdade do sistema nas extremidades das vigas $\mathrm{W}$, é patente que existe uma flexibilidade nessas regiões traduzida pela rigidez das conexões, poste e guia de deslizamento w. No entanto, afim de simplificar o sistema, a guia de deslizamento será considerada engastada nas extremidades.

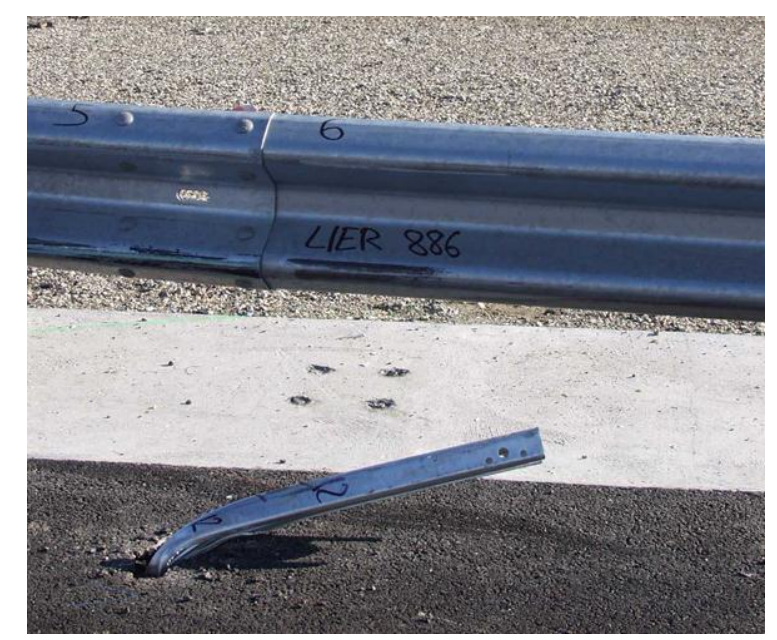

Figura 44 - Defensa metálica após colisão com um veículo evidenciando a falha das conexões entre o poste e a guia de deslizamento. As conexões entre as vigas $\mathrm{W}$ não sofrem danos significativos (LIER, 2004).

\subsection{MODELO ANALÍTICO SIMPLIFICADO}

A Figura 45 mostra um esquema do sistema composto por uma guia de deslizamento no topo e um poste, no qual as extremidades foram engastadas e uma carga $\mathrm{P}$ e aplicada na posição central. A viga horizontal AC possui as mesmas propriedades geométricas que uma guia de deslizamento w. O membro BD é conectado a AC e possui uma seção transversal sigma. 


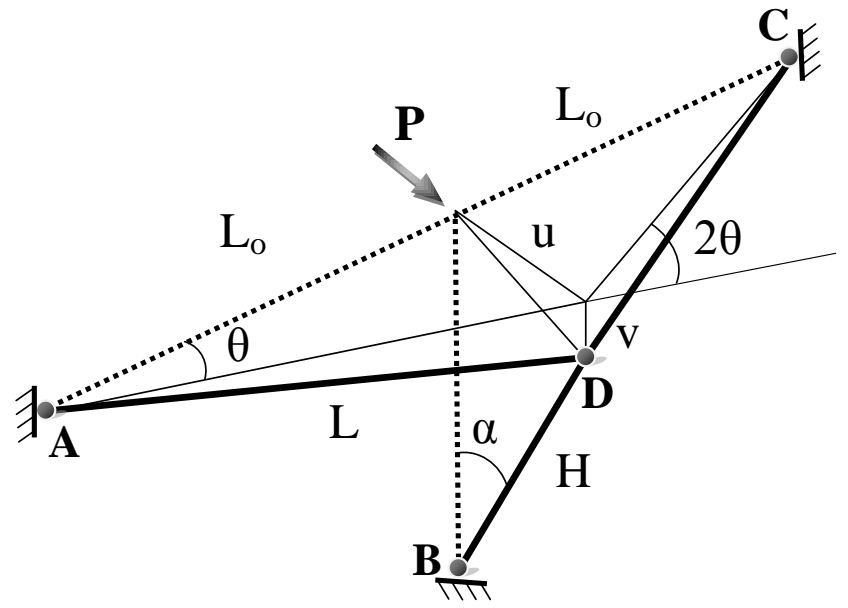

Figura 45 - Sistema composto por viga e poste engastado.

São consideradas 3 rótulas plásticas nos pontos $\mathrm{A}, \mathrm{B}, \mathrm{C}$ e $\mathrm{D}$. Na rótula $\mathrm{D}$, todas as deformações e rotações estão distribuídas nos membros AD e DC. Um corte na parte central do sistema é mostrada na Figura 46. Nela é ilustrado o comportamento antes e depois do poste sofrer deformação. Na base forma-se uma rótula plástica.

Hipóteses consideradas no modelo analítico:

- O poste possui uma curva de momento rígida e perfeitamente plástica.

- A guia de deslizamento w possui comportamento rígido e perfeitamente plástico e tanto forças de membrana quanto momento são considerados para efeitos de cálculo.

- A força é estática e aplicada sempre na direção horizontal e no meio da estrutura conforme Figura 45e Figura 46.

- A guia de deslizamento w e o poste estão engastados. 


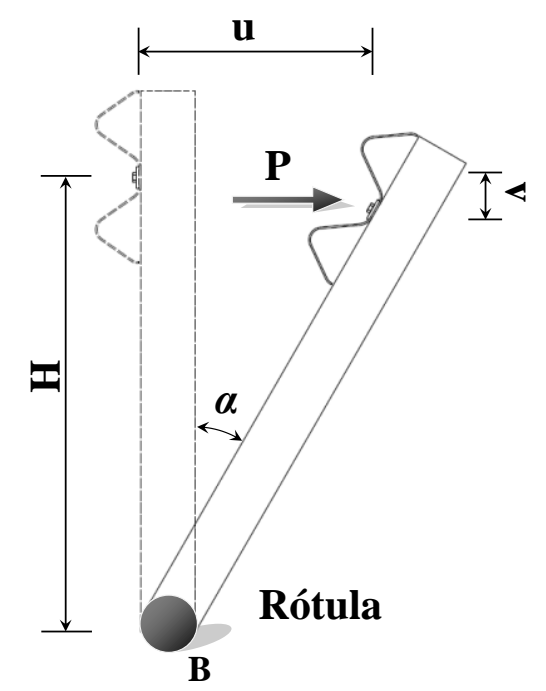

Figura 46 - Poste antes e depois de sofrer deformação.

Aplicando o deslocamento virtual $\delta u$ a partir do equilíbrio, obtém-se:

$$
P \delta u=M_{P} \delta \alpha+N_{w} \delta e_{A D}+N_{w} \delta e_{D C}+M_{w} 4 \delta \theta,
$$

onde $M_{P}$ é o momento de colapso do membro BD, $N_{w}$ a força de membrana na guia de deslizamento w, $M_{w}$ o momento fletor nas rótulas do membro AC, $\delta e_{A D}$ elongação do membro $\mathrm{AD}$, $\delta e_{D C}$ elongação do membro DC.

Para determinar as variáveis $\delta u, \delta e_{A D}, \delta e_{D C}, \delta \theta_{A}$ em função de $\delta \alpha$ foram utilizadas as relações geométricas obtidas pela Figura 45 e Figura 46, como segue:

$$
\begin{gathered}
u=H \sin \alpha, \\
v=H(1-\cos \alpha), \\
L^{2}=L_{o}^{2}+\left(u^{2}+v^{2}\right) .
\end{gathered}
$$

De acordo com a definição de Green, a deformação na guia de deslizamento w é expressa por, 


$$
\mathrm{E}_{\mathrm{xx}}=\frac{1}{2} \frac{\mathrm{L}^{2}-\mathrm{L}_{\mathrm{o}}^{2}}{\mathrm{~L}_{\mathrm{o}}^{2}} .
$$

Combinando as equações (5.2), (5.3), (5.4) e equação (5.5) resulta:

$$
E_{x x}=\left(\frac{H}{L_{o}}\right)^{2}(1-\cos \alpha)
$$

A elongação nos membros AD e DC é então obtida como segue,

$$
e_{A D}=e_{D C}=E_{x x} L_{o}=\frac{H^{2}}{L_{o}}(1-\cos \alpha) .
$$

De acordo com a Figura 45, qualquer rotação na guia de deslizamento w está concentrada nas rótulas plásticas $\mathrm{A}, \mathrm{C}$ e $\mathrm{D}$. O ângulo das rótulas é simplificado, ou seja, o ângulo $\theta$ é apenas a projeção do ângulo total no plano horizontal. Dessa foram, a elongação e a rotação nas rótulas plásticas A e C são:

$$
\begin{gathered}
e_{A}=e_{C}=\frac{1}{2} e_{A D}=\frac{1}{2} \frac{H^{2}}{L_{o}}(1-\cos \alpha), \\
\dot{e}_{A}=\dot{e}_{C}=\frac{1}{2} \frac{H^{2}}{L_{o}} \sin \alpha \cdot \dot{\alpha}, \\
\theta=\theta_{A}=\theta_{C}=\frac{u}{L_{o}}=\frac{H \sin \alpha}{L_{o}}, \\
\dot{\theta}=\dot{\theta}_{A}=\dot{\theta}_{C}=\frac{H \cos \alpha}{L_{o}} \dot{\alpha}, \\
\frac{\dot{e}_{A}}{\dot{\theta}_{A}}=\frac{\dot{e}_{C}}{\dot{\theta}_{C}}=\frac{H}{2} \tan \alpha .
\end{gathered}
$$

Adicionalmente, na rótula D: 


$$
\begin{array}{lll}
e_{D}=e_{A D}=\frac{H^{2}}{L_{o}}(1-\cos \alpha), & \theta_{D}=2 \theta=2 \frac{H \sin \alpha}{L_{o}}, & \frac{\dot{e}_{D}}{\dot{\theta}_{D}}=\frac{H}{2} \tan \alpha . \\
\dot{e}_{A}=\frac{H^{2}}{L_{o}} \sin \alpha \cdot \dot{\alpha}, & \dot{\theta}_{D}=2 \frac{H \cos \alpha}{L_{o}} \dot{\alpha}, &
\end{array}
$$

Portanto, os variacionais $\delta u, \delta e_{A D}, \delta \theta_{A}$ são dados abaixo:

$$
\begin{gathered}
\delta u=H \cos \alpha \cdot \delta \alpha, \\
\delta e_{A D}=\frac{H^{2}}{L_{o}} \sin \alpha \cdot \delta \alpha, \\
\delta \theta=\frac{H}{L_{o}} \cos \alpha \cdot \delta \alpha .
\end{gathered}
$$

Reescrevendo a equação (5.1) obtém-se a seguinte expressão,

$$
P H \cos \alpha=M_{P}+2 N_{w} \frac{H^{2}}{L_{o}} \sin \alpha+4 M_{w} \frac{H}{L_{o}} \cos \alpha .
$$

Para resolver a equação (5.15) é necessário estabelecer uma lei de escamento para a guia de deslizamento w. Nesse sentido, verificou-se que para um perfil simplificado muito similar a guia de deslizamento w original, Figura 47, a fórmula de interação entre momento e força normal aproxima-se da equação,

$$
f=\frac{M_{w}}{M_{o}}+\left(\frac{N_{w}}{N_{o}}\right)^{2}-1=0
$$

onde $M_{o}$ é o momento de colapso e $N_{o}$ a capacidade de força de membrana da guia de deslizamento w. A fórmula de interação é validada a partir da boa correlação entre o resultados apontados na Figura 48.Substituindo a equação (5.16) na (5.15) obtém-se,

$$
P H \cos \alpha=M_{P}+2 N_{w} \frac{H^{2}}{L_{o}} \sin \alpha+4 M_{o}\left[1-\left(\frac{N_{w}}{N_{o}}\right)^{2}\right] \frac{H}{L_{o}} \cos \alpha .
$$


A relação entre $\alpha$ e $N_{w}$ pode finalmente ser encontrada utilizando-se a lei escoamento:

$$
\begin{aligned}
& \dot{e}=\dot{\lambda} \frac{\partial f}{\partial N}=2 \dot{\lambda} \frac{N_{w}}{N_{o}^{2}}, \\
& \dot{\theta}=\dot{\lambda} \frac{\partial f}{\partial M}=\dot{\lambda} \frac{1}{M_{o}} .
\end{aligned}
$$

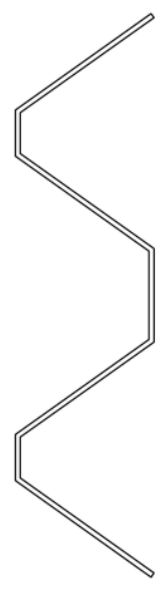

(a)

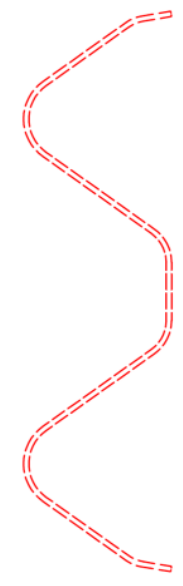

(b)

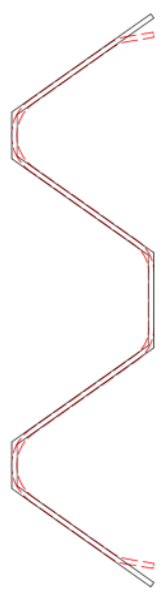

(c)

Figura 47 - (a) Simplificação geométrica da guia de deslizamento w, (b) perfil original da guia e em (c) sobreposição do perfil original e simplificado.

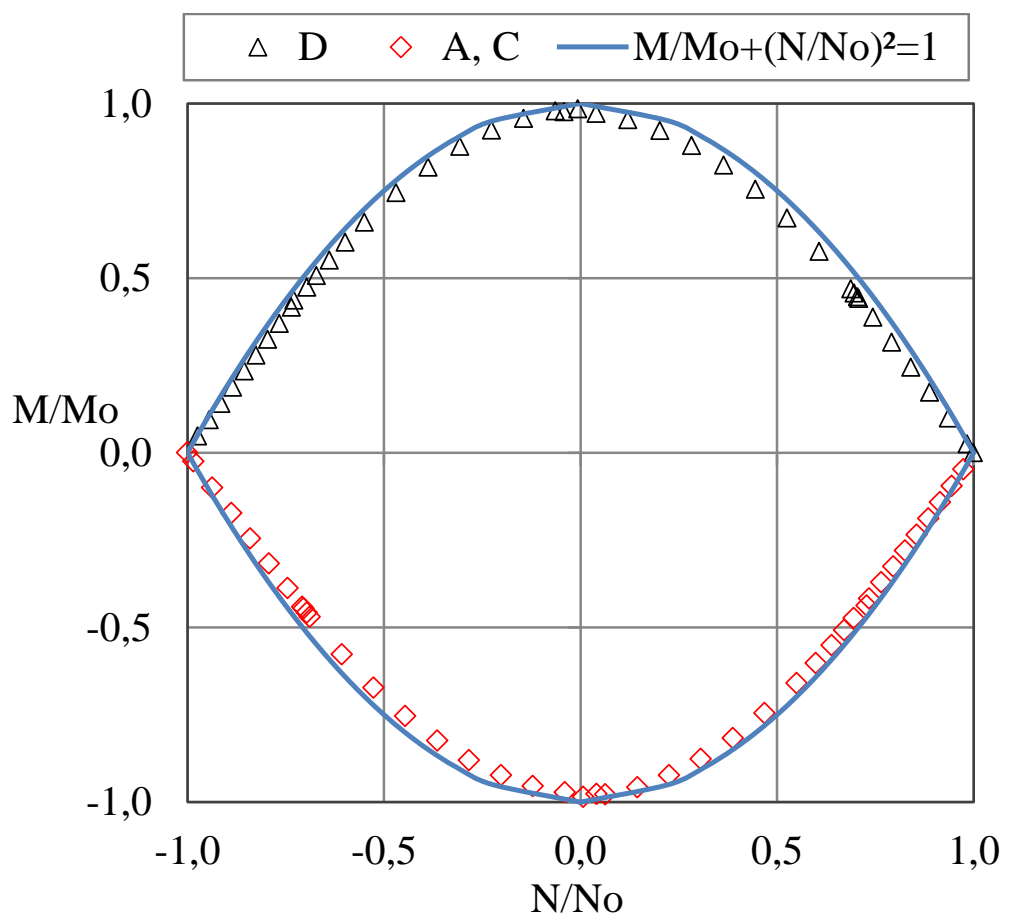

Figura 48 - Critério de escoamento da guia de deslizamento w. 
A partir das equações (5.8) e (5.11), a taxa $\dot{e} / \dot{\theta}$ pode ser escrita como:

$$
\frac{\dot{e}}{\dot{\theta}}=2 \frac{M_{o} N_{w}}{N_{o}^{2}}=\frac{H}{2} \tan \alpha
$$

Quando $N_{w}=N_{o}$ o ângulo $\alpha$ é dado pela relação,

$$
\alpha=\tan ^{-1}\left(\frac{4}{H} \frac{M_{o}}{N_{o}}\right)
$$

Quando $\alpha$ é maior que o lado direito da equação (5.20) a resistência devido ao momento fletor estagna. Desse ponto em diante, a absorção de energia do sistema é uma contribuição somente da tração dos elementos. No caso de momento puro, i.e. para $N_{w}<N_{o}$ a combinação da equação (5.17) e (5.19) resulta:

$$
P=\frac{M_{P}}{H \cos \alpha}+\frac{1}{2} \frac{N_{o}^{2}}{M_{o}} \frac{H^{2}}{L_{o}} \tan ^{2} \alpha+4 \frac{M_{o}}{L_{o}}\left[1-\frac{H^{2}}{16}\left(\frac{N_{o}}{M_{o}}\right)^{2} \cdot \tan ^{2} \alpha\right] .
$$

Enquanto se $N_{w}=N_{o}$ :

$$
P=\frac{M_{P}+2 N_{o} \frac{H^{2}}{L_{o}} \sin \alpha}{H \cos \alpha} .
$$

O resultado das equações (5.21) e (5.22) está plotado na Figura 49. A parte elástica não existe na figura devido à hipótese de material rígido perfeitamente plástico. Assim o deslocamento ocorre somente quando as rótulas plásticas se formam, quando a força aplicada alcança quase $40 \mathrm{kN}$. Desde esse momento até o patamar de $53 \mathrm{kN}$ as forças de flexão garantem majoritária resistência à deformação da estrutura. Em seguida, as forças de membrana (tensão) prevalecem na guia de deslizamento w e a absorção de energia de deformação é sobremaneira aumentada. 


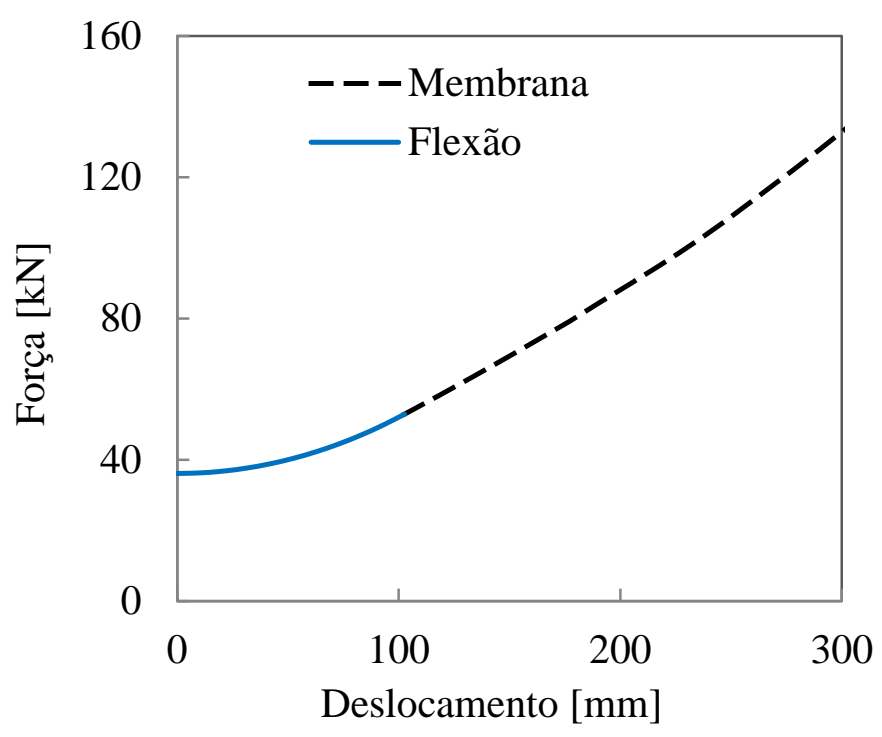

Figura 49 - Gráfico de força aplicada sobre sistema pela flecha máxima da guia de deslizamento w.

\subsection{MODELAGEM EM ELEMENTOS FINITOS}

Uma modelagem do sistema apresentado anteriormente foi elaborada em elementos finitos para verificação dos resultados analíticos. Dois modelos diferentes da conexão entre o poste e a guia de deslizamento w foram analisados: um completo, dotado do parafuso, porca e arruelas; outro simplificado, onde a conexão parafusada foi substituída por uma viga entre dois nós da guia de deslizamento w e o poste - definida pela cartão*CONSTRAINED_SPOTWELD. Os resultados obtidos por ambos os modelos são discutidos e comparados em relação aos resultados do modelo matemático desenvolvido anteriormente. A partir dessa metodologia busca-se validar um modelo para simulações de uma defensa metálica sujeita ao impacto de um veículo leve que combine baixo custo computacional e acurácia. O software utilizado para solução da modelo de elementos finitos foi o Ls-Dyna utilizando o método de cálculo implícito.

Uma vista frontal e lateral do modelo é ilustrada na Figura 50 com as dimensões gerais dos componentes na configuração de montagem. A guia de deslizamento w e o poste sigma foram criados em elementos de casca. Nos postes foram adotados elementos de aproximadamente $8 \times 3 \mathrm{~mm}$. A guia de deslizamento foi modelada majoritariamente com elementos de 10x10mm. 


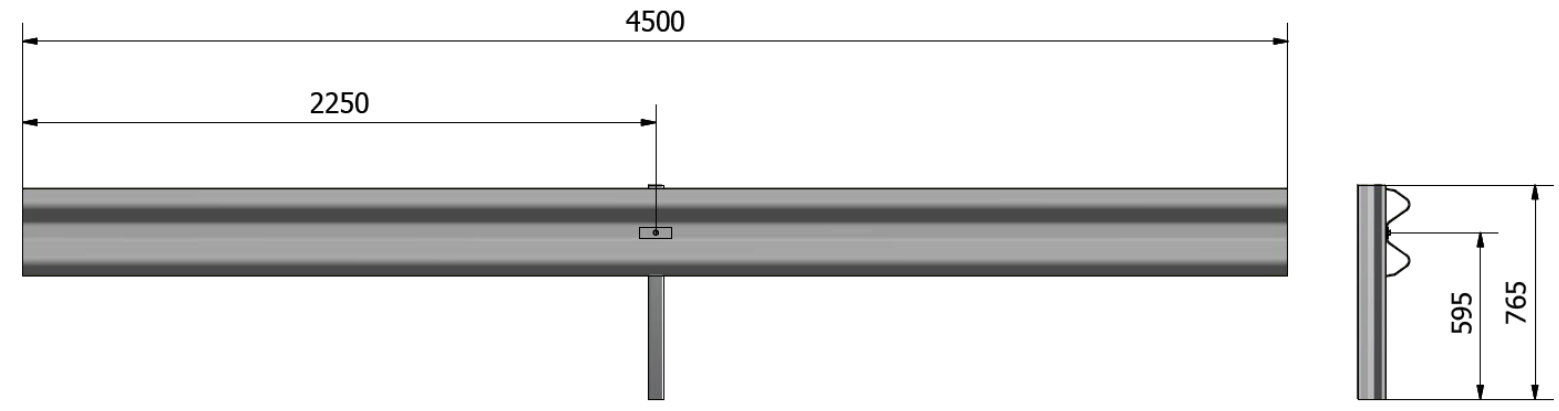

Figura 50 - Vista frontal e lateral do modelo

Na modelagem completa da conexão parafusada foram definidos o parafuso, a porca e as arruelas em elementos sólidos, conforme malha apresentada na Figura 51. A porca foi fixada ao parafuso e todos os deslocamentos relativos foram restringidos através do contato *CONTACT_AUTOMATIC_TIED_SURFACE_TO_SURFACE. O contato entre o parafuso, a guia de deslizamento w e o poste Sigma foi rastreado pela proximidade entre os nós dos elementos de casca e a superfície externa do parafuso utilizando o cartão *CONTACT _AUTOMATIC_NODES_TO_SURFACE. Para as demais superfícies de contato o atrito foi desprezado e o cartão *CONTACT_AUTOMATIC_SURFACE_TO_SURFACE foi adotado.

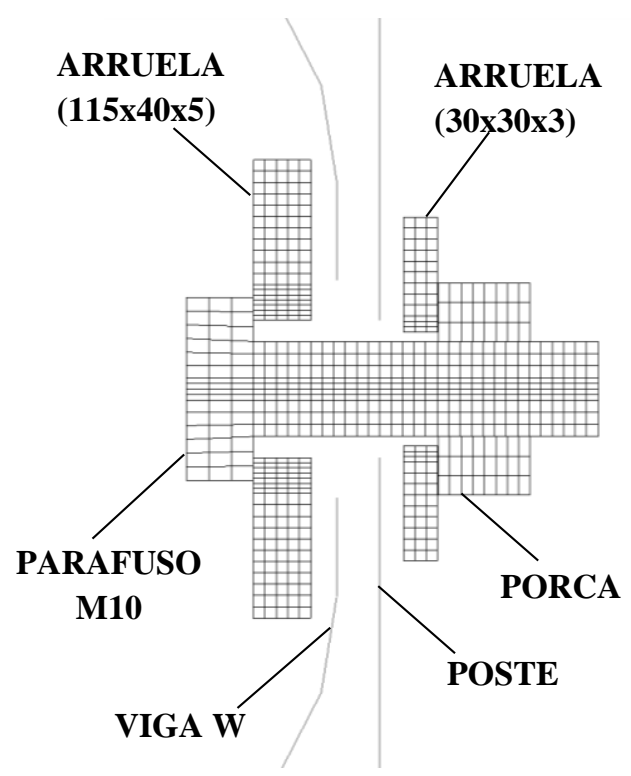

Figura 51 - Malha na região da conexão parafusada e corte na conexão entre o poste e a guia de deslizamento $w$. 
As terminações da guia de deslizamento w e a base do poste foram engastadas. Gravidade não foi considerada no modelo. A força foi aplicada em um conjunto de nós da guia de deslizamento w na posição média do seu comprimento e nas vizinhanças da conexão parafusada, conforme ilustrado na Figura 52. O módulo foi definido por um crescimento linear com o tempo, atingindo o máximo de $120 \mathrm{kN}$.

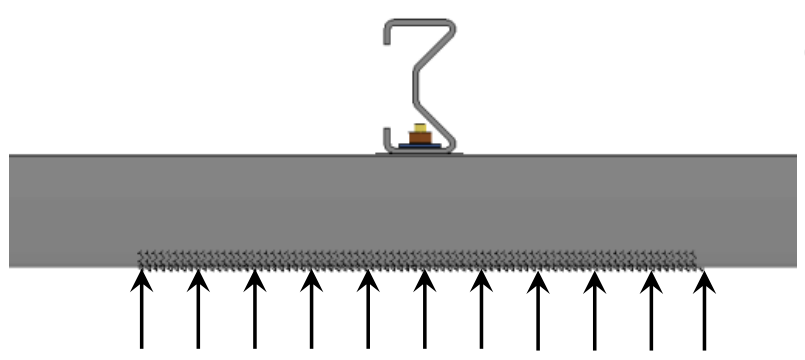

(a)

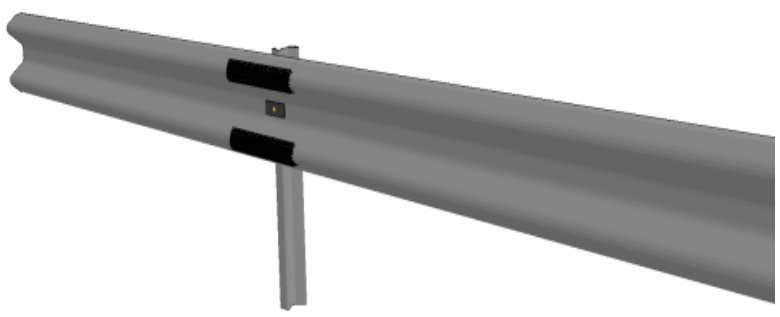

(b)

Figura 52 - Área onde o carregamento foi aplicado, sendo (a) uma vista superior da região central do modelo e em (b) uma vista isométrica.

As constantes do material determinadas no Capítulo 6 foram adotadas para definição da curva simplificada do material da guia de deslizamento w e o poste sigma, conforme Tabela 8. Para os componentes da conexão parafusada, as constantes utilizadas foram obtidas de testes realizados em parceria com o laboratório norueguês Simlab. Comportamento elásto-plástico linear foi adotado para todos os componentes.

Tabela 8 - Propriedades mecânicas adotadas na simulação numérica

\begin{tabular}{lcccc}
\hline \multicolumn{1}{c}{ Componente } & Densidade & $\begin{array}{c}\text { Módulo de } \\
\text { Elasticidade } \\
\mathrm{kg} / \mathrm{m}^{3}\end{array}$ & $\begin{array}{c}\text { Coeficiente de } \\
\text { Poisson }\end{array}$ & $\begin{array}{c}\text { Tensão de } \\
\text { Escoamento } \\
\mathrm{MPa}\end{array}$ \\
\hline Guia de deslizamento & 7850 & 200 & - & 256 \\
Poste Sigma & 7850 & 200 & 0,3 & 256 \\
Parafuso & 7850 & 210 & 0,3 & 240 \\
Porca & 7850 & 210 & 0,3 & 240 \\
Arruela 115x40x5 & 7850 & 210 & 0,3 & 240 \\
Arruela 30x30x3 & 7850 & 210 & 0,3 & 240 \\
\hline
\end{tabular}

\subsection{RESULTADOS}

O comportamento global da estrutura sob carregamento é apresentado pela sequência de imagens da Figura 53. Uma rótula plástica é detectada na base do poste nas vizinhanças da zona 
de engastamento. Adicionalmente, a parede posterior do poste colapsa na mesma região da rótula, o que reduz significativamente a capacidade de resistência por flexão, então a partir desse acontecimento a estrutura sofre grandes deformações.
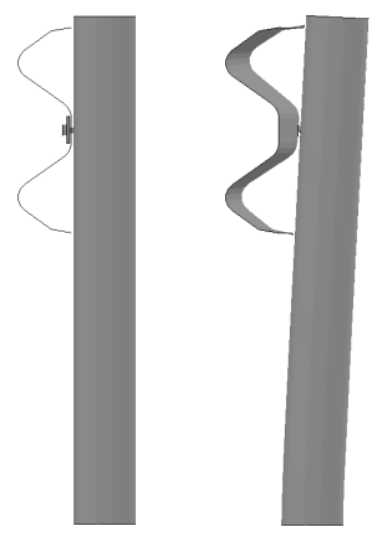

$0,0 \mathrm{kN}$

$\mathrm{t}=0,00 \mathrm{~s}$

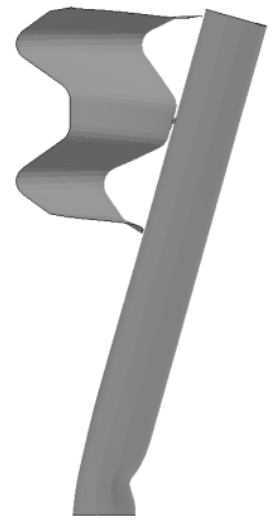

$$
60,0 \mathrm{kN}
$$$$
\mathrm{t}=0,50 \mathrm{~s}
$$
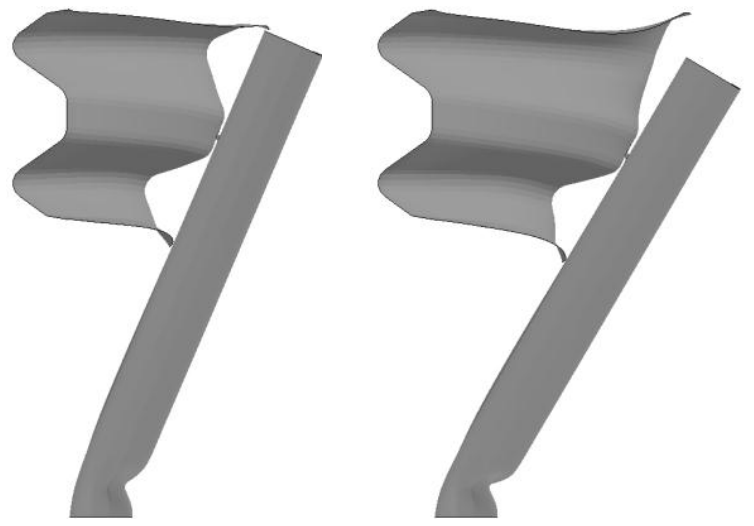

$91,2 \mathrm{kN}$
$120,0 \mathrm{kN}$
$\mathrm{t}=1,00 \mathrm{~s}$

Figura 53 - Comportamento global da estrutura sob carregamento.

Na Figura 54 é apresentado o resultado das deformações plásticas na estrutura deformada. É evidente a presença de três rótulas plásticas na guia de deslizamento w e uma na base do poste sigma, já citada anteriormente. O fato confirma a mesma hipótese considerada pelo modelo analítico desenvolvido na seção 5.2.

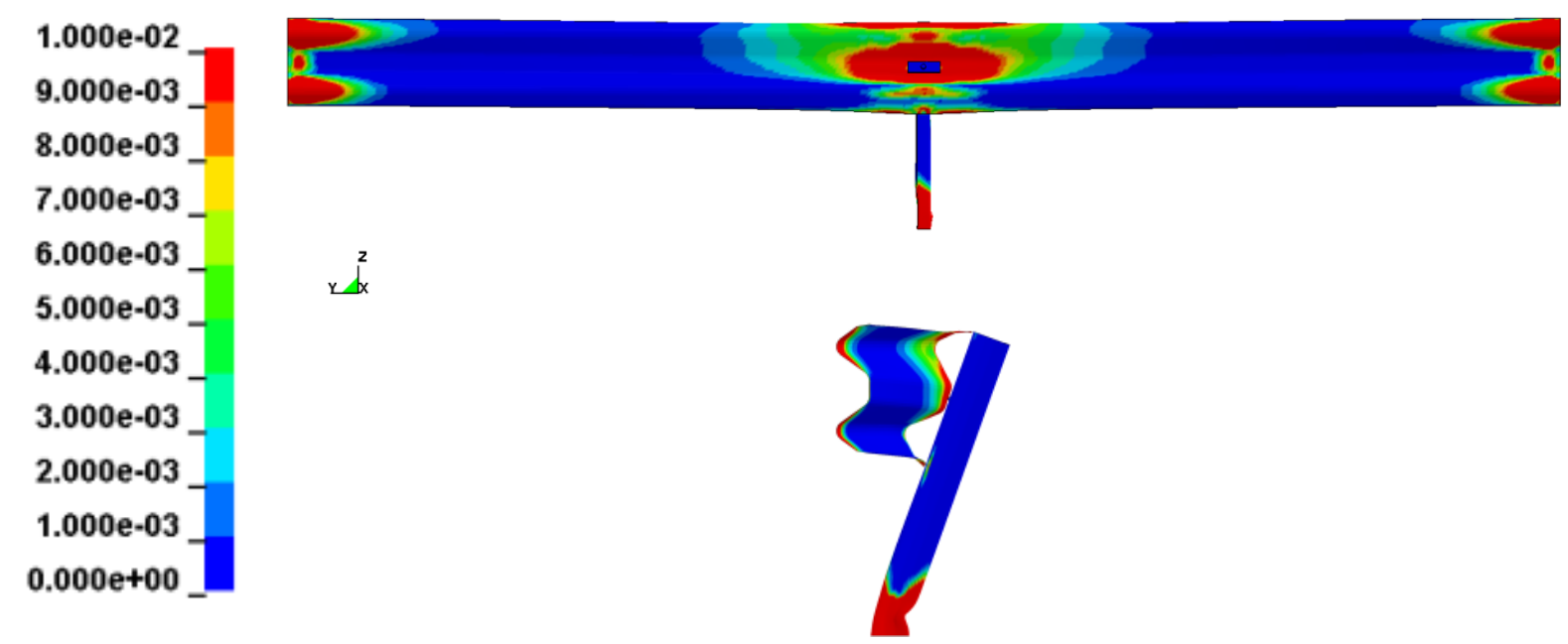

Figura 54 - Deformação plástica na estrutura no tempo de $0,61 \mathrm{~s}$ ou $73,6 \mathrm{kN}$ de força aplicada. As três rótulas plásticas na guia de deslizamento w e outra na base do poste são evidentes. 
Na Figura 55 é realizada uma análise simples da convergência da malha do parafuso. A malha e o número de elementos adotado em cada modelo são apresentados também na Figura 55. As curvas mostram semelhanças no aspecto da forma, porém desvios na zona de pico são evidentes em função da maior ou menor rigidez causada pelo tamanho dos elementos.

No primeiro pico é verificado um desvio de $29,6 \%$ entre os modelos. A malha grosseira subestima o valor máximo da força em 1,34 kN aproximadamente. No segundo caso, quando a força aplicada sobre a estrutura alcança $120 \mathrm{kN}$ ocorre novamente divergência entre os resultados numéricos. A malha grosseira aponta uma força 15,7\% menor que a esperada pela malha fina.

A Figura 56 mostra as curvas de deslocamento no ponto de máxima deformação da estrutura e próximo a conexão parafusada pela força aplicada na estruturas nos modelos analíticos e numéricos (com parafuso e o spotweld). As curvas obtidas por simulação numérica, diferentemente da curva analítica, possuem uma pequena região de deformação elástica até aproximadamente $21 \mathrm{kN}$, seguida pela formação da rótula plástica na base do poste entre $21 \mathrm{kN}$ e $37 \mathrm{kN}$. Essa diferença no comportamento inicial das curvas se deve a hipótese de material plástico perfeito adotada no modelo analítico. É patente que as curvas numéricas possuem pequeno desvio em relação ao modelo analítico simplificado, mostrando uma tendência de aproximação conforme os deslocamentos aumentam.

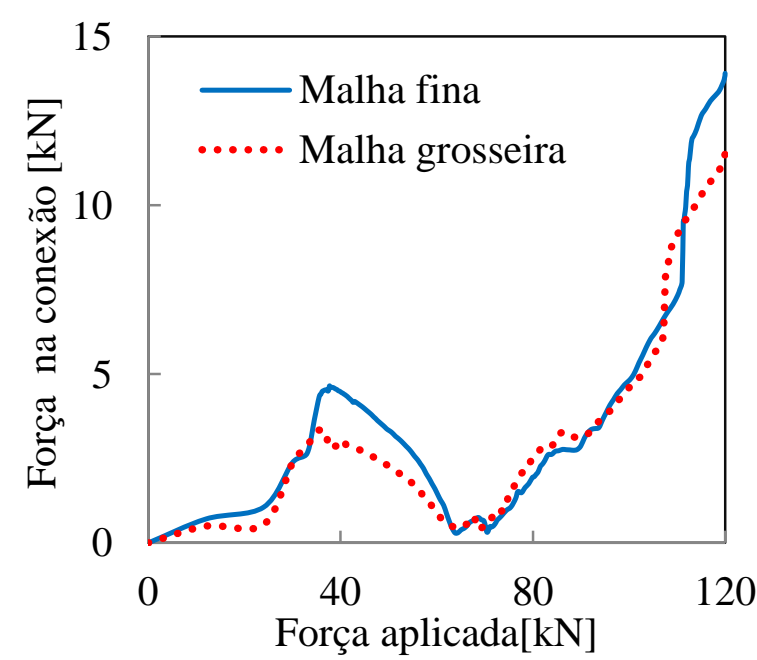

(a)
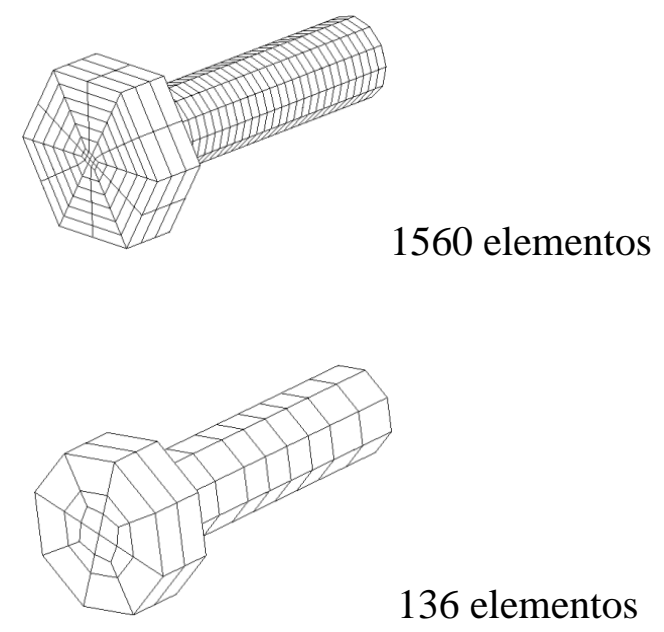

(b)

Figura 55 - Em (a) análise de convergência dos modelos de parafuso com diferentes malhas apresentadas em (b). 


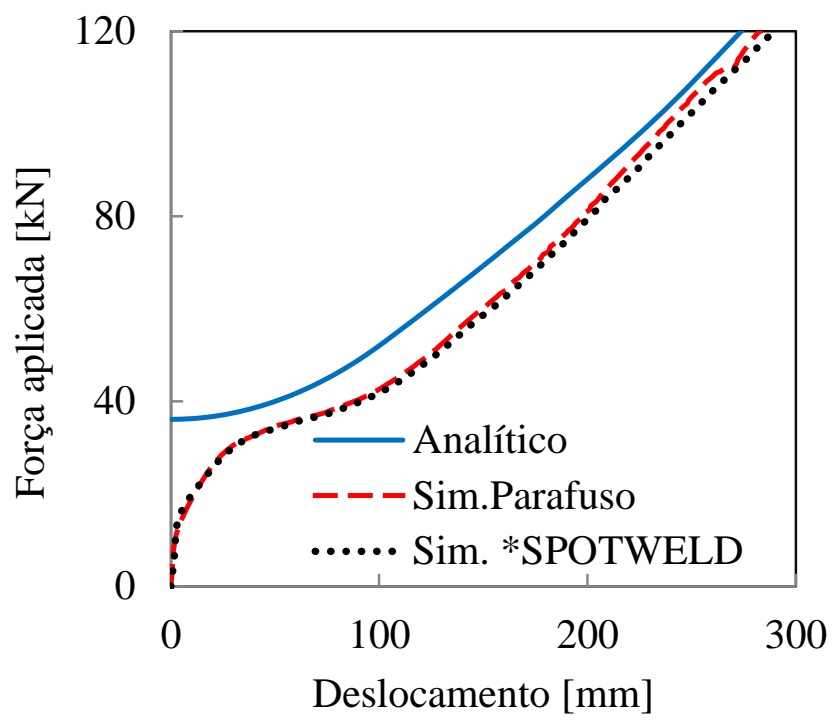

Figura 56 - Comparação entre os resultados obtidos pelo modelo analítico e via elementos finitos.

O comportamento da força resultante do modelo com parafuso e spotweld, Figura 57, demonstra forma similar embora exista divergência entre os valores absolutos. $\mathrm{O}$ primeiro pico das curvas é observado quando a força aplicada sobre o sistema alcança $40 \mathrm{kN}$. Nesse ponto, o valor da força resultante no modelo spotweld é $1,72 \mathrm{kN}$ maior, resultado $41 \%$ maior que o modelo com parafuso. De maneira oposta, a força resultante na conexão do modelo com parafuso é $4,58 \mathrm{kN}$ maior, aproximadamente $38 \%$ maior.

Na Figura 57, as curvas de força na conexão apontam a existência de um pico inicial seguido de um descarregamento, e, finalmente, um crescente aumento da força até o fim da simulação. Tal comportamento explica-se pelo deslocamento do parafuso no furo da guia de deslizamento w. Nos instantes iniciais o poste deforma-se sob flexão levando o parafuso em contato com a borda superior do furo na guia de deslizamento w. Então se verifica o primeiro pico de força. Mas devido à geometria e ao aumento da deformação da guia de deslizamento w, a situação modifica-se. O parafuso é deslocado para baixo o que causa inicialmente o seu descarregamento notado pelo vale na Figura 57. Acompanhando a tendência de deslocamento, o contato é estabelecido com a borda inferior do furo. A seguir a força aumenta progressivamente até o estado verificado na Figura 58 e Figura 59. 


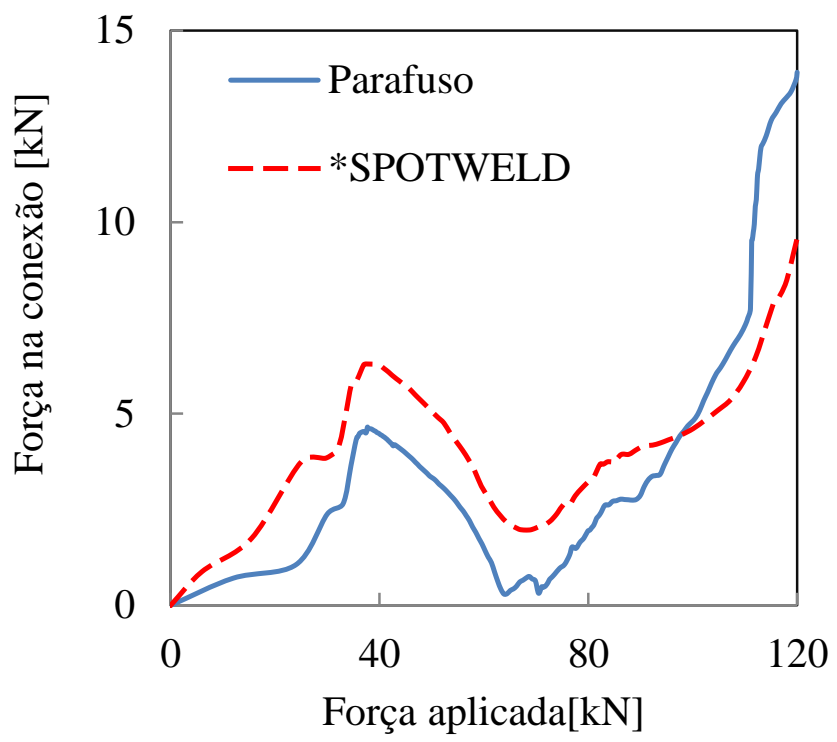

Figura 57 - Comparação entre a força resultante dos modelos com e sem parafuso.

Como nenhum critério de falha foi adotado, notam-se tensões e deformações plásticas elevadas, $616,0 \mathrm{MPa}$ e 46,8\% respectivamente, indicando que uma falha no parafuso seja iminente ou factual nessas condições.

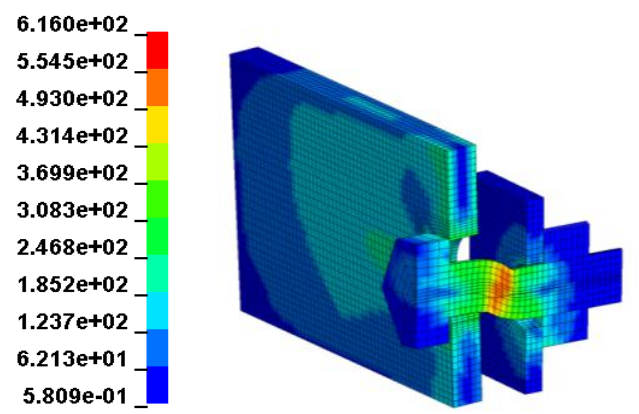

Figura 58 - Tensão de Von Mises em unidades MPa na conexão parafusada.

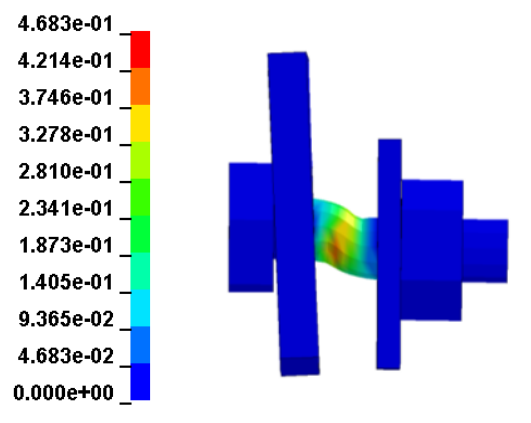

Figura 59 - Deformação plástica na conexão parafusada. 
Os módulos das componentes normais e de cisalhamento foram plotadas na Figura 60 e Figura 61, respectivamente. A força normal exibida pelo modelo spotweld no primeiro pico é aproximadamente cinco vezes maior que o modelo com parafuso, enquanto a seguir as curvas exibem razoável similaridade. No caso da força de cisalhamento existem semelhanças no comportamento, mas diferenças de valores absolutos em quase toda a curva. A deformação em planos paralelos e de sentido opostos a seção transversal do parafuso comprova uma característica típica de carga cisalhante predominantemente, também confirmado pela característica das curvas de força normal e cisalhante na seção.

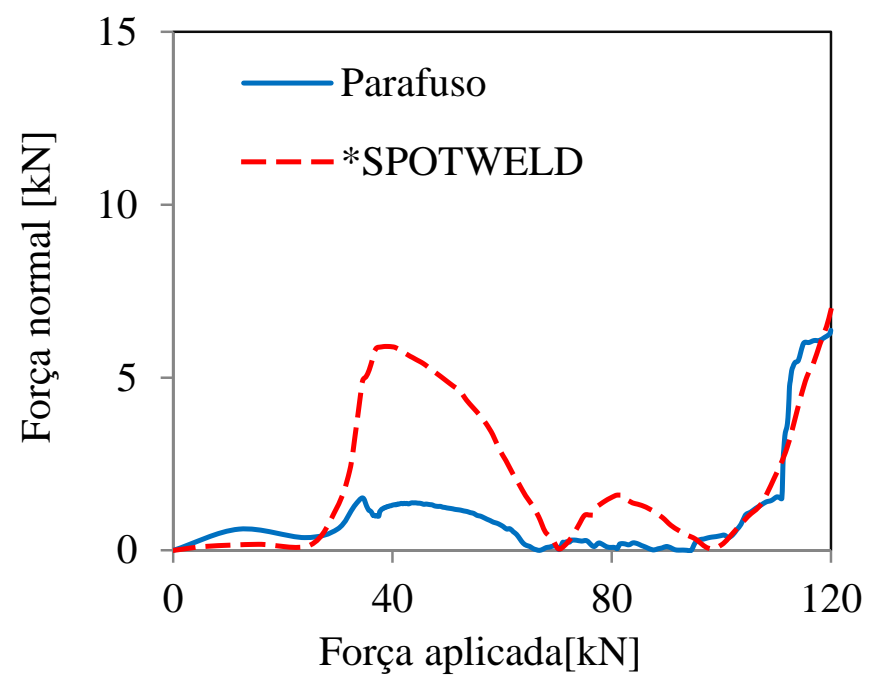

Figura 60 - Força normal obtida na conexão com e sem parafuso.

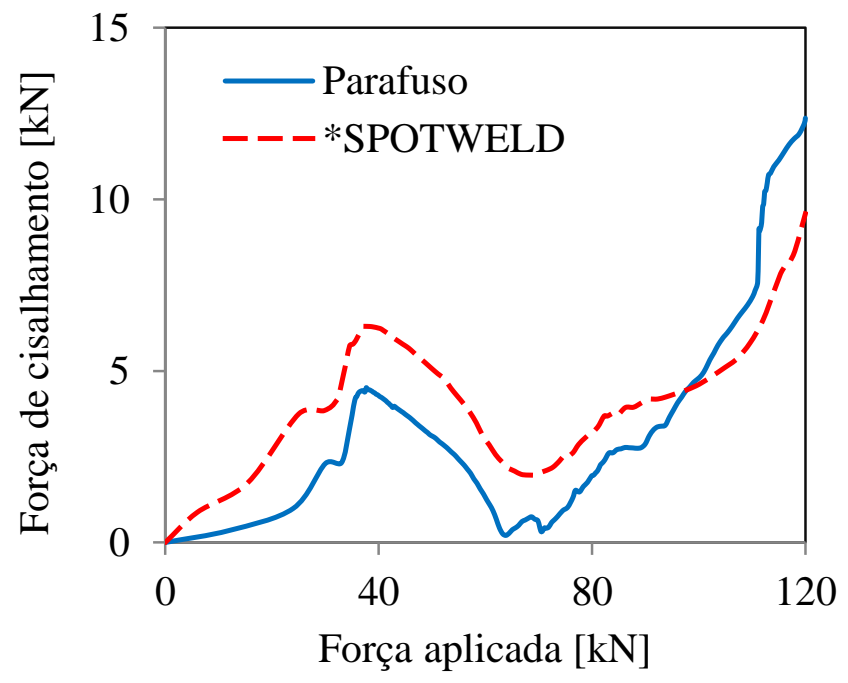

Figura 61 - Força de cisalhamento obtida na conexão com e sem parafuso. 
Um estudo paramétrico da falha na conexão entre o poste e a viga foi desenvolvido utilizando o modelo spotweld. O parâmetro avaliado foi o critério de falha da conexão definido pela deformação plástica dos nós restringidos. Na Figura 63 é apresentado o resultado do momento da falha da conexão spotweld obtido por simulações diferentes no qual o valor do parâmetro PS “plastic strain" foi variado. A curva plotada em linha contínua representa o comportamento da força resultante na conexão spotweld quando nenhum critério de falha foi adotado.

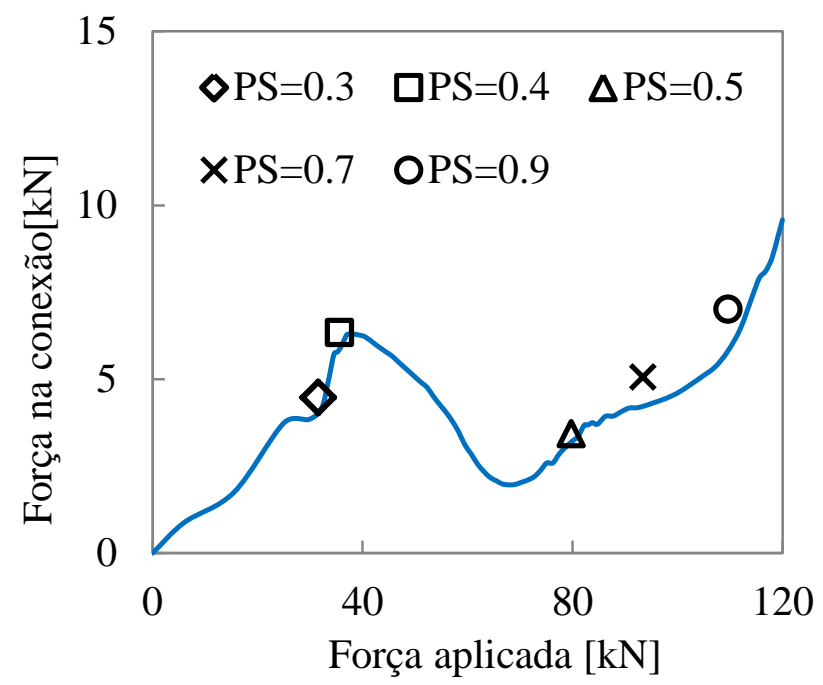

Figura 62 - Relação entre a força resultante na conexão spotweld e a forças de carregamento.

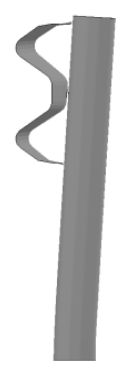

$\mathrm{PS}=0,3$

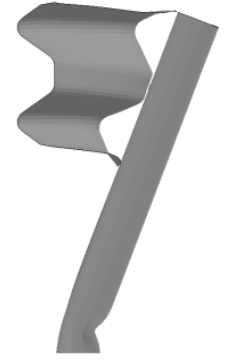

$\mathrm{PS}=0,5$

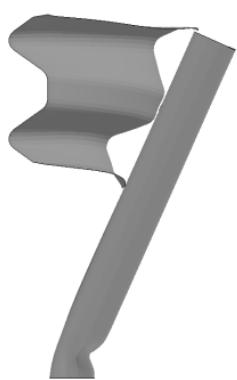

$\mathrm{PS}=0,7$

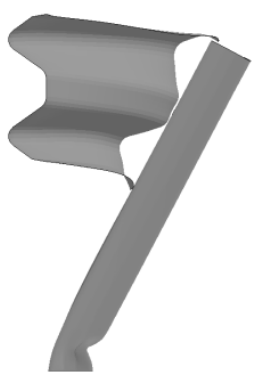

PS $=0,9$

Figura 63 - Análise paramétrica da falha da conexão spotweld.

A partir da Figura 64 é possível inferir que a de deformação da estrutura é acumulada em maior parte na guia de deslizamento w a partir de $100 \mathrm{~mm}$ de deslocamento total. Desse ponto em diante a energia absorvida é essencialmente devido às forças de membrana que causam a plastificação da guia de deslizamento w. Uma comparação entre a energia total acumulada entre o modelo com parafuso e spotweld mostra que os resultados são bastante similares. 


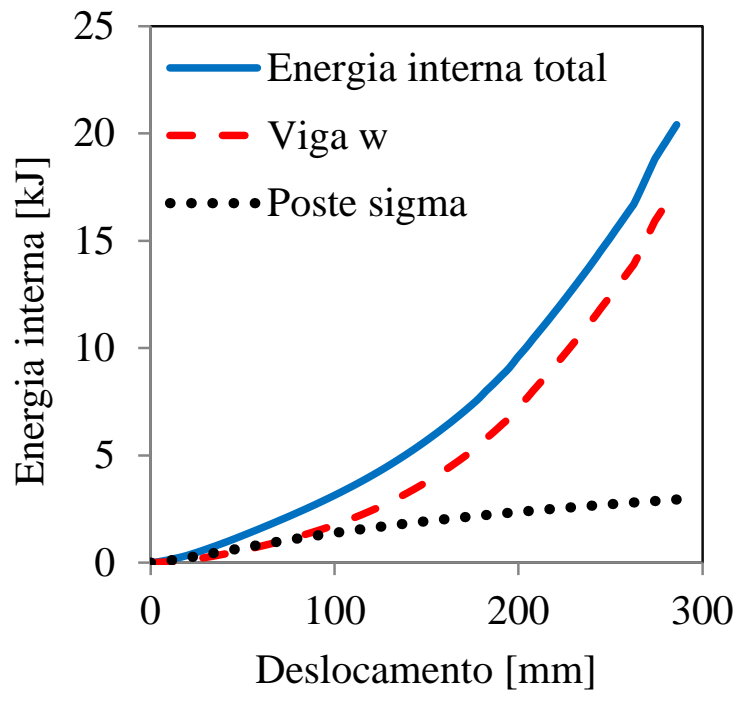

(a)

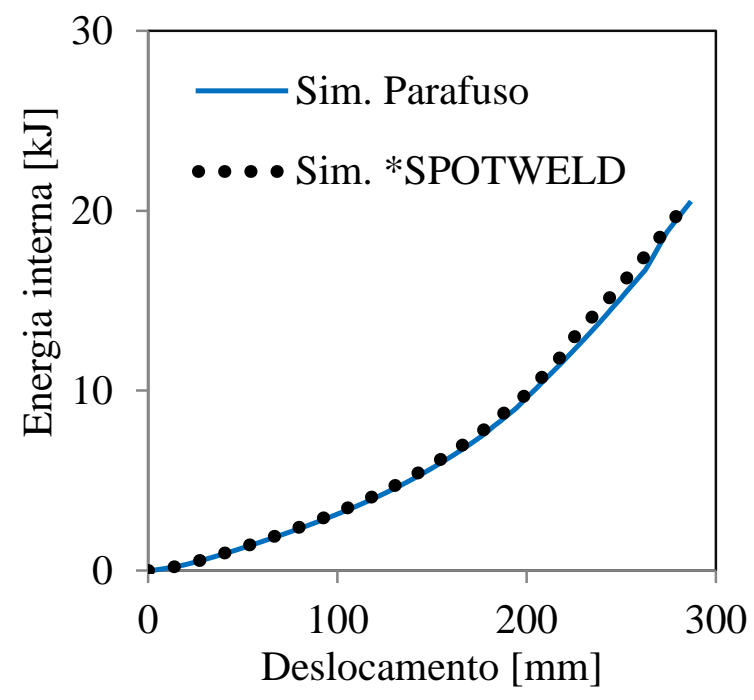

(b)

Figura 64 - Em (a) energia interna acumulada nos componentes da defensa e em (b) energia interna acumulada nos modelos de conexão durante a deformação da estrutura.

\subsection{DISCUSSÃO}

Uma verificação de dois modelos numéricos foi realizada contra resultados analíticos. O modelo completo do parafuso em elementos sólidos pode ser considerado mais realista. Pois representa os componentes em detalhes e, portanto, as previsões das tensões e deformações locais são consideradas estimativas razoáveis do fenômeno real. De acordo com essa premissa, os resultados do modelo spotweld são aproximações da resposta global da conexão parafusada.

Comparando os resultados dos dois modelos verifica-se que o comportamento da estrutura e os modos de deformação são bastante semelhantes e também compatíveis com o modelo analítico, segundo a Figura 56. Desvios na previsão das forças normais e de cisalhamento na conexão são evidentes entre os modelos numéricos, principalmente nos picos de força. Dada a simplicidade e eficiência computacional do modelo spotweld, vide Tabela 9, o comportamento das curvas exibidas na Figura 56 e Figura 57 demonstra que o modelo de conexão pontual é coerente do ponto de vista global, mas possui limitações para a uma análise local.

O estudo do parâmetro de falha na conexão spotweld é fundamental do ponto de vista de aplicação em uma análise de impacto onde um modelo completo da defensa metálica será implementado. Sabe-se que a determinação adequada da falha na conexão parafusada é crucial no 
comportamento do sistema e decisivo no redirecionamento do veículo ao colidir com a barreira. Fato que será abordado em maiores detalhes no Capítulo 6.

Tabela 9 - Tempo total despendido em cada modelo no software LS-Dyna Implicit

\begin{tabular}{ccc}
\hline \multicolumn{2}{c}{ Parafuso } & Spotweld \\
Malha grosseira & Malha fina & \\
\hline 136min e 13s & $152 \mathrm{~min}$ e 2s & 30min e 13s \\
\hline
\end{tabular}

A guia de deslizamento $\mathrm{w}$ absorve majoritária parcela da energia interna total, devido às forças de membrana, conforme os resultados da Figura 49 e Figura 64. Isso sugere que durante o impacto de um veículo a estrutura absorve a maior parte da energia de impacto através da deformação plástica da guia de deslizamento $\mathrm{w}$, seguido do poste e ínfima parcela devido ao parafuso. No caso em que o poste é enterrado no solo, mais comum na prática, o mesmo poderia mover-se e/ou girar com a plastificação do meio (solo), caso em que a energia acumulada pelo poste seria ainda menor.

A decisão sobre a escolha do refinamento da malha qualifica-se como uma relação de compromisso entre precisão e custo computacional. Nesse sentido é importante destacar as limitações de uma malha no aspecto do custo computacional. Elementos menores em determinadas áreas como furos, parafusos ou concordâncias são fundamentais em análises numéricas de tensão e deformação. Em simulações de impacto o time step não deve ser menor do que $0,1 \mu$ s por razões práticas que envolvem o tamanho do modelo e a capacidade dos hardwares disponíveis. Portanto, a escolha da malha torna-se um imperativo na viabilidade da análise. Nesse sentido, a malha grosseira do parafuso é mais adequada para análises de impacto. 


\section{SIMULAÇÕES NUMÉRICAS}

Nesse capítulo, serão desenvolvidas análises numéricas do impacto de um veículo leve em uma defensa metálica, uma defensa de concreto New Jersey e uma defensa de concreto vertical.

O estado da arte no desenvolvimento de defensas metálicas rodoviárias é tratado na revisão bibliográfica. Normas nacionais e internacionais sobre segurança e instalação de sistemas de contenção rodoviária são discutidas criticamente em seguida. Nesse contexto, a metodologia de análise de desempenho das defensas serão baseadas nos conceitos definidos pelas normas da União Européia (EN 1317-1, 1998) e (EN 1317-2, 1998).

\subsection{REVISÃO BIBLIOGRÁFICA}

As defensas metálicas rodoviárias são sistemas de barreiras fabricadas normalmente de chapas em aço e conformadas em perfil $\mathrm{w}$, fixadas ao solo por meio de postes e a esse último por meio de parafusos. Espaçadores ou calços são podem também ser utilizados de acordo com a aplicação da defensa (NBR 6971, 1999). Esse sistema possui duas finalidades principais, redirecionar com segurança o veículo que se choca contra a barreira e dissipar o máximo de energia cinética do veículo durante o evento de impacto (Hascall et al., 2007). O redirecionamento previne o veículo de escapar da rodovia e atingir uma zona de risco onde existam pedestres ou obstáculos físicos como ribanceiras e rios; também evita colisões secundárias com veículos da mesma via. De modo secundário, a absorção de energia de impacto pelo sistema de contenção pode reduzir significativamente a severidade do acidente aos ocupantes.

Quanto a geometria do perfil da guia de deslizamento, a comunidade científica ainda não alcançou unanimidade em relação a uma seção ótima, exemplo disso são os diversos modelos existentes em países como os Estados Unidos, Áustria, França, Japão e Suécia, patentes na Figura 65.

Apesar dos órgãos governamentais agirem no sentido de regulamentar os métodos apropriados de instalação e os requisitos mínimos para comercialização do produto, muitos problemas tecnológicos e científicos se debruçam no desenvolvimento de uma defensa metálica ideal. 

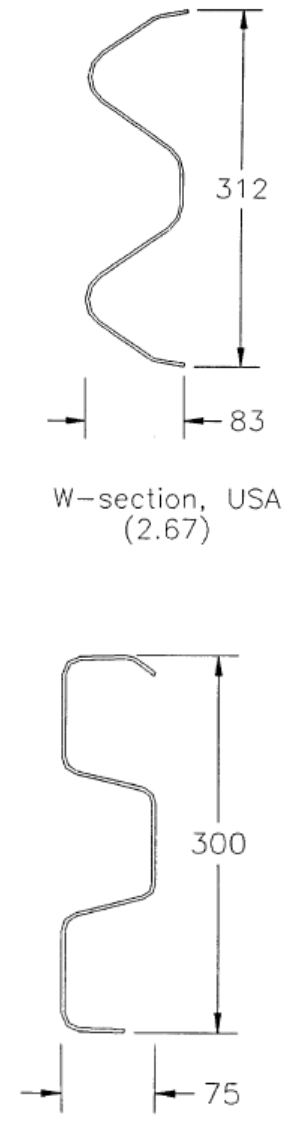

Profilafroid, France (3.0)

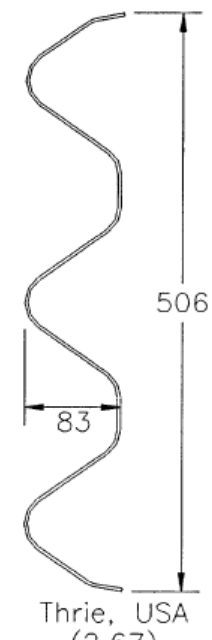

(2.67)

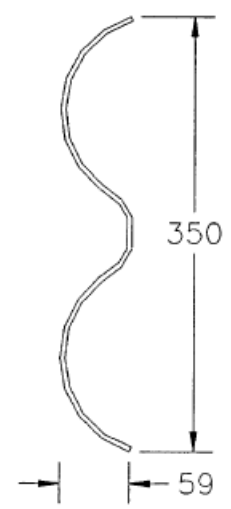

NKK type 5, Japan $(3.20)$

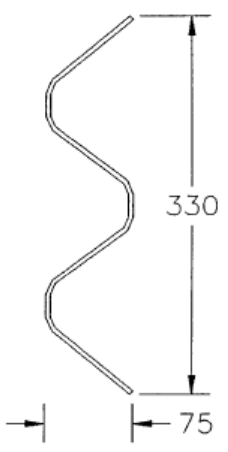

Voest, Austria (3.05)

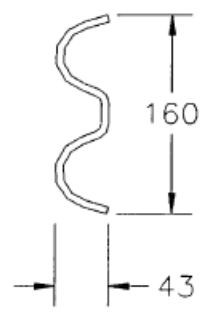

Swedish profile

$(6.0)$

Figura 65 - Seções transversais utilizadas em diversos países (Reid at al., 1997).

Boa parte desses itens tem sido motivo de pesquisa, (Merkes, 1999) analisa a utilização do polímero GFRP (Glass FIber Reinforced Plastic) como substituto às vigas metálicas em formato W. Vantagens como a leveza e resistência a corrosão reforçam a aplicação do polímero; desvantagens como o mecanismo de fixação e conexão não usuais, somam pontos desfavoráveis. Apesar de ter sido amplamente caracterizado via testes de tração e flexão das conexões e fixação, não foram realizados testes de impacto de escala real da estrutura proposta, por isso nenhuma conclusão sobre a eficácia do sistema pode ser estabelecida.

Hascall et al. (2007) analisam por meio de testes em escala real o desempenho de postes de madeira, em substituição ao poste metálico, considerando os requisitos da National Cooperative Highway research Program NCHRP n³50 (Ross et al., 1993). O mesmo deve ter resis- 
tência suficiente para rotacionar no solo sem fraturar-se. Nesse sentido, a pesquisa identifica o tamanho e o grau da madeira necessária para assegurar tal comportamento.

Modificações na profundidade de fixação de postes fabricados em madeira foram sugeridas por (Atahan, ASCE, \& Cansiz, 2005) para aumentar a estabilidade do veículo redirecionado e reduzir a súbita desaceleração durante o impacto.

A análise da falha da conexão parafusada entre as vigas w foi abordada por (Ray, Plaxico, \& Engstrand, 2001). O estudo sugere a alteração do posicionamento das conexões entre guias de deslizamento de modo a alcançar uma redução significativa das chances de falha das mesmas.

Novas seções transversais da barreira de perfil w foram analisadas por Reid et al. (1997) considerando as modificações dos para-choques e altura do centro de massa dos veículos novos. A Figura 66 exemplifica as seções analisadas, sendo a seção B-Beam aquela que obteve os melhores resultados de acordo com a NCHRP n³50.

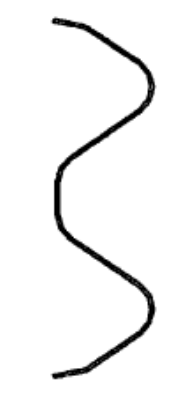

W-Beam

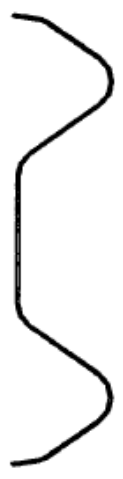

$1 \mathrm{~B}$

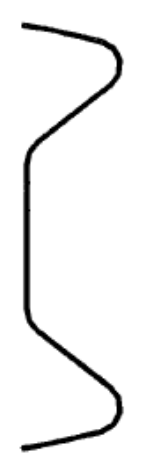

$3 \mathrm{C}$
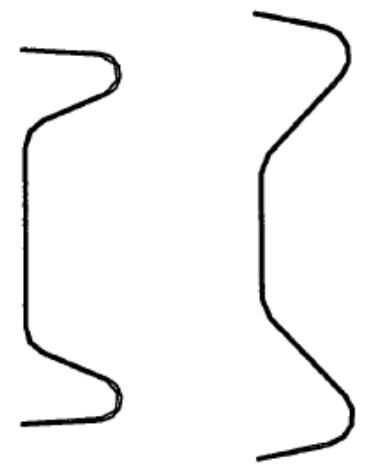

$5 \mathrm{C}$
B-Beam

Figura 66 - Exemplos dos perfis analisados por (Reid et al., 1997)

Modelos numéricos de impacto de veículos em uma defensa metálica são estudados por Sennah et al. (2003), Shen et al. (2008) e Plaxico et al. (2000), demonstrando que o método dos elementos finitos representa satisfatoriamente o fenômeno real. Isso demonstra que as ferramentas de simulação numérica existentes são capazes de oferecer uma evolução no conceito de defensas rodoviárias muito mais seguras a um custo de desenvolvimento de engenharia menor, posto que inúmeros testes em escala real possam ser reduzidos. 
A referência Sennah et al. (2003) analisa numericamente soluções de fixação da viga por postes de madeira e metálicos de formatos diferentes, afim de aumentar a energia de impacto absorvida pelo defensa metálica. Por outro lado, Shen et al. (2007) utilizam métodos de otimização para definir a posição vertical ótima de uma defensa metálica em relação ao centróide de um veículo, buscando a máxima absorção de energia do sistema.

Plaxico et al. (2000) comparam postes de madeira de dimensões diferentes realizando simulações numéricas e testes em escala real. Os resultados obtidos são muito favoráveis no que tange à convergência dos dados experimentais e de elementos finitos conforme exemplificado na Figura 67.

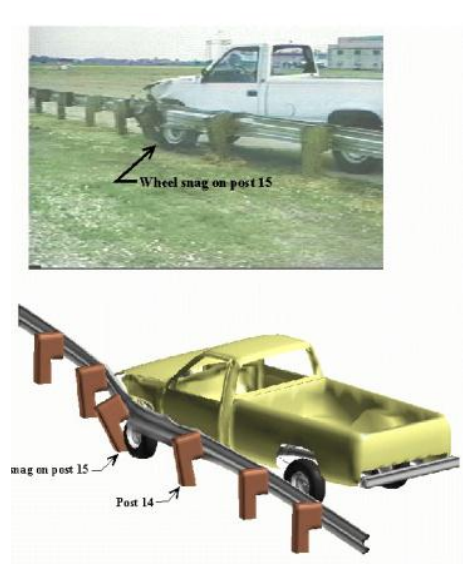

(a)

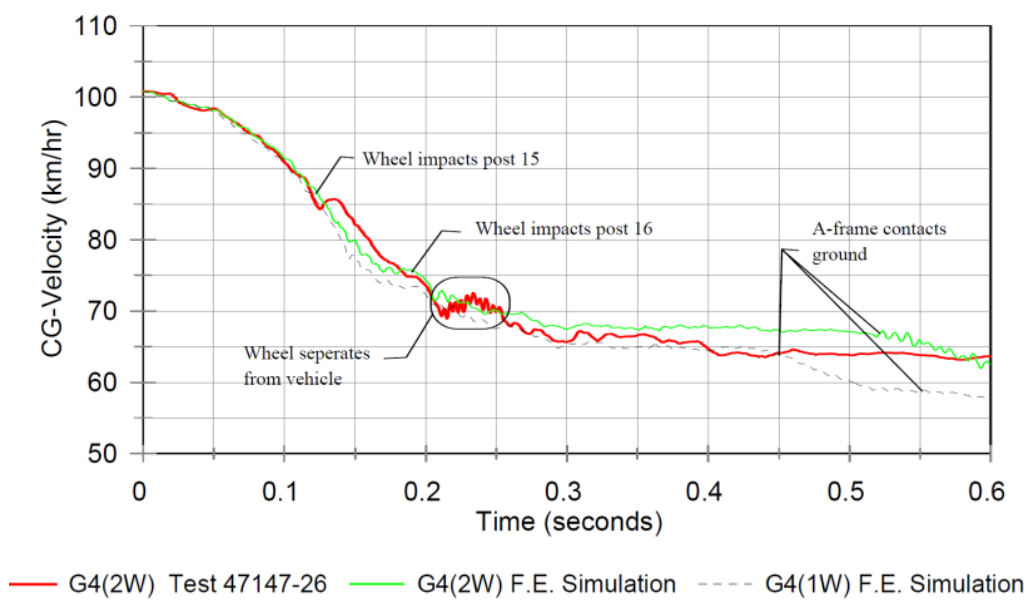

(b)

Figura 67 - Comparação entre o estado de deformações da defensa e do veículo no teste em escala real e simulação numérica em (a) e em (b) da velocidade do CG do veículo estudada por Plaxico et al. (2000).

O autor não encontrou referências na literatura que investigaram a influência da conexão parafusada entre o poste e a guia de deslizamento w no desempenho da defensa metálica. Outrossim Ray et al. (2001), analisoaram a resistência das conexões entre duas vigas w, fato que determinou algumas mudanças importantes na montagem do sistema.

\subsection{REVISÃO DE NORMAS}

A norma (NBR 6971, 1999) fixa as características de projeto e implantação de defensas metálicas no Brasil. Publicada em 1999, a norma não possui referências ou exigências de testes de 
impacto para comprovação do desempenho dos sistemas de contenção. Devido a ausência desse método de validação, a norma impõe o uso exclusivo de um modelo de defensa com variações na sua implantação em relação a presença ou ausência de espaçadores, tipo de fixação da base dos postes, métodos de ancarogem, espaçamento de postes, etc. Nesse sentido, as especificações técnicas de todos os componentes são definidos, como as propriedades do material, dimensões, espessura, comprimento, etc.

Nos Estados Unidos, uma defensa metálica deve satisfazer aos requisitos definidos pela NCHRP relatório $n^{\circ} 350$ (Ross et al., 1993) para serem aceitos no sistema de rodovias. De acordo com essa norma o sistema deve ser submetido a dois tipos de testes de impacto:

- Teste 3-10 - consiste em um veículo de aproximadamente $820 \mathrm{~kg}$ chocando-se com o sistema de defensa metálica a uma velocidade nominal de $100 \mathrm{~km} / \mathrm{h}$ e ângulo de 20 graus.

- Teste 3-11 - consiste em um veículo de aproximadamente 2000kg chocando-se com o sistema de defensa metálica a uma velocidade nominal de $100 \mathrm{~km} / \mathrm{h} \mathrm{e}$ ângulo de 25 graus.

O critério de avaliação do teste real é baseado em três áreas: adequação estrutural, risco aos ocupantes e a trajetória do veículo após colisão. O primeiro item avalia a capacidade da barreira em conter e redirecionar o veículo de maneira previsível. O risco aos ocupantes mede o grau de severidade no evento de impacto. O último item infere sobre a possível ocorrência de a trajetória do veículo desgovernado causar outros acidentes.

De modo similar, a norma EN 1317-2, (1998) define a velocidade, o ângulo de impacto e massa do veículo para diversos testes de impacto, indicados na Tabela 10, a fim de orientar os testes necessários para cada tipo de defensa e grau de contenção. De acordo com essas especificações, um sistema de contenção pode ser avaliado em função das condições do tráfico e características geométricas de uma dada rodovia. 
Tabela 10 - Classes e parâmetros para teste de impacto de defensas

\begin{tabular}{ccccc}
\hline Teste & $\begin{array}{c}\text { Velocidade de } \\
\text { Impacto }\end{array}$ & Ângulo & $\begin{array}{c}\text { Massa do } \\
\text { veículo }\end{array}$ & Tipo de veículo \\
- & $\mathrm{km} / \mathrm{h}$ & Graus & $\mathrm{kg}$ & - \\
\hline TB 11 & 100 & 20 & 900 & Carro \\
TB 21 & 80 & 8 & 1300 & Carro \\
TB 22 & 80 & 15 & 1300 & Carro \\
TB 31 & 80 & 20 & 1500 & Carro \\
TB 32 & 110 & 20 & 1500 & Carro \\
TB 41 & 70 & 8 & 10000 & Caminhão Rígido \\
TB 42 & 70 & 15 & 10000 & Caminhão Rígido \\
TB 51 & 70 & 20 & 13000 & Ônibus \\
TB 61 & 80 & 20 & 16000 & Caminhão Rígido \\
TB 71 & 65 & 20 & 30000 & Caminhão Rígido \\
TB 81 & 65 & 20 & 38000 & Caminhão Articulado \\
\hline
\end{tabular}

Na Tabela 11 são expostos diferentes níveis de contenção para uma barreira rodoviária, obtidos na norma EN1317-2 (1998). A contenção de pequenos ângulos - grupo T1, T2 e T3 - é aplicável somente a barreiras temporárias, porém as mesmas podem ser testadas em níveis superiores. Para qualquer um dos níveis acima da classe N2, a avaliação do sistema deve atender o teste de impacto de um veículo leve $(900 \mathrm{~kg})$, conforme teste TB 11 . A energia indicada para cada nível de contenção é calculada pelo limite máximo de energia cinética durante o impacto de acordo com a seguinte equação,

$$
\text { Energia }=\frac{1}{2} M \cdot(V \cdot \operatorname{sen} \alpha)^{2}
$$

onde $M$ é a massa do veículo, $V$ a velocidade e $\alpha$ o ângulo de impacto entre a defensa e a direção de movimento do veículo.

A correta aplicação de uma defensa depende da avaliação de características como o local de aplicação, tipo de estrada e condições do tráfego. De posse de tais dados é possível determinar o nível de contenção exigido ao sistema de contenção e de uma maneira simples fabricantes adotam as orientações apresentadas na Tabela 12. Os dados mostram que áreas de canteiro central e escape lateral de pistas exigem nível de contenção mínimo N2 em vias urbanas e 
baixa frequência de tráfego de veículos pesados. As defensas aplicadas em pontes exigem nível mínimo de contenção H2 para todos os tipos de estradas.

Tabela 11 - Níveis de contenção de uma barreira rodoviária

\begin{tabular}{lccc}
\hline Denominação & $\begin{array}{c}\text { Nível de } \\
\text { contenção }\end{array}$ & $\begin{array}{c}\text { Testes para } \\
\text { Aprovação }\end{array}$ & $\begin{array}{c}\text { Energia } \\
\text { kJ }\end{array}$ \\
\hline \multirow{3}{*}{ Pequeno ângulo de contenção } & T1 & TB 21 & 6,2 \\
& T2 & TB 22 & 21,5 \\
& T3 & TB 41 e TB 21 & 36,6 \\
\hline \multirow{2}{*}{ Contenção normal } & N1 & TB 31 & 43,3 \\
& N2 & TB32 e TB 11 & 81,9 \\
\hline \multirow{2}{*}{ Grande contenção } & H1 & TB 42 e TB 11 & 126,6 \\
& H2 & TB 51 e TB 11 & 287,5 \\
\multirow{2}{*}{ Máxima contenção } & H3 & TB 61 e TB 11 & 462,1 \\
\hline
\end{tabular}

Tabela 12 - Recomendações para aplicação de defensas (Patane, 2012)

\begin{tabular}{|c|c|c|c|c|}
\hline Tipo de estrada & $\begin{array}{l}\text { Tráfego de veículos } \\
\text { com mais de } 3000 \mathrm{~kg}\end{array}$ & $\begin{array}{l}\text { Canteiro } \\
\text { central }\end{array}$ & Lateral & Ponte \\
\hline \multirow{3}{*}{$\begin{array}{l}\text { Rodovias e estradas } \\
\text { principais }\end{array}$} & $<5 \%$ & $\mathrm{H} 2$ & $\mathrm{H} 1$ & $\mathrm{H} 2$ \\
\hline & $5 \% \leq$ valor $\leq 15 \%$ & H3 & $\mathrm{H} 2$ & H3 \\
\hline & $>15 \%$ & $\mathrm{H} 3 \mathrm{ou} \mathrm{H} 4$ & $\mathrm{H} 3$ ou H4 & $\mathrm{H} 4$ \\
\hline \multirow{3}{*}{ Estradas secundárias } & $<5 \%$ & $\mathrm{H} 1$ & $\mathrm{~N} 2$ & $\mathrm{H} 2$ \\
\hline & $5 \% \leq$ valor $\leq 15 \%$ & $\mathrm{H} 2$ & $\mathrm{H} 1$ & $\mathrm{H} 2$ \\
\hline & $>15 \%$ & $\mathrm{H} 2$ & $\mathrm{H} 2$ & $\mathrm{H} 3$ \\
\hline \multirow{3}{*}{ Vias urbanas e locais } & $<5 \%$ & $\mathrm{~N} 2$ & $\mathrm{~N} 2$ & $\mathrm{H} 2$ \\
\hline & $5 \% \leq$ valor $\leq 15 \%$ & $\mathrm{H} 1$ & $\mathrm{~N} 2$ & $\mathrm{H} 2$ \\
\hline & $>15 \%$ & $\mathrm{H} 1$ & $\mathrm{H} 1$ & $\mathrm{H} 2$ \\
\hline
\end{tabular}

A severidade do impacto aos ocupantes é medida de acordo com os seguintes índices:

- ASI: Acceleration Severity Index ou índice de severidade de aceleração;

- THIV: Theoretical Head Impact Velocity ou velocidade de impacto teórica da cabeça do ocupante, o que é determinado pelas coordenadas da posição inicial da cabeça e por isso é aplicável a qualquer um dos indivíduos no interior do veículo; 
- PHD: Post-impact Head Deceleration ou desaceleração da cabeça pósimpacto;

O índice ASI é uma medida escalar calculada em função do tempo através dos resultados de aceleração nos eixos ortogonais de um ponto selecionado no veículo, conforme equação abaixo,

$$
\operatorname{ASI}(t)=\sqrt{\left(\frac{\bar{a}_{x}(t)}{\hat{a}_{x}}\right)^{2}+\left(\frac{\bar{a}_{y}(t)}{\hat{a}_{y}}\right)^{2}+\left(\frac{\bar{a}_{z}(t)}{\hat{a}_{z}}\right)^{2}} .
$$

Onde $\hat{a}_{x}, \hat{a}_{y}$ e $\hat{a}_{z}$ são os limites de aceleração para um ocupante utilizando cintos de segurança indicados na norma EN 1317-2 (1998), cujos valores são baseados na aceleração da gravidade $g=9,81 \mathrm{~m} / \mathrm{s}^{2}$ e definidos abaixo:

$$
\hat{a}_{x}=12 g, \hat{a}_{y}=9 g, \hat{a}_{z}=10 g \text {. }
$$

As componentes de aceleração $\bar{a}_{x}, \bar{a}_{x}$ e $\bar{a}_{z}$ são médias móveis computadas em intervalos de tempo $\delta=50 \mathrm{~ms}$ de acordo com as seguintes expressões,

$$
\bar{a}_{x}(t)=\frac{1}{\delta} \int_{t}^{t+\delta} a_{x} d t ; \quad \bar{a}_{y}(t)=\frac{1}{\delta} \int_{t}^{t+\delta} a_{y} d t ; \quad \bar{a}_{z}(t)=\frac{1}{\delta} \int_{t}^{t+\delta} a_{z} d t
$$

O índice ASI mensura a severidade de impacto ao ocupante sentado nas proximidades do ponto onde é calculado. Em uma colisão, o valor máximo do índice ao longo do impacto define a severidade do teste, de modo que:

$$
A S I=\max [A S I(t)]
$$

Quanto mais o ASI excede a unidade maior é o risco aos ocupantes. Como a equação (6.2) é a forma mais simples de interação entre as variáveis $\bar{a}_{x}, \bar{a}_{y}$ e $\bar{a}_{z}$, se quaisquer duas componentes de aceleração são nulas, o ASI atinge o valor limite 1 quando a terceira componente alcança o valor máximo à segurança do passageiro. Porém, quando duas ou três componentes são não 
nulas o ASI pode atingir o limite unitário mesmo que uma componente tenha um valor bem abaixo do seu limite.

Assim os índices THIV e PHD também precisam ser conhecidos para determinar o nível de severidade do teste de impacto realizado, o que será determinado a seguir conforme norma EN 1317-1 (1998). O índice THIV avalia a severidade do movimento de corpo livre da cabeça do ocupante. Essa necessidade surge devido à mudança na velocidade do veículo com o contato da defensa, provocando a movimentação da cabeça do ocupante até o choque em alguma superfície no interior do veículo. Por isso a velocidade com que a cabeça atinge tal superfície determina o valor do THIV. Por outro lado, a desaceleração experimentada pela cabeça no instante do choque define o valor do índice PHD.

Para o cálculo do THIV, pressupõe-se que no início do impacto, a cabeça e o veículo possuem um movimento puramente de translação de mesma velocidade horizontal $V_{0}$. Durante a colisão, considera-se que o veículo se desloca somente no plano horizontal, pois os movimentos de rolagem, arfagem ou a translação vertical não são relevantes, a não ser que o veículo adquira uma tendência de capotamento. Esse caso particular não necessita consideração, pois a observação visual do teste indicará a reprovação imediata da defensa testada.

Dois referenciais são utilizados para o cálculo da velocidade relativa da cabeça conforme indicado na Figura 68, o referencial do veículo $C x y$, e o referencial inercial do solo $O X Y$. O ponto $C$ é considerado a posição do centro de gravidade ou CG do veículo, usado para o cálculo das acelerações longitudinal $\ddot{x}_{c}$, transversal $\ddot{y}_{c}$ e a taxa de variação de guinada $\dot{\psi}$. No referencial inercial $O X Y$, o eixo $X$ é alinhado com a velocidade inicial $V_{O}$ e a origem $O$ é coincidente com a posição inicial do veículo no ponto $C$. A coordenadas $X_{c}(t), Y_{c}(t)$ refletem a posição do CG do veículo em relação ao referencial inercial, enquanto as coordenas $X_{b}(t), Y_{b}(t)$ determinam a posição teórica da cabeça em relação ao mesmo referencial. 


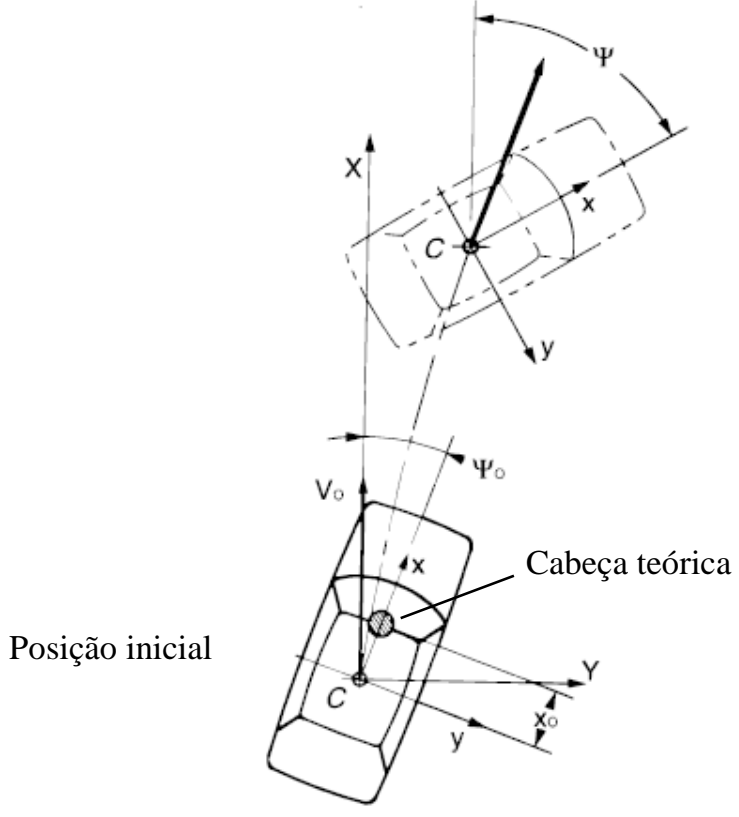

Figura 68 - Referenciais adotados e posição teórica da cabeça (EN 1317-1, 1998).

Considerando os eixos indicados na Figura 68, no instante inicial as coordenadas do ponto $C$, o ângulo de guinada $\psi$ e as respectivas derivadas no tempo são definidos abaixo:

$$
\begin{array}{lll}
X_{c}(t=0)=0 ; & Y_{c}(t=0)=0 ; & \psi(t=0)=\psi_{0} ; \\
\dot{X}_{c}(t=0)=V_{0} ; & \dot{Y}_{c}(t=0)=0 ; & \dot{\psi}(t=0)=0 .
\end{array}
$$

As componentes de aceleração do veículo em relação ao referencial inercial são obtidas através de relações trigonométricas simples, o que resulta no par de equações,

$$
\begin{aligned}
& \ddot{X}_{c}(t)=\ddot{x}_{c}(t) \cos \psi-\ddot{y}_{c}(t) \sin \psi ; \\
& \ddot{Y}_{c}(t)=\ddot{x}_{c}(t) \sin \psi+\ddot{y}_{c}(t) \cos \psi .
\end{aligned}
$$

Na condição inicial, a posição teórica da cabeça e a sua velocidade avaliadas no referencial inercial são escritas na forma,

$$
\begin{array}{ll}
X_{b}(t=0)=x_{0} \cos \psi=X_{0} ; & Y_{b}(t=0)=x_{b} \sin \psi=Y_{0} ; \\
\dot{X}_{b}(t=0)=V_{0} ; & \dot{Y}_{b}(t=0)=0 .
\end{array}
$$


Assim definido, se por hipótese a cabeça permanece em movimento uniforme e aceleração nula, infere-se que,

$$
X_{b}(t)=V_{0} t+X_{0} ; \quad Y_{b}=Y_{0}
$$

Então as componentes da velocidade relativa da cabeça são:

$$
\begin{aligned}
& \dot{x}_{b}(t)=-\Delta \dot{X}_{c} \cos \psi-\Delta \dot{Y}_{c} \sin \psi+y_{b} \dot{\psi} \\
& \dot{y}_{b}(t)=\Delta \dot{X}_{c} \sin \psi-\Delta \dot{Y}_{c} \cos \psi-x_{b} \dot{\psi}
\end{aligned}
$$

E as coordenadas da cabeça podem ser escritas da forma,

$$
\begin{aligned}
& x_{b}(t)=\Delta X_{b} \cos \psi+\Delta Y_{b} \sin \psi \\
& y_{b}(t)=-\Delta X_{b} \sin \psi+\Delta Y_{b} \cos \psi
\end{aligned}
$$

As superfícies de impacto internas do veículo são consideradas planas e perpendiculares ao veículo nos eixos $x$ e $y$, conforme a Figura 69. As distâncias dessa superfícies em relação a posição original da cabeça são definidas pelas cotas $D_{x}$ e $D_{y}$, equivalente a direção longitudinal e lateral, respectivamente.

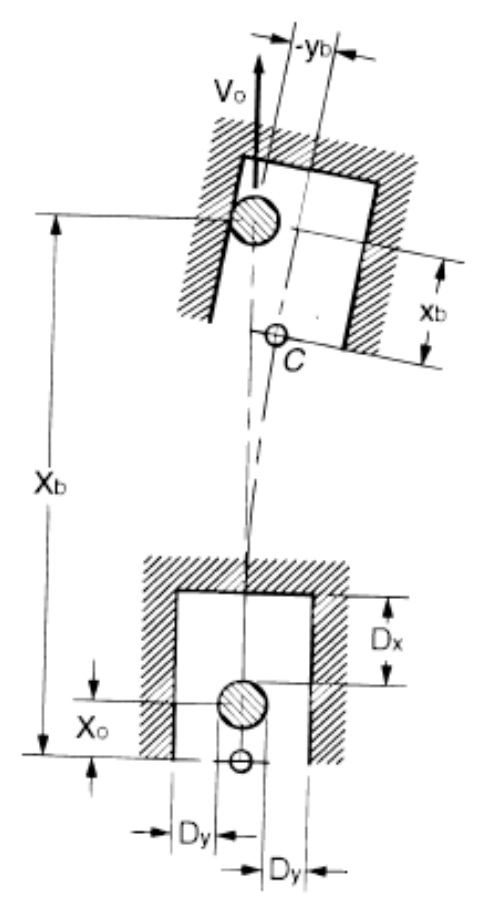

Figura 69 - Impacto da cabeça teórica no lado esquerdo do veículo (EN 1317-1, 1998). 
O tempo de deslocamento da cabeça até o impacto em uma das superfícies internas do veículo é definido como o tempo de vôo, com isso avalia-se o tempo $T_{v}$ no qual qualquer das igualdades abaixo torna-se satisfeita,

$$
\begin{gathered}
x_{b}\left(T_{v}\right)=D_{x}+x_{0} ; \\
\text { ou } \\
y_{b}\left(T_{v}\right)=D_{y} ; \\
\text { ou } \\
y_{b}\left(T_{v}\right)=-D_{y} .
\end{gathered}
$$

Os valores das distâncias $D_{x}$ e $D_{y}$ são definidos na norma EN 1317-1 (1998) como segue,

$$
D_{x}=0,6 m ; \quad D_{y}=0,3 m
$$

Finalmente, a velocidade teórica da cabeça THIV é definida pela velocidade relativa avaliada no instante de tempo $T_{v}$ de acordo com a seguinte expressão:

$$
T H I V=\sqrt{\dot{x}_{b}^{2}\left(T_{v}\right)+\dot{y}_{b}^{2}\left(T_{v}\right)}
$$

O THIV deve ser apresentado preferencialmente em unidades de $\mathrm{km} / \mathrm{h}$.

A brusca desaceleração da cabeça como resultado do impacto na superfície interna do veículo pode causar danos irreversíveis ao ocupante quando seu resultado é acima de 20 vezes a aceleração gravitacional. Por isso, a desaceleração da cabeça após impacto, índice PHD, é obtida pelo valor máximo da resultante de aceleração no CG do veículo em um intervalo de $10 \mathrm{~ms}$ após o instante $T_{v}$, como segue,

$$
P H D=\max \sqrt{\left\langle\ddot{x}_{c}\right\rangle^{2}+\left\langle\ddot{y}_{c}\right\rangle^{2}} \text { para } \mathrm{t} \geq T .
$$

O valor do PHD deve ser reportado em múltiplos da aceleração gravitacional $g=9,81 \mathrm{~m} / \mathrm{s}^{2}$.

Os níveis de severidade de impacto mensurados pelos índices ASI, THIV e PHD são definidos pela norma (EN 1317-2, 1998). Quanto à classificação, o nível de severidade A proporci- 
ona maior segurança aos ocupantes de um veículo, pois nenhum dos limites orgânicos do ocupante é ultrapassado. Em casos específicos onde a contenção do veículo tem importância extrema, principalmente quando a circulação de veículos pesados é relevante, a defensa preferida pode assumir níveis de severidade aos ocupantes acima do desejado. Na Tabela 13 são reunidas algumas classificações de severidade da defensa baseada nos índices ASI, THIV e PHD.

Tabela 13 - Classificação de severidade ao ocupante.

\begin{tabular}{cccc}
\hline Nota & Limites \\
\hline A & ASI $\leq 1,0$ & THIV $\leq 33 \mathrm{~km} / \mathrm{h}$ & PHD $\leq 20 \mathrm{~g}$ \\
B & $1,0<$ ASI $\leq 1,4$ & THIV $\leq 33 \mathrm{~km} / \mathrm{h}$ & PHD $\leq 20 \mathrm{~g}$ \\
C & $1,4 \leq$ ASI $>1,9$ & THIV $\leq 33 \mathrm{~km} / \mathrm{h}$ & PHD $\leq 20 \mathrm{~g}$ \\
\hline
\end{tabular}

Outro parâmetro avaliado pela norma é a deformação da defensa durante o impacto do veículo, índice que caracteriza a deflexão dinâmica da defensa de acordo com a deformação de trabalho W ilustrada na Figura 70.

O deslocamento de trabalho $\mathrm{W}$ é a máxima distância entre a face da defensa antes do impacto e o seu deslocamento lateral mensurado em qualquer parte da defensa. Ou, no caso em que o veículo se deforma ao redor da defensa de modo que o primeiro avance mais do que a própria defensa, utiliza-se alternativamente a parte do veículo que esteja mais avançada.

A deflexão dinâmica $\mathrm{D}$ é o máximo deslocamento lateral da defensa, medido face a face em qualquer parte da defensa.
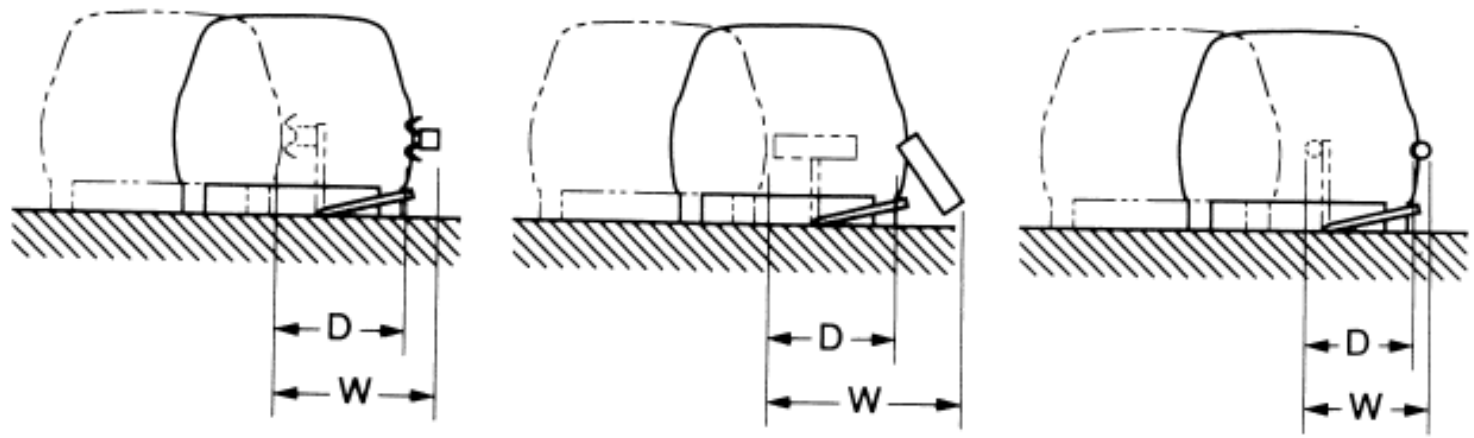

Figura 70 - Deflexão dinâmica (D) e deslocamento de trabalho (W) (EN 1317-1, 1998). 
Os valores do deslocamento da defensa são classificados de acordo com a Tabela 14. Quanto maior for o deslocamento de trabalho de uma defensa maior é a dispersão de energia de impacto oferecida pelo sistema de contenção, de modo que a força média atuando na direção perpendicular a defensa é menor. No Apêndice C é demonstrado o cálculo da força média exercida na defensa. No entanto, é importante observar que a deformação exibida seja compatível com o espaço existente no local da instalação.

Além de atender aos requisitos definidos pelos índices ASI, THIV, PHD e W, é importante definir o comportamento esperado do sistema de contenção no evento de impacto de um veículo. A norma (EN 1317-2, 1998) determina que a defensa deva conter e redirecionar o veículo sem apresentar falha completa de qualquer dos elementos longitudinais. Nenhuma parte pode desmontar-se completamente oferecendo perigo aos ocupantes, tráfico de veículos e pedestres, portanto é inaceitável que elementos da defensa penetrem no compartimento de passageiros.

Tabela 14 - Classificação do deslocamento da defensa

\begin{tabular}{cc}
\hline Classe de deslocamento & $\begin{array}{c}\text { Distância } \\
\text { m }\end{array}$ \\
\hline W1 & W $\leq 0,6$ \\
W2 & $\mathrm{W} \leq 0,8$ \\
W3 & $\mathrm{W} \leq 1,0$ \\
W4 & $\mathrm{W} \leq 1,3$ \\
W5 & $\mathrm{W} \leq 1,7$ \\
W6 & $\mathrm{W} \leq 2,1$ \\
W7 & $\mathrm{W} \leq 2,5$ \\
W8 & $\mathrm{W} \leq 3,5$ \\
\hline
\end{tabular}

A avaliação da dinâmica do veículo é incluída também na análise. O centro de gravidade do mesmo deve manter-se abaixo da linha de centro da defensa e apenas ângulos moderados de rolamento, arfagem e guinada são aceitáveis. Após o impacto, a trajetória do veículo deve ser segura e mesmo que outros impactos se sucedam apenas o primeiro será considerado para critério de aprovação ou desempenho.

A deformação experimentada pela estrutura interna do veículo é avaliada de acordo com alguns critérios que consolidam um índice denominado VCDI "Vehicle Cockpit Deformation Index" ou índice de deformação da cabine. $\mathrm{O}$ índice indica a porcentagem de redução de 7 
dimensões no interior do veículo para cada quadrante representado por um passageiro. Uma escala de grandeza dividida em três níveis entre 0 e 2 determinam uma redução menor do que $3 \%$, entre $3 \%$ e $10 \%$, ou maior do que $10 \%$, respectivamente.

Desse modo, o índice VCDI é determinado por um código alfanumérico composto por duas letras (LF, RF, RF, RB) referentes a posição do quadrante e sete números inteiros $(0,1,2)$ relativos ao nível de deformação das dimensões em sua ordem alfabética, ou seja, XXabcdefg. No entanto tal índice não será incluído na análise de impacto dos tópicos a seguir.

Definidos os principais índices de severidade de impacto, o comportamento desejado da defensa e do veículo, recorre-se a Tabela 15 para definir os testes necessários e o método de avaliação dos índices para um determinado nível de contenção desejado. Quando mais de um teste for exigido para um índice, considera-se para efeitos de desempenho aquele que resultar no pior resultado de severidade.

Tabela 15 - Nível de contenção de defensas rodoviárias.

\begin{tabular}{|c|c|c|c|c|}
\hline \multirow[b]{2}{*}{$\begin{array}{l}\text { Nível de } \\
\text { contenção }\end{array}$} & \multicolumn{4}{|c|}{ PARÂMETROS } \\
\hline & $\begin{array}{c}\text { Comportamento } \\
\text { do veículo e da } \\
\text { defensa }\end{array}$ & $\begin{array}{l}\text { Severidade de impacto } \\
\text { (ASI -THIV -PHD) }\end{array}$ & $\begin{array}{c}\text { Deformação do } \\
\text { veículo } \\
\text { (VCDI) }\end{array}$ & $\begin{array}{c}\text { Deformação } \\
\text { da defensa } \\
\text { (W) }\end{array}$ \\
\hline T1 & TB 21 & TB 21 & TB 21 & TB 21 \\
\hline $\mathrm{T} 2$ & TB 22 & TB 22 & TB 22 & TB 22 \\
\hline $\mathrm{T} 3$ & ТВ $41+$ TB 21 & TB 21 & TB 21 & TB 41 \\
\hline N1 & ТВ 31 & TВ 31 & TВ 31 & TB 31 \\
\hline $\mathrm{N} 2$ & TB $32+$ TB 11 & TВ 32+ TВ 11 & TB $32+$ TB 11 & TB 32 \\
\hline $\mathrm{H} 1$ & TB $42+$ TB 11 & TB 11 & TB 11 & TB 42 \\
\hline $\mathrm{H} 2$ & TB 51 + TB 11 & TB 11 & TB 11 & TB 51 \\
\hline $\mathrm{H} 3$ & ТВ 61 + TB 11 & TB 11 & TB 11 & TB 61 \\
\hline $\mathrm{H} 4 \mathrm{a}$ & ТВ 71 + ТВ 11 & TB 11 & TB 11 & TB 71 \\
\hline $\mathrm{H} 4 \mathrm{~b}$ & TB $81+$ TB 11 & TB 11 & TB 11 & TB 81 \\
\hline
\end{tabular}

\subsection{MODELO EM ELEMENTOS FINITOS DO VEÍCULO DE 900KG GEO-METRO}

O modelo de elementos finitos do veículo utilizado nas simulações de impacto foi obtido no banco de dados da (NCAC) cujo desenvolvimento tem a autoria da NHTSA National 
Highway Traffic Safety Administration. O modelo, chamado de Geo-metro, representa um veículo leve de $894 \mathrm{~kg}$ sem passageiros, cujas dimensões principais estão disponíveis na Figura 71.
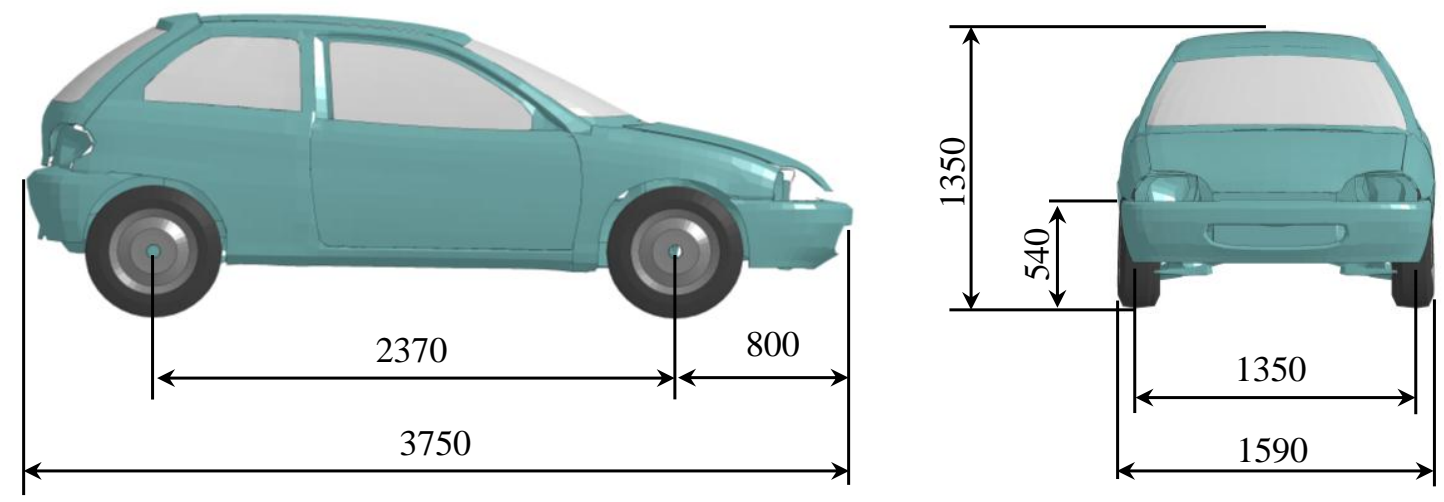

Figura 71 - Dimensões principais do modelo Geo-Metro.

Um número total de 25037 elementos e 28656 graus de liberdade compõe a malha desse modelo. Elementos de casca foram utilizados para representação da estrutura do veículo; o conjunto motor, câmbio, radiador, discos de freio e pinças foram modelados com elementos sólidos; as barras transversais da suspensão traseira foram criadas a partir de elementos de viga; as molas e os amortecedores foram tratados como elementos discretos. Além disso, diversas massas concentradas foram adicionadas em pontos específicos para caracterização adequada da inércia global do veículo. Uma visão geral da discretização da malha está exposta na Figura 72 .

Devido às grandes deformações resultantes do impacto, os elementos de casca foram definidos com 5 pontos de integração ao longo da espessura e integração completa de acordo com a opção ELFORM=16. Foi verificado durante avaliações de impacto preliminares que em nenhuma parte do veículo a energia de modos espúrios ultrapassou 5\% da energia de deformação. O modelo de material elasto-plástico linear do Ls-Dyna (*MAT_024) foi adotado com curvas de tensão e deformação pré-definidas. O critério de falha baseado na máxima deformação plástica de $50 \%$ foi considerado em todos os elementos deformáveis.

Afim de calcular os índices de severidade ao ocupante, um acelerômetro foi definido para capturar o histórico de acelerações e deslocamento angular do veículo através do cartão *ELEMENT_SEATBELT_ACCELEROMETER. Esse elemento é representado por um pe- 
queno bloco rígido posicionado próximo ao centro de gravidade do veículo, conectando-se a nós do mesmo ao acelerômetro formando uma ligação rígida entre os envolvidos, conforme exposto na Figura 72. De modo a atenuar a existência de ruídos de alta frequência, essa conexão necessita geralmente estar associada a um componente de massa relevante ao modelo. Considerando esses aspectos é possível obter o registro de acelerações em todos os eixos na posição do sensor no sistema local de coordenadas incluindo o cartão *DATABASE_HISTORY_NODE. A frequência de aquisição de dados deve ser especificada adequadamente no cartão *DATABASE_NODOUT.

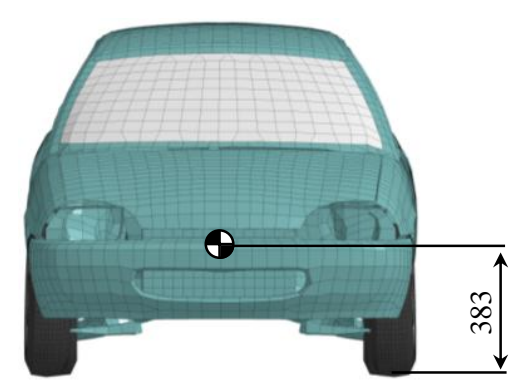

(a)

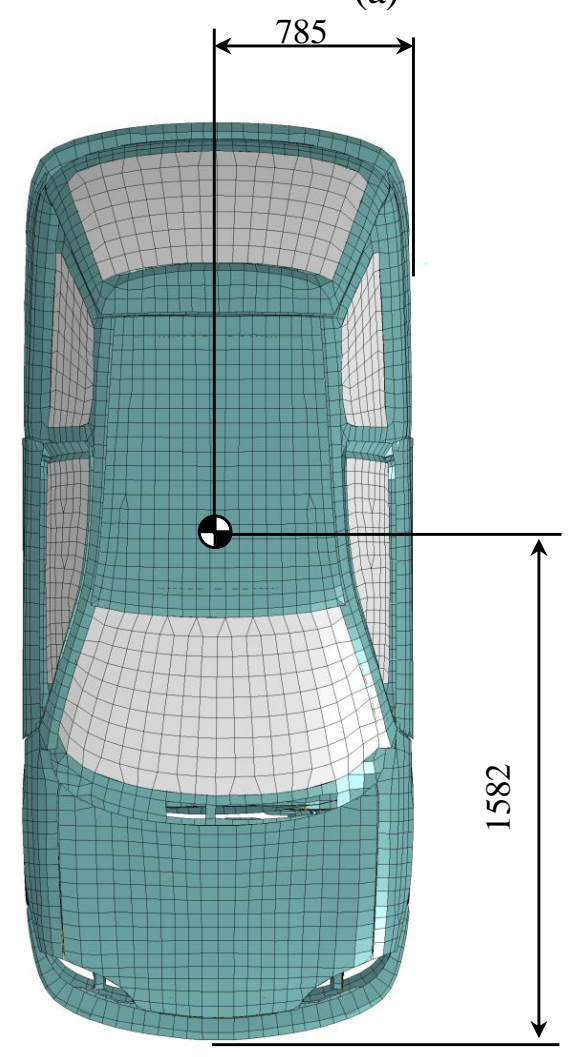

(c)

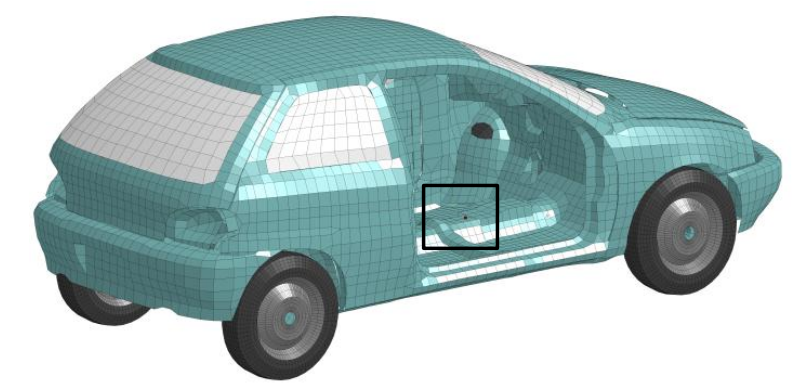

(b)

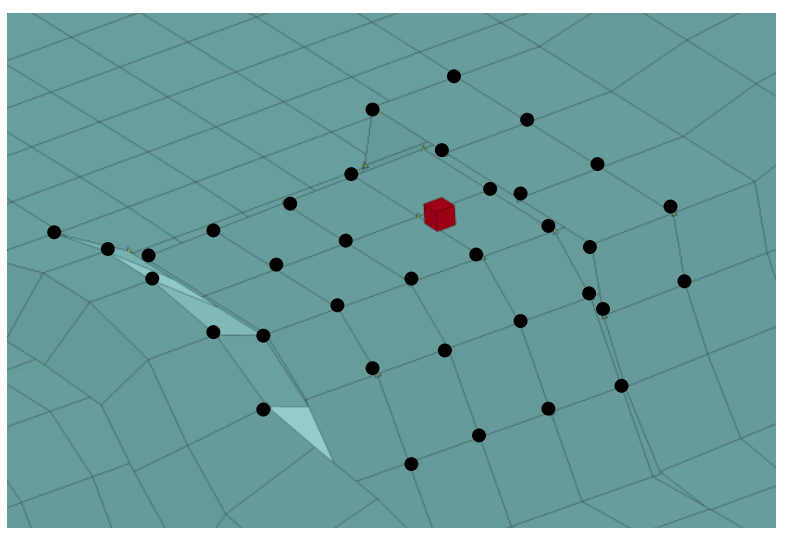

(d)

Figura 72 - Vista frontal (a) e vista de topo (c) da malha do veículo. Em (b) vista isométrica com detalhe da posição do acelerômetro e em (d) acelerômetro. 
A qualidade no pós-processamento dos índices de severidade depende significativamente da seleção correta da frequência de aquisição de dados. Defini-la considerando um período de amostragem cuja ordem de grandeza é semelhante ao timestep da simulação, mostra-se como uma solução prática ao problema. Nos casos de impacto analisados foi fixada uma frequência de $100 \mathrm{kHz}$ no qual o timestep aproximado da simulação foi de 10-6s. Os resultados salvos em $100 \mathrm{kHz}$ foram comparados com a aquisição em $1 \mathrm{MHz}$, demonstrando excelente concordância dos dados com a vantagem de um volume inferior de informação.

Um filtro SAE de $180 \mathrm{~Hz}$ foi aplicado antes do cálculo dos índices de severidade, de modo que a dinâmica veicular é analisada eliminando-se efeitos indesejáveis das componentes de vibração locais da estrutura. Esse procedimento está conforme metodologia de instrumentação do veículo incluída na norma EN1317-2. Os índices ASI, THIV e PHD foram então calculados a partir dos valores de aceleração, ângulo de guinada e velocidade de guinada seguindo a metodologia apresentada nas equações (6.2) a (6.15).

\subsection{IMPACTO EM DEFENSA METÁLICA}

\subsubsection{Modelagem em elementos finitos}

Um modelo de defensa metálica semi-rígida simples, ou seja, composta de guia de deslizamento em $\mathrm{W}$, poste sigma e fixações foi modelada em elementos finitos de maneira semelhante ao teste em escala real desenvolvido pelo relatório (LIER, 2004).

$\mathrm{Na}$ avaliação experimental, o poste foi fixado diretamente no asfalto de modo que a condição de contorno da base do poste pode ser simplificada por um engastamento. Na condição em que o poste é fixado ao solo, normalmente ocorrem deslocamentos devido à interação não rígida entre os corpos tornando a defensa mais flexível o que consequentemente minimiza os índices de severidade ao ocupante.

A defensa montada no local de teste tinha $84 \mathrm{~m}$ de comprimento, $2 \mathrm{~m}$ de espaçamento entre postes e 0,75m de altura entre o plano do solo e o topo do poste. Um Peugeot 106 ano 1991 de $903 \mathrm{~kg}$ foi arremessado a uma velocidade de $101,3 \mathrm{~km} / \mathrm{h}$ e ângulo de $20^{\circ}$ em relação ao plano médio da defensa. Na Figura 73 é mostrada uma foto da condição inicial de impacto no teste e no cenário equivalente de simulação em elementos finitos. 


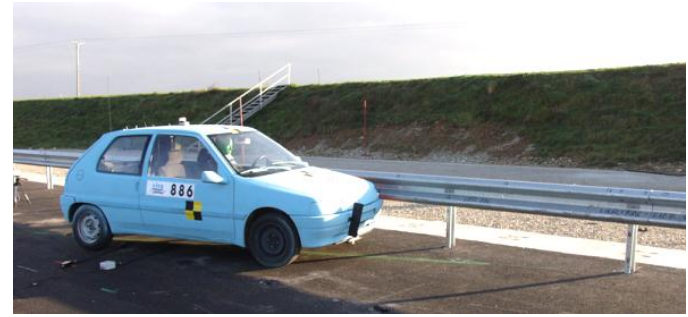

(a)

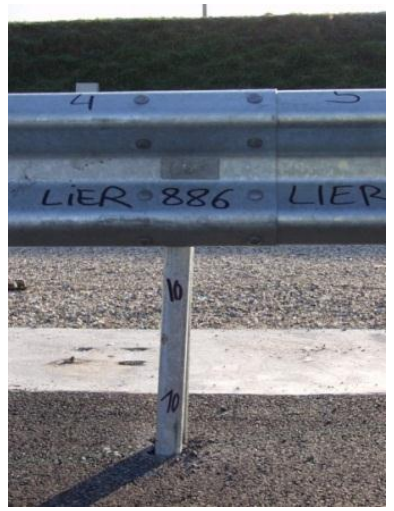

(c)

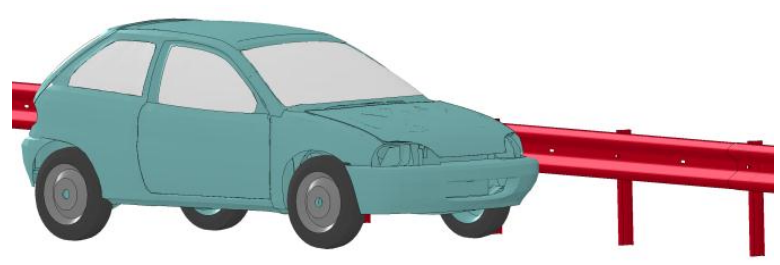

(b)

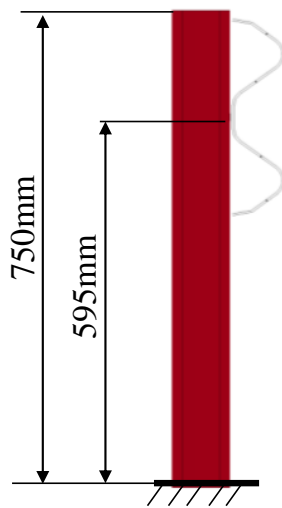

(d)

Figura 73 - (a) Situação inicial de impacto no teste realizado por (LIER, 2004) e (b) situação equivalente no cenário modelado em elementos finitos. Em (c) detalhe da fixação do poste ao asfalto e em (d) configuração do modelo numérico.

A guia de deslizamento e o poste modelado em elementos finitos tem a geometria detalhada no Apêndice B. Seis guias de 4,3m de comprimento foram suportadas por onze postes dispostos a cada $2 \mathrm{~m}$ de comprimento, totalizando 323301 elementos de casca no modelo numérico da defensa. As extremidades da defensa foram ancoradas utilizando uma condição de contorno de engastamento. O Geo-metro foi posicionado entre os postes 4 e 5 a um ângulo de impacto de $20^{\circ}$ com a defensa conforme Figura 74. Uma velocidade inicial de $27,78 \mathrm{~m} / \mathrm{s}$ $(100 \mathrm{~km} / \mathrm{h})$ de translação foi aplicada ao veículo na direção de $20^{\circ}$ em relação à barreira, conforme Figura 74. Velocidade angular de $88,97 \mathrm{rad} / \mathrm{s}$ foi definida aos componentes girantes, como os pneus e os respectivos aros. A aceleração gravitacional de módulo $9,81 \mathrm{~m} / \mathrm{s}^{2}$ foi adicionada ao modelo.

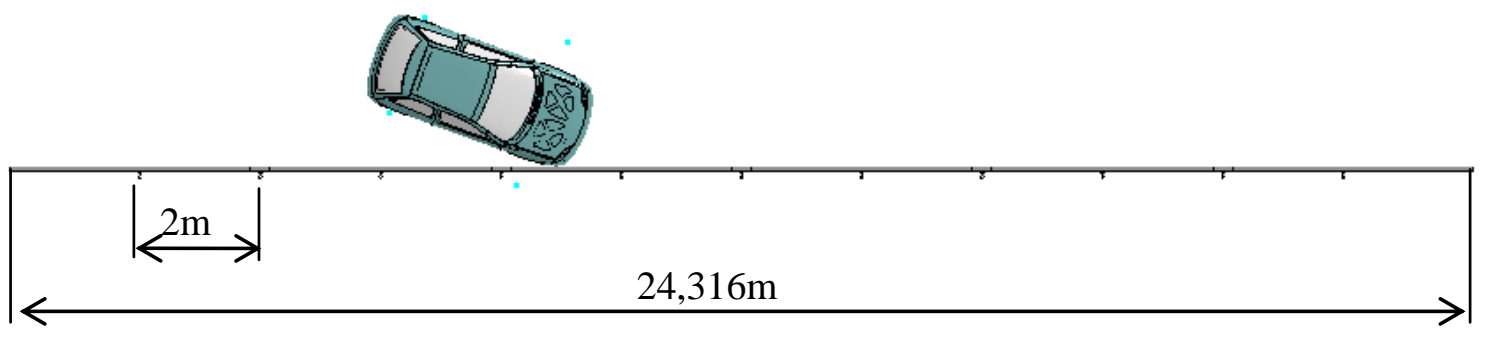

Figura 74 - Configuração de impacto inicial do modelo numérico. 
A malha do poste e da guia de deslizamento é apresentada na Figura 75. O poste foi discretizado com maior refinamento dos elementos na base $3 \times 3 \mathrm{~mm}$, na região de contato com a guia de deslizamento $3 \times 3 \mathrm{~mm}$ e nas proximidades do furo 1,5x1,5mm. Nas áreas adjacentes foram adotados elementos de aproximadamente $8 \times 3 \mathrm{~mm}$. A guia de deslizamento foi modelada majoritariamente com elementos de 10x10 mm aproximadamente.

Quatro pontos de integração e o método de integração reduzida de Belytschko-Tsay (ELFORM=2) foram adotados na modelagem dos elementos da guia de deslizamento e do poste. Devido às grandes deformações envolvidas no impacto com o veículo associada à força de membrana na guia de deslizamento nas regiões distantes do local de colisão foi verificada a presença de modos espúrios de energia em testes preliminares. Afim de reduzir esse efeito foi utilizado o cartão *HOURGLASS com controle do tipo Flanagan-Belytschko e coeficiente 0,03 .

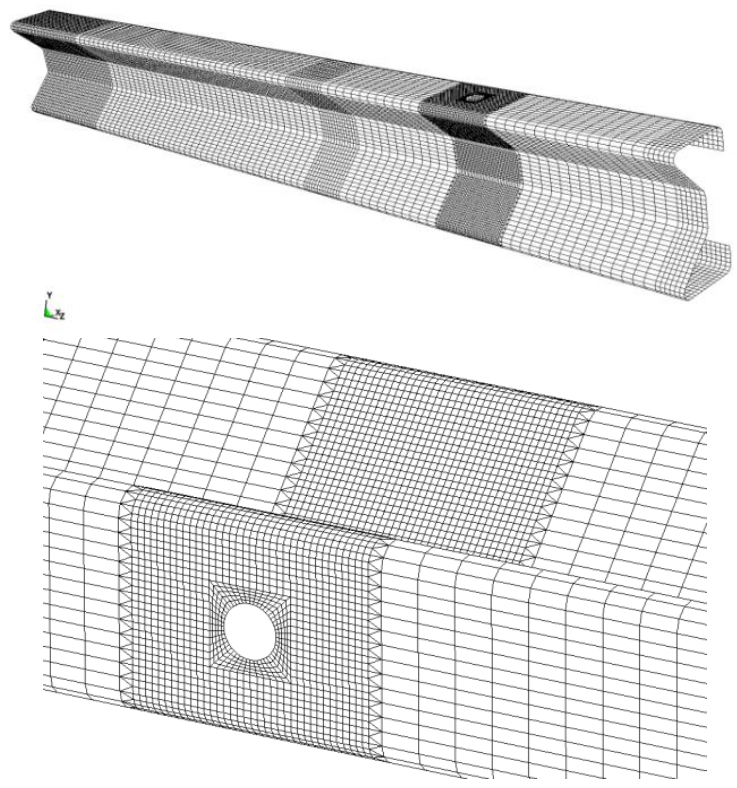

(a)

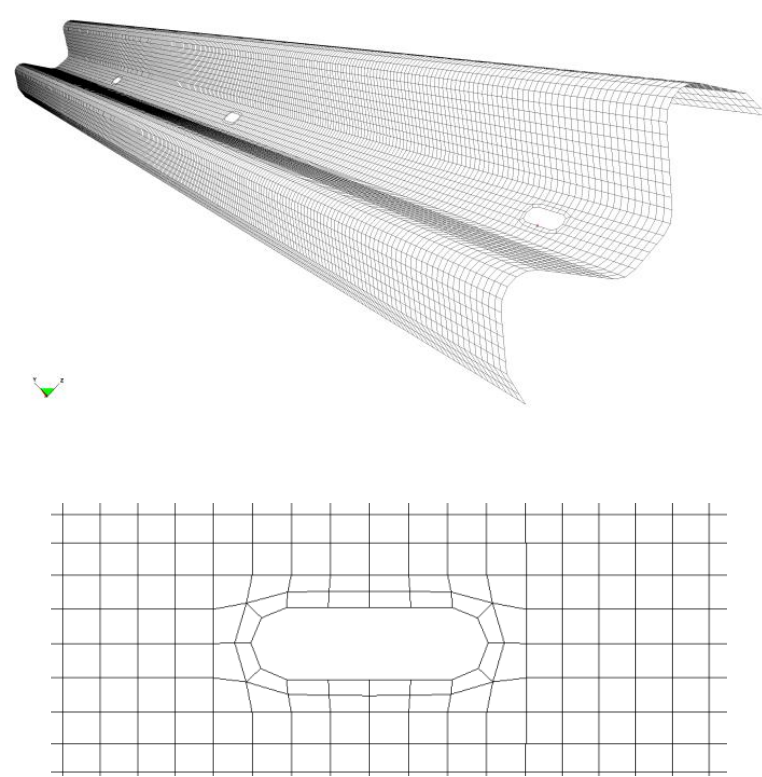

(c)

Figura 75 - (a) Malha do poste e em (b) da guia de deslizamento.

O material da guia de deslizamento e do poste foram determinados pelo modelo de material MAT024 de maneira consistente com os parâmetros de Cowper-Symonds definidos no Capítulo 4 tópico 4.6, cujos valores dos coeficientes são $C=1016 \mathrm{~s}^{-1}$ e $p=5,7$ seguindo a nomenclatura definida por (LSTC, 2007). 
A montagem do conjunto de guias de deslizamento inclui além da fixação com os postes com um parafuso, a sobreposição dos perfis w e sua a fixação por meio de oito parafusos. Em todas as conexões parafusadas mencionadas foi adotada uma conexão simplificada composta de uma viga rígida e sem massa entre os nós dos componentes envolvidos. Cada parafuso foi substituído por uma viga cujo comportamento em falha é definido pela média de deformações plásticas (PS) dos elementos de casca incluídos na conexão, desse modo o mecanismo de falha tem um comportamento dúctil aproximado. A definição dessas vigas é análoga ao conceito de uma solda pontual a qual define-se pelo cartão *CONSTRAINED_SPOTWELD, na Figura 76 é apresentado um exemplo dos nós incluídos na conexão.

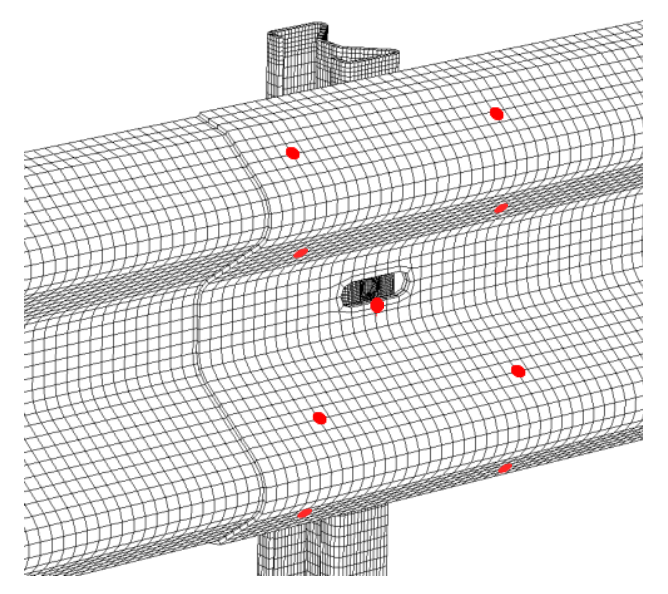

Figura 76 - Ilustração dos nós onde soldas pontuais foram definidas para simplificação da conexão parafusada.

Para permitir um encaixe entre as guias de deslizamento sobrepostas foi necessário gerar uma geometria de perfil w com um offset de $3,1 \mathrm{~mm}$ de modo que os nós das guias não sofram penetração nas regiões de concordância, conforme apontando na Figura 77.

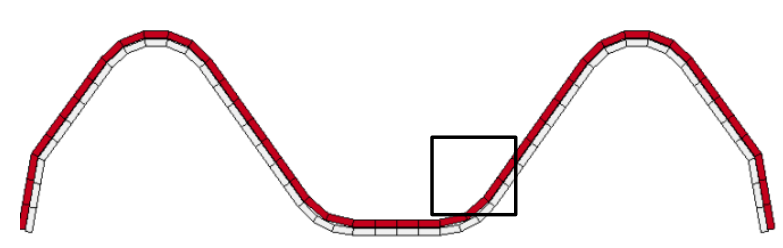

(a)

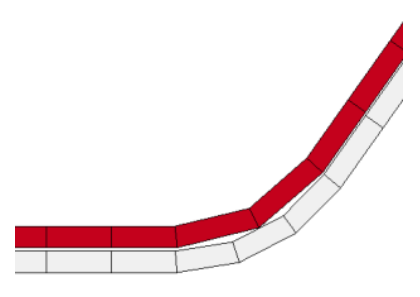

(b)

Figura 77 - (a) Guias de deslizamento sobrepostas. (b) Detalhe da concordância. 
O contato entre as superfícies do veículo e da defensa envolvidas no impacto foi definido através do cartão *AUTOMATIC_SINGLE_SURFACE e o atrito foi desprezado. O coeficiente de atrito entre a roda e o pneu foi definido em 0,6 .

\subsubsection{Influência da resistência da conexão parafusada}

A trajetória do veículo durante a colisão com a defensa foi levantada para diferentes valores de falha da conexão spotweld baseados no parâmetro de deformação plástica PS. A influência da resistência da conexão no comportamento da defensa pode ser observada de maneira global através da Figura 78. Os resultados apresentados foram obtidos das coordenadas do CG do veículo durante o impacto com a defensa.

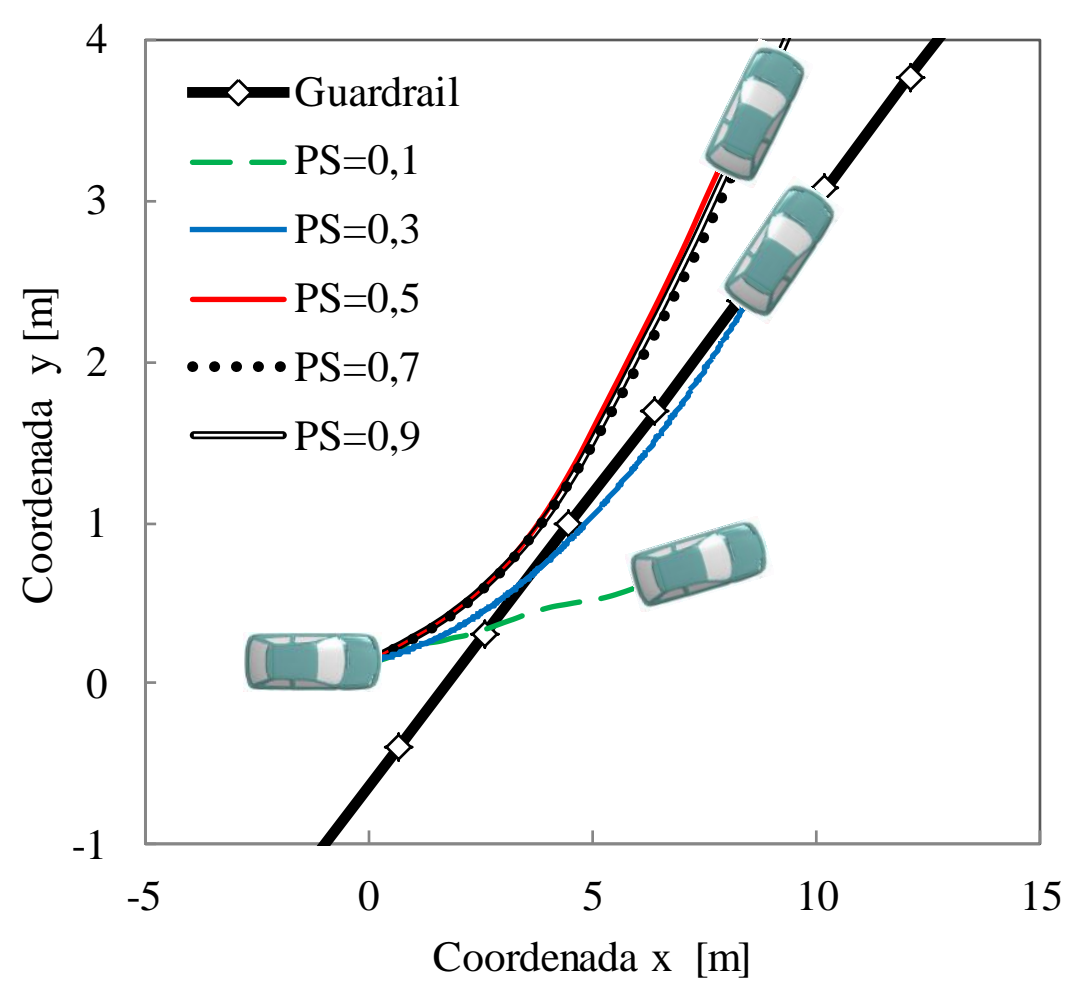

Figura 78 - Posição do CG do GeoMetro para simulações com diferentes critérios de falha da conexão entre o poste e a guia de deslizamento w.

Na Figura 78 nota-se que para valores de PS maiores que 0,5 a trajetória do veículo é praticamente a mesma, além disso, o veículo é redirecionado com sucesso e nenhuma parte da defensa penetra no habitáculo interno dos ocupantes, de acordo com a Figura 79. Na simulação realizada com PS=0,3 o veículo estabelece uma trajetória sob a guia de deslizamento e, portanto, o comportamento da análise visual de acordo com os critérios da norma (EN 1317-2, 
1998) a defensa é reprovada sem necessidade de avaliação dos índices de severidade. Não foi investigada a sensibilidade do resultado numérico com valores de PS entre 0,3 e 0,5 afim de determinar com precisão o limite inferior de PS que determina um redirecionamento adequado do veículo. Na simulação realizada com $\mathrm{PS}=0,1$ a defensa rompe-se e permite que o veículo atravesse a guia de deslizamento. Imagens do resultado da simulação para cada um dos valores de PS apontados anteriormente ilustram a Figura 79.

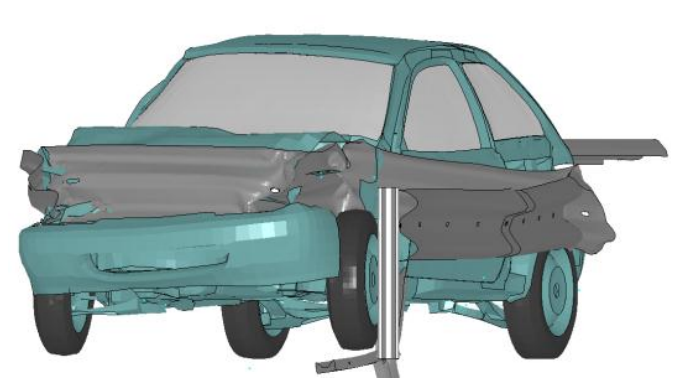

$\mathrm{PS}=0,1$

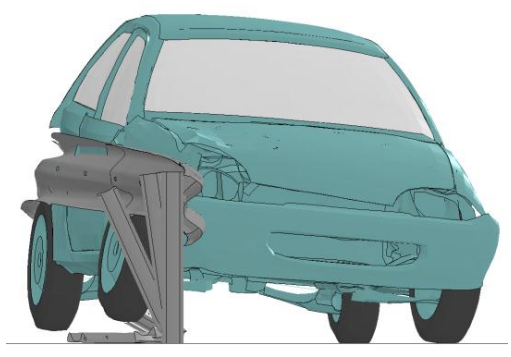

$\mathrm{PS}=0,5$

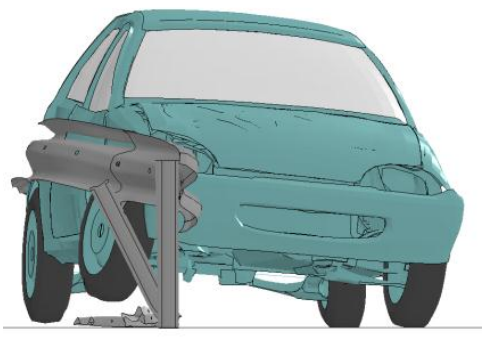

$\mathrm{PS}=0,7$

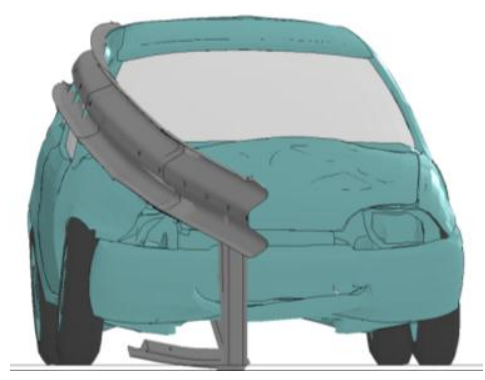

$\mathrm{PS}=0,3$

Figura 79 - Imagens do cenário resultante do impacto do veículo para os parâmetros PS avaliados.

\subsubsection{Resultados numéricos e comparação com teste em escala real}

As curvas dos índices de severidade ASI, THIV e PHD experimentais (LIER, 2004) e numéricos são apresentadas na Figura 80 e na Figura 81. A simulação foi realizada com o parâmetro de falha fixado em PS=0,9 e atrito nulo entre as superfícies de contato do veículo e da defensa metálica. Os pontos rotulados em cada uma das curvas indicam os índices de severidade nos casos experimental e numérico.

No intervalo de tempo de 0 a $0,1 \mathrm{~s}$, a curva ASI obtida numericamente exibe acelerações mais severas ao ocupante do que o dado experimental retrata, enquanto a seguir as curvas demons- 
tram maior semelhança conforme indica a Figura 80. Os índices THIV e PHD simulados são, por outro lado, mais bem comportados em relação ao resultado do teste.

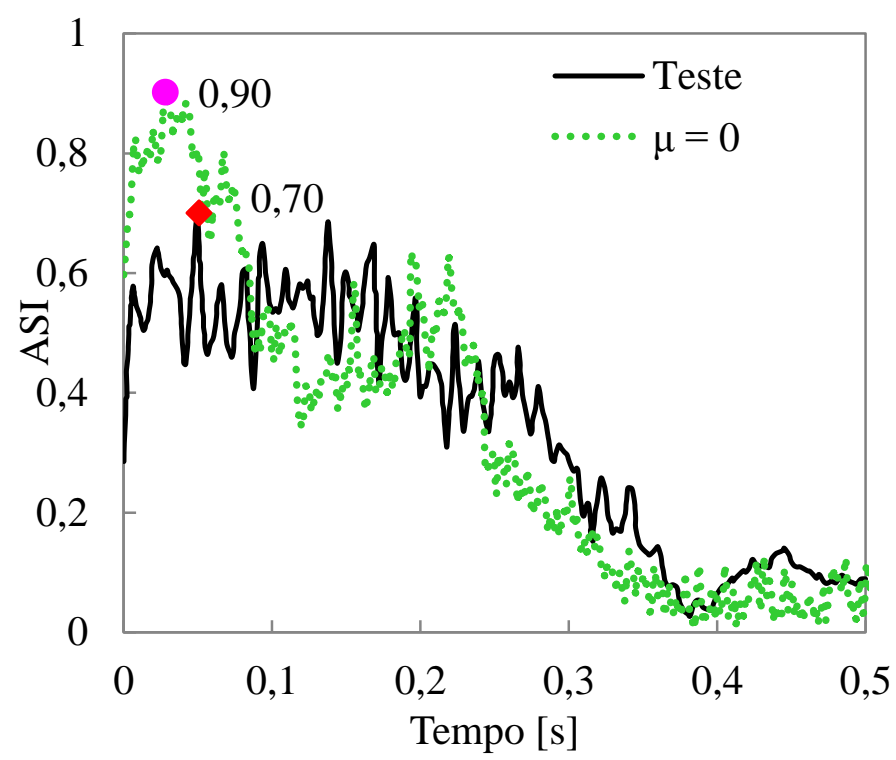

Figura 80 - Resultados do índice ASI no impacto do veículo com a defensa metálica.

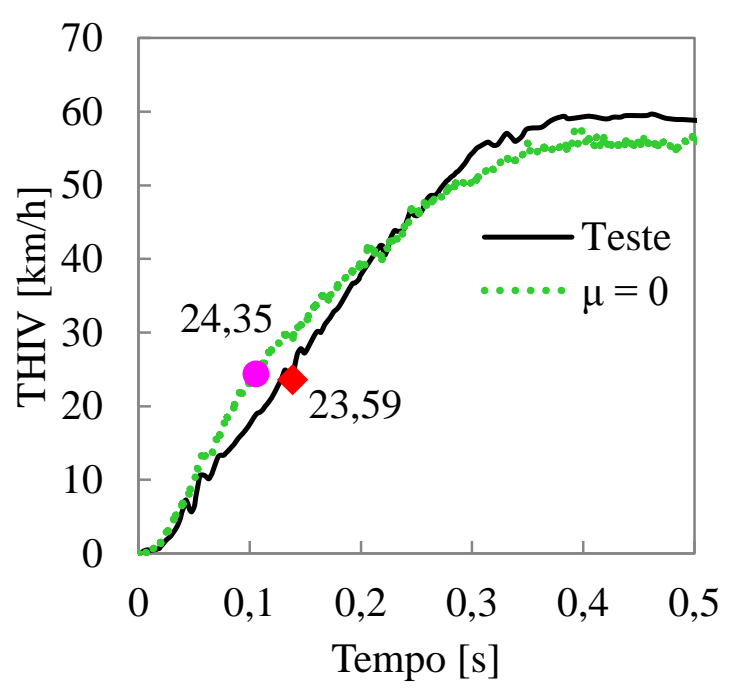

(a)

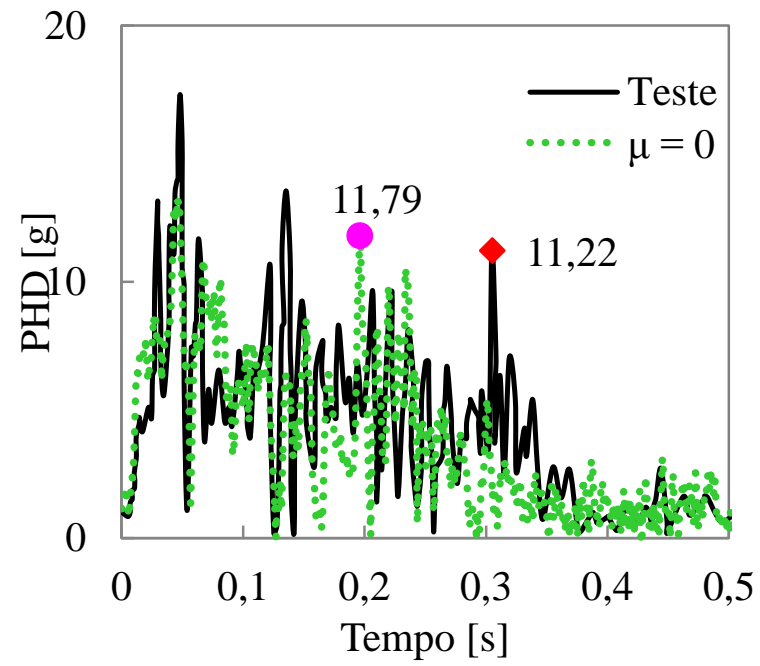

(b)

Figura 81 - Resultados do índice THIV (a) e PHD (b) no impacto do veículo com a defensa metálica.

Na Tabela 16 são apresentados os resultados dos índices de severidade calculados numericamente e no teste. A maior diferença percentual é encontrada no resultado do ASI, superesti- 
mada em $28,6 \%$. Os demais índices de severidade são atingidos com uma diferença percentual menor do que $5 \%$ aproximadamente.

Tabela 16 - Resultados dos índices de severidade para defensa metálica.

\begin{tabular}{lccc}
\hline Resultado & $\begin{array}{c}\text { ASI } \\
{[-]}\end{array}$ & $\begin{array}{c}\text { THIV } \\
{[\mathrm{km} / \mathrm{h}]}\end{array}$ & $\begin{array}{c}\text { PHD } \\
{[\mathrm{g}]}\end{array}$ \\
\hline Teste & 0,70 & 23,59 & 11,22 \\
$\mu=0$ & 0,90 & 24,35 & 11,79 \\
\hline $\begin{array}{l}\text { Diferença entre o resul- } \\
\text { tado experimental e } \\
\text { numérico }\end{array}$ & $28,6 \%$ & $3,2 \%$ & $5,3 \%$ \\
\hline
\end{tabular}

Na Figura 82 foram comparadas as imagens obtidas do teste em escala real realizado por (LIER, 2004) e imagens da simulação com valor de PS=0,5 a partir do instante inicial antes da colisão até fim da interação entre o veículo e a defensa. É notável que o modelo numérico demonstra fidelidade ao fenômeno de impacto registrado no teste no que tange o comportamento global do veículo e da defensa. Uma evidência detectada no teste e não constatada no resultado numérico é a falha do para-choque do veículo seguida da sua completa desmontagem do veículo. No entanto, é preciso levar em conta que o modelo Geo-metro não é o mesmo veículo usado nos testes.

Ainda avaliando o aspecto qualitativo da simulação desenvolvida, a Figura 83 mostra uma comparação do estado final da defensa metálica após um teste de impacto em condições semelhantes à analisada. Nota-se que nesse teste real os postes foram concretados ao asfalto o que condiz com a condição de contorno definida no modelo - que adota o engastamento dos postes na base. Além disso, componentes como a guia de deslizamento w, o poste sigma e a distância entre postes são semelhantes. Através da figura, nota-se também que o número de postes deformados até o solo é o mesmo, quatro. 

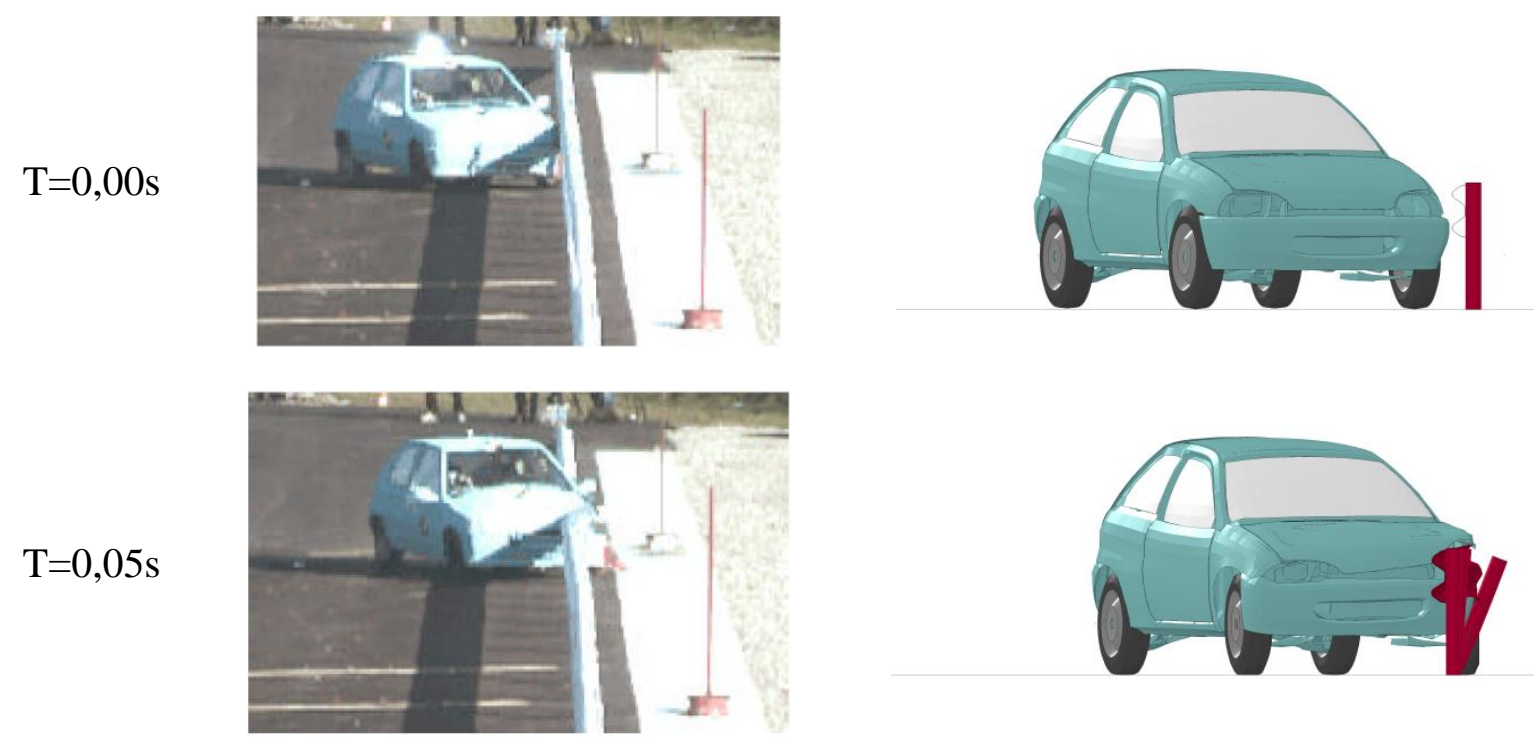

$\mathrm{T}=0,15 \mathrm{~s}$
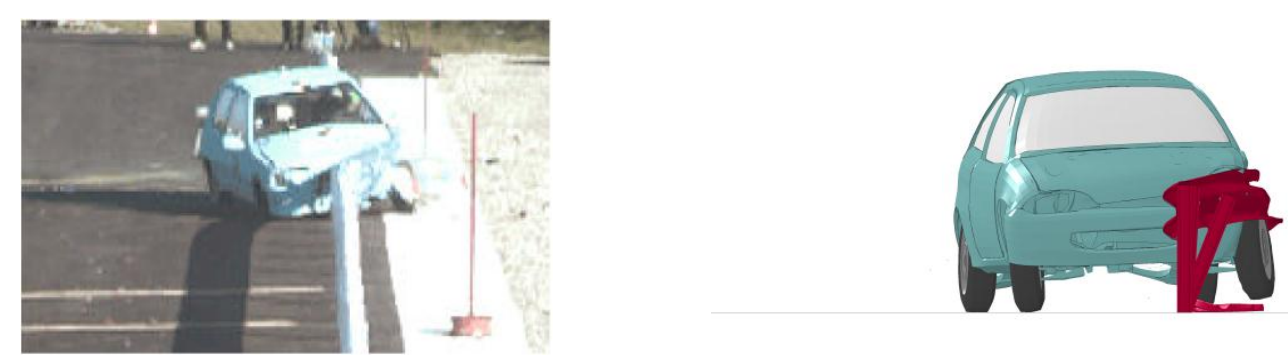

$\mathrm{T}=0,25 \mathrm{~s}$
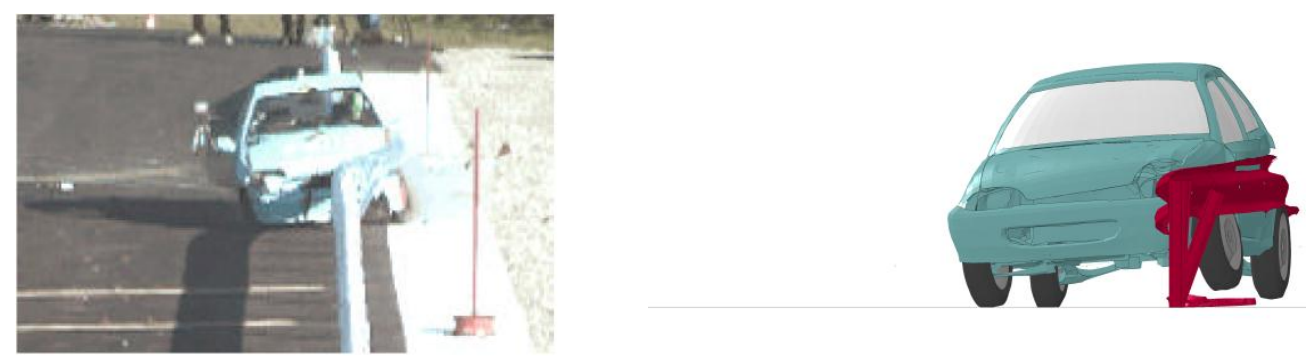

$\mathrm{T}=0,35 \mathrm{~s}$
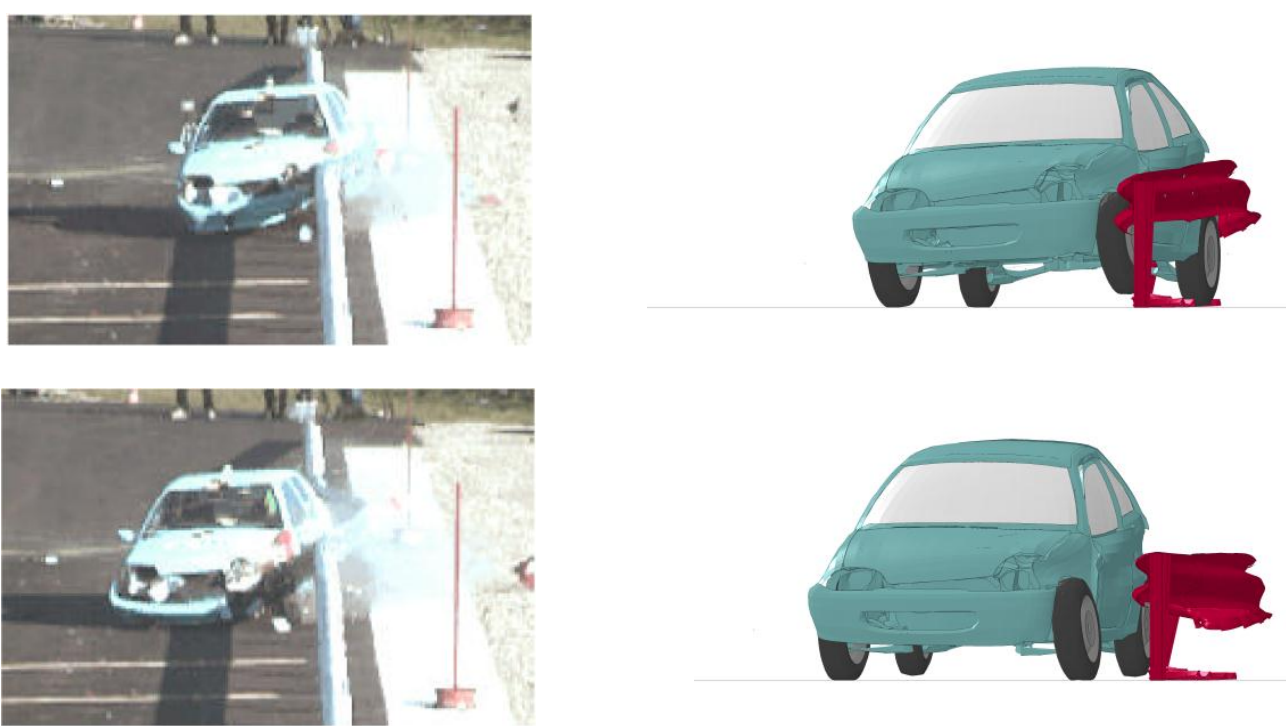

Figura 82 - Comparação das imagens do teste segundo (LIER, 2004) e da simulação com $\mathrm{PS}=0,9$. 
De fato, a comparação qualitativa da simulação com parâmetro PS=0,5 é semelhante à realidade de acordo com a. O veículo no caso real é diferente do modelo, porém ambos possuem dimensões compatíveis. Isso permite concluir, de modo qualitativo, que as simulações possuem boa reprodutividade do mundo real. E também sobre a importância da resitência da conexão parafusada no comportamento global da defensa metálica, sendo crucial na determinação do sucesso ou falha do sistema.

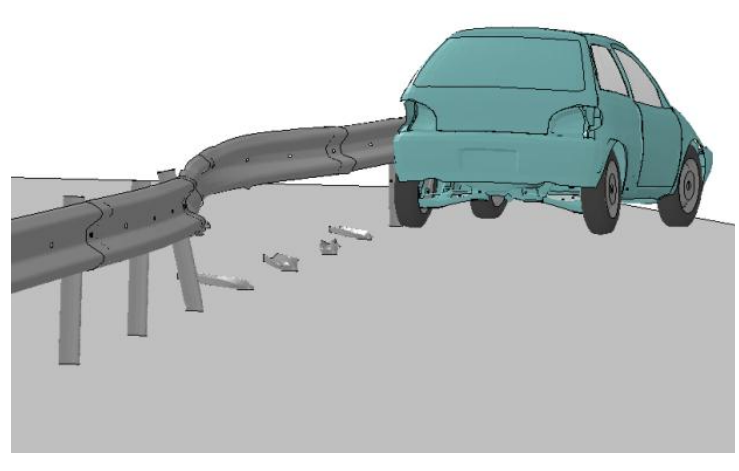

(a)

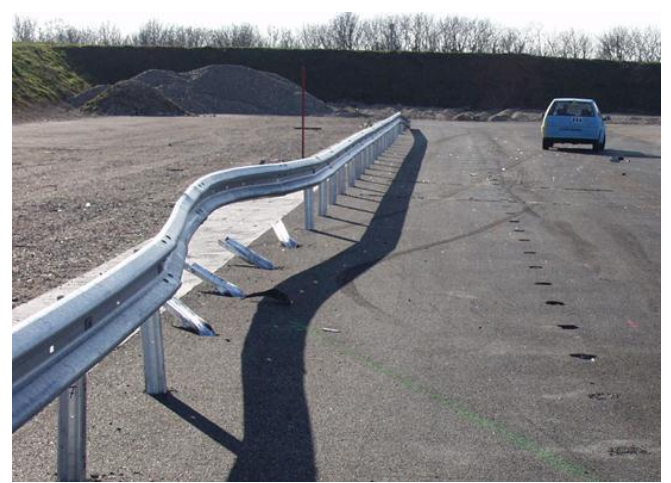

(b)

Figura 83 - (a) Imagem obtida no final da simulação numérica PS=0,5 e (b) foto no fim do teste realizado por (LIER, 2004).

\subsection{IMPACTO EM DEFENSA DE CONCRETO VERTICAL}

\subsubsection{Modelagem em elementos finitos}

A seguir serão apresentados resultados do teste de impacto de um veículo em uma barreira vertical de concreto desenvolvido por (LIER, 2002) e a comparação dos dados experimentais em relação a um conjunto de simulações numéricas equivalentes. O veículo utilizado no teste foi um Peugeot 205 Junior de aproximadamente $900 \mathrm{~kg}$ arremessado a $100,4 \mathrm{~km} / \mathrm{h}$ e $20^{\circ} \mathrm{em}$ relação ao plano da barreira, seguindo as especificações de teste TB11.

A barreira testada por (LIER, 2002) é do tipo temporária e composta por blocos de concreto pré-moldados de $3,15 \mathrm{~m}$ de comprimento e $2400 \mathrm{~kg}$ cada, conforme exposto na Figura 84 . Um total de 10 blocos foram montados sobre o asfalto conectados uns aos outros através de 2 parafusos M20 fixados na junção de cada módulo em ângulo de $45^{\circ} \mathrm{com}$ o plano vertical da defensa. Atrás da barreira e na posição afetada de impacto foram adicionados 3 blocos de con- 
creto de $1600 \mathrm{~kg}$ cada afim de evitar qualquer deslocamento da defensa. As extremidades laterais da barreira não foram ancoradas.

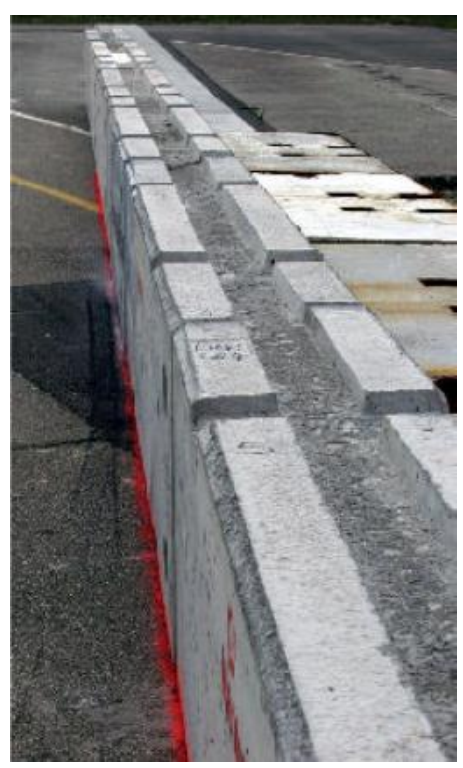

(a)

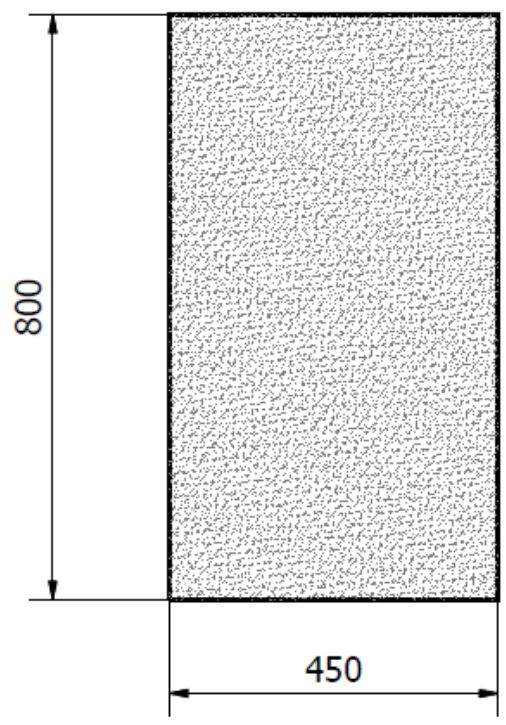

(b)

Figura 84 - (a) Defensa de concreto retangular testada em (LIER, 2004). Em (b) dimensões principais do bloco de concreto.

Considerando a configuração da barreira testada associada a uma quase incompressibilidade do concreto é possível assumir um comportamento rígido da defensa quando do impacto de um veículo leve. Desse modo, um bloco único discretizado em elementos sólidos de propriedades rígidas foi modelado em elementos finitos conforme malha exposta na Figura 85. Elementos sólidos de 500x200x225mm foram definidos nas áreas não afetadas do impacto com o veículo, enquanto na região central foram gerados elementos de 150x200x225mm em um vão de $12 \mathrm{~m}$. O total de 848 elementos compõe a barreira de $25 \mathrm{~m}$ de comprimento modelada em elementos finitos.

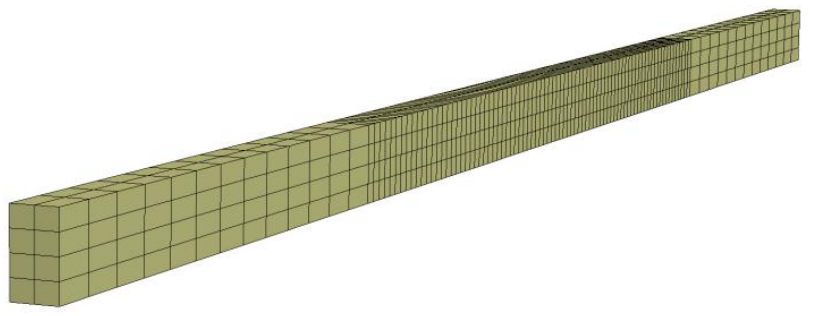

Figura 85 - Malha da barreira de concreto vertical. 
A base da defensa foi engastada e o cartão de *CONTACT_AUTOMATIC_SURFACE foi utilizado para definir o contato entre o veículo e a defensa. O coeficiente de atrito estático e dinâmico foi variado afim de investigar a sensibilidade no comportamento do veículo e nos resultados do índice de severidade ao ocupante, tema que será tratado a seguir.

\subsubsection{Resultados numéricos e comparação com teste em escala real}

Três simulações com diferentes de coeficientes de atrito foram realizadas considerando o cenário de impacto descrito no item 6.5.1. Os valores do coeficiente de atrito estático e dinâmico das superfícies envolvidas no impacto serão apontados ao longo do trabalho seguidos da letra grega $\mu$ e separados por um hífen, como descrito abaixo,

$$
\mu \text { = Coef.estático - Coef.dinâmico. }
$$

Três simulações de impacto com a defensa de concreto vertical foram realizadas com os seguintes coeficientes de atrito: $\mu=0-0 ; \mu=0,1-0,05$; e $\mu=0,3-0,2$. Na Figura 86 são apresentadas imagens em intervalos de 0,05 s do teste e da simulação cujos coeficientes de atrito são $\mu=0,1$ 0,05. A comparação das imagens do ponto de vista da trajetória e comportamento do veículo demonstra concordância do modelo numérico com a realidade, salvo exceção feita ao dano causado no capô do veículo não detectado nas simulações. Nos três casos simulados o comportamento do veículo é semelhante. 

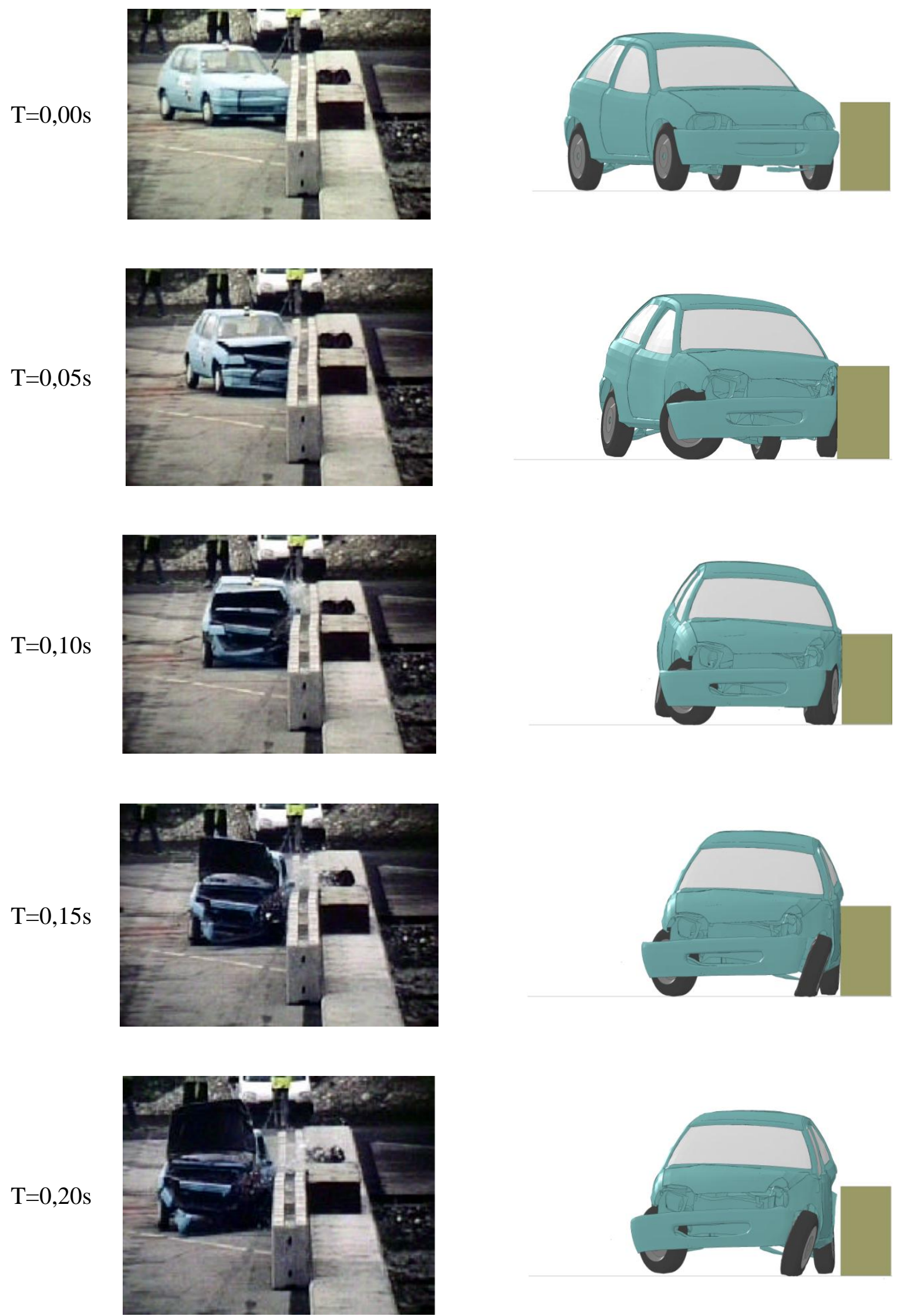

Figura 86 - Comparação das imagens do teste segundo (LIER, 2002) e da simulação com coeficiente de atrito $\mu=0,1-0,05$ 
As curvas dos índices de severidade ASI, THIV e PHD experimentais (LIER, 2002) e numéricos são apresentadas na Figura 87 e Figura 88. Nota-se nessas curvas que na simulação realizada com coeficientes de atrito $\mu=0,1-0,05$ há uma expressiva concordância na forma da curva experimental e numérica. Nas demais simulações as tendências da curva experimental são representadas com relativa aproximação, porém de maneira mais assimétrica.

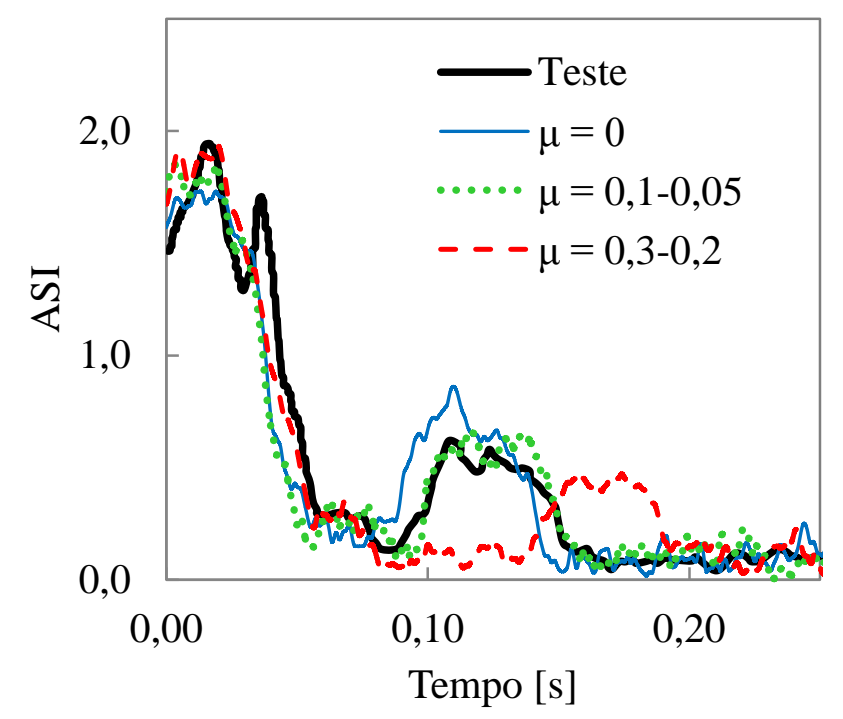

Figura 87 - Resultados do índice ASI no impacto do veículo com a defensa de concreto vertical.

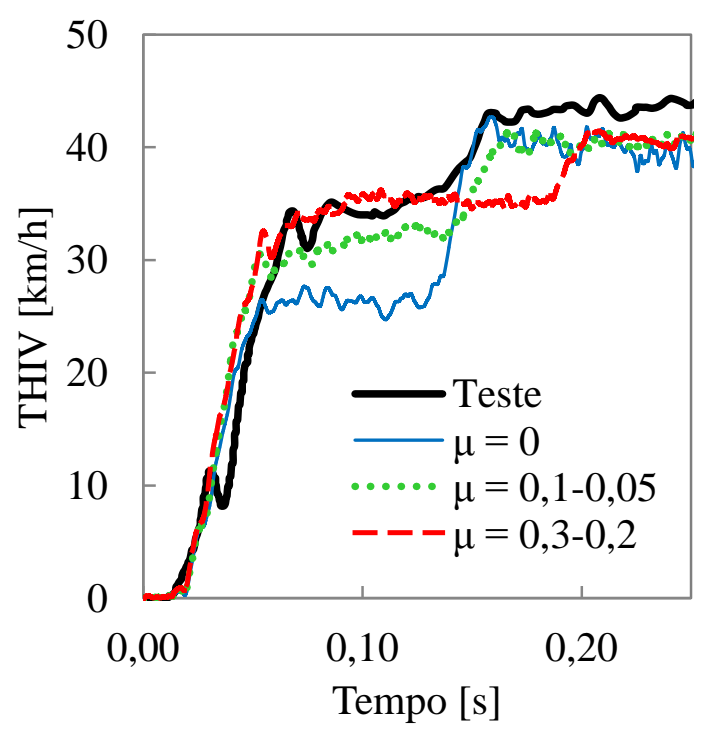

(a)

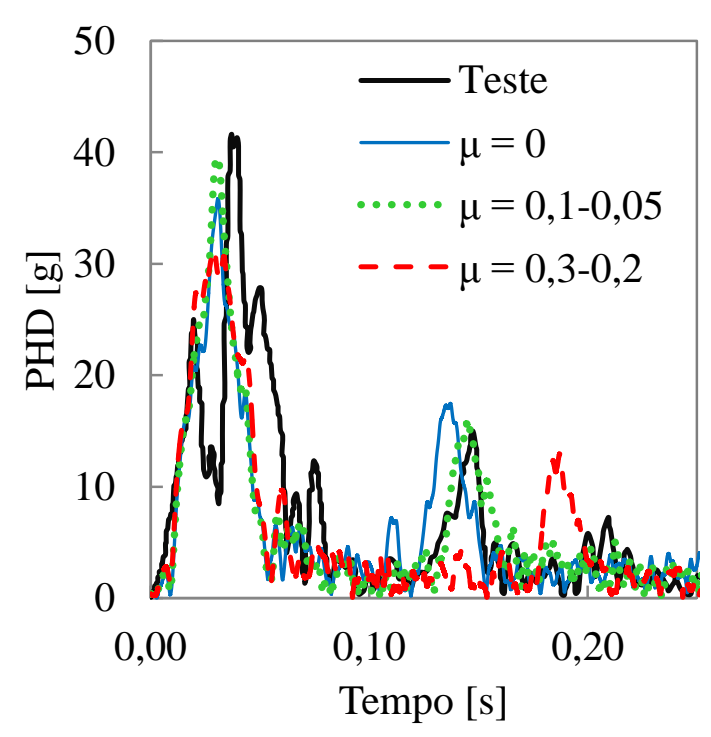

(b)

Figura 88 - Resultados do índice THIV (a) e PHD (b) no impacto do veículo com a defensa de concreto vertical. 
Os índices de severidade coletados a partir das curvas da Figura 87 e Figura 88 foram organizados na Tabela 17. Os tempos de vôo obtidos nas simulações numéricas conforme equação (6.12) considerando $x_{o}=0$ estão expostos na Tabela 17.

Tabela 17 - Resultados dos índices de severidade para defensa de concreto vertical.

\begin{tabular}{lccccc}
\hline Resultado & ASI & THIV & PHD & $\begin{array}{c}\text { Angulo de } \\
\text { saída } \\
\text { graus }\end{array}$ & $\mathrm{T}_{\mathrm{v}}$ \\
& - & $\mathrm{km} / \mathrm{h}$ & $\mathrm{g}$ & $\mathrm{s}$ \\
\hline Teste (LIER, 2002) & 1,94 & 32,00 & 15,00 & 24,2 & 0,078 \\
$\mu=0,0$ & 1,73 & 26,64 & 17,32 & 24,7 & 0,077 \\
$\mu=0,1-0,05$ & 1,85 & 30,61 & 15,60 & 21,4 & 0,079 \\
$\mu=0,3-0,2$ & 1,93 & 33,53 & 12,95 & 21,2 & 0,075 \\
\hline
\end{tabular}

A melhor predição do índice ASI ocorreu com a simulação $\mu=0,3-0,2$ com uma diferença de apenas $-0,4 \%$ em relação ao dado experimental; a simulação $\mu=0,1-0,05$ difere de $-4,6 \%$. Quanto aos índices THIV e PHD, a simulação $\mu=0,1-0,05$ tem as menores divergências detectadas, $-4,3 \%$ e 4,0\% respectivamente. Nota-se que no geral a simulação $\mu=0,1-0,05$ manteve a menor diferença em média nos índices de severidade 4,3\% em módulo contra 6,3\% da simulação $\mu=0,3-0,2$ e $14,3 \%$ da simulação $\mu=0$.

A avaliação da influência do coeficiente de atrito nos índices de severidade ao ocupante pode ser efetuada com o auxílio da Figura 89, que apresenta as diferenças entre as predições numéricas e os dados experimentais obtidos de (LIER, 2002). Observa-se na Figura 89 que a variação das predições dos índices ASI e THIV tem efeito positivo com o aumento do coeficiente de atrito, em contrapartida o índice PHD e ângulo de saída tem uma tendência oposta. 


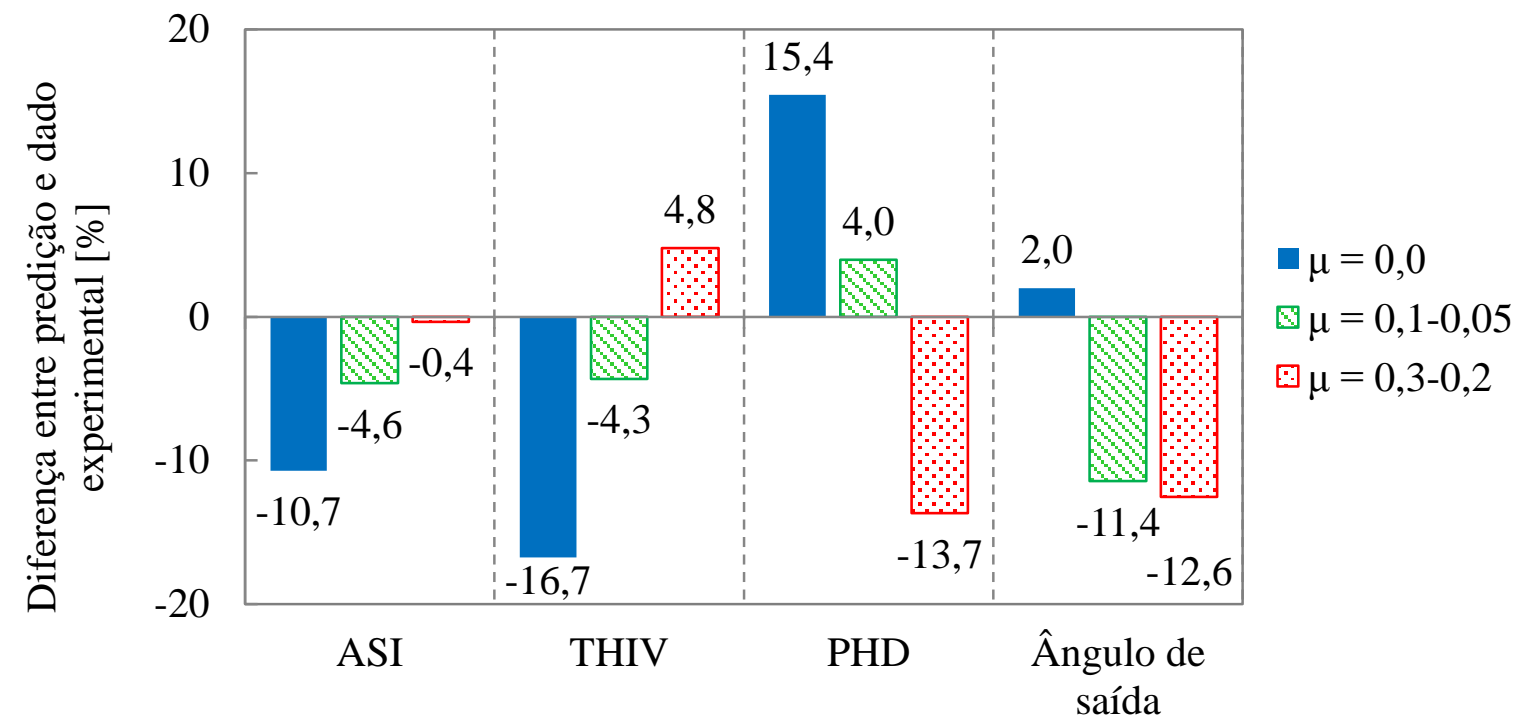

Figura 89 - Desvios em relação aos valores do teste para simulações com diferentes coeficientes de atrito entre as superfícies de contato do veículo e a defensa de concreto vertical.

\subsection{IMPACTO EM DEFENSA DE CONCRETO NEW JERSEY}

\subsubsection{Modelagem em elementos finitos}

Uma defensa de concreto com perfil New Jersey foi modelada em elementos finitos segundo geometria definida em (Departamento Nacional de Infraestrutura de Transportes, 2009) apresentada em perfil na Figura 90.

Esse tipo de barreira é normalmente instalada na divisão de pistas sendo fixada entre os pavimentos de ambos os lados da pista de modo que os deslocamentos da defensa em relação ao solo podem ser desprezados, por isso a base da defensa foi considerada engastada. Além disso, devido às características praticamente incompressíveis do concreto foram considerados elementos sólidos rígidos para modelagem da defensa em elementos finitos.

O total de 4884 elementos sólidos compõem a malha da defensa New Jersey de 25,0m de comprimento, mostrada na Figura 91. Na região central de impacto com o veículo os elementos foram refinados para melhor desempenho do algoritmo de contato, com dimensões aproximadas de 149x69mm, enquanto nas zonas não afetadas pelo impacto foram definidos elementos de aproximadamente 500x69mm. 
O cartão *CONTACT_AUTOMATIC_SURFACE foi utilizado para estabelecer as definições de contato entre o veículo e a defensa. O coeficiente de atrito estático e dinâmico foi variado para se investigar a sensibilidade no comportamento do veículo e nos resultados do índice de severidade ao ocupante, conforme será descrito no item a seguir.

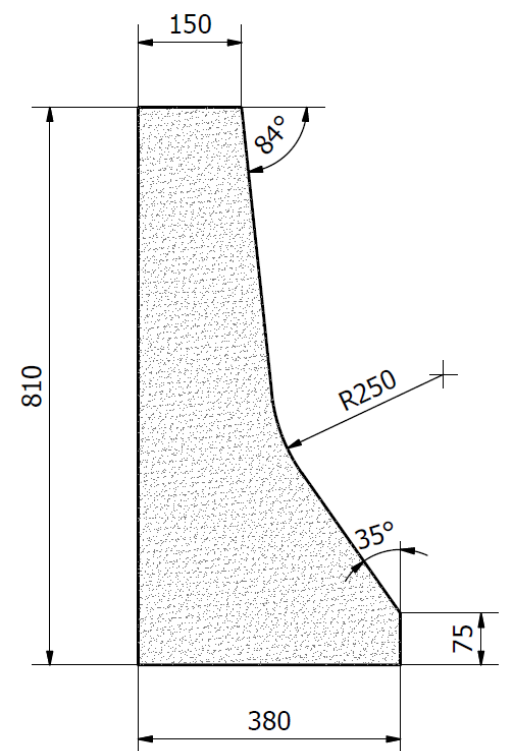

(a)

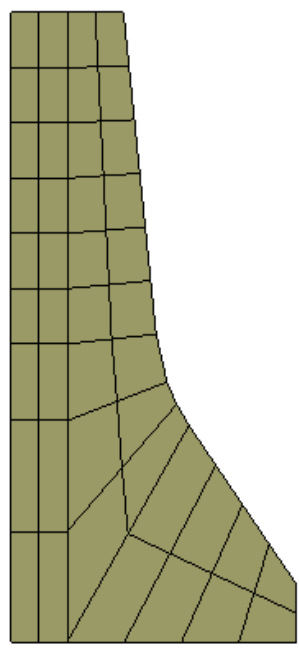

(b)

Figura 90 - Geometria da barreira de concreto New Jersey (a) e em (b) perfil da malha gerada em elementos finitos.

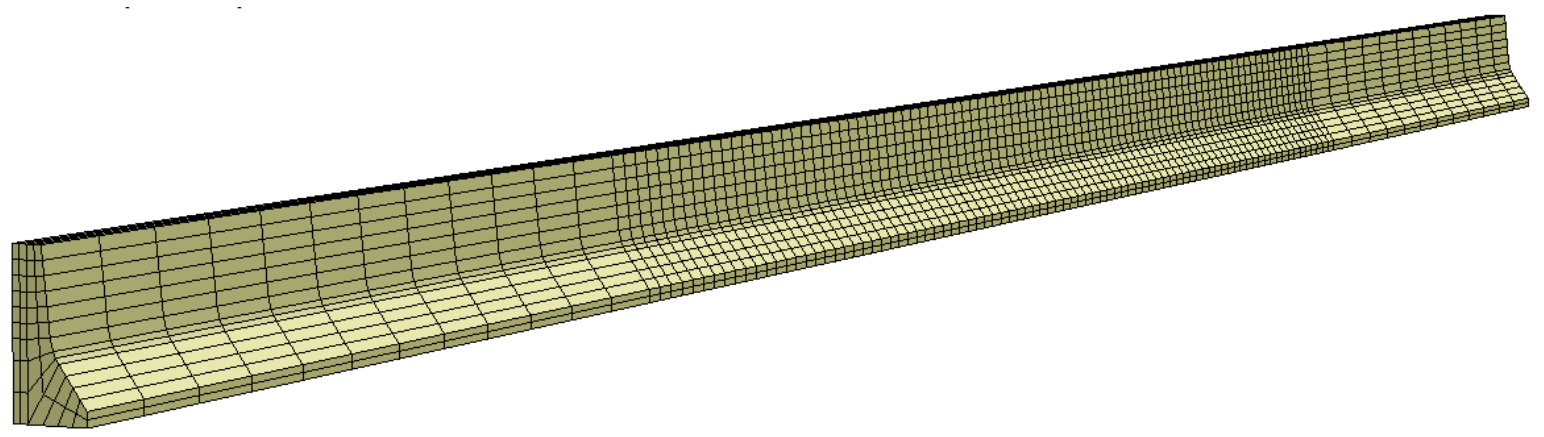

Figura 91 - Malha da defensa de concreto New Jersey.

\subsubsection{Resultados numéricos}

Três simulações de impacto do veículo contra a defensa New Jersey foram realizadas com os coeficientes de atrito: $\mu=0,1-0,05 \mu=0,2-0,2$; e $\mu=0,3-0,2$. Na Figura 92 são apresentadas imagens em intervalos de $0,05 \mathrm{~s}$ da simulação cujos coeficientes de atrito são $\mu=0,1-0,05$. As ima- 
gens apresentadas são semelhantes em todas as simulações realizadas. Para o caso de impacto analisado não foram encontrados dados experimentais para verificação dos resultados numéri$\cos$.

As imagens obtidas da simulação de impacto do veículo na defensa de concreto New Jersey são apresentadas na Figura 92. Nota-se que o modelo numérico do veículo é deslocado para cima ao mesmo tempo em que é redirecionado pela defensa devido a rampa existente na barreira. Atribui-se a esse movimento uma dissipação parcial da energia de impacto, no entanto, verifica-se uma acentuada tendência a rolagem conforme o veículo aproxima-se do solo. $\mathrm{O}$ comportamento do veículo, observado através das imagens da Figura 92, revela que esse tipo de defensa é mais perigosa aos ocupantes por causar maior rolagem do veículo.

Os índices de severidade ASI, THIV e PHD obtidos para as três simulações estão plotados na Figura 93 e Figura 94. A forma das curvas não difere significativamente, principalmente nas curvas dos índices ASI e THIV, porém na curva PHD são observadas divergências relativamente maiores nos picos de desaceleração. Considerando a média das três simulações, obtevese um índice PHD de 8,86g cujo coeficiente de variação é de $42 \%$, o maior dentre todos os índices de severidade calculados. O índice ASI foi de 1,72 e teve o menor coeficiente de variação $2,8 \%$. Um valor médio de $31,32 \mathrm{~km} / \mathrm{h}$ e coeficiente de variação de $6,9 \%$ foi obtido para o índice THIV. Todos os resultados estão organizados na Tabela 18.

Tabela 18 - Comparação dos resultados de simulação para diferentes coeficientes de atrito entre a barreira New Jersey e o veículo.

\begin{tabular}{lccccc}
\hline Simulação & ASI & THIV & PHD & $\begin{array}{c}\text { Angulo de } \\
\text { saída } \\
\text { [graus] }\end{array}$ & $\mathrm{T}_{\mathrm{v}}$ \\
\hline$\mu=0,1-0,05$ & - & {$[\mathrm{km} / \mathrm{h}]$} & {$[\mathrm{g}]$} & $\mathrm{s}$ \\
\hline$\mu=0,2-0,2$ & 1,68 & 28,94 & 12,27 & 21,8 & 0,0796 \\
$\mu=0,3-0,2$ & 1,70 & 31,81 & 9,43 & 21,4 & 0,0777 \\
Média & 1,77 & 33,20 & 4,89 & 21,1 & 0,0767 \\
Desvio padrão & 1,72 & 31,32 & 8,86 & 21,4 & 0,0780 \\
Coeficiente de variação & 0,047 & 2,171 & 3,724 & 0,330 & 0,00146 \\
& $2,8 \%$ & $6,9 \%$ & $42,0 \%$ & $1,5 \%$ & $1,9 \%$ \\
\hline
\end{tabular}



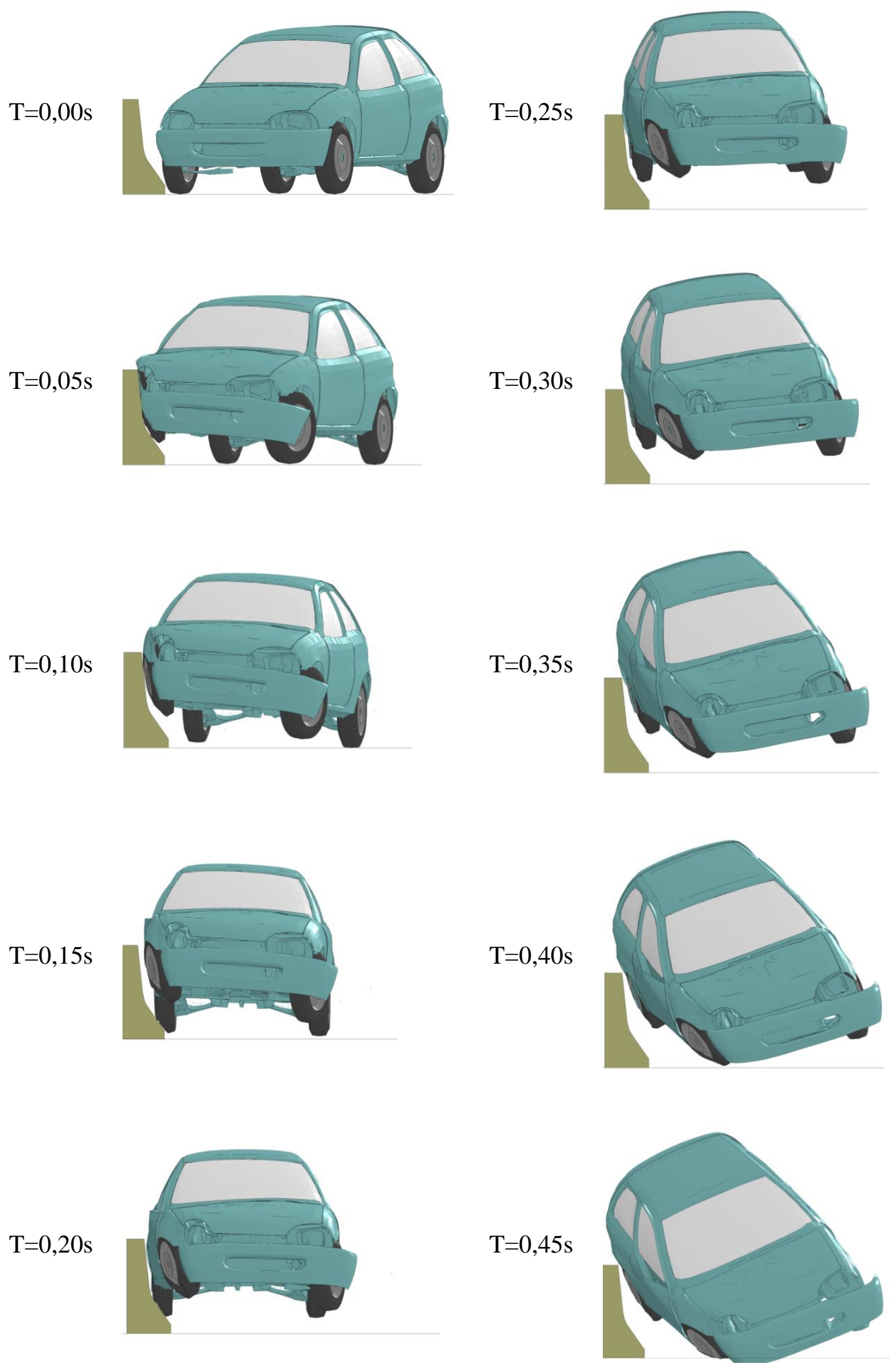

Figura 92 - Sequência de imagens em intervalos de 0,05 s da simulação de impacto em uma defensa de concreto com perfil New Jersey e coeficiente de atrito $\mu=0,1-0,05$. 


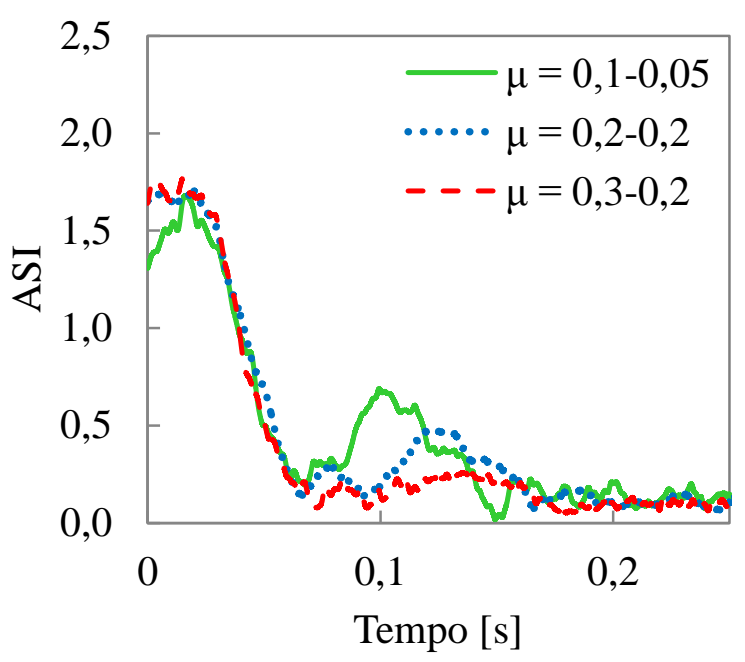

Figura 93 - Resultados do índice ASI no impacto do veículo com a defensa New Jersey.

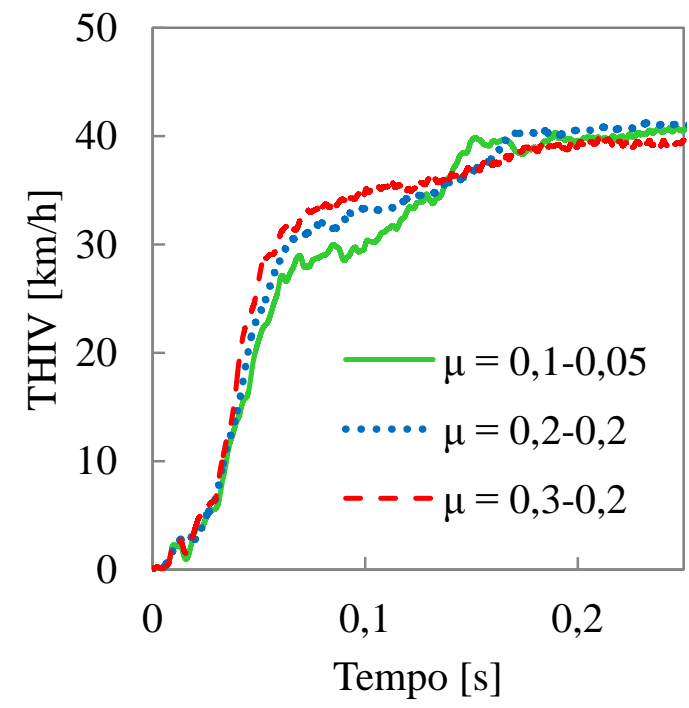

(a)

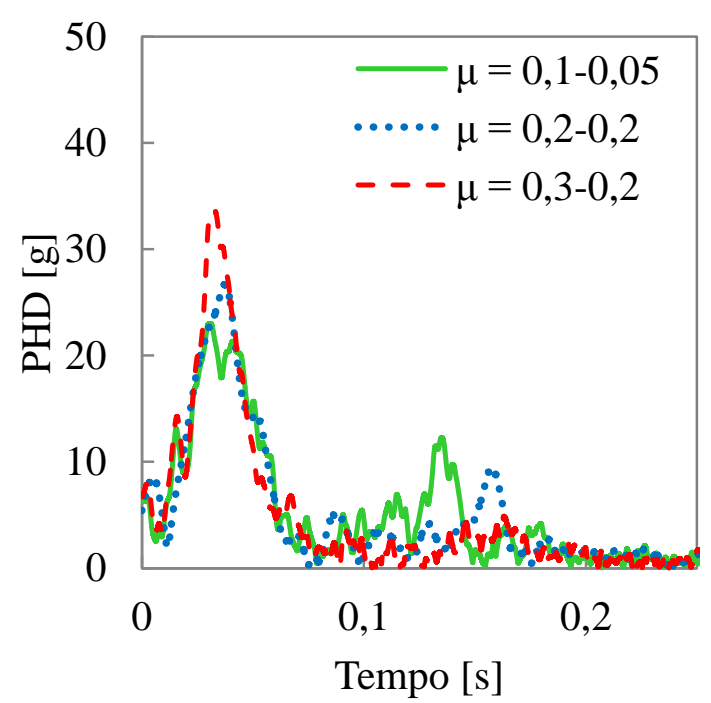

(b)

Figura 94 - Resultados do índice THIV e PHD no impacto do veículo com a defensa New Jersey.

\subsection{DISCUSSÃO DOS RESULTADOS}

O fenômeno de impacto de um veículo contra 3 tipos diferentes de defensas rodoviárias foi abordado de acordo com as especificações do teste TB11 definidas na Tabela 10, conforme norma EN 1317-2 (1998). O desempenho desses sistemas foi avaliado principalmente em relação aos índices de severidade ASI, THIV e PHD. Uma defensa metálica do tipo semi-rígida simples e outras duas defensas rígidas de concreto compõem a gama de barreiras de conten- 
ção rodoviária incluídas na análise. Na Tabela 19 foram comparados os resultados dos índices de severidade para cada uma das defensas citadas.

Tabela 19 - Comparação dos índices de severidade das defensas.

\begin{tabular}{lccc}
\hline Tipo de defensa & ASI & THIV & PHD \\
& {$[-]$} & {$[\mathrm{km} / \mathrm{h}]$} & {$[\mathrm{g}]$} \\
\hline Defensa metálica & 0,70 & 23,59 & 11,22 \\
Defensa rígida New Jersey & 1,68 & 28,94 & 12,27 \\
Defensa rígida vertical & 1,85 & 30,61 & 15,60 \\
\hline
\end{tabular}

O índice ASI de 0,7 na defensa metálica está abaixo da unidade, indicando que a aceleração da cabeça do ocupante não ultrapassou os limites orgânicos definidos pela EN 1317-1 (1998). Os demais índices THIV e PHD também estão abaixo dos limites de $33 \mathrm{~km} / \mathrm{h}$ e $20 \mathrm{~g}$, com isso a defensa metálica está alocada no patamar mínimo de severidade A, conforme Tabela 13. Diferentemente, as defensas de concreto vertical e New Jersey exibem índices ASI maiores que a unidade 1,68 e 1,85, respectivamente. Em conjunto com os índices THIV e PHD, as defensas de concreto assumem o conceito $\mathrm{C}$ de severidade, de acordo com a Tabela 13. Considerando apenas o índice ASI, é possível afirmar que as defensas rígidas oferecem um risco pelo menos duas vezes maior aos ocupantes.

Perante o nível de contenção, as defensas metálicas e de concreto são classificadas em categorias diferentes. A defensa metálica se enquadra no nível de contenção N2 (Tabela 11) capaz de suportar o impacto de veículos de $900 \mathrm{~kg}$ a $1500 \mathrm{~kg}$, enquanto as defensas de concreto assumem os níveis máximos de contenção H4 que incluem o impacto de caminhões articulados e ônibus, cuja massa é superior a 30000kg. Considerando a necessidade de contenção de cada tipo de defensa explica-se principalmente o desempenho desfavorável das defensas de concreto relativamente ao impacto de veículos leves.

Apesar das vantagens da defensa metálica na redução da severidade do impacto aos ocupantes nota-se que na configuração testada nenhuma proteção é dedicada ao motociclista. Pelo contrário, o impacto de um motociclista nesse tipo de defensa oferece um risco iminente à vida e quando não a perda de membros. Na Figura 95 são apresentadas defensas na qual o vão inferior entre a guia de deslizamento e o solo é protegida por estruturas de chapa metálica ou tu- 
bos para proteção de motociclistas conforme discutido pelo European Road Assesment Programme (2008)

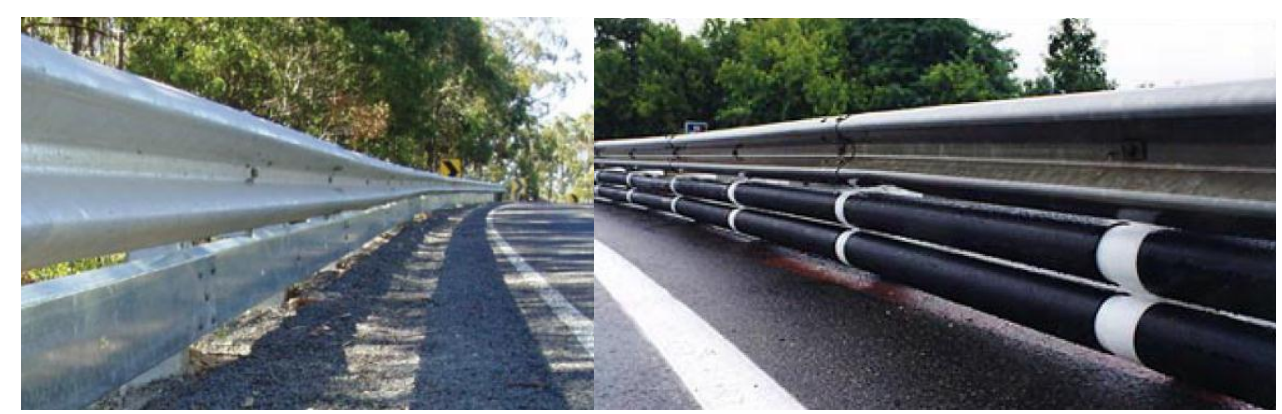

Figura 95 - Exemplos de dispositivos aplicados nas defensas metálicas para proteção de motociclistas (European Road Assesment Programme, 2008).

A defensa rígida New Jersey é amplamente utilizada nas rodovias nacionais e a configuração de instalação é equivalente ao modelo numérico avaliado no item 6.6. Notavelmente, os índices de severidade da defensa New Jersey são menos danosos ao ocupante do que a defensa vertical, principalmente devido à dissipação de energia de impacto vinculada ao movimento vertical do veículo; no entanto nota-se uma tendência à rolagem perigosa. A defensa rígida vertical não é comum nas rodovias brasileiras.

A defensa metálica semi-rígida simples é usualmente instalada com postes de secção transversal C no Brasil de acordo com a NBR 6971 (1999), enquanto na Europa o poste sigma é mais comum. A modelagem do poste sigma foi preferida afim de validar os resultados numéricos com os dados experimentais obtidos em (LIER, 2004) e realizados com tal configuração. Apesar dessa diferença, o comportamento da defensa sob impacto não deve divergir excessivamente devido à geometria do poste, pois as seções transversais dos mesmos possuem momentos de inércia equivalentes.

Ainda na norma NBR 6971 (1999) são indicadas 3 possibilidades de distanciamento entre postes $1 \mathrm{~m}, 2 \mathrm{~m}$ e $4 \mathrm{~m}$. Todas as simulações desenvolvidas e apresentadas neste trabalho consideram um espaçamento de $2 \mathrm{~m}$ entre postes; no entanto simulações preliminares com o espaçamento de postes de $4 \mathrm{~m}$ indicaram falha da defensa no redirecionamento do veículo mesmo com o valor de PS fixado em 0,7 , fato não verificado nas mesmas condições com os postes distanciados de $2 \mathrm{~m}$. Não foram avaliadas simulações de impacto com os postes separados em $1 \mathrm{~m}$. 
A inclusão do solo e suas respectivas propriedades soma maior flexibilidade à defensa metálica e torna o comportamento do sistema mais próximo a realidade de instalação nas rodovias. A modelagem do solo em elementos finitos foi avaliada experimental e numericamente por (Wu \& Thomson, 2007). Foi apontado nesse estudo que o mecanismo de interação entre o poste e o solo depende do grau de compactação do solo. Além desse fator de complexidade, o custo computacional incorporado na simulação devido à modelagem do solo ao redor de cada poste seria excepcional. 


\section{CONCLUSÕES}

No presente trabalho, os desempenhos de defensas rodoviárias sujeitas ao impacto de um veículo leve foram analisados segundo os índices de severidade ao ocupante ASI, THIV e PHD. No rol de sistemas rodoviários investigados, incluem-se: uma defensa metálica com guia de deslizamento em w e poste sigma, uma defensa de concreto vertical e uma defensa de concreto de perfil New Jersey; modelos similares aos utilizados em rodovias brasileiras e da Europa. Nesse cenário, o estudo compara resultados do fenômeno de impacto utilizando o solver de elementos finitos Ls-Dyna e dados experimentais obtidos da literatura, demonstrando que o modelo computacional pode reproduzir com pequenos desvios o caso real.

Aspectos da caracterização do material de uma defensa metálica foram abordados nos regimes estático e dinâmico, sendo este último a motivação do projeto de uma BH para caracterização de materiais em altas taxas de deformação. Os resultados obtidos pelos testes em uma máquina de tração universal e a BH desenvolvida conduziram à obtenção dos parâmetros do modelo de Cowper-Symonds para o material da defensa metálica. Dessa forma, foi possível predizer com precisão o comportamento da defensa sob o impacto de um veículo, fato demonstrado pela convergência dos resultados numéricos e experimentais.

Para se verificar a assertividade do modelo numérico foi desenvolvido um modelo analítico simplificado da defensa metálica sujeita a uma carga estática. Nesse contexto, foram comparados os resultados obtidos com modelo em elementos finitos dotado de conexão parafusada representada por elementos sólidos e a viga simplificada spotweld, inferindo-se que a última é capaz de representar com fidelidade o comportamento da conexão e com baixo custo computacional. Tal simplificação possui a vantagem de um baixo custo computacional combinada a uma previsão adequada das deformações globais da estrutura e forças internas na conexão. A verificação do modelo numérico via resultados analíticos mostra que é viável estimar as forças envolvidas na deformação da estrutura através de cálculos teóricos. Porém, é inviável estimar as forças na conexão parafusada no caso analítico.

No entanto, cuidado especial deve ser levantado quanto à sensibilidade do parâmetro de falha das conexões parafusadas em uma defensa metálica, pois existe uma relevante dependência desse parâmetro no sucesso de redirecionamento do veículo. Os resultados apontados no pre- 
sente estudo indicam que para uma correta modelagem do comportamento da defensa metálica o valor do parâmetro PS deve ser no mínimo igual a 0,5 .

Os resultados obtidos através das simulações de impacto com uma defensa metálica e uma defensa de concreto vertical foram validados segundo resultados de testes em escala real obtidos na literatura. A comparação dos resultados numéricos e experimentais demonstrou boa correlação tanto da representação do comportamento do veículo como dos índices de severidade ao ocupante. A verossimilhança das imagens obtidas no teste e nas simulações é evidente e as divergências dos índices calculados são pequenas em ambos os cenários de impacto.

Quanto aos modelos envolvendo o impacto em defensas de concreto, a investigação da sensibilidade do coeficiente de atrito entre o veículo e as barreiras indicou certa relevância na correta modelagem computacional do fenômeno de impacto.

Os índices de severidade expostos para cada tipo de defensa demonstra maior segurança aos ocupantes de um veículo ao colidir com uma defensa metálica do que em uma defensa de concreto. O índice ASI superior a unidade obtidos para as defensas de concreto indicam que os limites orgânicos para aceleração teórica da cabeça do ocupante foram ultrapassados, fato não verificado na defensa metálica.

A qualidade dos resultados obtidos pela modelagem numérica indica que a metodologia adotada para representação do fenômeno pode, por exemplo, ser utilizada para fins de melhoria dos sistemas de contenção existentes. Outro benefício seria a classificação de segurança oferecida por cada tipo de defensa a um custo bastante reduzido, pois poderiam ser dispensados inúmeros testes em escala real.

Para futuros estudos seria interessante incluir no modelo numérico um modelo de solo baseado em um líquido denso com molas independentes, de modo que a influência do solo no resultado de impacto seja acessada em maiores detalhes. Outras sugestões seriam: analisar uma defensa dotada de postes como o perfil C (típico no Brasil) ou outras seções conhecidas; avaliar a influência de um degrau ou valeta antes do impacto na defensa, caso comum instalações da defensa metálica; e investigar o impacto em defensas metálicas com veículos médios a pesados. 


\section{REFERÊNCIAS BIBLIOGRÁFICAS}

ASSOCIAÇÃO BRASILEIRA DE NORMAS TÉCNICAS. NBR 6971: Defensas metálicas: projeto e implantação. Rio de Janeiro, 1999.

ATAHAN, A. O.; ASCE, M.;CANSIZ, Ö. F. Improvements to G4(RW) strong-post roundwood, W-beam guardrail system. Journal of transportation engineering, p. 63-73, 2005.

BORSUTZKI, M.; CORNETTE, D.; KURIYAMA, Y.; UENISHI, A.; YAN, B. Recommendations for dynamic tensile testing of sheet steels. International Iron and Steel Institute, 2005.

CHREE, C. The equations of an isotropic elastic solid in polar and cylindrical coordinate, their solution and applications. Cambridge Philosophical Society Transactions. v.14, p.375-457, 1941.

CONFEDERAÇÃO NACIONAL DO TRANSPORTE. Pesquisa CNT de rodovias 2009: relatório gerencial. Brasília: CNT, SEST, SENAT, 2009.

CONFEDERAÇÃO NACIONAL DO TRANSPORTE. Pesquisa CNT de rodovias 2010. Brasília, 2011.

DEPARTAMENTO NACIONAL DE INFRAESTRUTURA DE TRANSPORTES. Obras complementares - Segurança no tráfego rodoviário - Projeto de barreiras de concreto Procedimento. DNIT 109/2009. Rio de Janeiro, 2009.

DIETER, G. E. Mechanical metallurgy. New York: McGraw Hill, 1986.

EASTWICK PRESS. Five Survive Crash Into Guard Rail In North Stephentown. Agosto de 2009. Disponível em: < http://eastwickpress.com/news/2009/08/five-survive-crashinto-guard-rail-in-north-stephentown/>. Acessado em: abril de 2011.

EUROPEAN COMMITTEE FOR STANDARDIZATION. EN 1317-1: Road restraint systems - Part 1: Terminology and general criteria for test methods. Oslo 1998. 
EUROPEAN COMMITTEE FOR STANDARDIZATION. EN 1317-2: Road restraint systems - Part 2: Performance classes, impact test acceptance criteria and test methods for safety barriers. Oslo, 1998.

EUROPEAN ROAD ASSESMENT PROGRAMME. Barriers to change: designing safe roads for motorcyclists. United Kingdom: EuroRAP AISBL, 2008.

FALLER, R. K.; SICKING, D. L.; BIELENBERG, R. W.; ROHDE, J. R.; POLIVKA, K. A.; REID, J. D. Performance of Steel-POst, W-beam guardrail systems . 86th Meeting Tansportation Research Board. Washington, D.C, 2007.

GALLINA, F. Flambagem progressiva e global de cascas cilíndricas de aço sob impacto axial: tese de mestrado. São Paulo: Universidade de São Paulo, 2004.

GOVENDER, R. A. Numerical Investigation of Dispersion in Hopkinson Pressure Bars: Tese de mestrado, University of Cape Town, 2005.

GRZEBIETA, R. H.; ZOU, R.; JIANG, T.; CAREY, A. Roadside hazard and barrier crashworthiness issues confronting vehicle and barrier manufactures and government regulators, 2005.

HASCALL, J. A.; FALLER, R. K.; REID, J. D.; SICKING, D. L. Investivting the use of small-diameter softwood as guardrail posts (dynamic test results). Madison, Wisconsin US: Forest Products Laboratory, 2007.

IPEA; DENATRAN; ANTP. Impactos sociais e econômicos dos acidentes de trânsito nas rodovias brasileiras. Brasília, 2006.

ITABASHI, M. Effect of output bar supporting methods on high velocity tensile behavior for steel plate. Journal of Solid Mechanics and Materials Engineering, Vol. 03, pp. 295317, 2009.

KAPOOR, R.; NEMAT-NASSER, S. Determination of temperature rise during high strain rate deformation. Mechanics of Materials. San Diego: University of California, 1998, p. 1-12.

LIER. Test report - Round Robin Phase 2 TB11. Lyon: Laboratoire d'essais INRETS Equipements de la Route, 2002. (Relatório técnico Robust Project). 
LIER. Barrier test Robust work package 4 - H2. Lyon: Laboratoire d'essais INRETS Equipements de la Route, 2004. (Relatório técnico Robust Project).

LISY. Defensas metálicas. Maio de 2008. Disponível em:

<http://www.lisy.com.br/defensasmetalicas/defensas-metalicas.html>. Acessado em: 18 abril 2011.

LSTC. LS-DYNA keyword user's manual (Version 971 ed.). California, 2007.

MERKES, D. J. Investigation of a connection system for a pultruded GFRP highway guardrail system: Tese de mestrado. Unversity of Wisconsin-Madison,1999.

MINISTÉRIO DA SAÚDE; Sistema de Informação sobre Mortalidade. Indicadores e dados básicos: IDB Brasil. Brasília, 2009.

NATIONAL CRASH ANALYSIS CENTER. Disponível em: 〈http://www.ncac.gwu.edu/>. Acessado em 15 de Fevereiro de 2010.

NEWS FROM THE POST-STANDARD. A Daewoo Nubira came to rest sandwiched underneath a guard rail. Novembro de 2010. Disponível em: <http://altercation.rssing.com/chan-2091553/all_p220.html>. Acessado em: Julho de 2011.

PATANE, F. Dispositivos de segurança rodoviária testados para contenção de veículos. Fasco, Belo Horizonte, 2012. (Relatório técnico).

PLAXICO, C. A.; RAY, M. H.; HIRANMAYEE, K. Comparison of the impact performance of the $\mathrm{G} 4(1 \mathrm{~W})$ and $\mathrm{G} 4(2 \mathrm{~W})$ guardrail systems under NCHRP report 350 test 3-11 conditions. 79th Annual Meeting of the Transportation Research Board. Washington D.C: National Research Council, 2000, p. 7-18.

POCHAMMER, L. (1876). On the propagation velocities of small oscilations in an unlimited isotropic circular cylinder. J. f. Math (Crelle), 81, 324-326.

RÁDIO CRICIUMA. Barreiras New Jersey instaladas na BR101. Setembro de 2012. Disponível em: <http://www.radiocriciuma.com.br/portal/vernoticia.php?id=15786>. Acessado em: Março 2011. 
RAY, M. H.; PLAXICO, C. A.; ENGSTRAND, K. Performance of W-beam splices. 80th Annual Meeting of the Transportation Research Board. Washington, D.C,2001.

RAYLEIGH, J. W. The theory of sound. New York: Dover Publications.1945, v.3.

REDDING.COM. CalTrans cable barriers raise questions. Agosto de 2009. Disponível em: <http://www.redding.com/news/2009/aug/20/caltrans-cable-barriers-raise-questions/>. Acessado em: Outubro de 2011.

REID, J. D.; SICKING, D. L.; FALLER, R. K.; PFEIFER, B. G. Development of a new guardrail system. Transportation Research Record, p. 72-80, 1997.

RIGHT TO RIDE. Maio de 2005. Crash barriers - Wire Up the danger for motorcyclists. Disponível em: < http://www.righttoride.co.uk/albumcrashbarriers/index.html>. Acessado em março de 2011.

RIPSA. Situação e tendências da violência do trânsito no Brasil: rede interagencial de informações para a saúde. Brasília, 2009.

ROSS, H. E.; SICKING, D. L.; ZIMMER, R. A.; MICHIE, J. D. Recommended procedures for safety performance evaluation of highway features. National Cooperative Research Program (NCHRP). Washington, D.C: Transportation Research Board, 1993.

SENNAH, K.; SAMAAN, M.; ELMARAKBI, A. Impact performance of flexible guardrail systems using LS-DYNA. 4th European LS-DYNAUsers Conference. Alemanha, 2003, p. 35-44.

SHEN, X.; GUO, L.; YANG, L.; DU, X.; CAO, P. Numerical analysis of impact effect on mechanical behaviour of strong guardrail system. International Symposium on Nonlinear Dynamics. IOP Publishing, 2007.

SINDIPEÇAS-ABIPEÇAS. Levantamento da frota circulante brasileira. Associação Brasileira da Insútria de Autopeças (Abipeças) e Sindicado Nacional da Indústria de Componentes para Veículos Automotores (Sindipeças), 2011.

SLYCKEN, J. V. Advanced use of a split hopkinson bar setup - application to TRIP steels: Tese de doutorado. Academiejaar, 2008. 
TIMOSHENKO, S. P.; GOODIER, J. N. Teoria da elasticidade. Rio de Janeiro: Guanabara Dois, 1980.

WORLD HEALTH ORGANIZATION. World report on road traffic injury prevention. Geneva, 2004.

WORLD HEALTH ORGANIZATION. Global status report on road safety: time for action. Geneva, 2009.

WU, W., \& THOMSON, R. A study og the interaction between a guardrail post and soil during quasi-static and dynamic loading. International Journal of Impact Engineering, 34, pp. 883-898, 2007. 


\section{Apêndice A}

\section{Propagação de ondas em meios elásticos}

As equações de equilíbrio dinâmico em coordenadas cartesianas para um elemento infinitesimal são dadas (Timoshenko \& Goodier, 1980):

$$
\begin{aligned}
& \frac{\partial \sigma_{x}}{\partial x}+\frac{\partial \tau_{x y}}{\partial y}+\frac{\partial \tau_{x z}}{\partial z}=\rho \frac{\partial^{2} u}{\partial t^{2}} \\
& \frac{\partial \tau_{x y}}{\partial x}+\frac{\partial \sigma_{y}}{\partial y}+\frac{\partial \tau_{y z}}{\partial z}=\rho \frac{\partial^{2} u}{\partial t^{2}} \\
& \frac{\partial \tau_{x z}}{\partial x}+\frac{\partial \tau_{y z}}{\partial y}+\frac{\partial \sigma_{z}}{\partial z}=\rho \frac{\partial^{2} u}{\partial t^{2}}
\end{aligned}
$$

Para o estudo da propagação de ondas em meios infinitos é interessante escrever as equações de equilíbrio (A.1) em função das deformações. Para tal, considerando um material isótropo, com comportamento elástico-linear a Lei de Hooke define as seguintes relações entre tensão e deformação:

$$
\begin{array}{ll}
\varepsilon_{x}=\frac{1}{E}\left(\sigma_{x}-v\left(\sigma_{y}+\sigma_{z}\right)\right) & \gamma_{x y}=\frac{1}{G} \tau_{x y} \\
\varepsilon_{y}=\frac{1}{E}\left(\sigma_{y}-v\left(\sigma_{x}+\sigma_{z}\right)\right) & \gamma_{x z}=\frac{1}{G} \tau_{x z} \\
\varepsilon_{z}=\frac{1}{E}\left(\sigma_{z}-v\left(\sigma_{x}+\sigma_{y}\right)\right) & \gamma_{y z}=\frac{1}{G} \tau_{y z}
\end{array}
$$

A Lei de Hooke expressa em função das componentes de deformação será necessária daqui para frente. Para isso, operando as equações (A.2) essas relações são obtidas como segue.

$$
\begin{aligned}
& \sigma_{x}=E \varepsilon_{x}+v\left(\sigma_{y}+\sigma_{z}\right) \\
& \sigma_{y}=E \varepsilon_{y}+v\left(\sigma_{x}+\sigma_{z}\right) \\
& \sigma_{z}=E \varepsilon_{z}+v\left(\sigma_{x}+\sigma_{y}\right)
\end{aligned}
$$

Somando as expressões da tensão $\sigma_{y}$ e $\sigma_{z}$, resulta: 


$$
\left(\sigma_{y}+\sigma_{z}\right)=\frac{1}{1-v}\left[E\left(\varepsilon_{y}+\varepsilon_{z}\right)+v\left(2 \sigma_{x}+\sigma_{y}+\sigma_{z}\right)\right]
$$

Substituindo a equação (A.6) em (A.3),

$$
\sigma_{x}=E \varepsilon_{x}+\frac{v}{1-v}\left[E\left(\varepsilon_{y}+\varepsilon_{z}\right)+v\left(2 \sigma_{x}+\sigma_{y}+\sigma_{z}\right)\right]
$$

Resolvendo a equação (A.7) obtém-se a seguinte expressão para $\sigma_{x}$ em função das componentes de deformação:

$$
\sigma_{x}=\frac{E v}{(1+v)(1-2 v)}\left(\varepsilon_{x}+\varepsilon_{y}+\varepsilon_{z}\right)+\frac{E}{1+v} \varepsilon_{x}
$$

Usando as notações,

$$
\begin{gathered}
e=\varepsilon_{x}+\varepsilon_{y}+\varepsilon_{z} \\
\lambda=\frac{v E}{(1+v)(1-2 v)} \\
G=\frac{E}{2(1+v)}
\end{gathered}
$$

Onde, $\lambda$ é a constante de Lamé, $G$ o módulo de elasticidade ao cisalhamento, $e$ a expansão volumétrica. Então a equação (A.8) pode ser reescrita, assim como as demais componentes de tensão por analogia:

$$
\begin{array}{ll}
\sigma_{x}=\lambda e+2 G \varepsilon_{x} & \tau_{x y}=G \gamma_{x y} \\
\sigma_{y}=\lambda e+2 G \varepsilon_{y} & \tau_{x z}=G \gamma_{x z} \\
\sigma_{z}=\lambda e+2 G \varepsilon_{z} & \tau_{y z}=G \gamma_{y z}
\end{array}
$$

Aplicando as equações (A.12) nas equações (A.1), vem que: 


$$
\frac{\partial\left(\lambda e+2 G \varepsilon_{x}\right)}{\partial x}+\frac{\partial\left(G \gamma_{x y}\right)}{\partial y}+\frac{\partial\left(G \gamma_{x z}\right)}{\partial z}=\rho \frac{\partial^{2} u}{\partial t^{2}}
$$

$\mathrm{Ou}$

$$
\lambda \frac{\partial e}{\partial x}+2 G \frac{\partial \varepsilon_{x}}{\partial x}+G \frac{\partial \gamma_{x y}}{\partial y}+G \frac{\partial \gamma_{x z}}{\partial z}=\rho \frac{\partial^{2} u}{\partial t^{2}}
$$

A partir das relações entre tensões e deformações,

$$
\begin{array}{ll}
\varepsilon_{x}=\frac{\partial u}{\partial x} & \gamma_{x y}=\frac{\partial u}{\partial y}+\frac{\partial v}{\partial x} \\
\varepsilon_{y}=\frac{\partial v}{\partial y} & \gamma_{x z}=\frac{\partial u}{\partial z}+\frac{\partial w}{\partial x} \\
\varepsilon_{z}=\frac{\partial w}{\partial z} & \gamma_{y z}=\frac{\partial v}{\partial z}+\frac{\partial w}{\partial y}
\end{array}
$$

Substituindo essas relações na equação (A.14), resulta:

$$
\lambda \frac{\partial e}{\partial x}+2 G \frac{\partial}{\partial x}\left(\frac{\partial u}{\partial x}\right)+G \frac{\partial}{\partial y}\left(\frac{\partial u}{\partial y}+\frac{\partial v}{\partial x}\right)+G \frac{\partial}{\partial z}\left(\frac{\partial u}{\partial z}+\frac{\partial w}{\partial x}\right)=\rho \frac{\partial^{2} u}{\partial t^{2}}
$$

Pela regra do produto:

$$
\lambda \frac{\partial e}{\partial x}+2 G \frac{\partial^{2} u}{\partial x^{2}}+G \frac{\partial^{2} u}{\partial y^{2}}+G \frac{\partial^{2} v}{\partial x \partial y}+G \frac{\partial^{2} u}{\partial z^{2}}+G \frac{\partial^{2} w}{\partial x \partial z}=\rho \frac{\partial^{2} u}{\partial t^{2}}
$$

$\mathrm{Ou}$,

$$
\lambda \frac{\partial e}{\partial x}+G\left(\frac{\partial^{2} u}{\partial x^{2}}+\frac{\partial^{2} u}{\partial y^{2}}+\frac{\partial^{2} u}{\partial z^{2}}\right)+G\left(\frac{\partial^{2} u}{\partial x^{2}}+\frac{\partial^{2} v}{\partial x \partial y}+\frac{\partial^{2} w}{\partial x \partial z}\right)=\rho \frac{\partial^{2} u}{\partial t^{2}}
$$

Colocando $u$ e $\frac{\partial}{\partial x}$ em evidência: 


$$
\lambda \frac{\partial e}{\partial x}+G\left(\frac{\partial^{2}}{\partial x^{2}}+\frac{\partial^{2}}{\partial y^{2}}+\frac{\partial^{2}}{\partial z^{2}}\right) u+G \frac{\partial}{\partial x}\left(\frac{\partial u}{\partial x}+\frac{\partial v}{\partial y}+\frac{\partial w}{\partial z}\right)=\rho \frac{\partial^{2} u}{\partial t^{2}}
$$

Definindo o operador $\nabla^{2}$,

$$
\nabla^{2}=\frac{\partial^{2}}{\partial x^{2}}+\frac{\partial^{2}}{\partial y^{2}}+\frac{\partial^{2}}{\partial z^{2}}
$$

Logo, usando as notações das equações (A.20) e (A.9), aplicadas a equação (A.19), obtém-se a equação de movimento de um material isótropo com comportamento elástico linear na ausência de forças de volume e de superfície, na direção de $x$. Analogamente, são obtidas as componentes nas direções $y$ e $z$.

$$
\begin{aligned}
& (\lambda+G) \frac{\partial e}{\partial x}+G \nabla^{2} u=\rho \frac{\partial^{2} u}{\partial t^{2}} \\
& (\lambda+G) \frac{\partial e}{\partial y}+G \nabla^{2} v=\rho \frac{\partial^{2} v}{\partial t^{2}} \\
& (\lambda+G) \frac{\partial e}{\partial z}+G \nabla^{2} w=\rho \frac{\partial^{2} w}{\partial t^{2}}
\end{aligned}
$$

As equações (A.21) são utilizadas para dedução das equações de propagação de onda longitudinal e distorcional. 


\section{Apêndice B}

Dimensões e geometria dos componentes utilizados no modelo da defensa

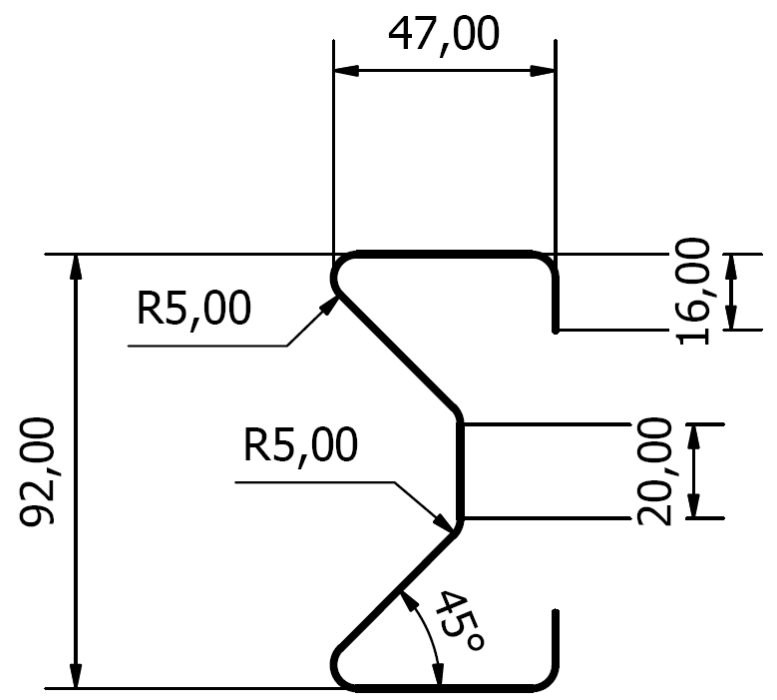

Figura 96 - Dimensões do poste.

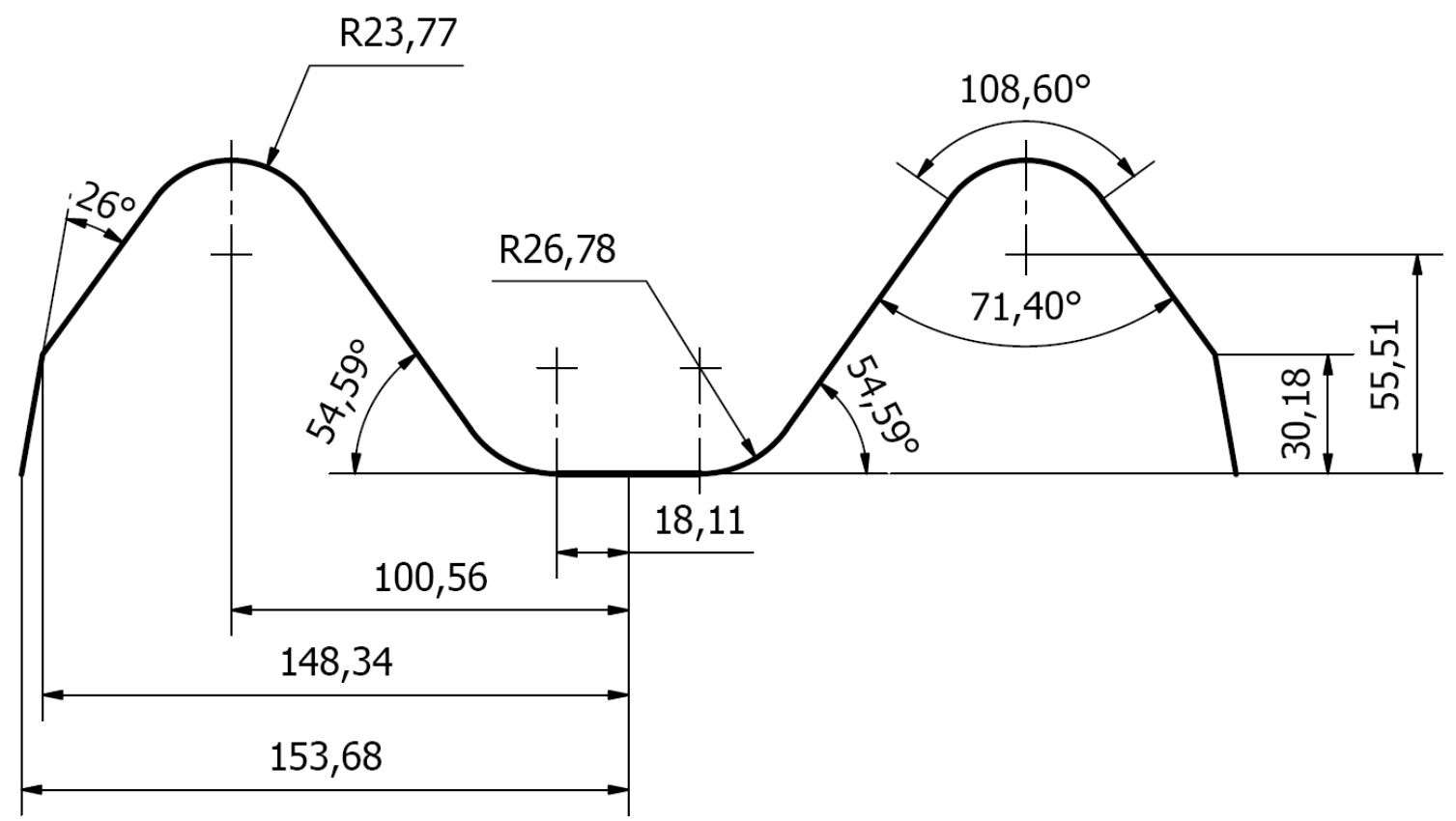

Figura 97 - Dimensões e geometria da guia de deslizamento w. 

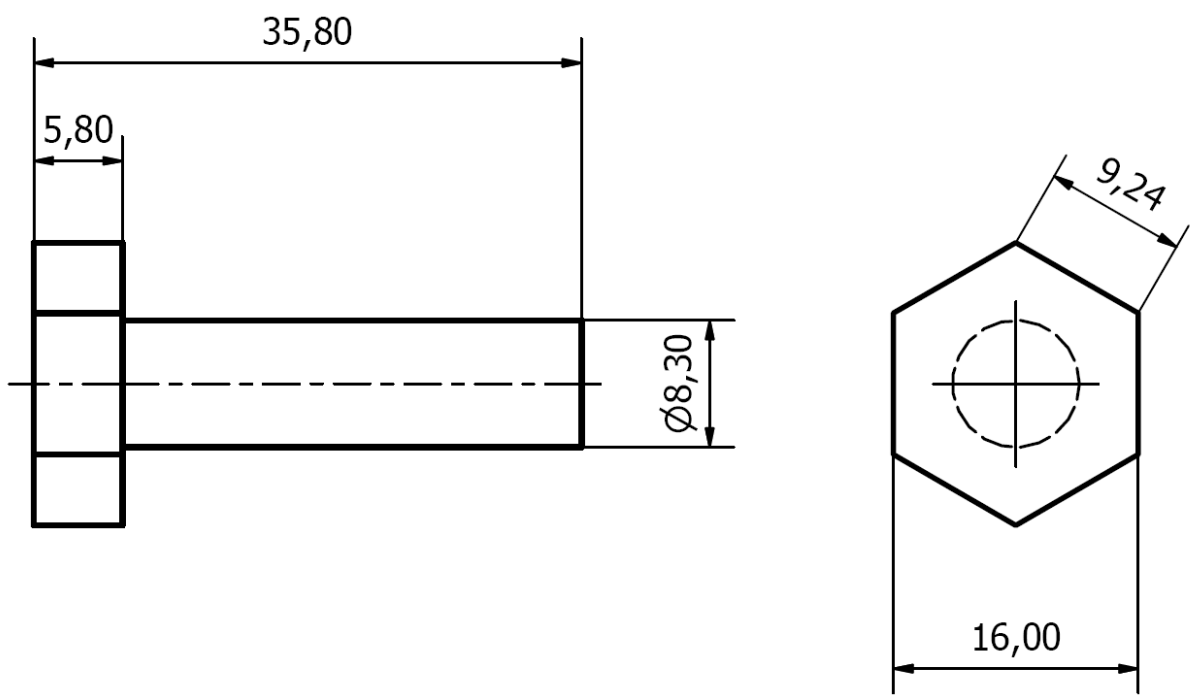

Figura 98 -Dimensões do parafuso M10.

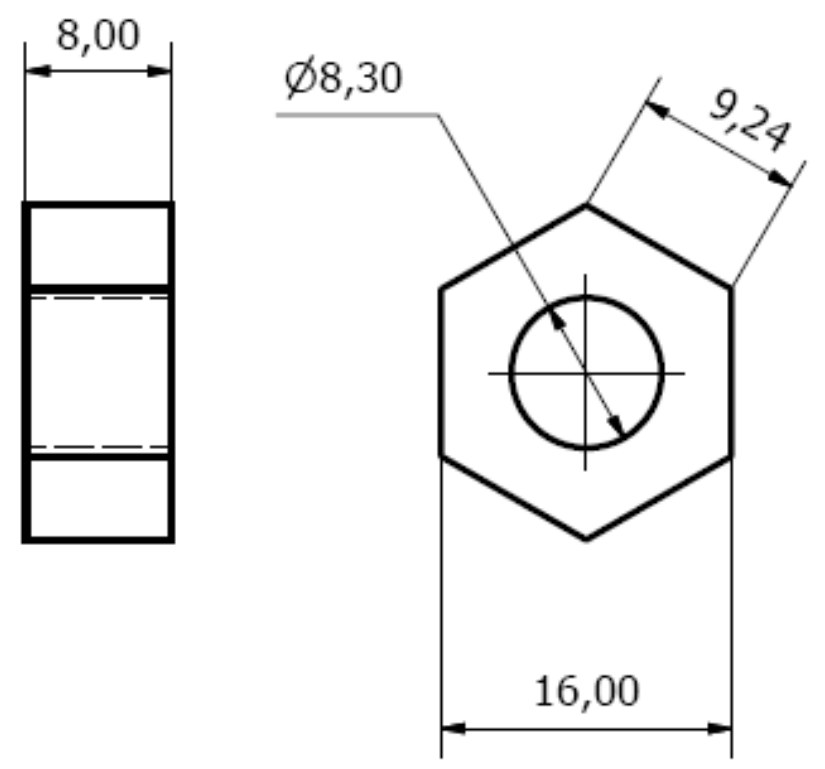

Figura 99 - Dimensões da porca. 


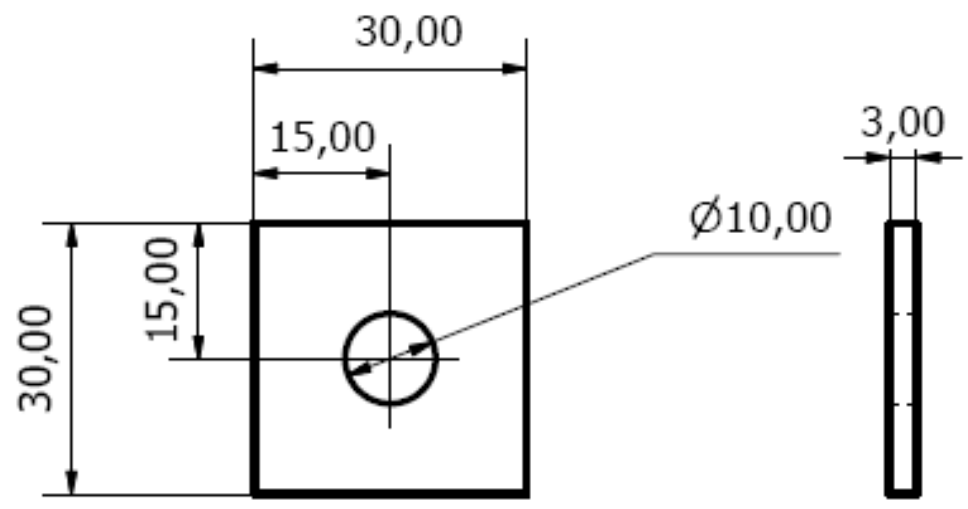

Figura 100 - Dimensões da arruela 30x30x3.
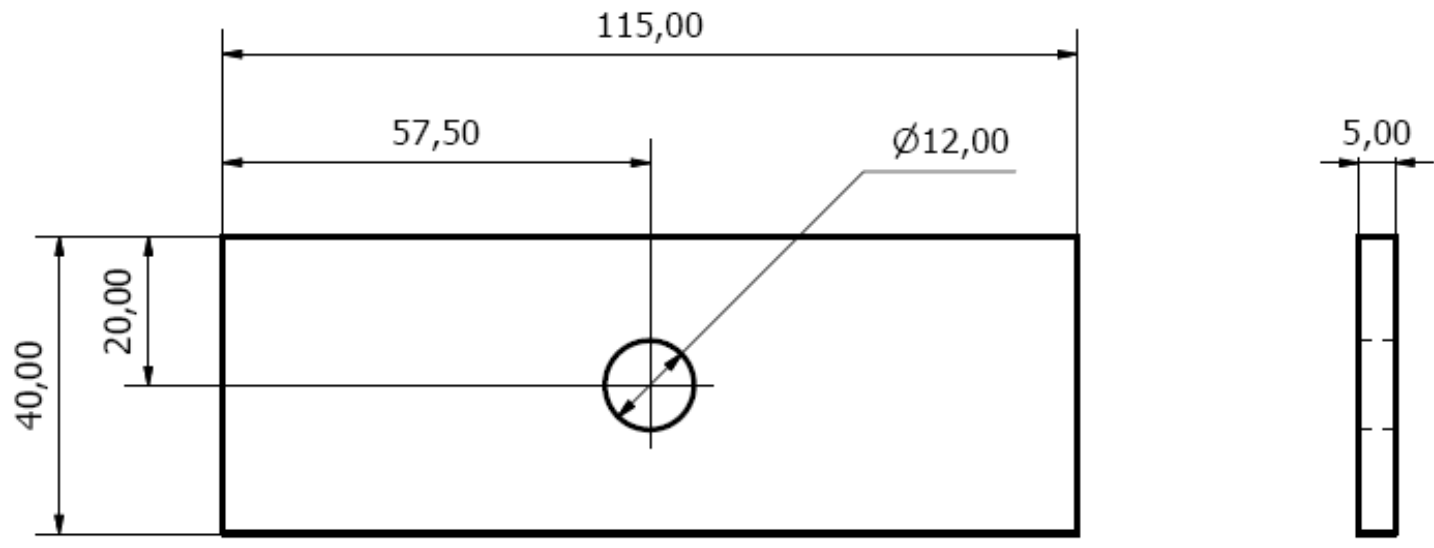

Figura 101 - Dimensões da arruela 115x40x5. 


\section{Apêndice C}

\section{Força média avaliada em função do deslocamento da defensa}

A Figura 102 demonstra a trajetória de um veículo em colisão com uma defensa. Para a análise aproximada da força média exercida pela defensa na direção perpendicular a sua face, considera-se um veículo de massa $M$ e velocidade $V$ com um ângulo $\alpha$ em relação a direção da defensa. O CG do veículo está posicionado a uma distância $c$ da face frontal e uma distância $b$ da face lateral de sua estrutura externa.

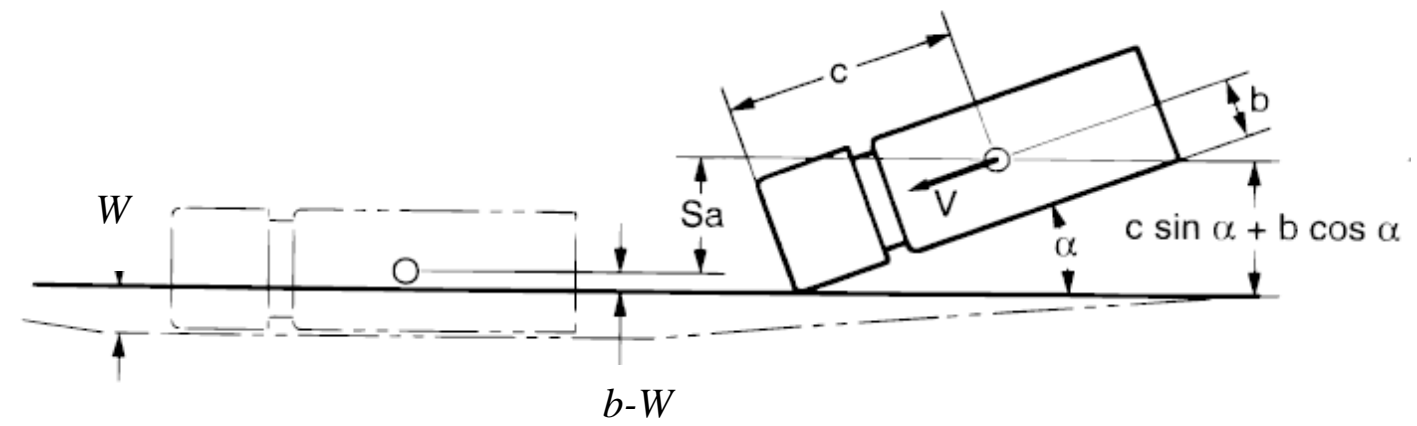

Figura 102 - Deslocamento do centro de gravidade devido ao impacto em uma defensa (EN 1317-1, 1998).

O deslocamento $S_{n}$ do CG do veículo na direção perpendicular a face da defensa é aproximado através da equação,

$$
S_{n}=c \cdot \operatorname{sen} \alpha+b(\cos \alpha-1)+W
$$

A componente vertical da velocidade do veículo $V_{n}$ deve diminuir de

$$
V_{n}=V \cdot \operatorname{sen} \alpha,
$$

até se anular devido ao impacto com a defensa. Assim a aceleração média do CG do veículo na direção perpendicular a barreira pode ser aproximada pela aceleração centrípeta $\bar{a}_{n}$, 


$$
\bar{a}_{n}=\frac{V_{n}^{2}}{2 S_{n}} .
$$

Desse modo, a força média $\bar{F}$ que atua sobre o veículo é igual a

$$
\bar{F}=\frac{M \cdot V_{n}^{2}}{2 \cdot S_{n}}
$$

Substituindo o resultado da equação (C.1) obtém-se:

$$
\bar{F}=\frac{M(V \cdot \operatorname{sen} \alpha)^{2}}{2 \cdot[c \cdot \operatorname{sen} \alpha+b(\cos \alpha-1)+W]}
$$

A força média $\bar{F}$ indica uma ordem de grandeza da interação entre a defensa e o veículo durante o impacto, o que é interessante para uma primeira avaliação da força atuante nas ancoragens da barreira e também da severidade de impacto aos ocupantes de maneira indireta. A força $\bar{F}$ é uma média em relação ao deslocamento lateral do veículo avaliada por,

$$
\bar{F}=\frac{1}{S_{n}} \int_{0}^{S_{n}} F(s) d s
$$

A norma (EN 1317-1, 1998) evidencia que o valor máximo da força $F(s)$ a ser considerada nas ancoragens pode chegar a 2,5 vezes maior que $\bar{F}$. 